\title{
Kristallographische Untersuchungen zur Schweren Kette von Dynein und dem
}

\section{Capping-Protein Cap32/34}

\author{
Dissertation \\ zur Erlangung des mathematisch-naturwissenschaftlichen Doktorgrades \\ „Doctor rerum naturalium“ \\ der Georg-August-Universität Göttingen
}

vorgelegt von

Christian Eckert

aus München

Göttingen, 2011 
Thesis Committee:

PD Dr. Martin Kollmar (Referent)

AG System-Biologie von Motorproteinen, Max-Planck-Institut für Biophysikalische Chemie Göttingen

Prof. Dr. Burkhard Morgenstern (Co-Referent)

Institut für Mikrobiologie und Genetik, Abteilung Bioinformatik, Georg-August-Universität Göttingen

\section{Prof. Dr. Markus Wahl}

Institut für Chemie und Biochemie, Freie Universität

Berlin 
Hiermit erkläre ich an Eides Statt, dass ich die vorliegende Arbeit selbstständig durchgeführt und mich dabei keiner anderen als der von mir ausdrücklich bezeichneten Quellen und Hilfen bedient habe.

Göttingen, den 07.11.2011

(Ort, Datum) 


\section{Publikationen:}

Eckert C, Hammesfahr B \& Kollmar M (2011) A holistic phylogeny of the coronin gene family reveals an ancient origin of the tandem-coronin, defines a new subfamily, and predicts protein function. BMC Evol Biol 11: 268-284

Eckert C, Goretzki A, Faberova M \& Kollmar M (2012)

Conservation and divergence between cytoplasmic and muscle-specific actin-capping proteins: insight from the crystal structure of cytoplasmic Cap32/34 from Dictyostelium discoideum (Submitted to BMC Structural Biology)

\section{Vorträge:}

November 2009

International Workshop Dynein 2009; Kobe, Japan

"Structural Characterization of the Cytoplasmic Dynein-Heavy-Chain from human and Dictyostelium discoideum"

März 2010

Alpbach Workshop on Molecular Motors 2010; Alpbach, Österreich

"Structural Characterization of the Cytoplasmic Dynein-Heavy-Chain from human and Dictyostelium discoideum"

\section{Posterpräsentationen:}

November 2009

International Workshop Dynein 2009; Kobe, Japan

"Structural Characterization of the Cytoplasmic Dynein-Heavy-Chain from human and Dictyostelium discoideum"

Februar 2010

MX School "Getting the most from the ESRF beamlines"; Grenoble, Frankreich

"Structural Characterization of the Cytoplasmic Dynein-Heavy-Chain from human and Dictyostelium discoideum"

März 2010

Alpbach Workshop on Molecular Motors 2010; Alpbach, Österreich

"Structural Characterization of the Cytoplasmic Dynein-Heavy-Chain from human and Dictyostelium discoideum"

September 2010

$13^{\text {th }}$ International Conference on the Crystallization of Biological Macromolecules; Dublin, Irland "Structural Characterization of the Cytoplasmic Dynein-Heavy-Chain from human and Dictyostelium discoideum" 


\section{Inhaltsverzeichnis}

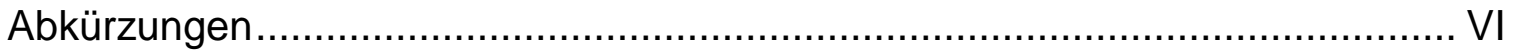

Zusammenfassung (Abstract) ………................................................... VIII

I. Strukturelle Studien zur Schweren Kette von Dynein .................1

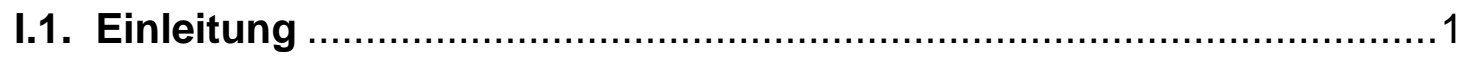

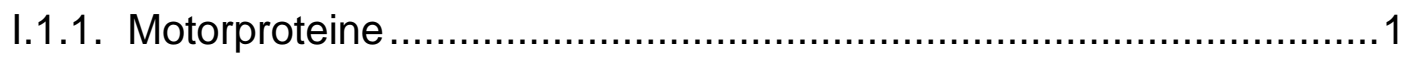

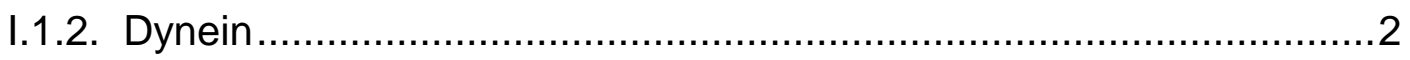

I.1.2.1. Zytoplasmatisches Dynein.....................................................

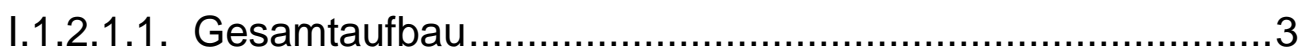

I.1.2.1.2. Zelluläre Funktionen ................................................... 4

I.1.2.1.3. Dynaktin als Co-Faktor von zytoplasmatischem Dynein......5

I.1.2.2. Axonemales Dynein .............................................................

I.1.2.3. Kraftschlag und Fortbewegung von Dynein ..............................

I.1.2.3.1. Aufbau der Schweren Kette - die Motoreinheit von Dynein 9

I.1.2.3.2. Mechanochemischer Zyklus ......................................... 18

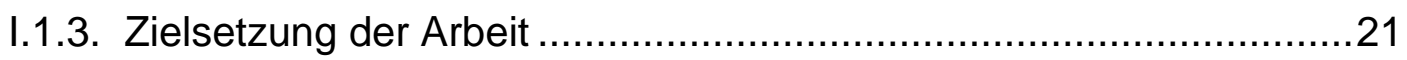

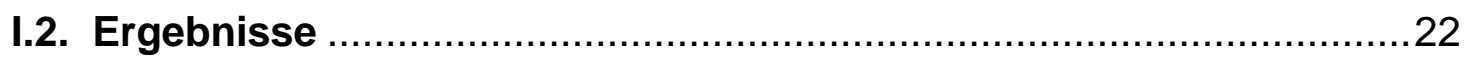

I.2.1. Bestimmung initialer Domänengrenzen für die zytoplasmatische DHC von Mensch und Dictyostelium discoideum..........................22

I.2.2. Klonierung, Herstellung und Expression von DHC-Konstrukten in Dictyostelium discoideum ........................................................23

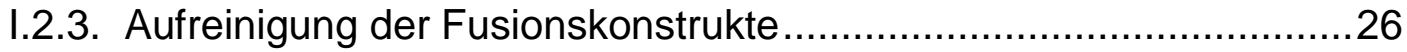

I.2.4. Analyse des Oligomerisierungszustandes der Fusionsproteine

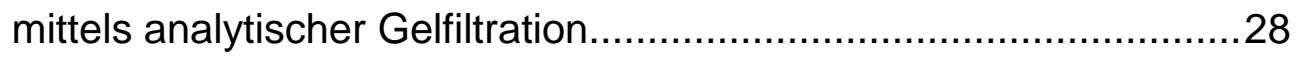

I.2.5. Erhalt von DHC-Konstrukten ohne MMD ......................................30

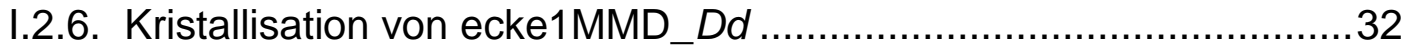

I.2.6.1. Erste Kristallisationsversuche ..............................................33

I.2.6.2. Optimierung der Aufreinigung von ecke1MMD_Dd und weitere

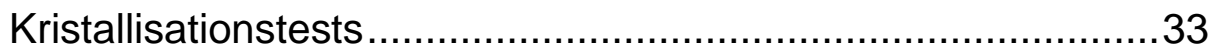

I.2.6.3. Optimierung der Kristalle und Diffraktionstests.........................35 
I.2.6.4. Weitere Optimierungsexperimente 38

I.2.7. Kristallisation von ecke10MMD_Hs............................................. 41

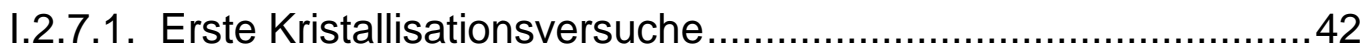

I.2.7.2. Optimierung der Kristalle und Diffraktionsmessungen...............43

I.2.7.3. Weitere Optimierungsexperimente …........................................ 45

I.3. Diskussion 49

I.3.1. Verwendung von Dictyostelium discoideum als Expressionssystem und des Myosin-Fusionssystems als Expressionsverstärker

I.3.2. Möglichkeiten, die zytoplasmatische DHC homogen in größeren Mengen zu erhalten

I.3.3. Herstellung von Konstrukten der zytoplasmatischen DHC und Expression in Dictyostelium discoideum ...................................... 51

I.3.3.1. Strategie zur Bestimmung von Fragmentgrenzen 51

I.3.3.2. Viele Abschnitte der DHC konnten in großen Mengen exprimiert werden

I.3.3.3. Der Großteil der Fusionskonstrukte unterlag starker Aggregation

I.3.3.4. Die DHC-Konstrukte konnten nur als Fusionsprotein in für die Kristallisation ausreichenden Mengen löslich erhalten werden .54

I.3.4. Kristallisation des Fusionskonstrukts ecke1MMD_Dd.....................55

I.3.4.1. ecke1MMD_Dd bildete nach Einbindung von Hydroxylapatit in den Aufreinigungsprozess erste Kristalle

I.3.4.2. Durch reduktive Methylierung des Proteins konnten größere Kristalle gezüchtet werden, die allerdings starke visuelle Mängel aufwiesen und schlecht beugten

I.3.4.3. Die Etablierung neuer Kristallisationsbedingungen in Kombination mit Mikroseeding brachte kompakte Kristalle hervor - allerdings keine nennenswerte Verbesserung der Beugungskraft

I.3.5. Kristallisation des Fusionskonstrukts ecke10MMD_Hs. 60

I.3.5.1. ecke10MMD_Hs bildete Monokristalle, die nicht reproduziert werden konnten - ein direkt gefrorener Kristall streute bis ca. $3.8 \AA$ 
I.3.5.2. Unter neuen Kristallisationsbedingungen entstanden in Kombination mit Mikroseeding deutlich größere Kristalle, die reproduzierbar erhalten werden konnten - allerdings keine nennenswerte Verbesserung des Streuvermögens

\section{Strukturelle Charakterisierung des Capping-Proteins}

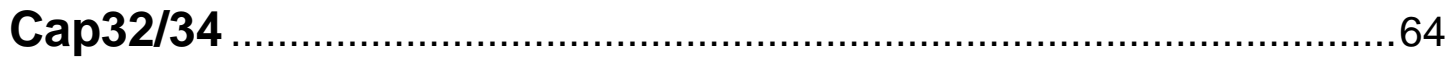

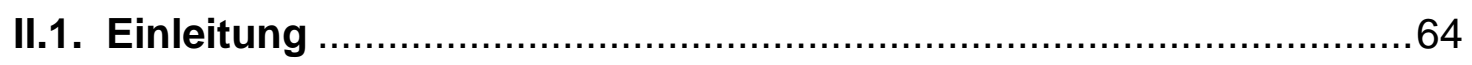

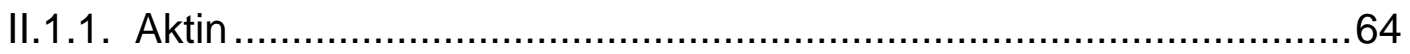

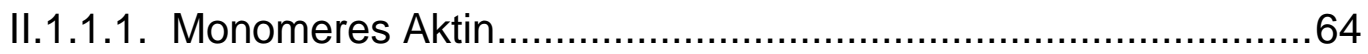

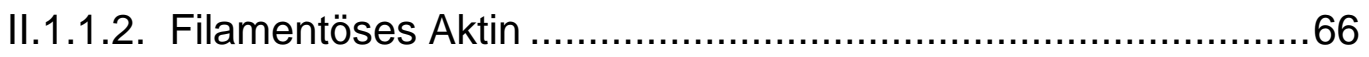

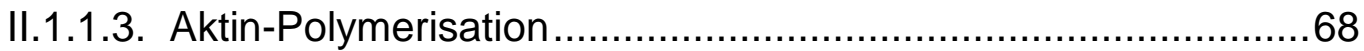

II.1.1.4. Aktin-bindende Proteine ………………........................... 70

II.1.1.5. Das dendritische Nukleationsmodell.....................................73

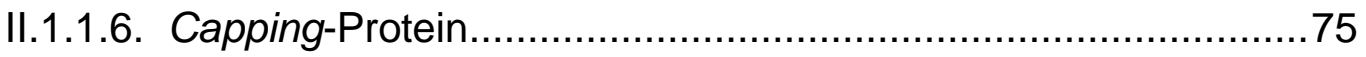

II.1.1.6.1. Regulation der CP-Aktivität ........................................79

II.1.1.6.2. Funktionen in zellulären Prozessen.................................82

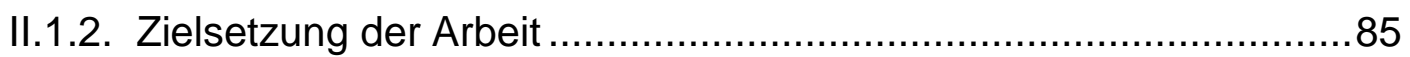

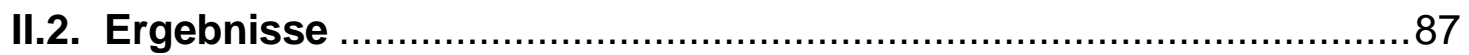

II.2.1. Klonierung, Expression und Isolierung von Cap32/34 ..................87

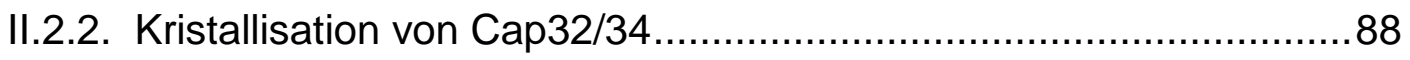

II.2.2.1. Soaking nativer Kristalle und Co-Kristallisation von Cap32/34 mit PI4,5P2 und diC8-PI4,5P2 .............................89

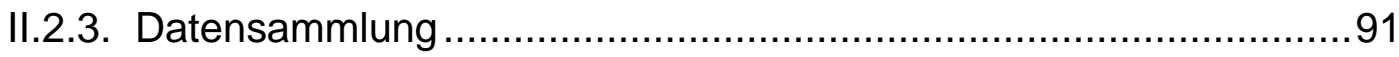

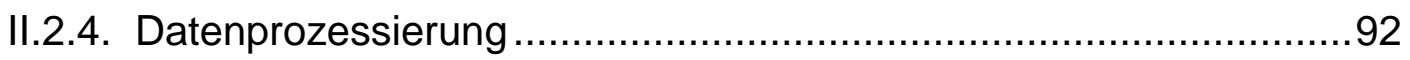

II.2.5. Strukturbestimmung durch Molekularen Ersatz.............................94

II.2.6. Modellbau und Modellverfeinerung .............................................96

II.2.7. Überblick über die Struktur von Cap32/34 ...............................100

II.2.8. Interaktion zwischen Cap32 und Cap34.................................... 104

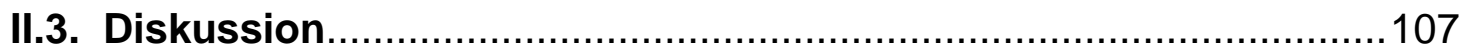

II.3.1. Kristallisation von Cap32/34 und Erhalt von Substrat-

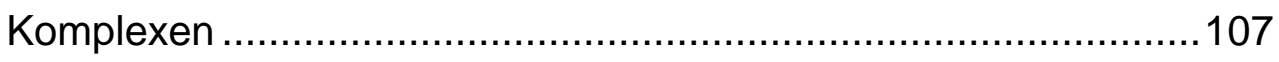

II.3.2. Datensammlung und Lösung des Phasenproblems.....................108 
II.3.3. Analyse der Cap32/34-Struktur und Vergleich mit dem Homologen GgCapZ

II.3.3.1. Die CP-Varianten zeigen deutliche Übereinstimmungen im Gesamtaufbau, wobei die $\beta$-Untereinheiten strukturell konservierter sind als die $\alpha$-Untereinheiten

II.3.3.2. Ein basischer Loop-Bereich, der in GgCapZ hoch geordnet ist, unterliegt in Cap32/34 einem hohen $\mathrm{Maß}$ an Beweglichkeit und fungiert möglicherweise als Bindungsstelle

II.3.3.3. Potenzielle Interaktionspartner der basischen LoopRegion

II.3.3.4. Mögliche Bindestelle der sarkomeren Variante für die Z-Scheiben im Muskelgewebe.

\section{Material und Methoden} 120

III.1. Material 120

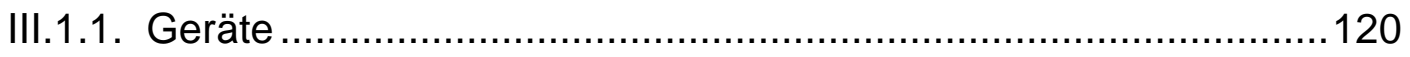

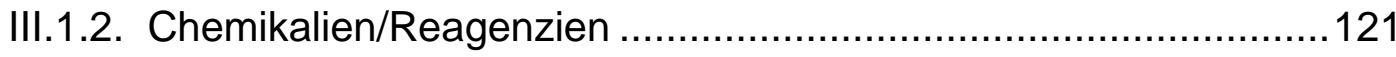

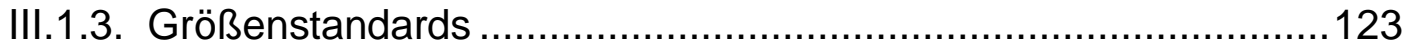

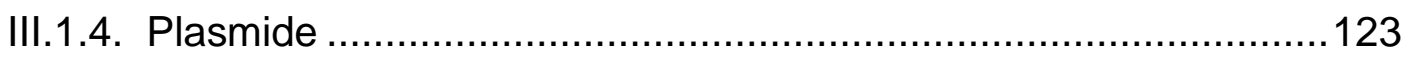

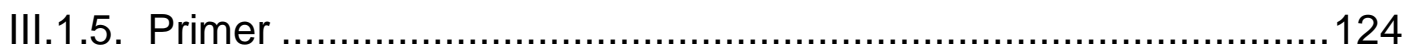

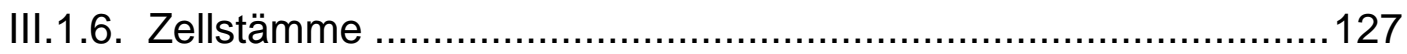

III.1.7. Medien für die Kultivierung von E. coli- und DictyosteliumZellen 127

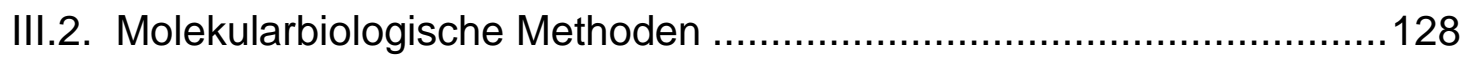

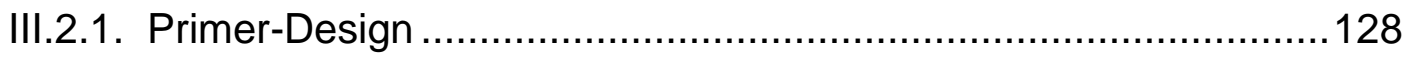

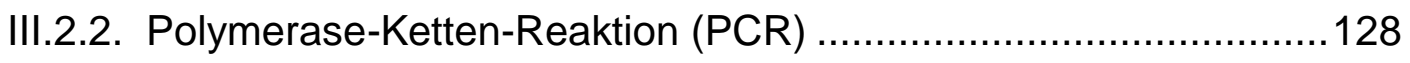

III.2.3. DNA-Aufreinigung aus PCR-Ansätzen ......................................129

III.2.4. Spaltung von DNA mit Restriktionsenzymen ..............................129

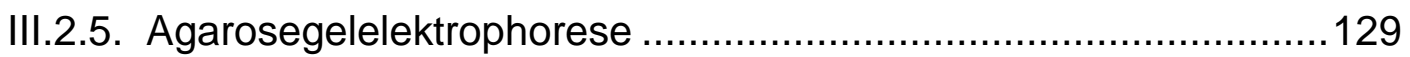

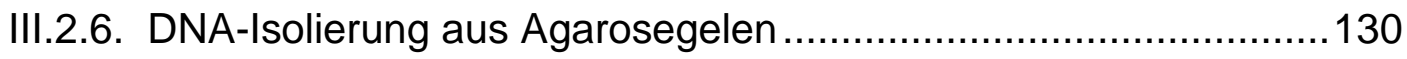

III.2.7. Ligation linearer DNA ...................................................... 130

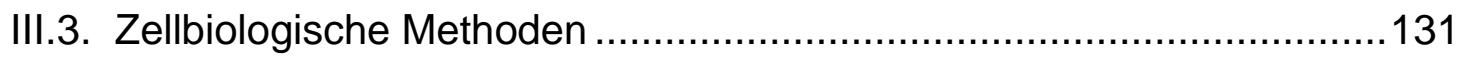

III.3.1. Hitzeschock-Transformation von DNA in kompetente E. coliZellen

III.3.2. Kultivierung und Lagerung von transformierten Bakterien ............131

III.3.3. Mini- und Midi-Präparation von Plasmid-DNA 


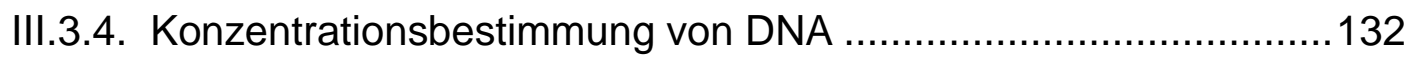

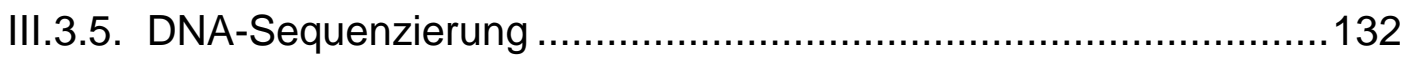

III.3.6. Bestimmung der Proteinkonzentration .....................................133

III.3.7. Kultivierung von Dictyostelium discoideum ................................133

III.3.8. Transformation von Dictyostelium discoideum ............................ 134

III.3.9. Konservierung von Dictyostelium-Sporen .................................134

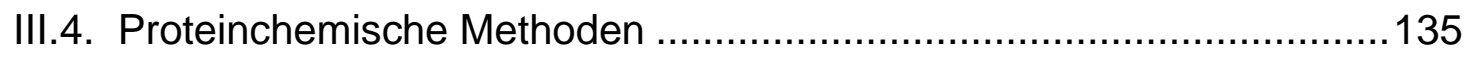

III.4.1. Analytische Reinigung von DHC-Konstrukten aus Dictyostelium-Zellen................................................................135

III.4.2. Analytische Reinigung von Myosin-Motor-Fusionsproteinen aus Dictyostelium-Zellen .........................................................136

III.4.3. Aufreinigung der Fusionskonstrukte ecke 1MMD_Dd und

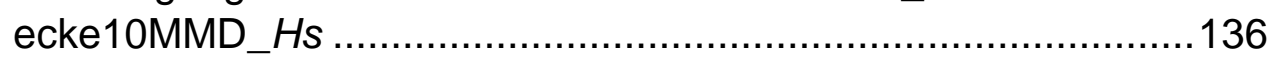

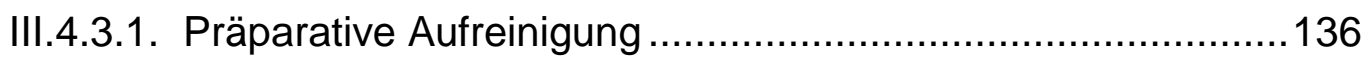

III.4.3.2. Optimierte Aufreinigung und reduktive Methylierung von ecke1MMD_Dd.....

III.4.4. Bindungstests der Fusionskonstrukte an verschiedene Säulenmaterialien

III.4.5. Abspaltung der Myosin-Motor-Domäne von den Fusionsproteinen....

III.4.6. Abspaltung des Histidin-Tags von den Fusionsproteinen ............140

III.4.7. Expressionstests von DHC-Konstrukten in E. coli-Zellen..............140

III.4.8. Rekombinante Expression von Cap32/34 in E. coli-Zellen............141

III.4.9. PIP-Strip-Inkubationstest ................................................. 142

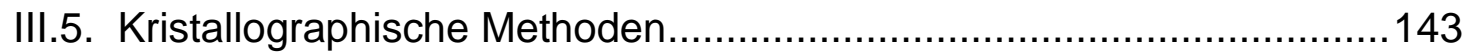

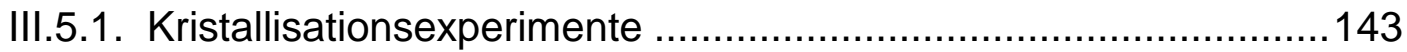

III.5.2. Additiv- und Detergenz-Screens ........................................... 144

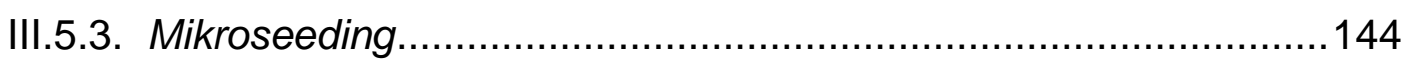

III.5.4. Färbung der Kristalle und Kontrolle der Identität der kristalli-

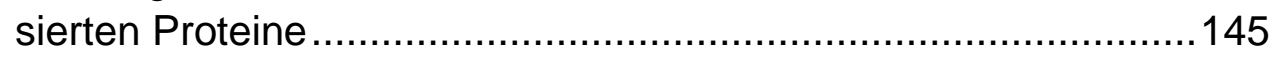

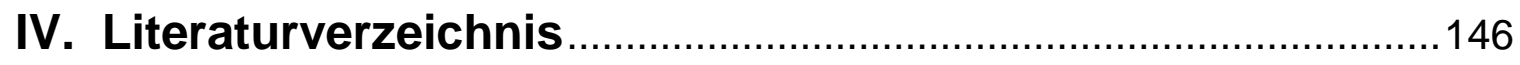

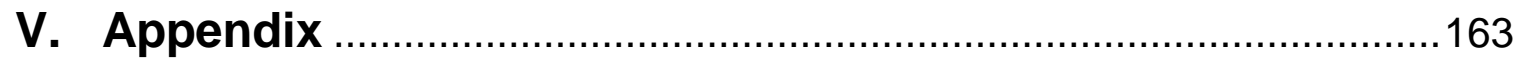

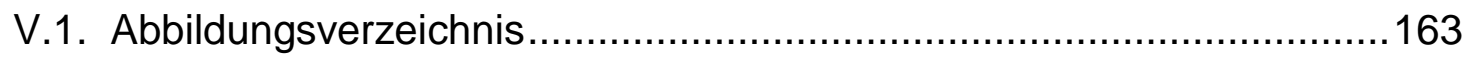

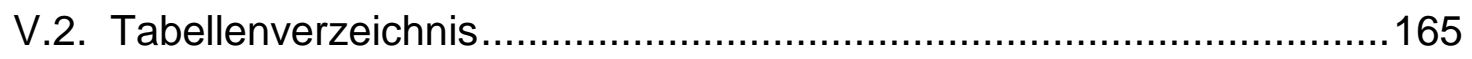

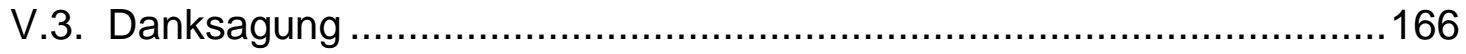

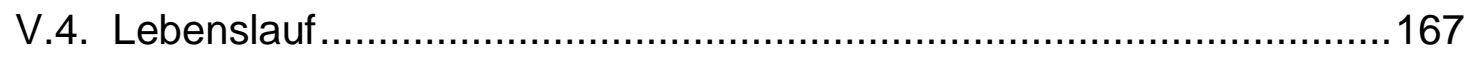




\section{Abkürzungen}

$\begin{array}{ll}\text { A } & \text { Ångström } \\ \text { ADP } & \text { Adenosin-5'-diphosphat } \\ \text { AMP } & \text { Ampicillin } \\ \text { AppyS } & \text { Adenosin-5'-[Y-thio]-triphosphat } \\ \text { AppCp } & \text { Adenosin-5'-[3/Y-methyleno]-triphosphat } \\ \text { AppNHp } & \text { Adenosin-5'-[3/Y-imido]-triphosphat } \\ \text { AS } & \text { Aminosäure } \\ \text { ATP } & \text { Adenosin-5'-triphosphat } \\ \text { ATPase } & \text { Adenosintriphosphatase } \\ \text { Bicin } & \text { N,N-Bis-(2-hydroxyethyl)-glyzin } \\ \text { bp } & \text { Basenpaare } \\ \text { BSA } & \text { Rinderserumalbumin } \\ \text { CAM } & \text { Chloramphenicol } \\ \text { CAPS } & \text { N-Cyclohexyl-3-aminopropansulfonsäure } \\ \text { c } & \text { Konzentration } \\ \text { cDNA } & \text { komplementäre DNA } \\ \text { CHES } & \text { N-Cyclohexyl-2-aminoethansulfonsäure } \\ \text { CP } & \text { Capping-Protein } \\ \text { C-Terminus } & \text { Carboxylende einer Peptidkette } \\ \text { d } & \text { Schichtdicke } \\ \text { DdDHC } & \text { Schwere Dynein-Kette von Dictyostelium discoideum } \\ \text { diC8-PI4,5P2 } & \text { Dioctanoyl-Phosphatidylinositol-4,5-bisphosphat } \\ \text { dNTP } & \text { 2'-Desoxynukleotid-5'-triphosphat } \\ \text { DTT } & \text { Dithiothreitol } \\ \text { DMAB } & \text { Boran-Dimethylamin-Komplex } \\ \text { E. coli } & \text { Escherichia coli } \\ \text { EDTA } & \text { Ethylendiamin-N,N,N',N'-tetraacetat } \\ \text { EGTA } & \text { Ethylenbis-(oxyethylennitrilo)-tetraacetat } \\ \text { EM } & \text { Elektronenmikroskopie } \\ \text { ESRF } & \text { European Synchrotron Radiation Facility } \\ \text { F-Aktin } & \text { filamentöses Aktin } \\ \text { FT } & \text { Durchlauf } \\ \text { G-Aktin } & \text { globuläres Aktin } \\ \text { HEPES } & \text { N-(2-Hydroxyethyl)-piperazinoethansulfonsäure } \\ \text { HsDHC } & \text { Schwere Dynein-Kette von Mensch } \\ & \end{array}$




\begin{tabular}{|c|c|}
\hline IDA & innerer Dynein-Arm \\
\hline IPTG & Isopropyl $\beta$-D-Thiogalactose \\
\hline K & Kelvin \\
\hline $\mathrm{kDa}$ & Kilodalton \\
\hline $\mathrm{kb}$ & Kilobasen \\
\hline LB & Luria-Bertrani-Medium \\
\hline $\mathrm{Pl} 4,5 \mathrm{P} 2$ & Phosphatidylinositol-4,5-bisphosphat \\
\hline PMSF & Phenylmethansulfonylfluorid \\
\hline MES & 2-Morpholinoethansulfonsäure-Monohydrat \\
\hline MMD & Myosin-Motor-Domäne \\
\hline MR & Molekularer Ersatz (molecular replacement) \\
\hline mRNA & Boten-Ribonukleinsäure \\
\hline MW & Molekulargewicht \\
\hline MWCO & Molekulargewichts-Ausschlußgrenze \\
\hline $\mathrm{N}_{2}$ & Stickstoff \\
\hline $\mathrm{Ni}^{2+}-$ IDA & Nickel-Iminodiessigsäure \\
\hline $\mathrm{Ni}^{2+}-\mathrm{NTA}$ & Nickel-Nitrilotriessigsäure \\
\hline $\mathrm{nm}$ & Nanometer \\
\hline $\mathrm{N}$-Terminus & Aminoende einer Polypeptidkette \\
\hline OD & optische Dichte \\
\hline ODA & äußerer Dynein-Arm \\
\hline ORF & offener Leserahmen (open reading frame) \\
\hline $\mathrm{P}_{\mathrm{i}}$ & Orthophospat \\
\hline PCR & Polymerase-Kettenreaktion (polymerase chain reaction) \\
\hline PEG & Polythylenglykol \\
\hline $\mathrm{PP}_{\mathrm{i}}$ & Pyrophosphat \\
\hline r.m.s.d. & mittlere quadratische Abweichung \\
\hline RNase & Ribonuklease \\
\hline $\mathrm{RT}$ & Raumtemperatur \\
\hline SDS-PAGE & Natriumdodecylsulfat-Polyacrylamidgelelektrophorese \\
\hline TAE & Tris-Azetat-EDTA \\
\hline TEMED & $\mathrm{N}, \mathrm{N}, \mathrm{N}^{\prime}, \mathrm{N}^{\star}$-Tetramethylethan-1,2-diamin \\
\hline$T_{m}$ & Schmelztemperatur \\
\hline TRIS & Tris-(hydroxymethyl)-aminomethan \\
\hline$U$ & internationale Unit \\
\hline Upm & Umdrehungen pro Minute \\
\hline $\mathrm{v} / \mathrm{v}$ & Volumenanteil am Gesamtvolumen \\
\hline$w / v$ & Gewichtsanteil am Gesamtvolumen \\
\hline
\end{tabular}




\section{Zusammenfassung}

Bewegungsvorgänge in Zellen sind fundamentale Prozesse, ohne die intrazellulärer Material-Transport, Zellteilung oder Nahrungsaufnahme nicht möglich wären. Diese können auf zwei verschiedene Arten vermittelt werden. Einerseits durch Motorproteine wie Dynein, Kinesin und Myosin, die die in ATP gespeicherte chemische Energie in gerichtete Bewegung umsetzen, um beispielsweise Organellen entlang von Mikrotubuli- oder Aktinfilamenten zu transportieren. Zum anderen durch die Polymerisation von Aktin oder Tubulin zu polarisierten Filamenten, wodurch ebenfalls unter ATP-Verbrauch gerichtete Bewegung generiert wird. Hierfür ist die präzise Regulation der Filamente, z. B. des F-Aktins durch Aktin-bindende Proteine wie das Capping-Protein (CP), von zentraler Bedeutung.

Der erste Teil dieser Arbeit fokussierte sich auf die strukturelle Charakterisierung der Schweren Kette (DHC) des Mikrotubuli-assoziierten Motorproteins Dynein von Mensch und Dictyostelium discoideum mittels Röntgenstrukturanalyse. Die DHC gehört mit einer molekularen Masse von ca. 520 kDa zu den größten Proteinen in eukaryotischen Zellen. Bedingt durch ihre Größe, konnte bisher nur ein kleiner Bereich der Schweren Kette in atomarer Auflösung beschrieben werden. Um Protein in für die Kristallisation ausreichenden Mengen zu erhalten, wurde die DHC systematisch in kleinere Abschnitte unterteilt und die Konstrukte im niederen Eukaryoten Dictyostelium discoideum exprimiert. Insgesamt gelang es, zahlreiche Teilbereiche der DHC in hoher Ausbeute zu produzieren. Für zwei Konstrukte, die jeweils entscheidende Domänen für die Krafterzeugung enthielten, konnten Kristalle erhalten werden. Allerdings beugten diese auch nach intensiven Optimierungsversuchen nur schwach und genügten daher nicht der atomaren Strukturaufklärung.

Im zweiten Teil dieser Arbeit gelang es, mit bakteriell exprimiertem Cap32/34 von Dictyostelium discoideum zum ersten Mal die Kristallstruktur eines zytoplasmatischen Capping-Proteins aufzuklären. Die Struktur wurde bei einer Auflösung 
von $2.2 \AA$ A röntgenkristallographisch mit der Methode des Molekularen Ersatzes gelöst. Das Heterodimer zeigt eine pilzähnliche Struktur, bestehend aus einer stiel- und einer hutförmigen Komponente. Trotz einer nur geringen Sequenzidentität, besitzen die beiden Untereinheiten sehr ähnliche Sekundärund Tertiärstrukturen, wodurch das Cap32/34 Molekül eine pseudo-zweifache Rotationssymmetrie besitzt. Vergleiche mit der Kristallstruktur von spezifisch im Muskelgewebe vorkommendem CP (GgCapZ) deckten zwei signifikante Unterschiede zwischen den Isoformen auf, deren Gesamtstrukturen sich als hoch konserviert herausstellten. Eine basische Loop-Region, die in Cap32/34 aufgrund stark ausgeprägter Flexibilität nicht in das Strukturmodell integriert werden konnte, liegt in GgCapZ hoch geordnet vor. Dies lässt vermuten, dass das Proteinsegment in Cap32/34 und potenziell in allen zytoplasmatischen CappingProteinen in die Interaktion mit negativ geladenen Bindungspartnern involviert ist. Mögliche Kandidaten wären F-Aktin und Phospholipide. Ferner zeigte der Strukturvergleich, dass sich die CP-Varianten in einer weiteren Schleifenregion deutlich unterscheiden, sowohl in struktureller Hinsicht als auch in Bezug auf die innen zugrunde liegenden Flexibilitätsgrade. In GgCapZ ist das Segment durch einen wesentlich höheren Temperaturfaktor charakterisiert und könnte aufgrund seiner Lösungsmittelzugänglichkeit an der Interaktion mit der Z-Scheibe des Sarkomers beteiligt sein, an der das Protein spezifisch lokalisiert ist. 


\section{Abstract}

Intracellular movements are an essential prerequisite for material transport, cell division and food ingestion. They can be mediated through two different ways. Firstly, through motor proteins, like dynein, kinesin and myosin, which transform the energy stored in ATP into directed movement to, for instance, facilitate organelle transport along microtubule- and actin-filaments. Secondly, via ATPdependent polymerization of actin and tubulin into polarized filaments and, thereby, generating directed movement. Therefore, the precise regulation of the cytoskeleton, for example, of F-actin through actin-binding proteins, such as capping protein $(\mathrm{CP})$, is of central significance.

The first part of this work focused on the structural characterization of the heavy chain of dynein (DHC), a microtubule-associated motor protein complex, from human and Dictyostelium discoideum by means of X-ray-crystallography. With a molecular mass of around $520 \mathrm{kDa}$, the DHC belongs to one of the largest proteins in eukaryotic cells. Due to its size, so far, only a small part of the DHC has been solved at atomic resolution. In order to obtain protein in amounts sufficient for structural studies, the DHC was systematically subdivided into smaller sections and the constructs were subsequently expressed in the lower eukaryote Dictyostelium discoideum. Altogether, numerous sections of the DHC could be produced in large amounts. For two constructs, each of which included domains essential for dynein force generation, crystals were obtained. However, although extensive optimization attempts were performed, the crystals diffracted to only low resolution and, thus, were not suitable for atomic structure solution.

In the second part of this work, the crystal structure of Cap32/34 from Dictyostelium discoideum - the first high resolution structure of a cytoplasmic capping protein - is reported. The structure was solved at $2.2 \AA$ via the method of molecular replacement. The heterodimer has the shape of a mushroom, comprising a stem and a cap. Despite sharing only low sequence-identity, the two subunits have very similar secondary- and tertiary-structures, resulting in a 
pseudo two-fold rotational axis of the Cap32/34 molecule. Comparisons with the crystal structure of muscle-specific CP (GgCapZ) revealed two marked differences between the isoforms, whose overall structures turned out to be strongly conserved. While a basic loop region could not be integrated into the structure of Cap32/34, due to a high degree of flexibility, the corresponding segment is highly ordered in GgCapZ. Therefore, it can be assumed that this part of the molecule might be involved in the interaction with negatively charged binding partners in Cap32/34 and possibly in every cytoplasmic capping protein. Possible candidates are F-actin and phospholipids. Moreover, the CP-variants greatly differ in another loop-region, not only in structural regard, but also in terms of flexibility. In GgCapZ, this segment is characterized by a substantially higher temperature factor, and - since it is solvent-exposed - it might be involved in the interaction with the Z-disc of the sarcomere, where the protein is specifically located at. 


\section{Strukturelle Studien zur Schweren Kette von Dynein}

\section{l.1. Einleitung}

\section{I.1.1. Motorproteine}

Motorproteine sind allosterische Enzyme, die chemische Energie durch die Hydrolyse von ATP in mechanische Arbeit konvertieren und dabei gerichtete Bewegungsvorgänge auslösen können. Sie vermitteln eine Reihe von lebenswichtigen Prozessen, wie die Trennung replizierter Chromosomenstränge im Rahmen der Zellteilung sowie die Kontraktion der Muskeln und sind somit für die Generierung von Bewegung auch auf makroskopischer Ebene verantwortlich (Vale \& Milligan, 2000).

Zu den zytoskeletalen molekularen Motoren gehören die Vertreter der Dynein-, Kinesin- und Myosin-Familien. Die Mikrotubuli-assoziierten Motorproteine umfassen die Vertreter der Dynein- und Kinesin-Familien und sind für den Langstreckentransport verantwortlich. Die meisten Kinesine transportieren ihre Frachten hin zum Pluspol des Mikrotubulus und damit aus dem Zellinneren in die Zellperipherie (anterograder Transport). Dyneine gleiten retrograd in Richtung des negativen Pols am Mikrotubulus entlang und bewegen so Transportgüter von der Zellperipherie in ihr Zentrum (Vale \& Milligan, 2000). Die an Aktinfilamente anbindenden Myosine sind hingegen für die gerichtete Translokation biologischer Lasten über kurze Distanzen zuständig.

Die zytoskeletalen Motorproteine assoziieren mit ihrem „Schienennetz“ mittels einer „Kopf“-Region, die ATPase-Eigenschaft besitzt. Allosterische Konformationsänderungen innerhalb der globulären Motordomäne ermöglichen eine Anbindung an das Filament oder eine Ablösung davon. So wird eine schrittweise, gerichtete Versetzung des molekularen Motors entlang des Filaments erreicht. Der „Kopf“ gibt dabei die Bewegungsrichtung an, wohingegen die „Schwanz“- 
Region für die Art der zu transportierenden Fracht verantwortlich ist (Schliwa \& Woehlke, 2003).

Dynein unterscheidet sich strukturell grundsätzlich von den anderen Motorproteinen. Während die energieerzeugenden Einheiten von Myosin und Kinesin einen gemeinsamen evolutionären Ursprung haben (Vale \& Milligan, 2000), gehört Dynein einer anderen, nicht verwandten Proteinklasse an [Familie der AAA-Proteine $(\mathrm{AAA}=\underline{\text { ATPases }}$ associated with diverse cellular activities $)$ ] (Neuwald et al, 1999). Des Weiteren ist Dynein durch eine sehr viel höhere molekulare Komplexität charakterisiert. Allein die Schwere Dynein-Kette besitzt mehr als die zweifache Größe von Myosin und die vierfache Größe von Kinesin (Asai \& Koonce, 2001). Daraus lässt sich ableiten, dass dem Dynein-Motor ein grundlegend anderes Funktionsprinzip zugrunde liegt als den Motoren von Myosin und Kinesin.

\section{I.1.2. Dynein}

Das Protein Dynein wurde im Jahr 1965 von Gibbons und Rowe in eukaryotischen Axonemen entdeckt und als ATPase beschrieben (Gibbons \& Rowe, 1965). Die Benennung des Motorproteins erfolgte in Anlehnung an die für Kraft stehende physikalische Größe „dyn“. Die Dynein-Familie hat zwei Hauptvertreter, die zytoplasmatischen und die axonemalen Dyneine. Dabei wird zwischen zwei zytoplasmatischen und fünf verschiedenen axonemalen Formen unterschieden.

Zytoplasmatisches Dynein 1 ist ubiquitär exprimiert und dient unter anderem dem intrazellulären Transport von Organellen und mRNAs (Kardon \& Vale, 2009). Zytoplasmatisches Dynein 2 (auch IFT-Dynein oder Dynein 1B genannt) ist fast ausschließlich innerhalb und an der Basis von Zilien und Flagellen lokalisiert, wo es für den intraflagellaren Transport zuständig ist (Mikami et al, 2002). Die axonemalen Dyneine treiben die Bewegung von Zilien und Flagellen (Gibbons \& Rowe, 1965). 


\section{I.1.2.1. Zytoplasmatisches Dynein}

\section{I.1.2.1.1. Gesamtaufbau}

Zytoplasmatisches Dynein ist ein Multidomänenprotein mit einer molekularen Masse von 1.5 MDa. Der Komplex besteht neben zwei gleichartigen Schweren Ketten (HC), die jeweils eine Größe von $\sim 520$ kDa aufweisen, aus einer Reihe kleinerer Untereinheiten (Abbildung I.1.). Diese umfassen zwei Intermediäre Ketten (IC; 70-74 kDa), vier Leicht-Intermediäre Ketten (LIC; 52-61 kDa) und mehrere Leichte Ketten (LC; TcTex-1, robl, LC8; 8-13 kDa). Die Schweren Ketten liegen als Homodimer vor und interagieren über ihre „Kopf“-Region mit den Mikrotubuli. Die Intermediären Ketten assoziieren an die Schweren Ketten und vermitteln die Interaktion mit dem sogenannten Dynaktin-Komplex (Karki \& Holzbaur, 1995; Vaughan \& Vallee, 1995).

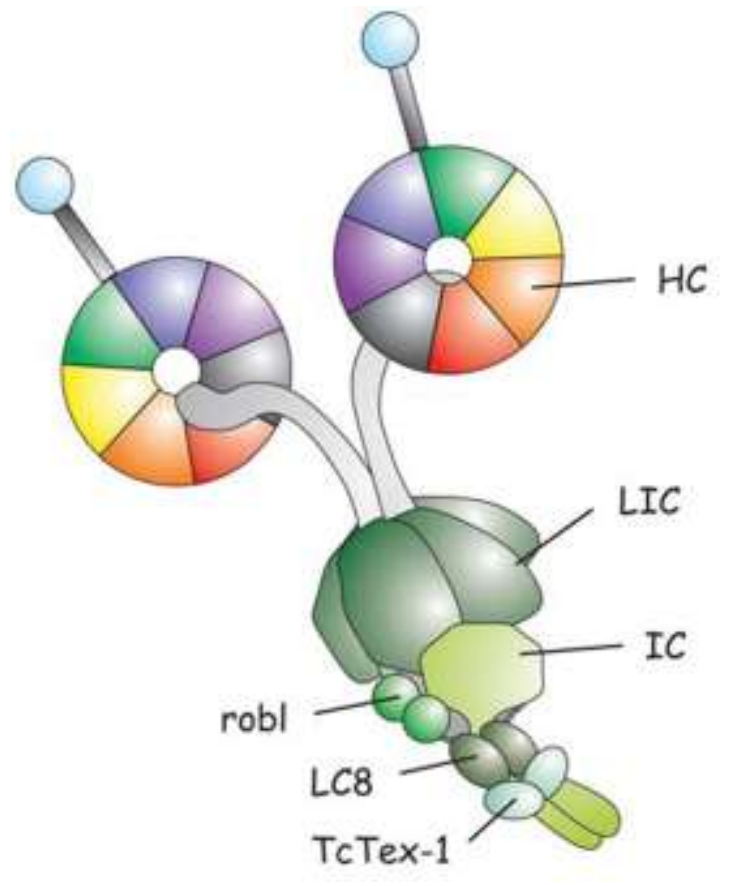

Abbildung I.1. Schematische Darstellung von zytoplasmatischem Dynein. Gezeigt ist die vermutliche Anordnung der einzelnen Untereinheiten im Komplex.

Die ebenfalls an die Schweren Ketten anbindenden Leicht-Intermediären Ketten beinhalten ein GTP-bindendes Motiv, dessen Funktion unbekannt ist (Hughes et al, 1995). Die Leichten Ketten interagieren mit der N-terminalen Domäne der 
Intermediären Kette und spielen eine wichtige Rolle im subzellulären Targeting (Tai et al, 1999). Aufgrund des Fehlens einer hochaufgelösten Struktur herrscht noch Unklarheit über die genaue Organisation der Untereinheiten innerhalb des Dynein-Komplexes.

\section{I.1.2.1.2. Zelluläre Funktionen}

Zytoplasmatisches Dynein wird für eine Reihe von zytoplasmatischen Motoraktivitäten benötigt. Dabei stellt Dynein unter anderem eine der Hauptkomponenten der Mikrotubuli-Organisation während der Mitose dar. So zeigte sich, dass die Injektion spezifischer Antikörper gegen die Schwere Kette während der Mitose eine defekte Trennung der Spindelpole (Vaisberg et al, 1993) und ein abnormales Zusammenziehen der Chromosomen (Echeverri et al, 1996) zur Folge hat. Dadurch verbleibt die Zelle im Pseudoprometaphasezustand. Dynein ist in der Anaphase vermutlich an der polwärts gerichteten Chromosomenwanderung beteiligt (Gusnowski \& Srayko, 2011). Mit fluoreszenzmarkierten Antikörpern konnte gezeigt werden, dass Dynein während der Interphase im Zytoplasma lokalisiert ist. Sobald die Zelle aber in die Mitose eintritt, befindet sich das Protein an den Spindelpolen und den Kinetochoren. Da sich Dynein an einem Mikrotubulus entlang zum Minus-Ende bewegt, würde es demnach auch ein angeheftetes Chromosom in Richtung des Pols ziehen. Darüber hinaus fanden Schmidt et al (2005), dass die Hemmung der DyneinFunktion während der Anaphase mit einer erheblich verlangsamten Chromosomenwanderung korreliert.

In weiteren Versuchen mit spezifischen Antikörpern konnte der Nachweis erbracht werden, dass eine Störung der Dynein-Funktion zur Fragmentierung des Golgi-Apparats führt (Vaisberg et al, 1996). Außerdem bewirkte die Ausschaltung der Schweren Kette in transgenen Mäusen eine Umverteilung von Endosomen und Lysosomen ins Zytoplasma sowie einen gehemmten Vesikel-Transport vom Endoplamatischen Retikulum (ER) zum Golgi-Komplex (Burkhardt et al, 1997; Harada et al, 1998, Presley et al, 1997). Diese Zusammenhänge lassen 
vermuten, dass Dynein an der Organisation und Lokalisierung des GolgiKomplexes, am Transport von Endosomen und Lysosomen zum Zellzentrum als auch an der Bewegung von ER-Golgi- Transportkomplexen beteiligt ist.

Dynein befördert wohl ebenfalls Toxine (z. B. Tetanustoxin; Lalli et al, 2003) und Viren (z. B. Herpesviren; Douglas et al, 2004) intraaxonal aus dem peripheren ins zentrale Nervensystem.

In vitro Beweglichkeitsassays, immunozytochemische Analysen und subzelluläre Fraktionierungen deuten ferner darauf hin, dass zytoplasmatisches Dynein für den retrograden Transport von Lipid-Tropfen (Valetti et al, 1999), mRNAs (Ling et al, 2004), Transkriptionsfaktoren (Harrell et al, 2004) und aggregierten Proteinen (Johnston et al, 2002) verantwortlich ist.

\section{I.1.2.1.3. Dynaktin als Co-Faktor von zytoplasmatischem Dynein}

Um der gerade erwähnten Bandbreite an subzellulären Bewegungsfunktionen gerecht werden zu können, arbeitet der zytoplasmatische Dynein-Komplex zusammen mit einem Co-Faktor, dem sogenannten Dynaktin. Die Interaktion erfolgt über die Intermediären Dynein-Ketten. Dynaktin ist analog zu Dynein ein aus zahlreichen Untereinheiten bestehender Proteinkomplex (Allan, 2000). Er umfasst insgesamt 11 verschiedene Untereinheiten ungleicher Stöchiometrie, die in zwei strukturell distinkten Domänen organisiert sind. Dabei ist eine Domäne durch ein Aktin-ähnliches Minifilament charakterisiert, die andere besteht aus einem flexibel herausstehenden Seitenarm (Abbildung I.2.).

Das Aktin-ähnliche Minifilament ist für die Bindung an subzelluläre Strukturen verantwortlich und setzt sich aus acht Einheiten des Aktin-verwandten Proteins (acctin-related protein) ARP1 und einem Molekül konventionellen Aktins zusammen. Das Polymer wird an einer Seite durch CapZ und an der anderen Seite durch die Untereinheiten p25, p27, p62 und ARP11 begrenzt.

Der Dynaktin-Seitenarm ist aus den Proteinen p24 und p150 Glued aufgebaut. p24 liegt dabei als Tetramer vor, p150 ${ }^{\text {Glued }}$ bildet ein Dimer und stellt die größte und am weitgehendsten charakterisierte Untereinheit von Dynaktin dar. Dynaktin 
bindet über den mittleren Bereich von p150 ${ }^{\text {Glued }}$ an Dynein. Außerdem befindet sich am N-Terminus von $\mathrm{p} 150^{\text {Glued }}$ eine sogenannte CAP-Gly-Domäne (ㄷytoskeleton-âssociated protein glycine-rich), die die Interaktion mit Mikrotubuli vermittelt. Dadurch wird ein stabilisierter Transport der Lasten über lange Distanzen entlang des Filaments ermöglicht.

Die Bindung von $\mathrm{p} 150^{\text {Glued }}$ an ARP1 wird über das Protein Dynamitin (p50) vermittelt. Die Überexpression von Dynamitin bewirkt die Loslösung von p150 ${ }^{\text {Glued }}$ und p24 vom ARP1-Minifilament. Dieser Befund deutet darauf hin, dass Dynamitin für den Zusammenhalt von Seitenarm und Minifilament verantwortlich ist (Burkhardt et al, 1997).

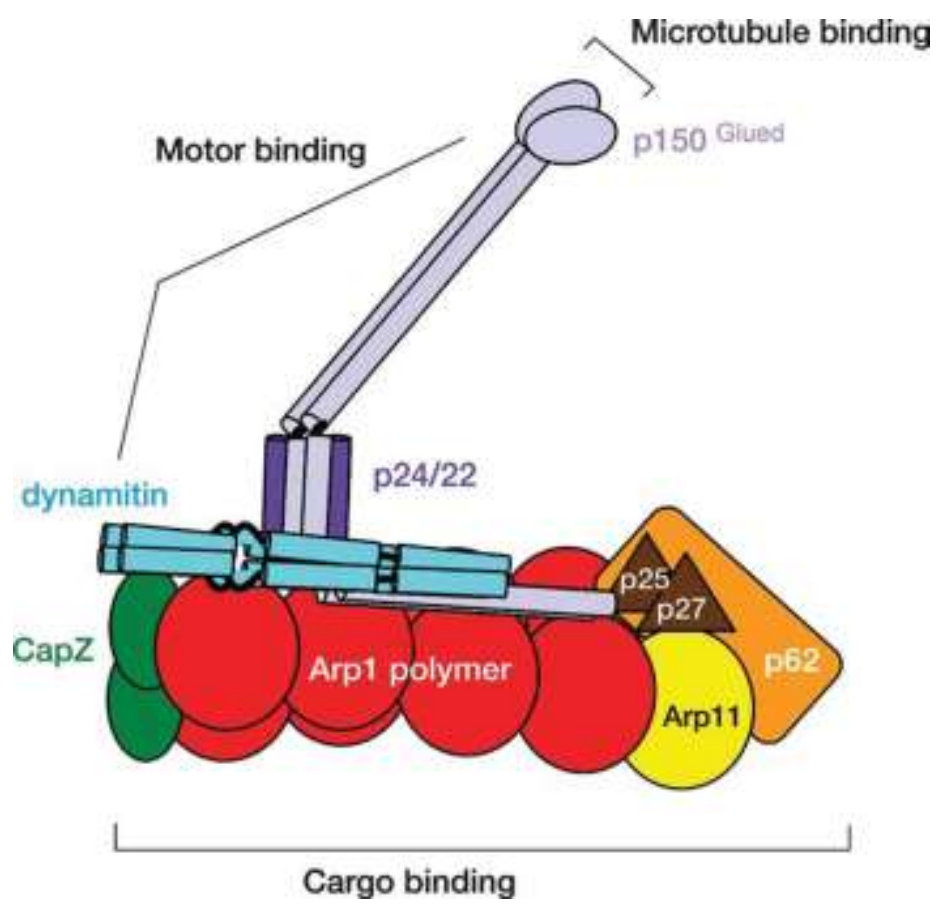

Abbildung 1.2. Modell des DynaktinKomplexes (Abbildung nach Schroer, 2004). Dargestellt ist die vermutete Anordnung der einzelnen Untereinheiten im Dynaktin-Komplex. Die für Interaktionen verantwortlichen Strukturen sind gekennzeichnet.

Dynaktin wurde zuerst in vitro als Aktivator des von zytoplasmatischem Dynein getriebenen Vesikel-Transports entdeckt (Allan, 2000; Schroer \& Sheetz, 1991). Mittlerweile weiß man, dass Dynaktin für alle Formen von Dynein-abhängiger Bewegung erforderlich ist (Allan, 2000; Vallee \& Sheetz, 1996). Während Dynein die Kraft für die Bewegung liefert, fungiert Dynaktin aller Wahrscheinlichkeit nach als Schaltzentrale, welche die Aktivitäten des Dynein-Motors dirigiert und 
koordiniert. In diesem Zusammenhang ist der Dynaktin-Komplex in der Lage, als Bindungsplattform die Assoziation von Dynein an seine Fracht zu vermitteln. Außerdem kann Dynaktin eine verbesserte Effizienz des Dynein-Motors hervorrufen, indem es dessen Prozessivität erhöht (King \& Schroer, 2000; Kardon et al, 2009).

\section{I.1.2.2. Axonemales Dynein}

Axonemales und zytoplasmatisches Dynein zeigen große Unterschiede im Gesamtaufbau, auch wenn sie sich biochemisch sehr ähnlich sind. Im Vergleich zur zytoplasmatischen Form unterliegt der Aufbau von axonemalem Dynein einer extrem hohen Komplexität. So sind axonemale Dyneine durch eine sehr viel größere Diversität an ICs (69-120 kDa) und LCs (10-20 kDa) charakterisiert (Pfister et al, 1982; Piperno \& Luck, 1979; Tang et al, 1982). Des Weiteren besitzen sie mindestens sechs Isoformen der Schweren Kette, wobei diese im Dynein-Komplex als Monomere, Heterodimere oder Heterotrimere vorliegen können (Holzbaur \& Vallee, 1994). In zytoplasmatischem Dynein hingegen bilden die Schweren Ketten Homodimere aus.

Schließlich unterscheiden sich die beiden Dynein-Formen auch in ihrem Verbreitungsgrad. Im Vergleich zu axonemalem Dynein, welches in mehreren Spezies, wie in den Pilzen und im Nematoden Caenorhabditis elegans, fehlt, ist die zytoplasmatische Form mit Ausnahme der Taxa der Pflanzen in allen Organismen vertreten.

Axonemales Dynein vermittelt die Bewegung von Zilien und Flagellen (Gibbons \& Rowe, 1965). Dabei handelt es sich um ca. $0.5 \mu \mathrm{m}$ dicke bewegliche Fortsätze der Zelloberfläche, die unterschiedliche Längen aufweisen. Zilien sind $\leq 10 \mu \mathrm{m}$, Flagellen hingegen 100 bis $200 \mu \mathrm{m}$ lang. Daraus ergeben sich verschiedene Bewegungsabläufe. Zilien vollziehen einen Ruderschlag, Flagellen hingegen wellenförmige Bewegungen. Während die beiden Bewegungsorganellen den freien Zellen der aktiven Fortbewegung dienen, werden sie im 
Gewebeverbund dazu eingesetzt, um einen die Nahrung transportierenden Wasserstrom zu erzeugen.

Zilien und Flagellen besitzen in ihrem Inneren einen charakteristischen (9+2)Aufbau aus Mikrotubuli, der als Axonem bezeichnet wird. Dabei stehen jeweils neun periphere Dupletts von Mikrotubuli zwei zentralen Mikrotubuli gegenüber. Ein Duplett besteht aus einem vollständigen Mikrotubulus, dem sogenannten ATubulus, und einem unvollständigen B-Tubulus. Ausgehend vom A-Tubulus ragen auf gleicher Ebene ein innerer und äußerer Arm zum B-Tubulus des benachbarten Dupletts. Die Arme bestehen aus Dynein-Komplexen und werden deshalb als innere und äußere Dynein-Arme bezeichnet. Die äußeren Arme bestehen aus einem Dynein-Komplex, der drei verschiedene Isoformen der HC (ODA- $\alpha$, ODA- $\beta$ und ODA- $\gamma$ ) umfasst, wohingegen die inneren Arme zum Teil aus Komplexen heterodimerer HCs (IDA-1 $\alpha$, IDA-1 $\beta$ ), aber auch aus monomeren HCs aufgebaut sind.

Während der „Stamm“ jedes Dynein-Moleküls fest an der Außenseite des ATubulus verankert ist, setzt das andere Ende des Proteins ohne permanente Bindung am benachbarten Mikrotubuli-Duplett an. Auf dieser reversiblen Verbindung beruht die Bewegung von Zilien und Flagellen. Der aktive Schlag wird durch ein Aneinandergleiten benachbarter Mikrotubuli-Dupletts bei gleichzeitiger Krümmung des Ziliums oder Flagellums erreicht. Die dafür erforderliche Energie wird von den Dynein-Armen geliefert, die dabei ATP verbrauchen. Ein direkter Nachweis für diese "Gleitmikrotubuli“-Hypothese ergab sich aus Versuchen mit axonemalen Mikrotubuli, die mit Goldpartikeln dekoriert wurden. Deren Bewegung konnte daraufhin unter dem Mikroskop verfolgt werden (Brokaw, 1989).

Aus Experimenten mit Mutanten, denen jeweils einzelne Isoformen der axonemalen Dyneine fehlen, ging hervor, dass die inneren Arme für die schlängelnden Bewegungen von Zilien und Flagellen verantwortlich sind, wohingegen die äußeren Arme den Großteil der Kraft erzeugen und die Schlagfrequenz bestimmen (Brokaw \& Kamiya, 1987). 


\section{I.1.2.3. Kraftschlag und Fortbewegung von Dynein}

\section{I.1.2.3.1. Aufbau der Schweren Kette - die Motoreinheit von Dynein}

Ausgehend von elektronenmikroskopischen (Burgess et al, 2003; Roberts et al, 2009) und röntgenkristallographischen Untersuchungen (Carter et al, 2011; Kon et al, 2011) kann die Schwere Kette von Dynein (DHC) in folgende funktionell distinkte Abschnitte unterteilt werden (Abbildung I.3.):

- „Stamm“

- Linker

- „Kopf“

- AAA-Module

- "Stiel“ und buttress

- C-Terminus 

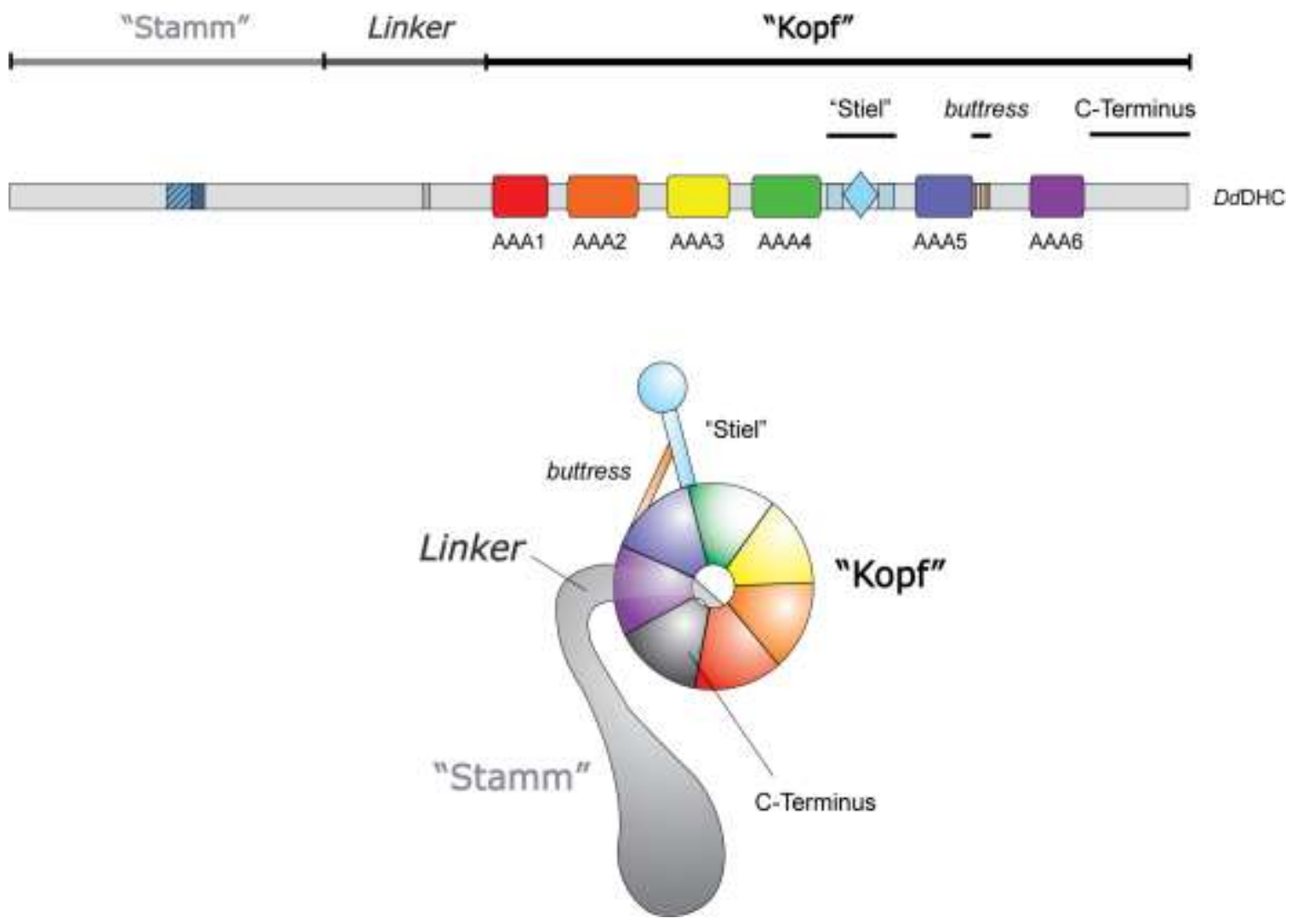

Abbildung I.3. Schematische Darstellung der Domänen-Architektur der Schweren Dynein-Kette. Gezeigt sind sowohl die sequenzbasierte (oben) als auch die räumliche (unten) DomänenOrganisation der DHC am Beispiel von Dictyostelium discoideum (Dd).

- „Stamm“

Die „Stamm“-Domäne bildet den rund 1.300 Aminosäuren langen N-Terminus der Schweren Kette. In ihren Funktionsbereich fallen die Dimerisierung der DHC sowie die Bindung akzessorischer Polypeptide, die unter anderem an der Beladung von Fracht beteiligt sind.

- „Kopf“

Die „Kopf“-Region beinhaltet die für die Kraftübertragung erforderlichen Einheiten und ist somit für die Translokation des Dynein-Komplexes entlang des 
Mikrotubulus verantwortlich (Mikami et al, 1993; Vallee \& Sheetz, 1996; Zhang et al, 1993).

\section{- AAA-Module}

Vor wenigen Monaten konnten die Kristallstrukturen der DHC-Motordomänen (umfasst Linker und „Kopf“) von Dictyostelium discoideum (Kon et al, 2011) und Saccharomyces cerevisae (Carter et al, 2011) bei einer Auflösung von 4.5 bzw. $6 \AA ̊$ beschrieben werden (Abbildung I.4.). Dieser $350 \mathrm{KDa}$ große Abschnitt der DHC besteht unter anderem aus sechs kovalent miteinander verbundene AAADomänen, die in einer Ringstruktur organisiert sind. Die AAA-Einheiten sind dabei aus je einer großen $\mathrm{N}$-terminalen und einer kleinen C-terminalen Subdomäne aufgebaut. Die große Domäne enthält ein zentrales $\beta$-Faltblatt, welches sich aus fünf parallelen Strängen zusammensetzt und von insgesamt fünf $\alpha$-Helices flankiert wird. Die kleine Subdomäne besteht aus fünf $\alpha$-Helices.

Von den sechs AAA-Domänen sind nur die zentralen Module AAA1-AAA4 fähig, ATP zu binden (Gibbons et al, 1991; Ogawa, 1991). Sie beinhalten sogenannte P-Loop-Motive, welche die Nukleotid-Bindungsstellen im Molekül darstellen und in allen bisher bekannten Dynein-Sequenzen stark konserviert sind. Dagegen sind die P-Loop-Motive in den AAA-Domänen 5 und 6 entweder teilweise oder vollständig degeneriert, sodass die entsprechenden Module kein ATP binden (Asai \& Koonce, 2001). Die Motordomäne kann demnach insgesamt vier ATP-Moleküle aufnehmen (Mocz \& Gibbons, 1996). In Aktivitätstests stellte sich heraus, dass nur AAA1 in der Lage ist, ATP effektiv umzusetzen. Während dem Modul AAA3 noch geringe ATP-Hydrolyseraten nachgewiesen werden konnten, zeigten weder AAA2 noch AAA4 ATPase-Aktivität (Mocz et al, 1998; Reck-Peterson \& Vale, 2004). Die Funktion der beiden letztgenannten Domänen ist daher Gegenstand kontroverser Diskussionen. 


\section{Dictyostelium discoideum}

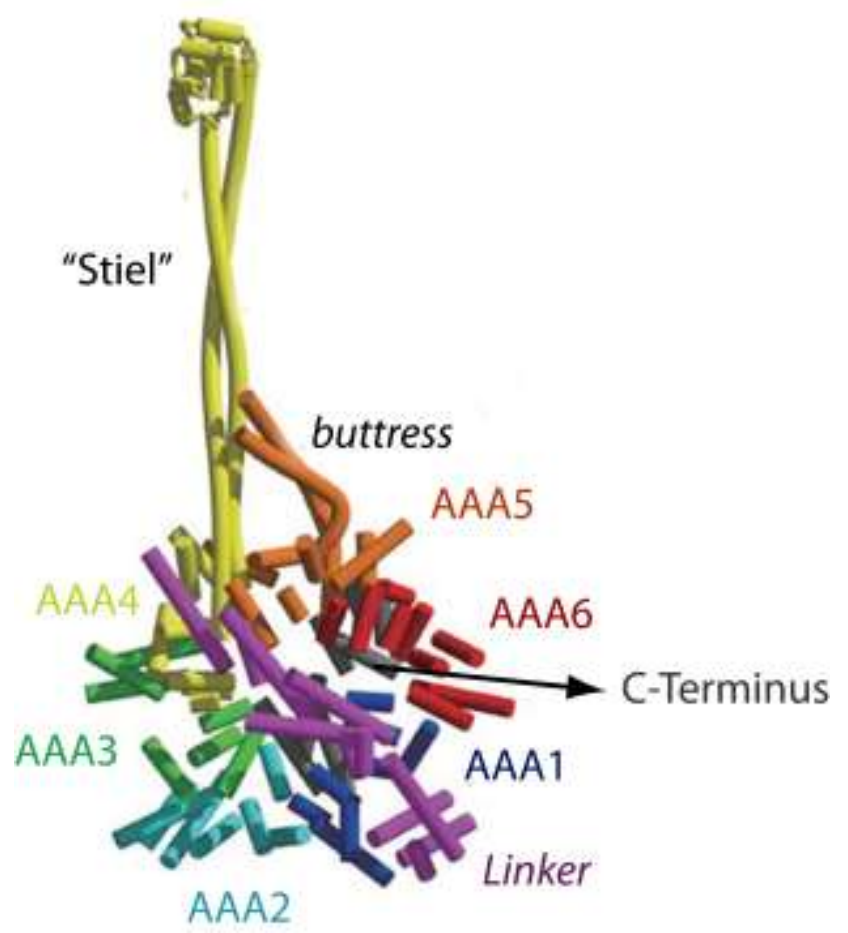

\section{Saccharomyces cerevisae}

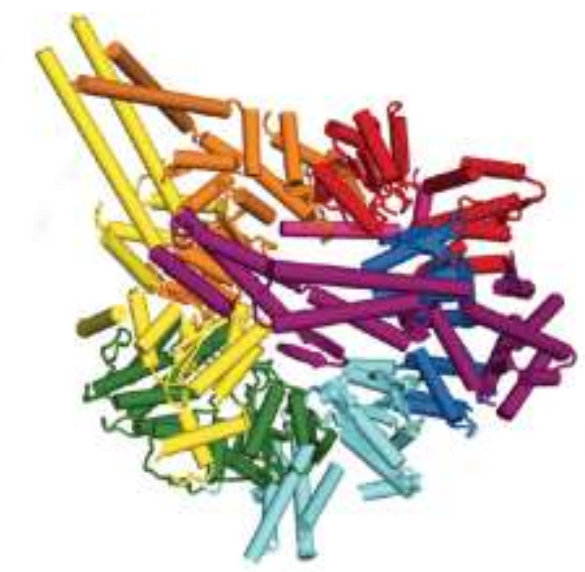

Abbildung 1.4. Zylindermodelle der DHC-Motordomäne von Dictyostelium discoideum und Saccharomyces cerevisae (modifiziert nach Kon et al, 2011 sowie Carter et al, 2011). Aufgrund seiner hohen Flexibilität wurde der "Stiel“ aus dem Konstrukt von Saccharomyces cerevisae entfernt. Für das Modell von Dictyostelium discoideum sind die einzelnen Domänen benannt. Die DHC-Motordomänen sind gleichfarbig dargestellt.

Aus phylogenetischen Analysen der Dynein-Familie geht hervor, dass das sogenannte Arginin-Finger-Motiv in den Modulen AAA2 und AAA4 von zytoplasmatischem Dynein hoch konserviert ist (Höök \& Vallee, 2006). Der positiv geladene Arginin-Finger kann mit dem $\mathrm{Y}$-Phosphat des in der benachbarten Bindungstasche aufgenommenen ATP-Moleküls in Kontakt treten und so zur Beschleunigung der ATP-Hydrolyse beitragen (Matveeva et al, 2002; Ogura \& Wilkinson, 2001). Insofern dienen die Domänen AAA2 und AAA4 möglicherweise der Feinregulation der Dynein-Motoraktivität (Höök, 2010).

Dyneine gehören zwar der AAA-Familie der ATPasen an, unterscheiden sich jedoch deutlich von typischen Vertretern dieser Proteinklasse. So organisieren 
sich die meisten AAA-Proteine zu hexameren Ringkomplexen, bestehend aus monomeren oder dimeren Bausteinen. Dynein hingegen ist durch sechs ungleich aufgebaute AAA-Module charakterisiert, die in einer Polypeptidkette vereint sind.

\section{- „Stiel“ und buttress}

Zwischen den AAA-Modulen 4 und 5 ist ein ca. $13 \mathrm{~nm}$ langer, intramolekularer „Stiel“ lokalisiert. Dieser besitzt eine coiled-coil-Struktur (Gee et al, 1997; ReckPeterson et al, 2006) und ragt aus dem Dynein-„Kopf“ heraus. An seiner Spitze befindet sich eine kleine globuläre Domäne, die die Anbindung an Mikrotubuli vermittelt ( $\rightarrow$ MTBD; microțubule-binding domain) (Carter et al, 2008; Gee et al, 1997). Diese Architektur ist unter den zytoskeletalen Motorproteinen einzigartig. Während sich die für Energieerzeugung und Filamentbindung verantwortlichen Einheiten in Kinesin und Myosin innerhalb einer globulären Domäne befinden, liegt innen in Dynein eine große räumliche Distanz zugrunde ( $250 \AA$ ). Daher ist die Frage von zentraler Bedeutung, wie allosterische Konformationsänderungen periodisch von AAA1 zur MTBD und wieder zurück übermittelt werden.

Röntgenkristallographische Untersuchungen der Dynein-Motordomäne deckten auf, dass der "Stiel“ eine Extension der AAA4-Domäne darstellt (Carter et al, 2011; Kon et al, 2011). Zudem stellte sich heraus, dass der "Stiel“ von einer aus Domäne AAA5 hervorgehenden strukturellen Einheit gestützt wird, welche ebenfalls durch ein coiled-coil-Motiv charakterisiert ist. Dieser Proteinabschnitt dient möglicherweise dem stabilisierten Transport schwerer Lasten und wurde aufgrund seiner Stützfunktion als buttress bezeichnet (Carter et al, 2011). Die MTBD einschließlich eines kurzen Abschnitts des "Stiels“ ( $20 \mathrm{kDa})$ ist der einzige Teilbereich der DHC ( $520 \mathrm{kDa})$, der bislang in atomarer Auflösung beschrieben werden konnte (Carter et al, 2008). Dabei zeigte sich, dass die coiled-coil-Struktur des "Stiels“ aus zwei antiparallelen a-Helices (CC1, CC2) besteht und die MTBD von insgesamt sechs a-helikalen Elementen $(\mathrm{H} 1-\mathrm{H} 6)$ geformt wird (Abbildung I.5.). In Mutationsexperimenten konnte $\mathrm{H} 1$ als primäre Mikrotubuli-Interaktionsstelle identifiziert werden (Carter et al, 2008). Ferner 
konnte der Kristallstruktur entnommen werden, dass die $\alpha$-Helices im proximalen Abschnitt des „Stiels“ eine stabile coiled-coil-Faltung zeigen, nahe der MTBD allerdings teilweise ungeordnet sind. Die entsprechende Region ist durch eine Krümmung des "Stiels“ charakterisiert, die von zwei hochkonservierten und zueinander versetzt liegenden Prolinresten (Pro ${ }^{3285}$ in CC1 und Pro ${ }^{3409}$ in CC2) hervorgerufen wird. Dadurch tritt eine Störung der regulären coiled-coil-Packung ein. Dies hat zur Folge, dass der distale Bereich des "Stiels" Flexibilität aufweist, die möglicherweise konformationelle Umgestaltungen erlaubt. Tatsächlich konnte in Crosslinking-Versuchen demonstriert werden, dass eine in dieser Region erfolgte Verlagerung von $\mathrm{CC} 1$ und $\mathrm{CC} 2$ um vier Aminosäuren relativ zueinander eine deutlich veränderte Affinität des „Stiels“ zu den Mikrotubuli nach sich zieht (Gibbons et al, 2005).

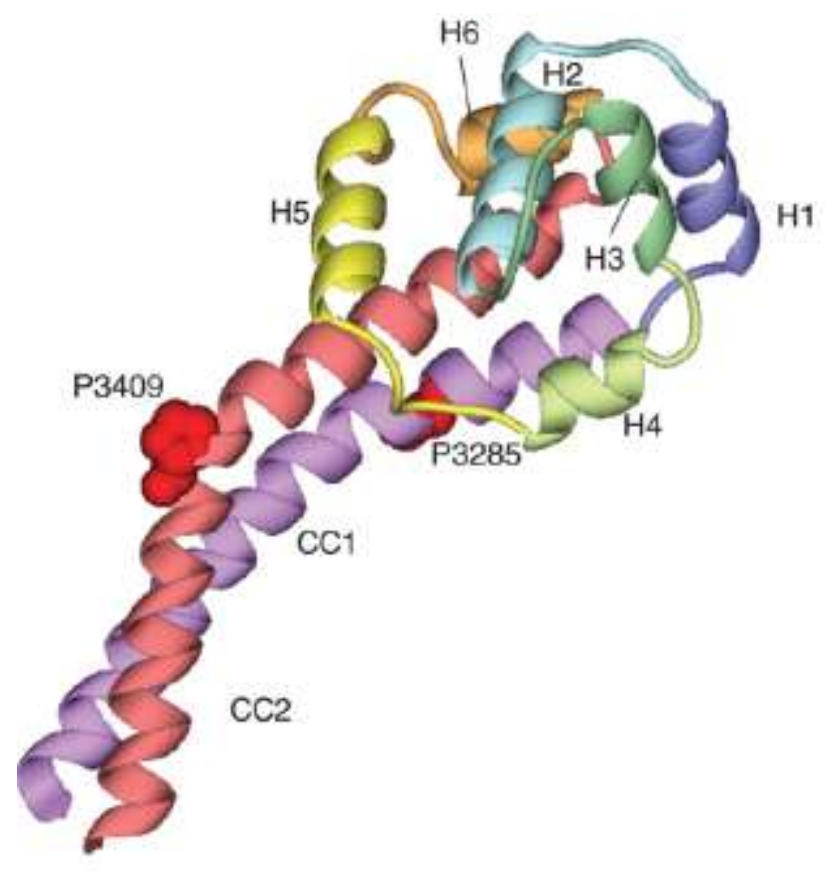

Abbildung I.5. Hochaufgelöste Struktur der MTBD und eines kurzen Bereichs des "Stiels" (Abbildung nach Carter et al, 2008). Die den „Stiel“ formenden antiparallelen $\alpha$-Helices (CC1 und CC2) gehen in insgesamt 6 a-helikale Bündel $(\mathrm{H} 1-\mathrm{H} 6)$ über, die die globuläre Interaktionsstelle für Mikrotubuli ausbilden. Zwei hochkonservierte Proline $\left(\mathrm{Pro}^{3285}\right.$ in CC1, Pro ${ }^{3409}$ in CC2) rufen eine Krümmung des „Stiels“ und daraus resultierend eine Störung der regulären coiledcoil-Packung im distalen Bereich hervor.

Dieser Effekt beruht auf einem Wechsel des Heptaden-Registers innerhalb der coiled-coil-Struktur. Im sogenannten $\beta$-Register, das den Zustand des kristallisierten "Stiels“ widerspiegelt, bindet die MTBD nur schwachaffin an 
Mikrotubuli. Im $\alpha$-Register hingegen konnte eine starke Interaktion beobachtet werden. Der Wechsel im coiled-coil-Register wird dabei aller Voraussicht nach durch eine laterale Gleitbewegung von $\mathrm{CC} 1$ gegen stationäres $\mathrm{CC} 2$ erzielt (Carter et al, 2008). Dies ist darin begründet, dass CC2 im Vergleich zu CC1 in der Kristallstruktur mit zahlreichen Helices der MTBD interagiert und CC1 darüber hinaus direkt an die primäre Mikrotubuli-Bindestelle $\mathrm{H} 1$ angrenzt. Dem zuvor erwähnten buttress, der den proximalen Bereich des "Stiels“ kontaktiert, könnte in Hinblick auf den "Gleitprozess" eine bedeutende Rolle zukommen. So wäre denkbar, dass allosterische Konformationsänderungen innerhalb des AAARings eine Krümmung des buttress hervorrufen, wodurch im „Stiel“ ein Wechsel des Heptaden-Registers induziert werden könnte (Carter et al, 2011).

Neben Dynein verfügen auch andere mechanochemische AAA-Proteine, darunter z. B. die molekularen Chaperone ClpB und HsIU als auch die transkriptionellen Aktivatoren $\mathrm{NtrC} 1$ und $\mathrm{DctD}$, über ausgeprägte coiled-coilStrukturen (Kon et al, 2009). Die coiled-coil-Domäne von ClpB etwa besitzt Eigenschaften, die denen des Dynein-,,Stiels“ sehr ähnlich sind. In strukturellen und biochemischen Experimenten konnte nachgewiesen werden, dass die $\alpha$ Helices in der coiled-coil-Struktur des Chaperons antiparallel angeordnet sind und Regionen beinhalten, die durch eine hohe Flexibilität charakterisiert sind. Ferner zeigte sich, dass Bewegungsvorgänge innerhalb des coiled-coil-Motivs für die Funktionalität des Proteins kritisch sind und dessen ATPase-Aktivität beeinflussen. Diese Befunde legen nahe, dass Dynein und $\mathrm{ClpB}$ von einem gemeinsamen AAA-Vorfahren abstammen, der eine coiled-coil-Faltung besaß. Möglicherweise gelang es Dynein unter Anpassung der Bewegungsprozesse innerhalb seiner coiled-coil-Domäne, die Vorgänge der ATP-Umsetzung und Mikrotubuli-Bindung zu koppeln und so eine gerichtete Bewegung entlang des Filaments zu erreichen (Kon et al, 2009). 


\section{- C-Terminus}

Der Aufbau des C-Terminus der DHC gliedert sich in zwei Abschnitte - den proximalen C-Terminus ( $14 \mathrm{kDa})$, der in allen Dyneinen existiert, und den distalen C-Terminus $(\sim 31 \mathrm{kDa})$, der in den zytoplasmatischen Dyneinen zahlreicher Pilze (z. B. Saccharomyces cerevisae) fehlt. Die beiden Regionen stehen über ein ca. 25 Aminosäuren umfassendes Segment miteinander in Verbindung, welches sich in Proteolyse-Versuchen als ungeordnet herausstellte und möglicherweise als flexibles „Scharnier“ fungiert (Rost et al, 2004).

Kinetische Untersuchungen von Dynein aus Saccharomyces cerevisae lieferten erste Anhaltspunkte für die funktionale Bedeutung des distalen CTerminus. Im Vergleich zu Dynein von Säugetieren lag dem Protein aus Saccharomyces cerevisae eine geringere Transportgeschwindigkeit, eine höhere maximale Anlauflast und ein wesentlich längerer Laufweg zugrunde (Gennerich et al, 2007; Mallik et al, 2004; McKenney et al, 2010; Reck-Peterson et al, 2006), der ein $\mathrm{Maß}$ für die Prozessivität des Motors darstellt. Des Weiteren konnte für Dynein aus Dictyostelium gezeigt werden, dass das Protein nach Deletion des CTerminus nicht mehr fähig ist, an Mikrotubuli zu assoziieren (Roberts et al, 2009). Diese Ergebnisse deuten auf eine direkte Verbindung zwischen distalem CTerminus und "Stiel“ hin. Röntgenstrukturanalysen deckten auf, dass der CTerminus kein integraler Bestandteil des AAA-Rings ist (Carter et al, 2011; Kon et al, 2011). Der distale C-Terminus konnte zwischen AAA1 und AAA5 lokalisiert werden (Kon et al, 2011) und verknüpft diese Module möglicherweise miteinander. Dadurch könnten allosterische Konformationsänderungen direkt von AAA1 nach AAA5 übermittelt und von dort aus über den buttress und den „Stiel“ zur MTBD weitergeleitet werden.

\section{- Linker}

Der bis zum AAA1-Modul reichende N-terminale Bereich der Motorregion wird als Linker-Domäne bezeichnet. Neueste Erkenntnisse deuten darauf hin, dass diese $\sim 60 \mathrm{kDa}$ große strukturelle Komponente wesentlich zur Translokation des 
Dynein-Moleküls entlang der Mikrotubuli beiträgt. Fluoreszenzspektroskopische Untersuchungen brachten hervor, dass die Linker-Domäne Nukleotid-abhängig periodischen Verlagerungen unterliegt. Dabei vollzieht sie zwischen den Modulen AAA2 und AAA4 eine Schwingbewegung, die sich über ca. $17 \mathrm{~nm}$ erstreckt (Burgess et al, 2003). Demnach fungiert der Linker möglicherweise als mechanischer Hebelarm, der kleine Konformationsänderungen verstärkt und so maßgeblich an der Entstehung des Kraftschlags beteiligt ist (Roberts et al, 2009).

Die Linker-Domäne scheint ebenfalls großen Einfluss auf die ATPase-Aktivität von Dynein zu haben. So konnte der Nachweis erbracht werden, dass die Motordomäne in Abwesenheit der Linker-Region eine stark reduzierte basale ATPase-Aktivität aufweist (Reck-Peterson et al, 2006; Roberts et al, 2009). Über welchen Mechanismus der Linker die ATPase-Aktivität reguliert, ist noch unklar. Eine Möglichkeit ist, dass die Anlagerung der Linker-Domäne an AAA2 bzw. AAA4 mit Konformationsänderungen in diesen Modulen einhergeht, die anschließend über die domänenübergreifenden Arginin-Finger Motive an AAA1 bzw. AAA3 weitergeleitet werden. Dies könnte eine veränderte ATPase-Aktivität des Motorproteins zur Folge haben (Höök, 2010).

Ausgehend von den hochaufgelösten Strukturen der Dynein-Motoreinheit, setzt sich der Linker aus insgesamt 4 Unterdomänen zusammen, die einen vornehmlich helikalen Aufbau haben. Indes gibt es widersprüchliche Befunde zur Positionierung dieser strukturellen Einheit innerhalb der „Kopf“-Region. So lagerte sich der N-terminale Bereich der Linker-Domäne in den Kristallstrukturen an unterschiedliche AAA-Module an - AAA4 (Kon et al, 2011) bzw. AAA5 (Carter et al, 2011). Jedoch ist anzumerken, dass die Dynein-Motordomäne in den Studien in unterschiedlichen Zuständen kristallisiert wurde, nämlich in Abwesenheit von Nukleotid ( $\rightarrow$ AAA5) bzw. im Komplex mit MgADP ( $\rightarrow$ AAA4). Insofern scheint es möglich, dass die abweichende Ausrichtung des Linkers auf eine durch ADP-Dissoziation hervorgerufene Umgestaltung innerhalb der Motordomäne zurückzuführen ist. 


\section{I.1.2.3.2. Mechanochemischer Zyklus}

Aus Crosslinking-Experimenten an Dynein-„,Köpfen“ ging hervor, dass der Wechsel vom $\beta$ - in das $\alpha$-Register des "Stiels“ nicht nur mit einer verbesserten Anbindung an die Mikrotubuli einhergeht, sondern auch mit einer reduzierten ATPase-Aktivität korreliert (Kon et al, 2009). Dieser Befund deutet darauf hin, dass die ATP-Hydrolyse an AAA1 und AAA3 einen Übergang des „Stiels“ vom $\beta$ in den $\alpha$-Zustand nach sich zieht. Durch die Bindung von ATP an die „Kopf“Region von Dynein wird die coiled-coil Domäne daraufhin wieder in den $\beta$ Zustand überführt.

Basierend auf diesen Erkenntnissen wurde folgendes Modell für den zyklischen Informationsfluss zwischen AAA1 und MTBD vorgeschlagen (Abbildung I.6.; Carter \& Vale, 2010): Im sogenannten Apo-Zustand, d. h. in Abwesenheit von Nukleotid, liegt die coiled-coil-Domäne des Dynein-,Stiels“ im a-Register vor. Dabei bindet Dynein stark an den Mikrotubulus (1). Die Anlagerung von ATP an die Motorregion bewirkt konformationelle Änderungen innerhalb des AAA-Rings, die zum „Stiel“ weitergeleitet werden. Die coiled-coilDomäne geht in das $\beta$-Register über, wodurch die Ablösung des Motorproteins vom Mikrotubulus induziert wird (2). Gleich danach vollzieht der Linker, der im Apo-Zustand die AAA4-Domäne nahe der Basis des "Stiels" passiert, eine Ausholbewegung (Primed) zur entgegengesetzten Seite des AAA-Rings, sodass der Austritt nahe AAA2 erfolgt (3).

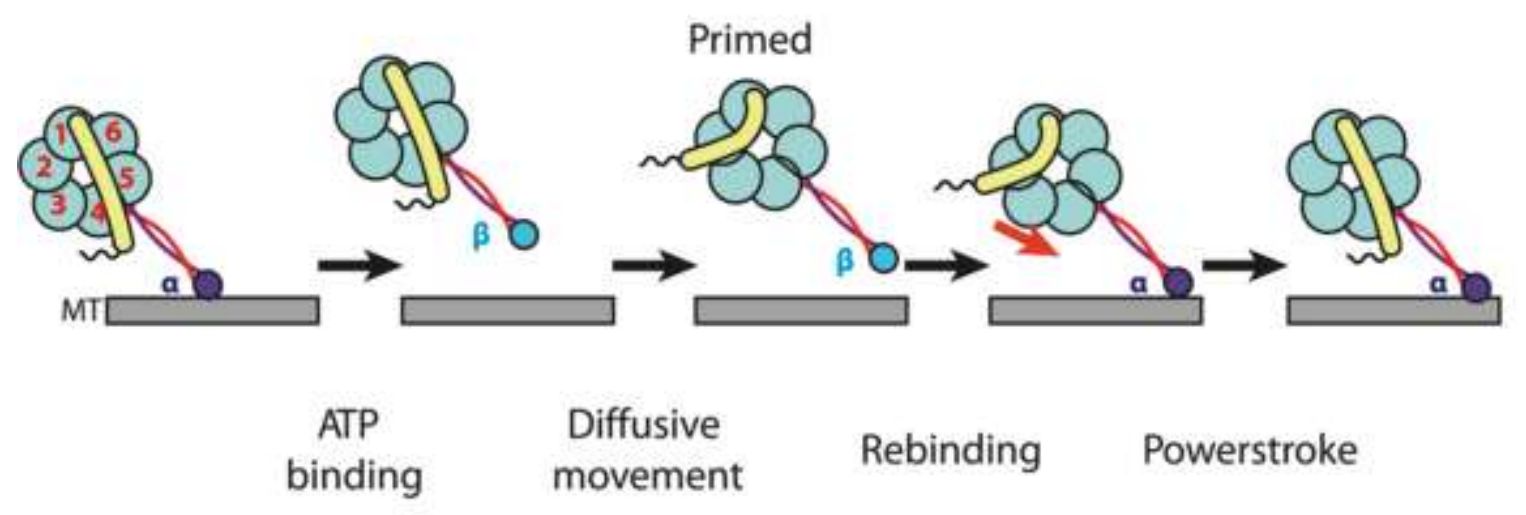

Abbildung I.6. Modell für den mechanochemischen Zyklus von zytoplasmatischem Dynein (Abbildung modifiziert nach Carter \& Vale, 2010). Einzelheiten siehe Text. 
Außerdem kommt es an AAA1 und AAA3 zu einer beschleunigten Hydrolyse von ATP zu ADP und $P_{i}$. Nach ATP-Hydrolyse bindet Dynein mit schwacher Affinität gewinkelt in Richtung Minus-Ende an den Mikrotubulus. Im Anschluß daran wird $P_{i}$ freigesetzt und die coiled-coil-Domäne des „Stiels“ wechselt zurück in das $\alpha$ Register. Daraus resultierend assoziiert der Dynein-,Kopf“ hochaffin an den Mikrotubulus. Der darauffolgende Schwung des Linkers in seine Ausgangsposition ist an den Kraftschlag (Powerstroke) von Dynein gekoppelt (4). Dabei sorgt der senkrecht zur "Stiel“-Achse gerichtete Kraft-Vektor der LinkerBewegung für die retrograde Fortbewegung des Motorproteins. Würde der Dynein-„Stiel“ senkrecht an den Mikrotubulus anbinden, würde der Schwung des Linkers keine effektive Verlagerung des molekularen Motors entlang seines „Schienennetzes“ zur Folge haben. Zusätzlich tritt eine beschleunigte ADPFreisetzung von den Domänen AAA1 und AAA3 ein, woraufhin Dynein einen neuen mechanochemischen Zyklus durchlaufen kann (5).

Die Annahme einer gewinkelten Anbindung des "Stiels“ an den Mikrotubulus wird von Experimenten mit Dynein-Konstrukten gestützt, deren coiled-coilDomäne um sieben Heptaden-Wiederholungen verlängert bzw. verkürzt wurde (Carter et al, 2008). Beide Längenveränderungen gehen mit einer Drehung des AAA-Rings um $180^{\circ}$ gegenüber der MTBD einher. Da die Linker-Domäne folglich in die entgegengesetzte Richtung schwingt, wäre bei senkrechter Anbindung der Konstrukte an den Mikrotubulus eine Fortbewegung in anterograder Richtung zu erwarten gewesen. Jedoch führten die modifizierten Proteine nach wie vor retrograde Bewegungen aus. Diese Ergebnisse setzen voraus, dass Dynein gewinkelt in Richtung Minus-Ende an den Mikrotubulus assoziiert und bestätigen somit die Beobachtungen von Ueno et al (2008), wonach der "Stiel“ sowohl vor als auch nach dem Dynein-Kraftschlag hin zum Minus-Ende des Filaments ausgerichtet ist.

Ermöglicht durch die abwechselnde Bindung der beiden Dynein-„Köpfe“ an die Mikrotubuli kann ein Dynein-Molekül, auch unter der Beladung mit Fracht, lange Wegstrecken zurücklegen ohne sich vom Mikrotubulus abzulösen. Diese prozessive Fortbewegung setzt die Dimerisierung der Schweren Ketten voraus. 
Die koordinierte schrittweise Bewegung von Dynein entlang des MikrotubuliNetzwerks konnte als "Hand über Hand“ Mechanismus charakterisiert werden (Mallik et al, 2004; Toba et al, 2006). Dabei hangelt sich Dynein am Filament entlang, indem die beiden „Kopf“-Regionen abwechselnd an den Mikrotubulus binden und sich wieder ablösen, wobei zu jedem Zeitpunkt mindestens eine „Kopf“-Region gebunden ist. Pro Schritt eines „Kopfes“ wird vorwiegend eine ca. $8 \mathrm{~nm}$ lange Wegstrecke zurückgelegt (Cho et al, 2008), was der Entfernung zwischen zwei benachbarten $\beta$-Tubulin-Untereinheiten entspricht. Dynein ist aber auch in der Lage, Schritte von bis zu $32 \mathrm{~nm}$ vorzunehmen, oder sich einige Schritte rückwärts in Richtung Plus-Ende des Mikrotubulus zu bewegen. Ebenso konnten für Dynein größere seitliche Bewegungen zwischen den Protofilamenten beobachtet werden (Cho et al, 2008). Diese flexible Fortbewegung ermöglicht es dem Motorprotein unter Umständen, Hindernissen auf dem Mikrotubulus auszuweichen.

Allerdings herrscht große Unklarheit darüber, über welchen Mechanismus die beiden „Kopf“-Regionen miteinander kommunizieren, um eine synchrone Fortbewegung entlang des Filaments zu gewährleisten. Die erst kürzlich kristallisierte Motordomäne von Dictyostelium discoideum (Kon et al, 2011) liefert einen möglichen Hinweis auf eine direkte Interaktion zwischen den Dynein„Köpfen“. Das Protein lag in zwei Kopien in der asymmetrischen Einheit vor, wobei die "Köpfe" über ihren C-Terminus und die Module AAA2, AAA3 und AAA4 miteinander assoziierten. Jedoch könnte es sich hierbei auch um ein kristallographisches Artefakt handeln.

\section{I.1.3. Zielsetzung der Arbeit}

Aufgrund seiner hohen molekularen Komplexität und seines ausladenden Gesamtaufbaus gestalten sich strukturelle Untersuchungen an Dynein sehr schwierig. Daraus resultierend war die Struktur des Proteins bis vor kurzem noch kaum verstanden. Allein die Schwere Kette, welche die für die Energieumwandlung entscheidenden Domänen enthält, ist mit einer molekularen Masse 
von $\sim 520 \mathrm{kDa}$ wesentlich größer als die Motorproteine Myosin und Kinesin zusammen. Während für diese Proteine sehr viele Kristallstrukturen in den verschiedensten Nukleotid-Komplexen bekannt sind und ihr Mechanismus der Kraftübertragung dementsprechend gut verstanden ist, verhält es sich bei Dynein ganz anders. Zu Beginn dieser Arbeit waren Strukturinformationen zur DHC auf elektronenmikroskopische Aufnahmen begrenzt (Burgess et al, 2003). Diese konnten in den letzten Jahren und Monaten durch hochaufgelöste Daten ergänzt werden. Neben der Mikrotubuli-Bindedomäne zusammen mit einem kurzen Stück des „Stiels“ ( $20 \mathrm{kDa}$; Carter et al, 2008) wurden jüngst auch die Kristallstrukturen der DHC-Motordomänen von Dictyostelium discoideum ( $380 \mathrm{kDa})$ und Saccharomyces cerevisae ( $360 \mathrm{kDa}$ ) bei 4.5 bzw. $6 \AA$ gelöst (Carter et al, 2011; Kon et al, 2011). Trotz damit verbundener Fortschritte im Verständnis der DHC-Organisation, fehlen nach wie vor Daten in atomarer Auflösung, um Einblicke in die Funktionsweise des Dynein-Motors erhalten zu können. Um diesem Ziel einen Schritt näher zu kommen, sollten im Rahmen dieser Arbeit Teilbereiche der zytoplasmatischen DHC exprimiert, kristallisiert und mittels Röntgenstrukturanalyse beschrieben werden. 


\section{I.2. Ergebnisse}

\section{I.2.1. Bestimmung initialer Domänengrenzen für die zytoplasma- tische DHC von Mensch und Dictyostelium discoideum}

Um die zytoplasmatische DHC strukturell zu charakterisieren, wurde das Polypeptid in Abschnitte unterteilt, die einzeln exprimiert und kristallisiert werden sollten. Die Bestimmung initialer Domänengrenzen basierte auf der Kenntniss, dass die DHC einiger Pilze (z. B. Ustilago maydis und Laccaria bicolor) von zwei Genen codiert wird und sich demnach aus zwei separat exprimierten Proteinen zusammensetzt (Kollmar, persönliche Mitteilung; Straube et al, 2001).
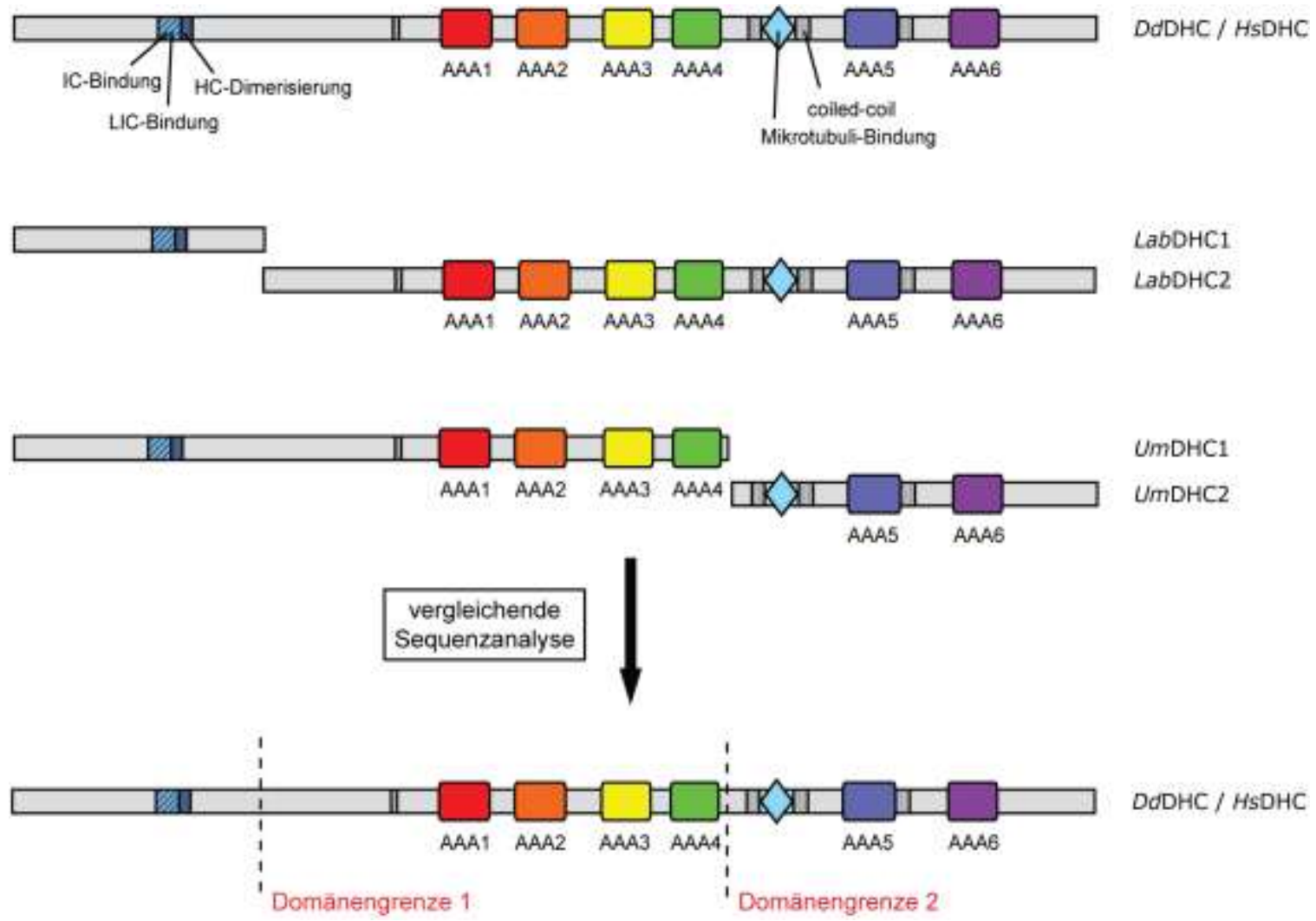

Abbildung I.7. Schematische Darstellung der Domänen-Organisation der zytoplasmatischen DHC von Dictyostelium discoideum $(\mathrm{Dd})$ und Mensch $(\mathrm{Hs})$ sowie der Pilze Ustilago maydis $(\mathrm{Um})$ und Laccaria bicolor (Lab). Durch vergleichende Sequenzanalyse wurden die Trennpunkte der pilzlichen DHC-Gene in die Schweren Ketten von Dictyostelium discoideum und Mensch übertragen und als Domänengrenzen verwendet. 
Dabei konnten zwei unterschiedliche Trennpunkte der Gene identifiziert werden (Kollmar, persönliche Mitteilung). Deren exakte Positionen wurden, wie in Abbildung I.7. schematisch dargestellt, mittels vergleichender Sequenzanalyse in die DHC von Mensch und Dictyostelium discoideum übertragen. Dort wurden sie als Grenzen für Expressionskonstrukte verwendet.

\section{I.2.2. Klonierung, Herstellung und Expression von DHC-Konstrukten in Dictyostelium discoideum}

Um zu überprüfen, ob die ermittelten Domänengrenzen für die stabile Expression von Teilbereichen der Schweren Kette geeignet sind, wurden verschiedene an die beiden Trennpunkte angrenzende Konstrukte der zytoplasmatischen DHC von Mensch und Dictyostelium discoideum hergestellt und basierend auf dem Myosin-Fusionssystem (Kollmar, 2006) exprimiert. Die jeweiligen DNAFragmente wurden ausgehend von genomischer DNA (DHC von Dictyostelium discoideum) oder cDNA (DHC von Mensch) über PCR amplifiziert und anschließend über die Schnittstellen Mlul und BsrGl in den Expressionsvektor pDXA-mako2b einkloniert. Das Plasmid codiert für einen N-terminalen TandemAffinitäts-Tag, bestehend aus der Motor-Domäne des Klasse-II-Myosins von Dictyostelium (MMD) und einem Okta-Histidin-Peptid. Nach Transformation in E. coli-Zellen des Stammes XL2-blue wurde die Plasmid-DNA positiver Klone mittels Elektroporation in Dictyostelium AX3-ORF ${ }^{+}$-Zellen eingebracht. Daraufhin wurden die gewachsenen Kolonien gemäß dem Protokoll für die analytische Reinigung von Myosin-Motor-Fusionsproteinen (siehe Punkt III.4.2.) auf Expression getestet. Der Großteil der Fusionskonstrukte konnte in Dictyostelium discoideum stabil hergestellt werden (Abbildung I.8.). Für die zytoplasmatische DHC von Mensch und Dictyostelium discoideum ergaben sich dabei einheitliche Ergebnisse. Während sich Trennpunkt 1 nur als N-terminale Grenze für die Expression stabiler Fusionskonstrukte als geeignet erwies, konnte Trennpunkt 2 hierfür sowohl als N- als auch als C-terminale Grenze herangezogen werden. 


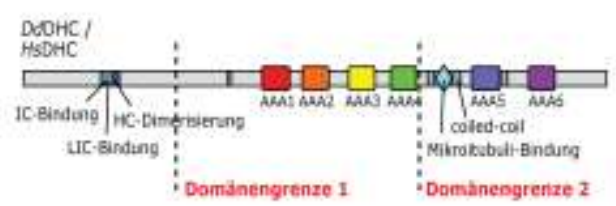

\section{Dd}

Testkenstrukt1_Dd (N3174-C4730)

Testkonstrukt2_Od (N2-C1403)

Testkonstrukt3_Od (N593-C1403)

Testkonstrukt4_Dd (N1404-C1963)

Testkonstrukt5_Dd (N2661-C3175)

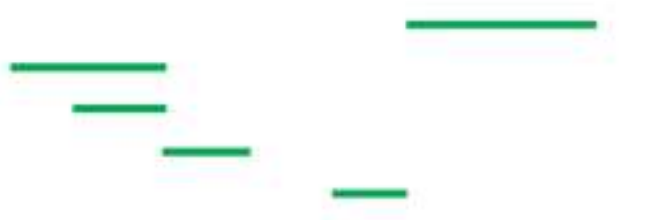

++ "Stiel", buttress, AAA5+6, C-Terminus.

Stamm

Linker

$\mathrm{AAA} 3+4$

\section{Hs}

Testhonstrukt1 Hs (N3096-C4546)

Testionstrukt2 Hs (N2-C1335)

Testionstrukt3 Hs (N634-Cl335)

Testhonstrukt4_H5 (N1336-C3095)

Testkonstrukt5_Hs (N1336-C1895)

Testivonstrukt6_Hs \{N2582-C3095)

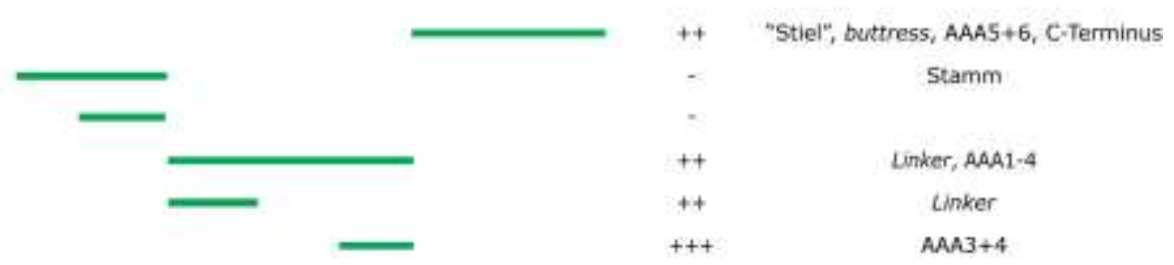

Abbildung 1.8. Überblick über die für anfängliche Expressionstests herangezogenen DHCKonstrukte von Dictyostelium discoideum $(D d)$ und Mensch $(H s)$ sowie deren Expressionslevel $(-\rightarrow$ keine Expression, $+\rightarrow$ schwache Expression, $++\rightarrow$ moderate Expression, $+++\rightarrow$ starke Expression). Die Konstrukte wurden als Myosin-Fusionsproteine exprimiert. Hinter dem jeweiligen Konstruktnamen sind in Klammern Start- und Endpunkt der das Konstrukt umfassenden Aminosäuresequenz angegeben. Die grün eingefärbten Querbalken veranschaulichen, über welche Abschnitte der DHC sich die jeweiligen Konstrukte erstrecken. Zudem ist angeführt, welche strukturellen Einheiten der DHC die entsprechenden Konstrukte beinhalten.

Ausgehend von diesen Befunden wurden zahlreiche weitere Konstrukte der Schweren Kette von Mensch und Dictyostelium discoideum generiert und auf Expression getestet. Des Weiteren wurden diverse Abschnitte der DHC unabhängig von den ermittelten Domänengrenzen hergestellt, darunter der „Stiel“ und verschiedene AAA-Module. 


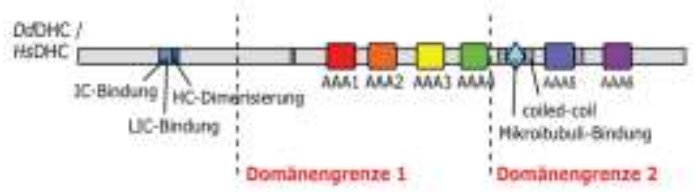

Dd

eckel od (N3174-C4730) ecke2 od (N3557-C4730) edke3 $D d$ (N2-C1403) ecket od (N593-C1403) eckes od (N1404-C2445) ecke6_Od (N1404-C210B) ecke7 of (N1404-C1953) eckes od (N2263-C2445) ecker od (N2651-C3175) edke10_Dd (N3003-C3175)

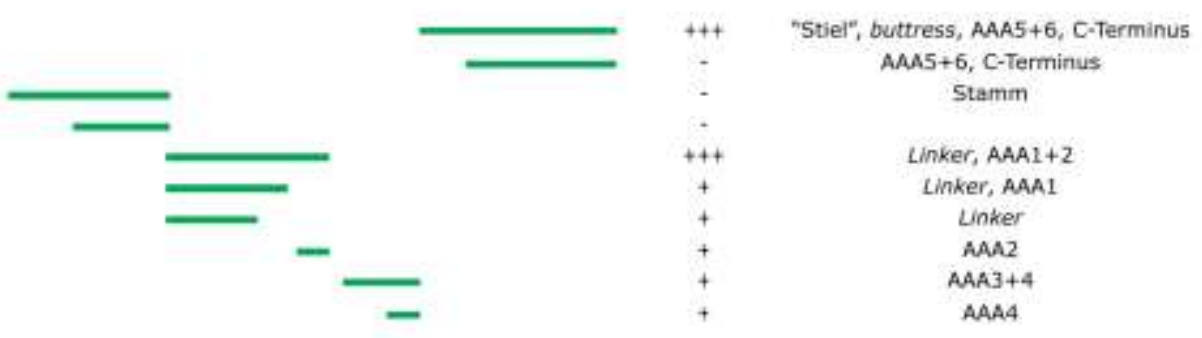

Hs

ecke1_H5 (N1337-C4646) ecke2 Hs (N2582-C4645) ecke3 HS (N3096-C4646) ecke4 Hs (N3498-C4646) eckes_H5 (N2-C3095) ecke6_Hs (N2.C1335) ecke7_H5 (N634-C1335) ecke8 Hs (N1336-C3095) ecke9 H5 (N1336-C2393) ecke10_is (N1336-C2049) ecke11_Hs (N1336-C1895) ecke12 its (N1896-C2352) ecke13 its (N1896-C2049) ecke14 its (N2221-C3095) ecke15_Hs (N2211-C2362) ecke16 its (N2582-C3095) ecke17_Hs (N2924-C3476) ecke18 its (N2924-C3095) ecke19_Hs (N3206-C3476)
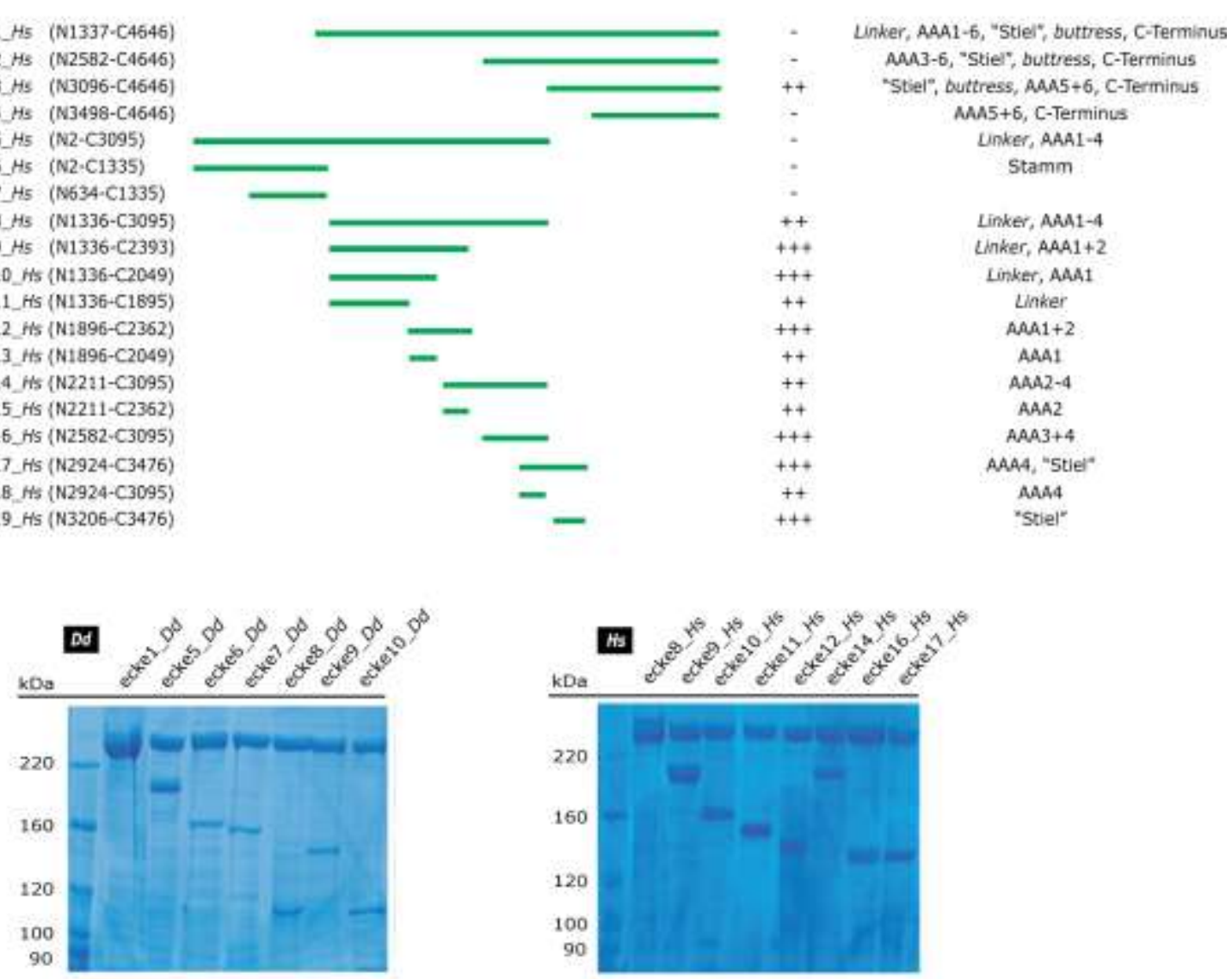

Abbildung I.9. Übersicht über alle in die Expressionstests eingebundenen DHC-Konstrukte von Dictyostelium discoideum $(D d)$ und Mensch $(H s)$ sowie deren Expressionslevel. Darunter sind die dazugehörigen SDS-Gele (5\%) abgebildet, wobei für die DHC von Mensch nur die Proteinbanden einiger repräsentativer Konstrukte gezeigt sind. Die Banden bei $250 \mathrm{kDa}$ rühren von endogenem Klasse-II-Myosin aus Dictyostelium her. Ansonsten entsprechen sich Abbildung I.8. und I.9. in ihren Erklärungen. 
In diesem Zusammenhang sei erwähnt, dass die DHC-Sequenz von Dictyostelium discoideum in Form zweier sich überlappender genomischer DNAAbschnitte vorlag (Sequenz 1: N1-C2510; Sequenz 2: N2500-C4730), deren Ligation misslang. Demzufolge konnten für den Schleimpilz keine sequenzübergreifenden Fragmente konstruiert werden.

Wie in Abbildung 1.9. gezeigt, wurden zahlreiche Abschnitte der DHC in Dictyostelium discoideum gut exprimiert. Allerdings waren abhängig vom Ausgangsorganismus deutliche Unterschiede in der Proteinausbeute feststellbar. Lagen den als Myosin-Fusionsprotein exprimierten Teilbereichen der menschlichen DHC mittlere bis hohe Expressionsraten zu Grunde, konnten die Fusionskonstrukte von Dictyostelium discoideum, mit Ausnahme von ecke1MMD_Dd und ecke5MMD_Dd, in nur geringen Mengen erhalten werden. Die nur schwach exprimierten Proteine blieben für Nachfolgeversuche unberücksichtigt, da sie nicht in den für die strukturellen Untersuchungen erforderlichen Mengen hätten hergestellt werden können.

\section{I.2.3. Aufreinigung der Fusionskonstrukte}

$\mathrm{Ni}^{2+}$-NTA-Bindestudien sollten Aufschluss darüber geben, wie effektiv sich die in Dictyostelium discoideum überexprimierten Fusionskonstrukte affinitätschromatographisch aufreinigen lassen. Die Durchführung der Bindungstests ist in Punkt III.4.4. beschrieben. Wider Erwarten war nur ein geringer Anteil der Fusionsproteine in der Lage, effektiv an das Säulenmaterial zu binden. Dabei handelte es sich um ecke1MMD_Dd, ecke10MMD_Hs, ecke11MMD_Hs und ecke19MMD_Hs. Alle anderen Proteine banden in nur sehr geringen Mengen an die $\mathrm{Ni}^{2+}$-NTA-Matrix. In entsprechenden Fällen lag ca. $90 \%$ des Gesamtproteins im Durchlauf vor. Es folgten zahlreiche Versuche, um eine verbesserte Aufreinigung $\mathrm{zu}$ erzielen. Dazu wurde von den stark exprimierten Fusionskonstrukten ecke5MMD_Dd, ecke12MMD_Hs und ecke16MMD_Hs Gebrauch gemacht, die exemplarisch für sämtliche Proteine standen, deren Affinitätsaufreinigung fehlschlug. Diese wurden zunächst mit einer großen 
Bandbreite an unterschiedlichen Additiva versetzt (Tabelle I.1.), die eine Relaxation des Moleküls und daraus resultierend eine Freilegung des potenziell sterisch gehinderten Affinitäts-Tags bewirken sollten. Die Inkubationszeit betrug jeweils 60 Minuten bei RT.

Tabelle I.1. Überblick über die in den Protein-Aufreinigungstest einbezogenen Additiva, einschließlich der jeweils verwendeten Endkonzentration.

\begin{tabular}{|c|c|c|}
\hline & Additiv & Endkonzentration \\
\hline Kosmotrope Agenzien & $\begin{array}{l}\mathrm{MgSO}_{4} \\
\left(\mathrm{NH}_{4}\right)_{2} \mathrm{SO}_{4}\end{array}$ & $\begin{array}{l}0.2 \mathrm{M} \\
0.2 \mathrm{M}\end{array}$ \\
\hline Schwach kosmotrope Agenzien & $\begin{array}{l}\mathrm{NaCl} \\
\mathrm{KCl}\end{array}$ & $\begin{array}{l}0.5 \mathrm{M} \\
0.5 \mathrm{M}\end{array}$ \\
\hline Chaotrope Agenzien & $\begin{array}{l}\mathrm{CaCl}_{2} \\
\text { Harnstoff }\end{array}$ & $\begin{array}{l}0.2 \mathrm{M} \\
0.2 \mathrm{M}\end{array}$ \\
\hline Aminosäuren & $\begin{array}{l}\text { Glyzin } \\
\text { L-Arginin }\end{array}$ & $\begin{array}{l}1 \% \\
0.3 \mathrm{M}\end{array}$ \\
\hline Zucker und Alkohole & $\begin{array}{l}\text { Sukrose } \\
\text { Glyzerol }\end{array}$ & $\begin{array}{l}0.3 \mathrm{M} \\
5 \%\end{array}$ \\
\hline Detergenzien & $\begin{array}{l}\text { Tween } 20 \\
\text { Nonidet P-40 }\end{array}$ & $\begin{array}{l}40 \mu \mathrm{M} \\
0.5 \%\end{array}$ \\
\hline
\end{tabular}

Jedoch ging diese Maßnahme mit keiner verbesserten Anbindung der Proteine an die $\mathrm{Ni}^{2+}-$ NTA-Matrix einher. Selbiges traf auf das Einklonieren eines Cterminalen Histidin-Tags in die DHC-Konstrukte zu, infolgedessen die Fusionsproteine über einen beidseitigen Affinitäts-Tag verfügten. Als nächstes wurde der Einfluss unterschiedlicher Säulenmaterialien auf die Aufreinigung der Fusionskonstrukte untersucht. Dabei kamen die Affinitätsmaterialien $\mathrm{Co}^{2+}$-NTA und $\mathrm{Ni}^{2+}$-IDA sowie die lonenaustauscher DEAE, SP und Hydroxylapatit zum Einsatz (Tabelle I.2.). 
Tabelle I.2. Übersicht über die für Protein-Bindungstests herangezogenen Säulenmatrices, einschließlich der entsprechenden Versuchsbedingungen.

\begin{tabular}{|c|c|c|}
\hline Säulenmaterial & Proben- und Waschpuffer & Elutionspuffer \\
\hline $\mathrm{Co}^{2+}-\mathrm{NTA} / \mathrm{Ni}^{2+}-$ IDA & 50 mM Hepes, pH 7.3; 100 mM NaCl & 500 mM Imidazol, pH 7.3 \\
\hline DEAE-Sepharose & $50 \mathrm{mM}$ Tris, $\mathrm{pH} 8.5 ; 10 \mathrm{mM} \mathrm{NaCl}$ & $50 \mathrm{mM}$ Tris, $\mathrm{pH}$ 8.5; $500 \mathrm{mM} \mathrm{NaCl}$ \\
\hline SP-Sepharose & 50 mM MES, pH 6.0; $10 \mathrm{mM} \mathrm{NaCl}$ & $50 \mathrm{mM}$ MES, pH 6.0; $500 \mathrm{mM} \mathrm{NaCl}$ \\
\hline Hydroxylapatit & $10 \mathrm{mM} \mathrm{KP}, \mathrm{pH} 7.0 ; 100 \mathrm{mM} \mathrm{NaCl}$ & $100 \mathrm{mM} \mathrm{KP}, 7.0 ; 500 \mathrm{mM} \mathrm{NaCl}$ \\
\hline
\end{tabular}

Unter Verwendung der Affinitäts-Materialien $\mathrm{Co}^{2+}$-NTA und $\mathrm{Ni}^{2+}$-IDA lag nach wie vor ca. $90 \%$ des Gesamtproteins im Durchlauf vor. Auch die lonenaustauscher DEAE und SP erwiesen sich für die Aufreinigung als ungeeignet. In beiden Fällen banden die Fusionskonstrukte in nur sehr geringen Mengen an die Matrix. Außerdem war es auch in Gegenwart hoher Salzkonzentrationen (1.5 M NaCl) nicht möglich, das gebundene Protein von der Säule zu eluieren. Mit Hydroxylapatit konnten hingegen wesentlich bessere Ergebnisse erzielt werden. So war das Material in der Lage, die Fusionsproteine sehr effektiv zu binden. Zwar verblieb unter oben aufgeführter Elutionsbedingung der Großteil der aufgetragenen Probe auf dem Säulenmaterial, allerdings konnte diese in Folgeversuchen unter gleichzeitiger Erhöhung der $\mathrm{KP}_{\mathrm{i}}$ - und $\mathrm{NaCl}$-Konzentration vollständig eluiert werden. Unabhängig vom verwendeten Konstrukt erfolgte die Elution im Bereich von $250 \mathrm{mM}$ bis $300 \mathrm{mM} \mathrm{KP}$, $\mathrm{pH} 7.0$, und $800 \mathrm{mM} \mathrm{NaCl}$.

\section{I.2.4. Analyse des Oligomerisierungszustandes der Fusionsproteine mittels analytischer Gelfiltration}

Um herauszufinden, in welchem Oligomerisierungszustand die aufgereinigten Fusionskonstrukte vorliegen, wurden sie unter Verwendung von Superdex 200 (Hi Load 16/60 Superdex) als Säulenmaterial einer GrößenausschlussChromatographie unterzogen. Aggregate hätten weitreichende Folgen für 
Kristallisationsversuche, da das Protein zu diesem Zweck als homogene Population, z. B. als Monomer oder Dimer, vorliegen sollte. Nur homogene Gruppen von Molekülen können ein regelmäßiges Kristallgitter und damit einhergehend qualitativ hochwertige Kristalle ausbilden. Aus den in Abbildung I.10. gezeigten Elutionsprofilen geht hervor, dass die über Hydroxylapatit gereinigten Proben ausnahmslos im Ausschlussvolumen der Säule eluiert wurden und demzufolge starker Aggregation unterlagen. Selbiges trifft aller Voraussicht nach auf sämtliche Proteine $\mathrm{zu}$, die nur schwachaffin an die $\mathrm{Ni}^{2+}$ NTA-Matrix banden. Die über $\mathrm{Ni}^{2+}$-NTA-Chromatographie erfolgreich aufgereinigten Fusionskonstrukte ecke1MMD_Dd, ecke10MMD_Hs, ecke11MMD_Hs und ecke19MMD_Hs lagen hingegen in einem jeweils definierten Oligomerisierungszustand vor (Abbildung I.11.). Durch Vergleich mit einem Standardspektrum konnten die Proben als Dimere identifiziert werden.

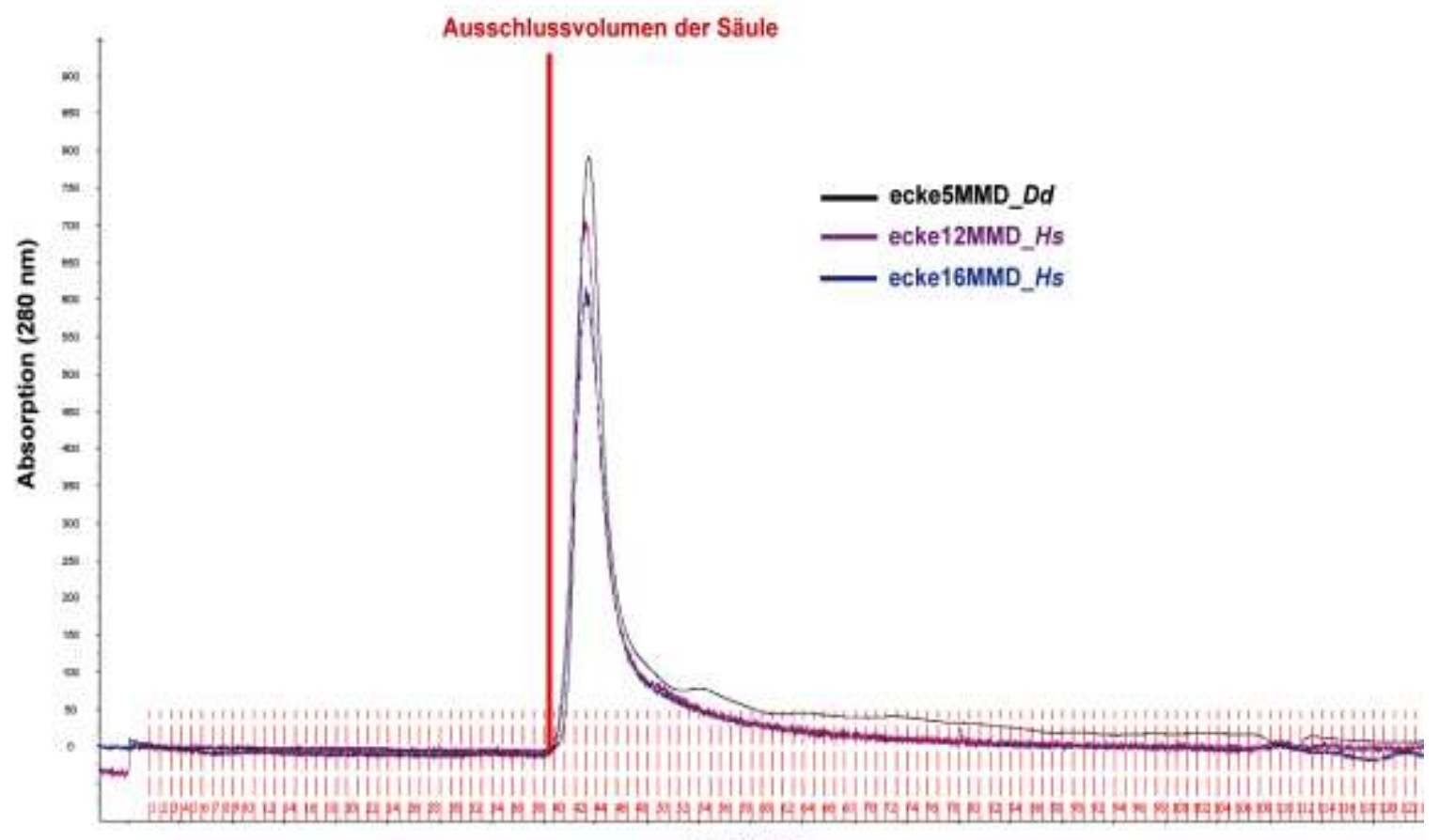

Fraktionen

Abbildung I.10. Elutionsprofile aus den Gelfiltrationsläufen der über Hydroxylapatit vorgereinigten Fusionskonstrukte. Alle Proben eluierten im Ausschlussvolumen der Säule. 


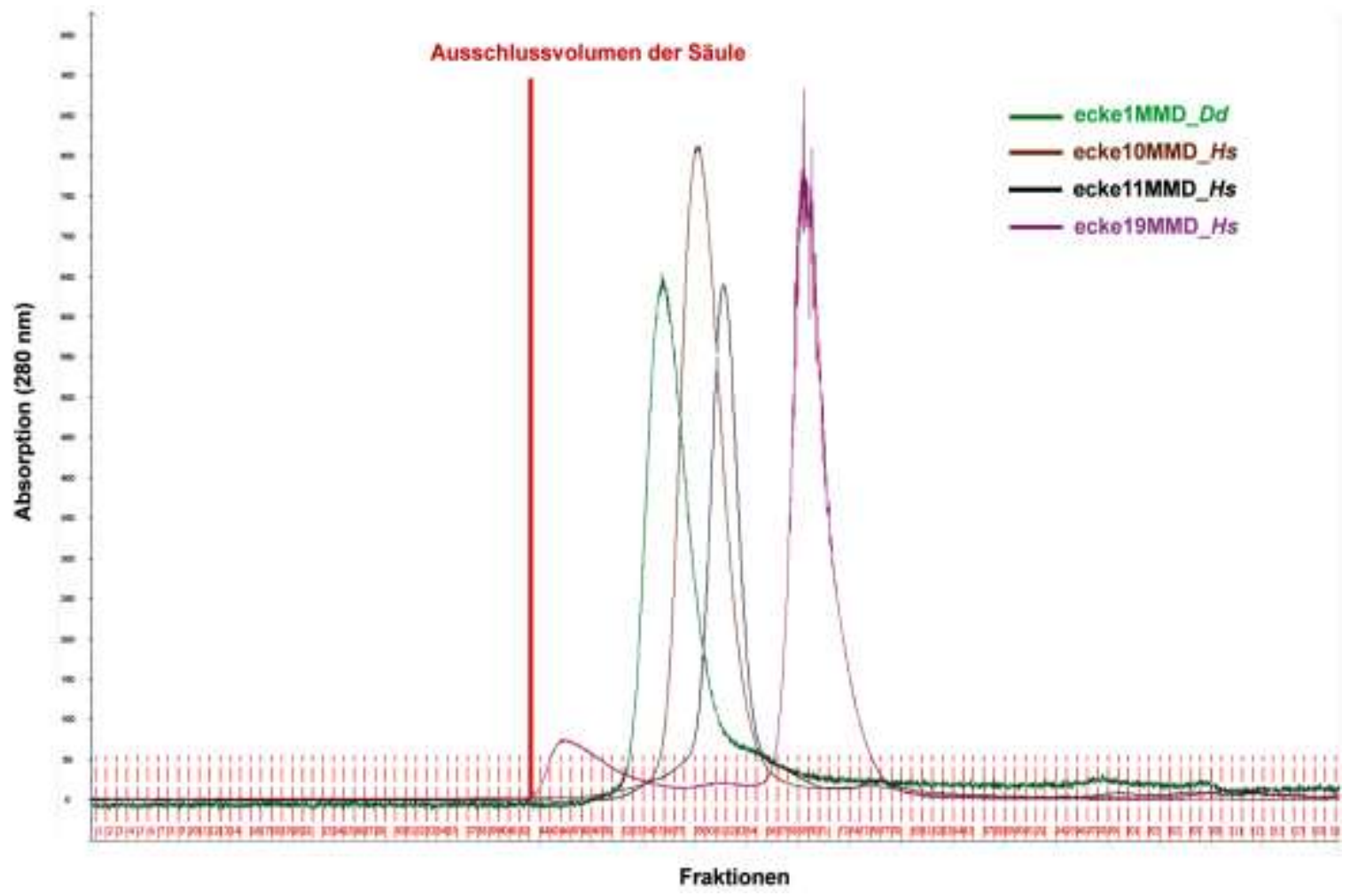

Abbildung I.11. Elutionsprofile aus den Gelfiltrationsläufen der über $\mathrm{Ni}^{2+}{ }^{2} \mathrm{NTA}-C h r o m a t o g r a p h i e$ vorgereinigten Fusionskonstrukte. Das Ausschlussvolumen der Säule ist gekennzeichnet. Die Fusionsproteine eluierten als Dimere bei einem apparenten Molekulargewicht von $\sim 500 \mathrm{kDa}$ (ecke1MMD_Dd), $330 \mathrm{kDa}$ (ecke10MMD_Hs), $300 \mathrm{kDa}$ (ecke11MMD_Hs) und $\sim 250 \mathrm{kDa}$ (ecke19MMD_Hs). ecke19MMD_Hs aggregierte in geringen Mengen.

\section{I.2.5. Erhalt von DHC-Konstrukten ohne MMD}

Neben den homogenen Fusionsproteinen sollten zusätzlich die entsprechenden DHC-Konstrukte in Kristallisationstests eingesetzt werden. Zu diesem Zweck sollte der Einsatz von TEV-Protease eine spezifische Trennung der N-terminalen MMD von den Konstrukten bewirken. In Restriktionsexperimenten stellte sich heraus, dass das Enzym auch in starkem Überschuss nicht in der Lage war, den Myosin-Tag abzuspalten. Durch Vergrößerung des räumlichen Abstands zwischen MMD und TEV-Schnittstelle wurde daraufhin einer möglichen sterischen Abschirmung der Protease entgegengewirkt. Dazu wurde den DHCKonstrukten am N-Terminus eine TEV-Restriktionssequenz einkloniert, wodurch die Fusionsproteine zwei aneinandergrenzende TEV-Schnittstellen beinhalteten. 
In Nachfolgeversuchen verlief die Abspaltung der MMD erfolgreich. Jedoch entstand mit zunehmender TEV-Inkubationsdauer immer stärker werdendes Präzipitat, welches durch SDS-PAGE-Analyse den DHC-Konstrukten zugeordnet werden konnte. Veränderungen des Spaltpuffers (Erhöhung der Salzkonzentration, Zugabe von Glyzerol) hatten keine verbesserte Stabilität der Proteine zur Folge.

Daher wurde als nächstes die Expression der DHC-Konstrukte unabhängig des Myosin-Fusionssystems in Dictyostelium discoideum getestet. Zu diesem Zweck wurden die Konstrukte mittels der Restriktionsenzyme Mlul und BsrGl aus Vektor pDXA-mako2b geschnitten und in pDXA-mako1 einkloniert. Dieser codiert für keine $\mathrm{MMD}$, entspricht davon abgesehen aber pDXA-mako2b. Die Expressionstests wurden nach dem Protokoll für die analytische Aufreinigung von DHC-Konstrukten durchgeführt (siehe Punkt III.4.1.). Für ecke10_Hs und ecke11_Hs konnte keine Expression festgestellt werden. ecke1_Dd und ecke19_Hs wurden exprimiert, allerdings in für kristallographische Unterschungen zu geringen Mengen.

Daraufhin wurde ein Wechsel des Expressionssystems vorgenommen. So sollten die Proteine in E. coli.-Bakterienzellen zur Überexpression gebracht werden. Dabei kam Vektor pETmako17/m15 zum Einsatz, der ein N-terminales Okta-Histidin-Peptid codiert und die gleiche MCS enthält wie pDXA-mako1 und pDXA-mako2b. Dadurch konnten die Konstrukte unkompliziert umkloniert werden. Zwar zeigte sich, dass alle DHC-Konstrukte stark exprimiert werden, jedoch lagen sie fast vollständig in unlöslichen Einschlusskörpern vor. Nachfolgende Optimierungsversuche, in denen die IPTG-Konzentration sowie die Inkubationstemperatur und -dauer stufenweise herabgesetzt wurden, führten zu keinen verbesserten Ergebnissen. Insofern misslang der Versuch, die DHCKonstrukte ecke1_Dd, ecke10_Hs, ecke11_Hs und ecke19_Hs in für die Strukturanalyse ausreichenden Mengen zu erhalten. Demnach beschränkten sich Kristallisationsversuche auf die entsprechenden Fusionsproteine.

Im Folgenden werden die Konstrukte näher besprochen, die Kristalle bildeten (ecke1MMD_Dd und ecke10MMD_Hs). 


\section{I.2.6. Kristallisation von ecke1MMD_Dd}

Das als Myosin-Fusionsprotein exprimierte Konstrukt ecke1_Dd wurde, wie in Punkt III.4.3.1. beschrieben, über $\mathrm{Ni}^{2+}$-NTA-Chromatographie und anschließende Gelfiltration aufgereinigt (Abbildung I.12.). Nach Analyse durch SDS-PAGE konnten schwache Abbaubanden des Fusionskonstrukts detektiert werden, denen zunächst keine größere Beachtung geschenkt wurde. Aus $30 \mathrm{~g}$ Zellen konnten im Durchschnitt ca. $5 \mathrm{mg}$ reines Protein erhalten werden. ecke1MMD_Dd, das im dimeren Zustand vorlag, wurde unter Gebrauch eines Vivaspin-Konzentrators (MWCO 100.000) auf $15 \mathrm{mg} / \mathrm{ml}$ eingeengt. Das Protein wurde entweder unmittelbar in Kristallisationstests eingesetzt, oder nach Zugabe von $3 \%$ Sukrose zum Aufbewahrungspuffer aliquotiert, in flüssigen Stickstoff schockgefroren und bei $-80^{\circ} \mathrm{C}$ aufbewahrt. Aufgetaute Proben wurden im KühIraum auf Eis gelagert und blieben im Durchschnitt über einen Zeitraum von 2 Wochen stabil. Vor der Kristallisation wurde das Protein jeweils für 5 Minuten bei $10.000 \mathrm{~g}$ zentrifugiert, um gröbere Partikel zu entfernen.
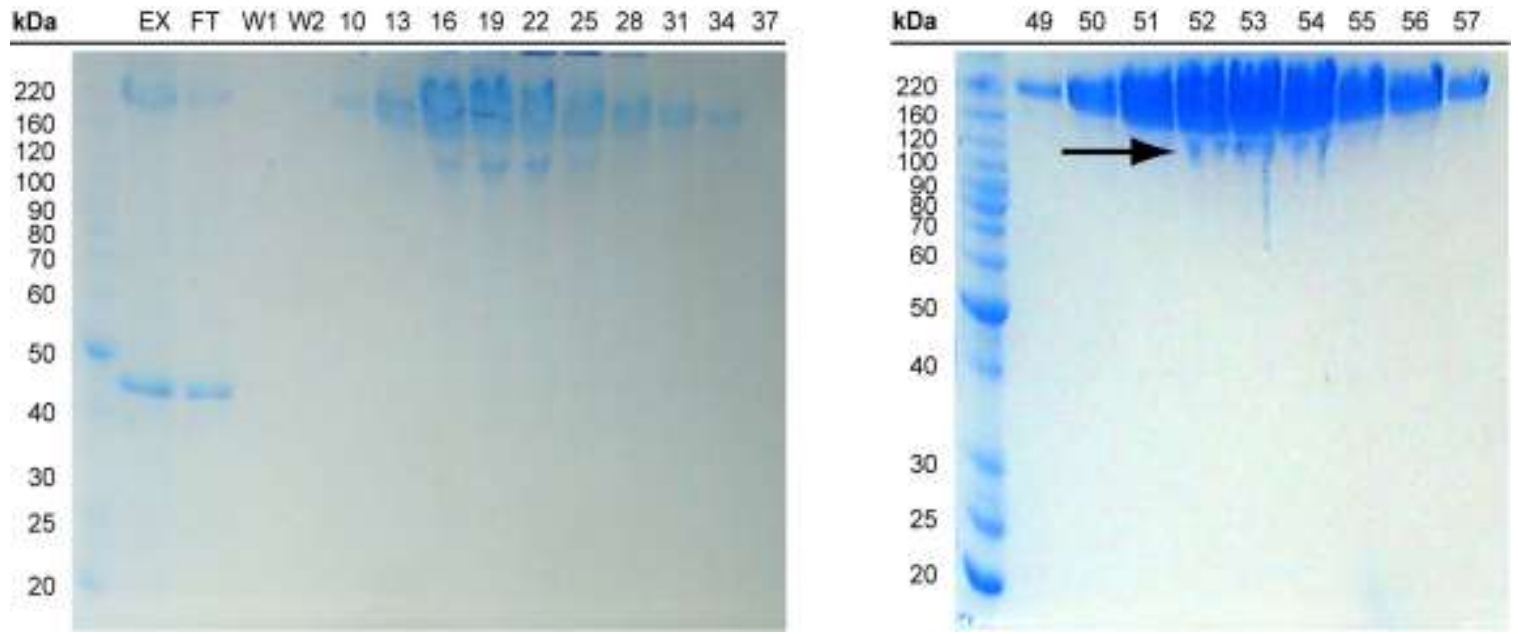

Abbildung I.12. SDS-Gele (10\%) der Aufreinigung von ecke1MMD_Dd. Der Protein-Standard ist mit den jeweiligen Größenangaben am jeweils linken Rand gezeigt. Die Zahlen über den Gelen entsprechen den jeweiligen Elutions-Fraktionen. (Links) SDS-Gel nach $\mathrm{Ni}^{2+}$-NTAchromatographischer Aufreinigung. EX (Protein-Extrakt) ist eine Probe nach ATP-Extraktion des Proteins; FT (flow through) ist eine Probe der Protein-Lösung, die nach dem Auftragen auf die Säule durchlief; W1 ist eine Probe des Waschschrittes mit Hochsalz-Puffer; W2 ist eine Probe des Waschschrittes mit $45 \mathrm{mM}$ Imidazol. (Rechts) SDS-Gel nach GrößenausschlussChromatographie. Der Pfeil markiert schwache Abbaubanden des Fusionskonstrukts. 


\section{I.2.6.1. Erste Kristallisationsversuche}

Die Suche nach Ausgangsbedingungen für die Kristallisation wurde mit den kommerziell erhältlichen Sparse Matrix Screens Wizard 1+2 (Emerald Bioscience), Index- und Crystal-Screen 1+2 (Hampton Research) sowie JCSG Core 1-4 (Qiagen) im Sitting-Drop-Verfahren durchgeführt. Das Fusionskonstrukt wurde sowohl im Komplex mit MgADP als auch MgADP. $\mathrm{VO}_{4}$ in die Screens eingesetzt. Vor Durchführung der Kristallisationsversuche wurde das Fusionsprotein auf Eis für eine Stunde mit MgADP oder MgADP.VO $\mathrm{O}_{4}(2 \mathrm{mM}$ MgADP, $3 \mathrm{mM}$ Vanadat) inkubiert. Die Herstellung der MgADP. $\mathrm{VO}_{4}$-Lösung erfolgte nach einer Vorschrift von Goodno (Goodno, 1982). Die Proteinlösung wurde mithilfe des Mikrodispensers Mosquito (Molecular Dimensions) vollautomatisch im Konzentrationsverhältnis 1:1 $(0.2 \mu l+0.2 \mu l)$ von Proteinlösung zu Präzipitationsmittel in 96 Well-Mikroplatten (Low Profile, Greiner) pipettiert. Leider konnten weder bei RT noch bei $4^{\circ} \mathrm{C}$ über einen Zeitraum von 8 Wochen Kristalle erhalten oder vielversprechende Pufferbedingungen gefunden werden.

\section{I.2.6.2. Optimierung der Aufreinigung von ecke1MMD_Dd und weitere Kristallisationstests}

Womöglich lag es an den Abbauprodukten des Fusionskonstrukts, dass keine Kristallisationstreffer erzielt worden waren. Um diese zu beseitigen, wurde ein zusätzlicher Schritt in den Protein-Aufreinigungsprozess eingebunden. Das in Vorversuchen erfolgreich getestete Material Hydroxylapatit kam im Anschluss an die $\mathrm{Ni}^{2+}$-NTA-Chromatographie zum Einsatz. Obwohl der Reinheitsgrad von ecke1MMD_Dd dadurch nur geringfügig verbessert werden konnte, brachten nachfolgende Kristallisationstests mit Sparse Matrix Screens erste Kristalle hervor. Das Screening ergab folgende Pufferbedingungen, unter denen das Protein komplexiert mit MgADP nach 2-3 Tagen bei RT nadelförmige Kristalle ausbildete (Abbildung I.13.). 
- $\quad 1.26 \mathrm{M}\left(\mathrm{NH}_{4}\right)_{2} \mathrm{SO}_{4}, 0.1 \mathrm{M} \mathrm{Na}$-Cacodylat $6.5 \quad$ (Wizard 1, Bedingung 13)

- $1.26 \mathrm{M}\left(\mathrm{NH}_{4}\right)_{2} \mathrm{SO}_{4}, 0.2 \mathrm{M} \mathrm{Li}_{2} \mathrm{SO}_{4}$,

$0.1 \mathrm{M}$ Tris $\cdot \mathrm{HCl} 8.5$

(Wizard 1, Bedingung 47)

- $1.26 \mathrm{M}\left(\mathrm{NH}_{4}\right)_{2} \mathrm{SO}_{4}, 0.1 \mathrm{M}$ Hepes 7.5

(Wizard 2, Bedingung 15)

- 1.1 Di-Ammonium-Tartrat 7.0

(Index, Bedingung 26)

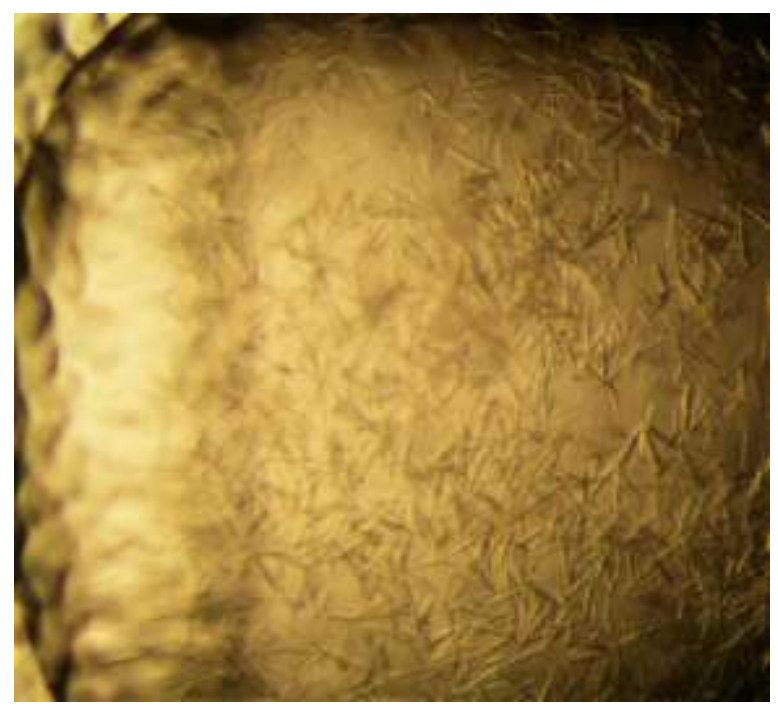

Abbildung I.13. Initiale Kristalle von ecke1MMD_Dd im Komplex mit MgADP, die mit der SittingDrop-Methode bei RT nach 2-3 Tagen erhalten worden waren.

Die Kristalle färbten sich kurze Zeit nach Zugabe des Farbstoffes Izit (Hampton Research) blau, wodurch ein Nachweis für das Vorliegen von Proteinkristallen erbracht werden konnte. Oben aufgeführte Pufferbedingungen verdeutlichen, dass die Kristalle ausnahmslos in Gegenwart hoher Salzkonzentrationen entstanden. PEG-haltige Bedingungen führten hingegen in der Regel bereits nach wenigen Stunden zu starker Proteinpräzipitation und erwiesen sich demnach für die Kristallisation von ecke1MMD_Dd als ungeeignet. $\mathrm{Da}$ die Kristalle sehr klein blieben $(5 \times 5 \times 10 \mu \mathrm{m})$, kamen sie für Diffraktionstests nicht infrage. 


\section{I.2.6.3. Optimierung der Kristalle und Diffraktionstests}

In der Folge wurde von zahlreichen Optimierungsmöglichkeiten Gebrauch gemacht, um größere Kristalle zu erhalten: Grid-Screen-Tests, Verwendung unterschiedlicher Proteinkonzentrationen und verschiedener Verhältnisse von Proteinlösung zu Fällungsmittel im Kristallisationstropfen (2:1;1:2), Abspaltung des N-terminalen Histidin-Tags sowie Mikroseeding-Experimente. Trotz der Vielzahl an Versuchen gelang es nicht, die Kristalle zu optimieren. Daraufhin wurde das Protein chemisch modifiziert, indem es einer reduktiven Methylierung unterzogen wurde. Dadurch sollte das Kristallwachstum angeregt werden. In sich daran anschließenden Kristallisationstests mit Sparse Matrix Screens bildete ecke1MMD_Dd im Komplex mit MgADP über Nacht bei RT unter folgenden Bedingungen Kristalle:

- $10 \%(w / v)$ PEG 6.000, 0.1 M Hepes 7.5 (JCSG Core 1, Bedingung 15)

- $10 \%(w / v)$ PEG 8.000, 0.1 M Hepes 7.0 (JCSG Core 2, Bedingung 34)

- $12 \%(\mathrm{w} / \mathrm{v})$ PEG 20.000, 0.1 M MES 6.5 (JCSG Core 2, Bedingung 47)

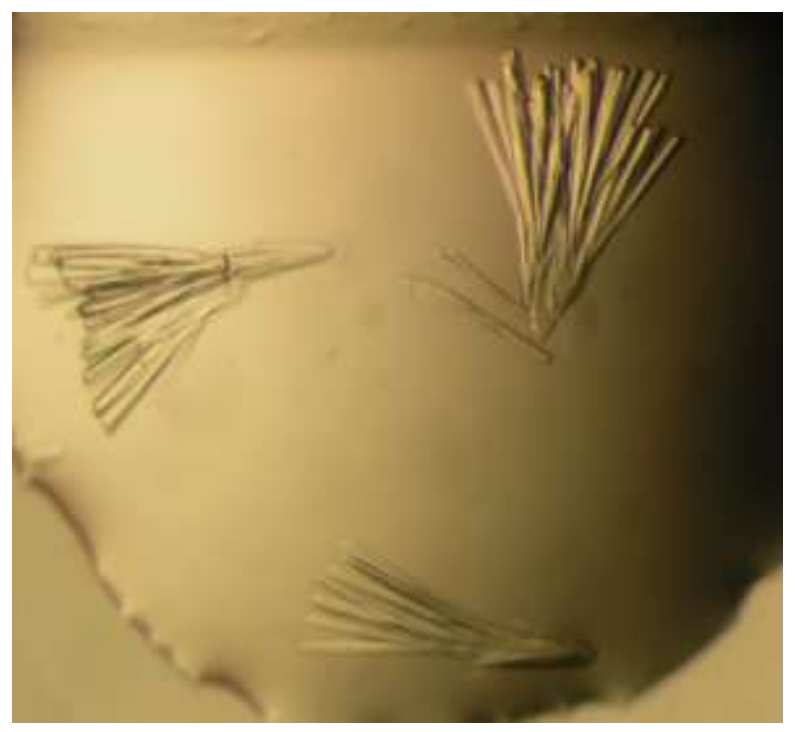

Abbildung I.14. Typische Kristall-,_Büschel“ von reduktiv methyliertem ecke1MMD_Dd im Komplex mit MgADP, die mit der Sitting-Drop-Methode bei RT nach 24 Stunden erhalten worden waren. 
Die ebenfalls in Stäbchenform gewachsenen Kristalle waren mit maximalen Dimensionen von $15 \times 15 \times 60 \mu \mathrm{m}$ wesentlich größer als die nativen Kristalle, lagen allerdings stark verwachsen vor (Abbildung I.14.). Nach ca. 24 Stunden erreichten sie ihre endgültige Größe. Auffällig war, dass die Kristalle ausschließlich in PEG-haltigen Pufferbedingungen entstanden, wohingegen natives ecke1MMD_Dd nur in Gegenwart von Hochsalzpuffern zur Kristallisation gebracht werden konnte. Ausgehend von den beiden erstgenannten Bedingungen, war es in nachfolgenden Grid-Screen-Experimenten unter geringfügiger Erhöhung des pH-Wertes [10 \% (w/v) PEG 6.000, $0.1 \mathrm{M}$ Hepes 7.7; $10 \%(w / v)$ PEG 8.000, $0.1 \mathrm{M}$ Hepes 7.2] möglich, Monokristalle zu erzeugen (Abbildung I.15.). Deren Größe $(20 \times 20 \times 80 \mu \mathrm{m})$ konnte im 24-Well-Format nach der Hanging-Drop-Methode optimiert werden $(30 \times 30 \times 100 \mu \mathrm{m})$. Der anschließende Einsatz verschiedener Additiva und Detergenzien (Additiv- und Detergenz-Screen, Hampton Research) beeinflusste weder Größe noch Form der Kristalle. Unter der letztgenannten Bedingung konnten hingegen trotz intensiver Variation der Pufferkomponenten keine Einkristalle erhalten werden.

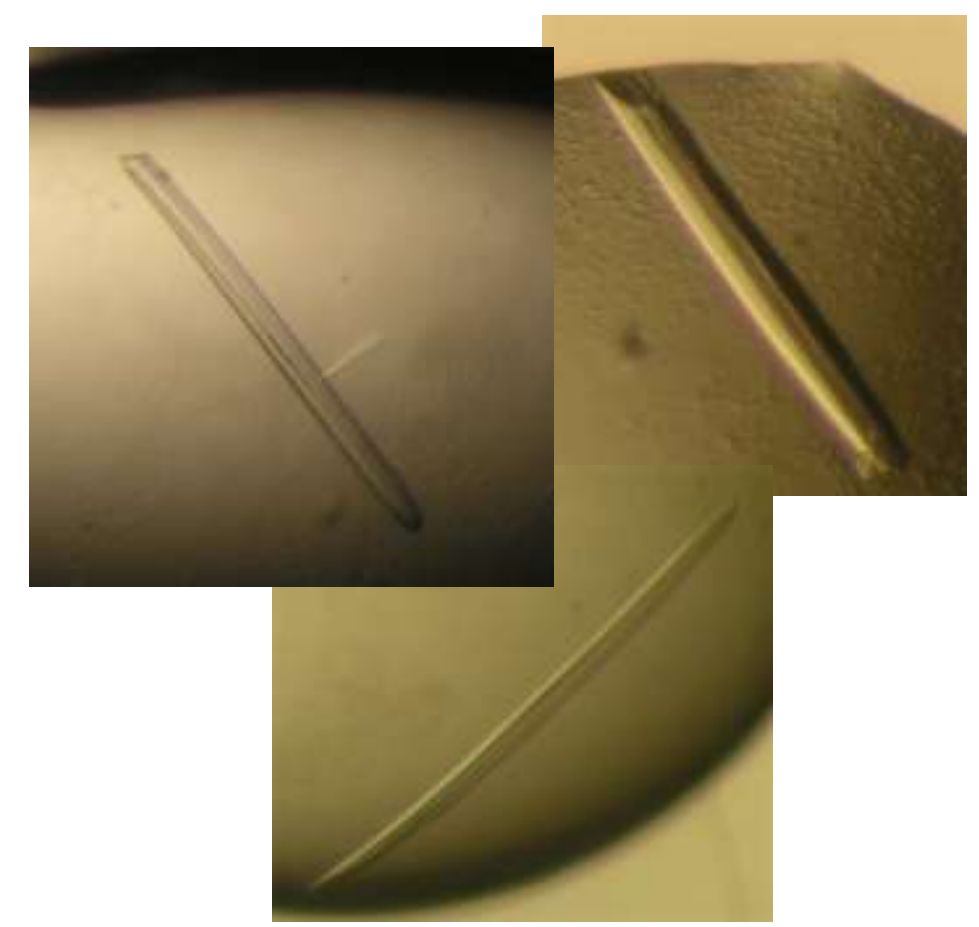

Abbildung I.15. Erste Monokristalle, die für reduktiv methyliertes ecke1MMD_Dd gezüchtet werden konnten. 
Schließlich wurden einige Kristalle für Testmessungen weggefroren, wobei die jeweilige Kristallisationsbedingung einschließlich $15 \%$ Glyzerol (v/v) als Kryobedingung diente. Allerdings erwiesen sich die Stäbchen beim „Fischen“ als mechanisch sehr instabil. An Bruchstücken war zu erkennen, dass die Kristalle im Inneren hohl sind (Abbildung I.16., B). Dieser signifikante Qualitätsmangel ging möglicherweise auf ihr rapides Wachstum zurück. Die Beugungsexperimente wurden an Beamline ID23-2 am ESRF in Grenoble durchgeführt. Zur Überprüfung der Kristallqualität wurden Einzelaufnahmen vorgenommen. So zeigte sich schnell, dass das Diffraktionsvermögen der Kristalle nicht annähernd der atomaren Strukturaufklärung genügte. Die vermessenen Kristalle streuten bis zu einer maximalen Auflösung von 9-10 ̊ (Abbildung I.16., C).
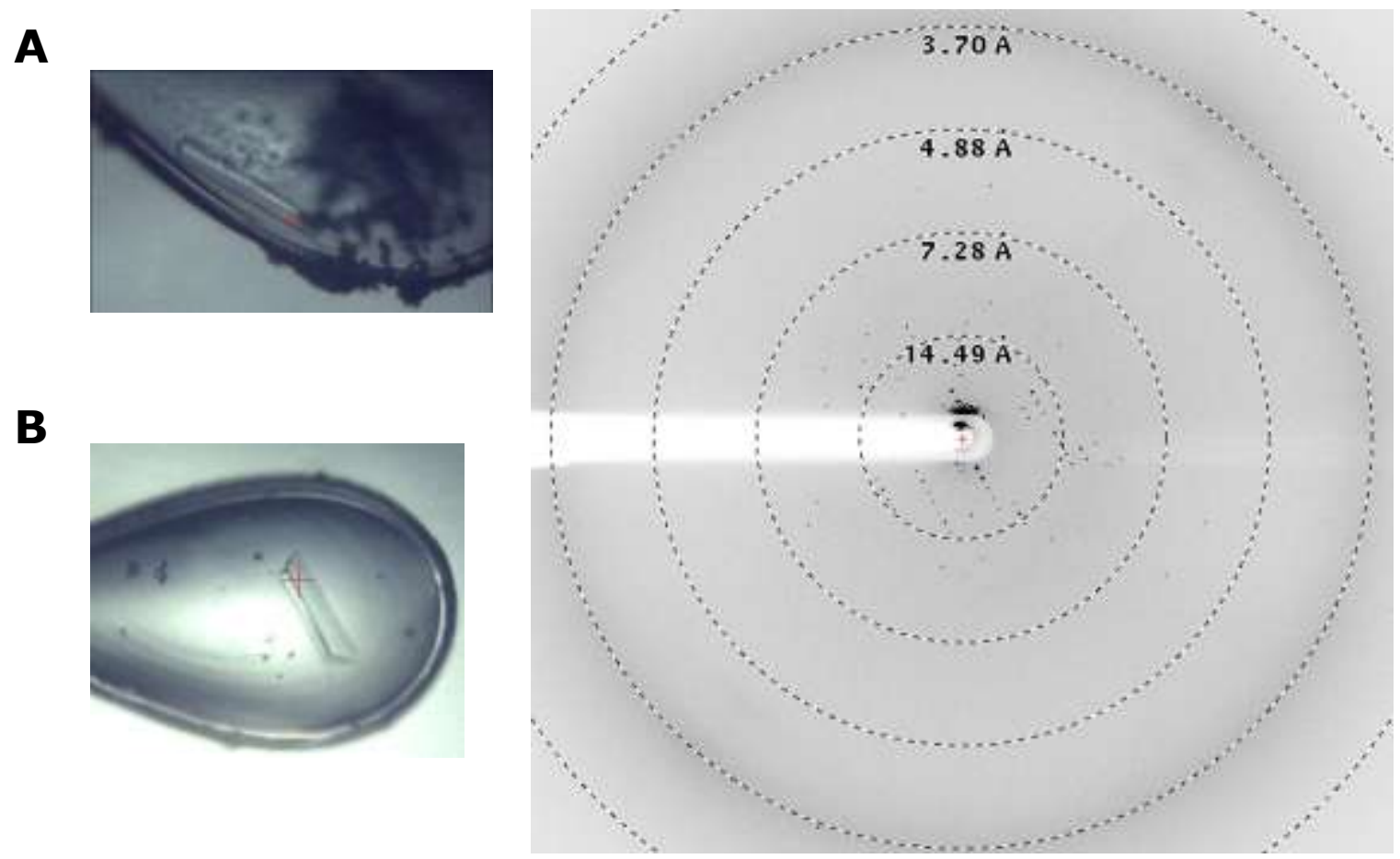

Abbildung I.16. Vermessung von Kristallen des Fusionsproteins ecke1MMD_Dd. (A, B) Kristalle des Konstrukts im Loop. (A) Braune Rückstände und Eiskristalle im verwendeten Gefrierschutzpuffer, die auf eine ungünstig gewählte Kryobedingung schließen lassen. (B) Bruchstück eines Kristalls von ecke1MMD_Dd, an dem die stark ausgeprägten Hohlräume ersichtlich sind. (C) Typisches mit Synchrotronstrahlung an der Beamline ID23-2 (ESRF) aufgenommenes Beugungsbild eines Kristalls von ecke1MMD_Dd. 
Außerdem konnte den Diffraktionsbildern entnommen werden, dass die Kryobedingungen nicht optimal gewählt worden waren. Neben „Eisringen“ war oftmals ein hohes Hintergrundrauschen erkennbar. Dies geht mit Beobachtungen einher, wonach das Lösungsmittel im Loop regelmäßig deutliche braune Rückstände hinterließ und kristallines Eis enthielt (Abbildung I.16., A).

\section{I.2.6.4. Weitere Optimierungsexperimente}

Um qualitativ bessere Kristalle zu erhalten, wurde ausgehend von den optimierten Präzipitationsbedingungen [10 \% (w/v) PEG 6.000, $0.1 \mathrm{M}$ Hepes 7.7; $10 \%$ (w/v) PEG 8.000, 0.1 M Hepes 7.2] eine Retardation des Kristallwachstums angestrebt. Dazu wurde das Protein in geringeren Konzentrationen (5 und 10 $\mathrm{mg} / \mathrm{ml}$ ) in die Kristallisationstests eingesetzt, die Reservoirlösungen mit unterschiedlichen Mengen an Öl (Al's Oil, Hampton Research) überschichtet und die Kristallisationsplatten bei tieferen Temperaturen $\left(8\right.$ und $15^{\circ} \mathrm{C}$ ) gelagert. Allerdings gelang es nicht, kompaktere Kristalle zu züchten. Daraufhin wurde nach neuen Kristallisationsbedingungen gesucht. Zur Erinnerung sei erwähnt, dass Kristalle von reduktiv methyliertem ecke1MMD_Dd MgADP nur in Gegenwart von PEG als Präzipitant wuchsen. Unter Verwendung zweier bis dahin nicht benutzter, auf PEG basierender Sparse Matrix Screens (PEGs Suite, Hampton Research; ProteinComplex-Screen, Qiagen), entstanden in Mikroseeding-Experimenten über Nacht bei RT unter einer großen Bandbreite an unterschiedlichen Pufferbedingungen Kristallstäbchen (Tabelle I.3.). Eine Bedingung [PC Screen, Bedingung $10 \rightarrow 15 \%(\mathrm{w} / \mathrm{v})$ PEGMME 2.000, $0.1 \mathrm{M} \mathrm{KCl}$, $0.1 \mathrm{M}$ Tris $\cdot \mathrm{HCl} \mathrm{pH} \mathrm{8.0]} \mathrm{brachte} \mathrm{dabei} \mathrm{auffallend} \mathrm{robuste} \mathrm{Kristalle} \mathrm{hervor,} \mathrm{die} \mathrm{nur}$ noch kleine Hohlräume aufwiesen. In sich daran anschließenden Grid-ScreenExperimenten konnten die Kristalle nicht weiter optimiert werden. Allerdings deckten die Verfeinerungsversuche auf, dass die Kristalle mit abnehmendem $\mathrm{pH}$ Wert der Pufferbedingung wieder deutlich fragiler wurden. 
Tabelle I.3. Übersicht über die Präzipitationsbedingungen, unter denen reduktiv methyliertes ecke1MMD_Dd auskristallisierte.

\begin{tabular}{|c|c|c|}
\hline Kristallisations-Screen & $\#$ & Pufferzusammensetzung \\
\hline PEGs Suite & 11 & $25 \%(w / v)$ PEG 1.000, 0.1 M MES pH 6.5 \\
\hline PEGs Suite & 23 & $25 \%$ (w/v) PEG 1.000, $0.1 \mathrm{M}$ Tris. $\mathrm{HCl}$ pH 8.5 \\
\hline PEGs Suite & 32 & $25 \%(w / v)$ PEG 4.000, $0.1 \mathrm{M}$ MES pH 6.5 \\
\hline PEGs Suite & 34 & $25 \%$ (w/v) PEG 8.000, 0.1 M MES pH 6.5 \\
\hline PEGs Suite & 39 & $25 \%(w / v)$ PEG 4.000, $0.1 \mathrm{M}$ Hepes pH 6.5 \\
\hline PEGs Suite & 45 & $25 \%$ (w/v) PEG 6.000, $0.1 \mathrm{M}$ Tris $\cdot \mathrm{HCl} \mathrm{pH} 8.5$ \\
\hline PEGs Suite & 47 & $20 \%(w / v)$ PEG 10.000, 0.1 M Tris. HCl pH 8.5 \\
\hline PEGs Suite & 49 & $15 \%$ (w/v) PEG 20.000, 0.1 M Tris. $\mathrm{HCl} \mathrm{pH} 8.5$ \\
\hline PC Screen & 10 & $15 \%$ (w/v) PEGMME 2.000, 0.1 M KCl, 0.1 M Tris· HCl pH 8.0 \\
\hline PC Screen & 28 & $20 \%$ (w/v) PEG 4.000, 0.2 $\mathrm{M} \mathrm{Li}_{2} \mathrm{SO}_{4}, 0.1 \mathrm{M} \mathrm{MES} \mathrm{pH} 6.0$ \\
\hline PC Screen & 29 & $20 \%(w / v)$ PEG 4.000, $0.1 \mathrm{M}$ Tris. $\mathrm{HCl}$ pH 8.0 \\
\hline PC Screen & 30 & $20 \%(w / v)$ PEG 4.000, $0.15 \mathrm{M}\left(\mathrm{NH}_{4}\right)_{2} \mathrm{SO}_{4}, 0.1 \mathrm{M}$ Hepes $\mathrm{pH} 7.0$ \\
\hline PC Screen & 32 & $20 \%(w / v)$ PEG 4.000, 0.2 M NaCl, 0.1 M Tris. HCl pH 8.0 \\
\hline PC Screen & 34 & $20 \%$ (w/v) PEG 6.000, $0.1 \mathrm{M}$ Tris. $\mathrm{HCl}$ pH 8.5 \\
\hline PC Screen & 48 & $20 \%(w / v)$ PEG 8.000, $0.2 \mathrm{M}\left(\mathrm{NH}_{4}\right)_{2} \mathrm{SO}_{4}, 0.1 \mathrm{M} \mathrm{MES} \mathrm{pH} 6.5$ \\
\hline PC Screen & 60 & $20 \%(w / v)$ PEG 8.000, $0.1 \mathrm{M}$ Hepes pH 7.5 \\
\hline PC Screen & 61 & $20 \%(w / v)$ PEG 8.000, $0.2 \mathrm{M} \mathrm{Li}_{2} \mathrm{Cl}, 0.1 \mathrm{M}$ Tris. $\mathrm{HCl} \mathrm{pH} 8.0$ \\
\hline PC Screen & 62 & $18 \%(w / v)$ PEG 2.000, $0.1 \mathrm{M}$ Hepes pH 7.0 \\
\hline PC Screen & 64 & $15 \%$ (w/v) PEG 20.000, 0.1 M Hepes pH 7.0 \\
\hline
\end{tabular}

Angeregt durch diesen Befund gelang es, unter Gebrauch der stark basischen Puffersysteme Bicin, CHES und CAPS im pH-Bereich 9-9.5 [15\% (w/v) PEGMME 2.000, 0.1 M KCl, 0.1 M Bicin pH 9.0; $15 \%$ (w/v) PEGMME 2.000, 0.1 $\mathrm{M} \mathrm{KCl}, 0.1 \mathrm{M}$ CHES pH 9.2; 15 \% (w/v) PEGMME 2.000, 0.1 M KCl, 0.1 M CAPS $\mathrm{pH}$ 9.5] reproduzierbar Kristalle zu züchten, die optisch fehlerfrei und sehr stabil waren (Abbildung I.17.). Diese erreichten ebenfalls nach ca. 24 Stunden ihre endgültige Größe $(20$ × 20 × $80 \mu \mathrm{m})$. 


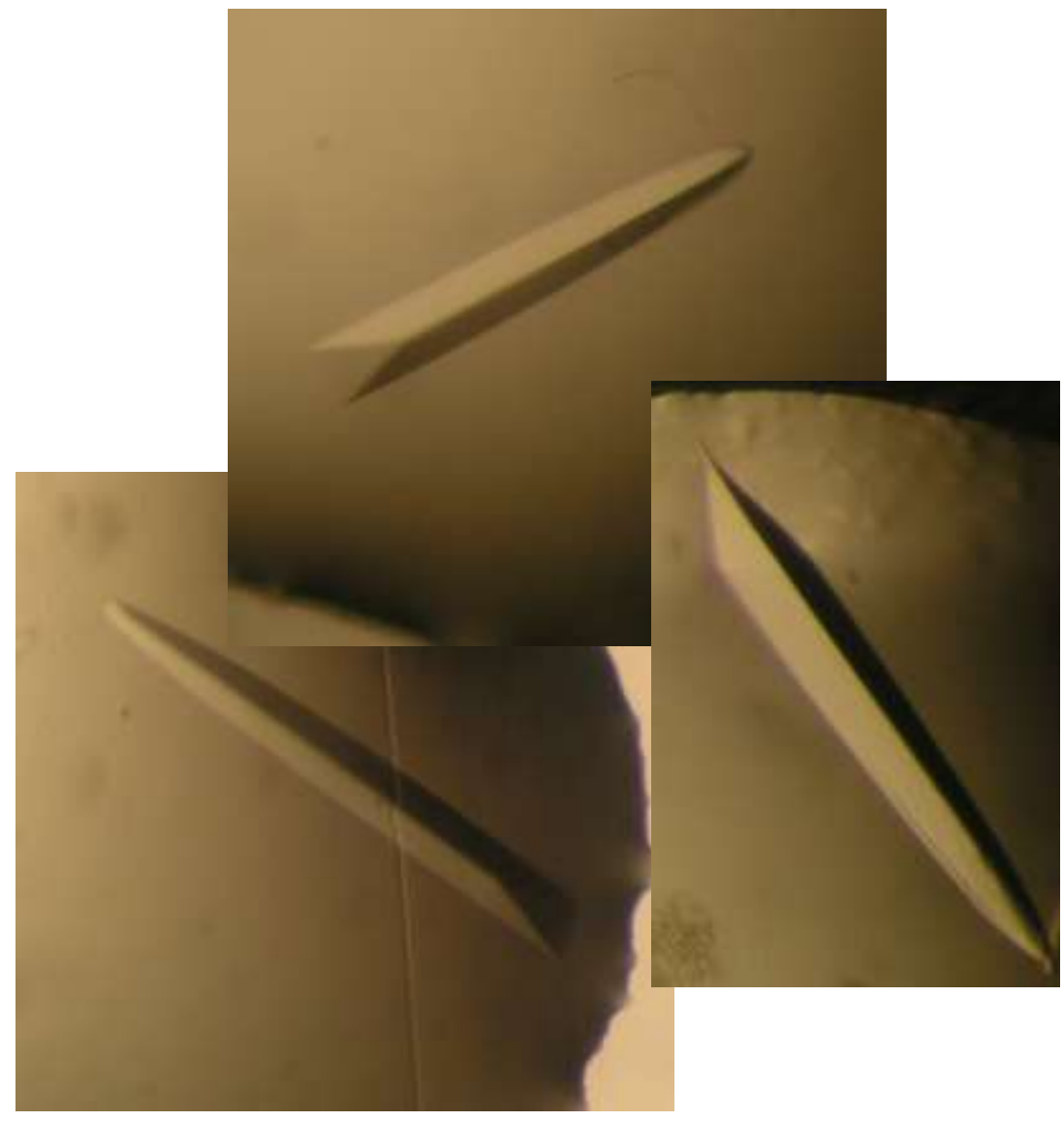

Abbildung I.17. Beispiele für typische Kristalle von reduktiv methyliertem ecke1MMD_Dd, die nach erfolgter Optimierung keine optischen Mängel mehr aufwiesen.

Unter geringfügiger Abänderung der optimierten, auf Bicin basierenden Pufferbedingung, wurden außerdem Kristalle in Gegenwart der ATP-Analoga AppCp, AppNHp, ATPYS und MgADP.AlF 4 sowie im Komplex mit $\mathrm{PP}_{\mathrm{i}}$ erhalten. Diese wiesen keine morphologischen Unterschiede zu den bereits erzeugten Stäbchen auf. Nach den Erfahrungen der Diffraktionstests wurde ferner ein großes Augenmerk auf die Verwendung geeigneter Kryoprotektanten gelegt. Dabei kamen die Substanzen Glyzerol, Sukrose, PEG 400, und Ethylenglykol in einer Endkonzentration von jeweils 20 \% zum Einsatz. Spätere Messungen ergaben, dass diese Konzentration jeweils ausreichend war, um den Kristallisationsbedingungen gute Gefrierschutzeigenschaften zu verleihen. Schließlich wurden auch kontrollierte Dehydrationsexperimente mit einigen Kristallen in Gegenwart 
von PEGMME 2.000 durchgeführt. Trotz intensiver Optimierung und signifikanter visueller Qualitätssteigerung zeigten die Kristalle allerdings eine nur geringfügig verbesserte Beugungskraft. Die besten Kristalle streuten an Beamline ID23-2 am ESRF in Grenoble bis maximal 7-8 ̊.

\section{I.2.7. Kristallisation von ecke10MMD_Hs}

Das als Myosin-Fusionsprotein exprimierte Konstrukt ecke10_Hs wurde, wie in Punkt III.4.3.1. beschrieben, über $\mathrm{Ni}^{2+}-\mathrm{NTA}$-Chromatographie und anschließende Gelfiltration bis zur Homogenität aufgereinigt (Abbildung 1.18.). Aus $30 \mathrm{~g}$ Zellen ergab sich eine durchschnittliche Ausbeute von ca. $3 \mathrm{mg}$ an reinem Protein. ecke10MMD_Hs lag als Dimer vor und wurde für Kristallisationstests mittels eines Vivaspin-Konzentrators (MWCO 100.000) auf eine Konzentration von $20 \mathrm{mg} / \mathrm{ml}$ gebracht. Von einer langfristigen Lagerung des Proteins musste abgesehen werden, da es trotz Zugabe von $3 \%$ Sukrose oder $5 \%$ Glyzerol zum Aufbewahrungspuffer das Schockgefrieren nicht tolerierte und instabil wurde. Außerdem zeigte sich, dass die Probe trotz Lagerung auf Eis im Kühlraum nur über einen Zeitraum von maximal 3 Tagen stabil blieb. Vor der Kristallisation wurde das Protein jeweils für 5 Minuten bei $10.000 \mathrm{~g}$ zentrifugiert, um gröbere Partikel zu entfernen. 

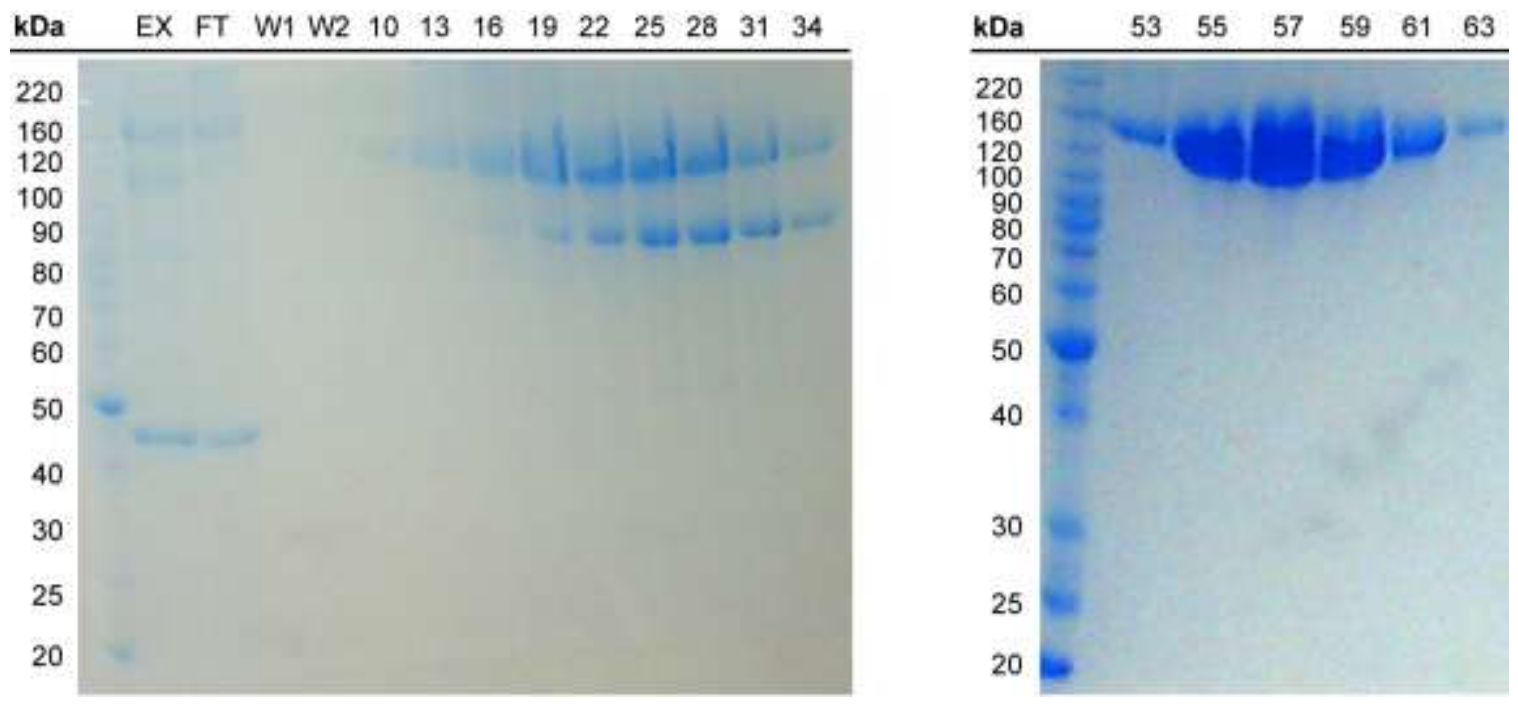

Abbildung I.18. SDS-Gele (10\%) der Aufreinigung von ecke10MMD_Hs. Der Protein-Standard ist mit den jeweiligen Größenangaben am jeweils linken Rand gezeigt. Die Zahlen über den Gelen entsprechen den jeweiligen Elutions-Fraktionen. (Links) SDS-Gel nach $\mathrm{Ni}^{2+}$-NTAchromatographischer Aufreinigung. Die prominente Bande bei $\sim 90 \mathrm{kDa}$ resultiert aus einem Abbauprodukt, das durch Gelfiltration aber gut vom Fusionskonstrukt abgetrennt werden konnte (siehe rechts). EX (Protein-Extrakt) ist eine Probe nach ATP-Extraktion des Proteins; FT (flow through) ist eine Probe der Protein-Lösung, die nach dem Auftragen auf die Säule durchlief; W1 ist eine Probe des Waschschrittes mit Hochsalz-Puffer; W2 ist eine Probe des Waschschrittes mit 45 mM Imidazol. (Rechts) SDS-Gel nach Größenausschluss-Chromatographie.

\section{I.2.7.1. Erste Kristallisationsversuche}

Die Suche nach Ausgangsbedingungen für die Kristallisation wurde mit den kommerziell erhältlichen Sparse Matrix Screens Wizard 1+2 (Emerald Bioscience), Index- und Crystal-Screen 1+2 (Hampton Research) sowie JCSG Core 1-4 (Qiagen) im Sitting-Drop-Verfahren durchgeführt. Das Fusionskonstrukt wurde sowohl im Komplex mit MgADP als auch MgADP. $\mathrm{VO}_{4}$ in die Screens eingesetzt. Die Proteinlösung wurde mithilfe des Mikrodispensers Mosquito (Molecular Dimensions) vollautomatisch im Konzentrationsverhältnis 1:1 $(0.2 \mu \mathrm{l}+0.2 \mu \mathrm{l})$ von Proteinlösung zu Präzipitationsmittel in 96 WellMikroplatten (Low Profile, Greiner) pipettiert. Am nächsten Tag konnte für eckeMMD_10Hs im Komplex mit MgADP. $\mathrm{VO}_{4}$ bei RT unter folgenden

Pufferbedingungen feinkristallines Material entdeckt werden (Abbildung I.19.): 
- $2.0 \mathrm{M}(\mathrm{NH} 4)_{2} \mathrm{SO}_{4}, 0.1 \mathrm{M}$ Tris $\cdot \mathrm{HCl} 8.5$

- $1.26 \mathrm{M}(\mathrm{NH} 4)_{2} \mathrm{SO}_{4}, 0.2 \mathrm{M} \mathrm{Li}_{2} \mathrm{SO}_{4}$, $0.1 \mathrm{M}$ Tris $\cdot \mathrm{HCl} 8.5$
(JCSG Core 2, Bedingung 13)

(JCSG Core 3, Bedingung 14)

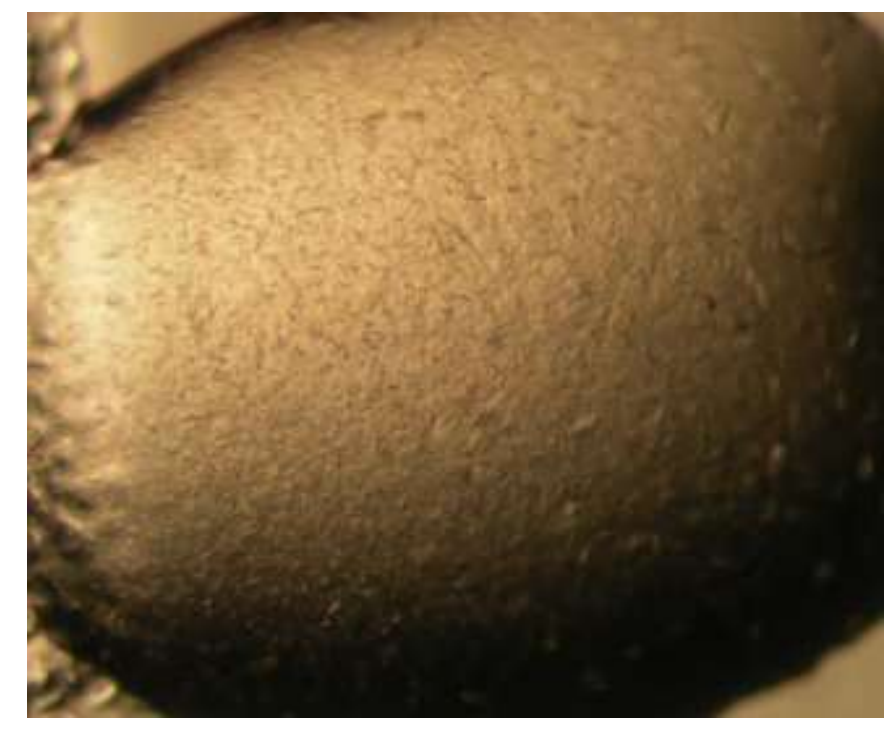

Abbildung I.19. Feinkristallines Material von ecke10MMD_Hs im Komplex mit MgADP.VO 4 , das mit der Sitting-Drop-Methode bei RT nach 24 Stunden entstand.

\section{I.2.7.2. Optimierung der Kristalle und Diffraktionsmessungen}

Um größere Kristalle zu erhalten, wurden daraufhin Grid-Screen-Experimente durchgeführt. Diese resultierten unter dem Gebrauch geringfügig reduzierter Salzkonzentrationen [1.9 M (NH4) $)_{2} \mathrm{SO}_{4}, 0.1 \mathrm{M}$ Tris. $\mathrm{HCl} 8.5 ; 1.2 \mathrm{M}(\mathrm{NH} 4)_{2} \mathrm{SO}_{4}$, $0.18 \mathrm{M} \mathrm{Li}_{2} \mathrm{SO}_{4}, 0.1 \mathrm{M}$ Tris. $\mathrm{HCl}$ 8.5] in der Entstehung scheibenförmiger Kristalle, die nach Anfärbung mit Izit als Proteinkristalle identifiziert werden konnten. Die Scheiben waren stark verwachsen und bildeten eine Art vielschichtiges Hexagon (Abbildung I.20., A). Die weitere Optimierung der Kristalle gestaltete sich sehr schwierig. Mit Protein in etwas geringerer Konzentration $(17 \mathrm{mg} / \mathrm{ml})$ brachte eine Bedingung [1.2 M (NH4) $)_{2} \mathrm{SO}_{4}, 0.2 \mathrm{M} \mathrm{Li}_{2} \mathrm{SO}_{4}, 0.1 \mathrm{M}$ Tris. $\mathrm{HCl}$ 8.5] unter dem Einsatz von Protein zu Präzipitationsmittel im Verhältnis 2:1 einzelne kleine Scheiben hervor. Auch in Hanging-Drop-Experimenten im 24-Well-Format 
wuchsen unter einer nahezu identischen Bedingung [1.15 M (NH4) ${ }_{2} \mathrm{SO}_{4}, 0.2 \mathrm{M}$ $\mathrm{Li}_{2} \mathrm{SO}_{4}, 0.1 \mathrm{M}$ Tris. $\mathrm{HCl}$ 8.5] Einkristalle. Allerdings gelang es in beiden Fällen nicht, die Kristalle zu reproduzieren. Die Scheiben entstanden nach ca. 48 Stunden bei RT, wobei sich ihr Wachstumsprozess über ca. 24 Stunden erstreckte. Die größten Kristalle wiesen dabei Dimensionen von $10 \times 10 \times 30 \mu \mathrm{m}$ auf (Abbildung I.20., B).

A

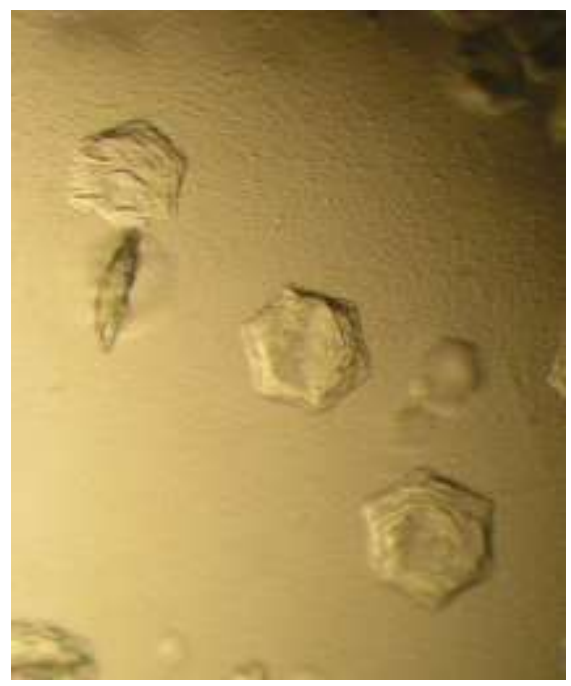

B

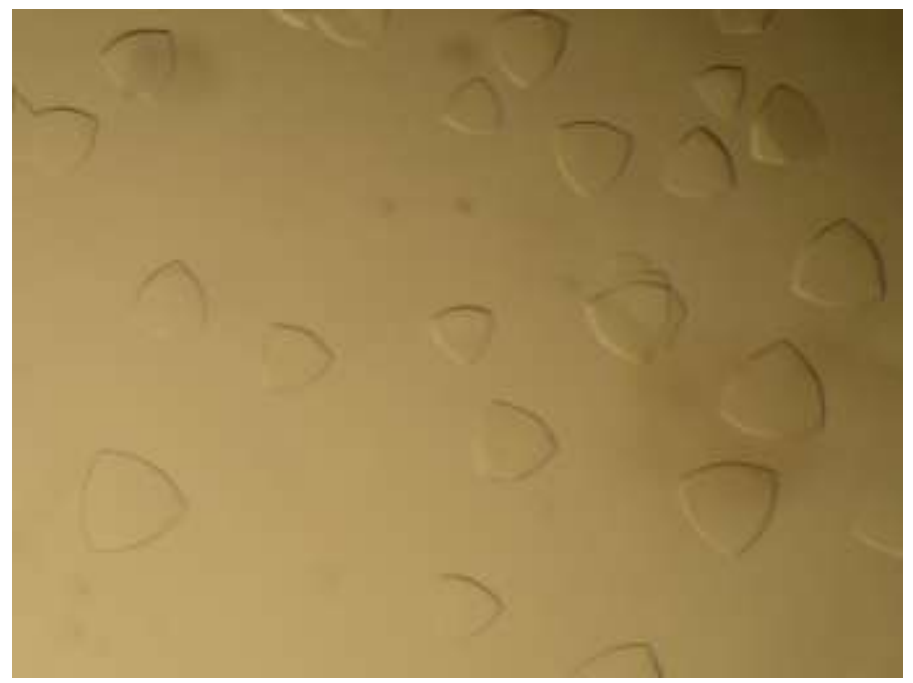

Abbildung I.20. Erste Kristalle von ecke 10MMD_Hs. (A) Zu einem vielschichtigen Hexagon verwachsene Kristalle. (B) Nach Optimierung erhaltene Monokristalle.

Einige Kristalle wurden daraufhin für Testmessungen eingefroren, wobei Glyzerol in einer Endkonzentration von $20 \%(\mathrm{v} / \mathrm{v})$ als Gefrierschutzmittel diente. Außerdem wurden ein paar Kristalle ohne Kryoprotektion direkt in flüssigen Stickstoff schockgefroren (Abbildung I.21., A und B). Diffraktionsmessungen an Beamline ID23-2 am ESRF in Grenoble ergaben, dass die Kristalle bis auf eine Ausnahme nur bis ca. $9 \AA$ streuten. Ein direkt in flüssigen Stickstoff überführter Kristall zeigte eine Beugungskraft bis ca. $3.8 \AA$ (Abbildung I.21., C). Allerdings wies der Kristall eine stark ausgeprägte Mosaizität auf. Diese konnte zwar durch Annealing reduziert werden, trotzdem gelang es nicht, den aufgenommenen Datensatz zu prozessieren. 
A
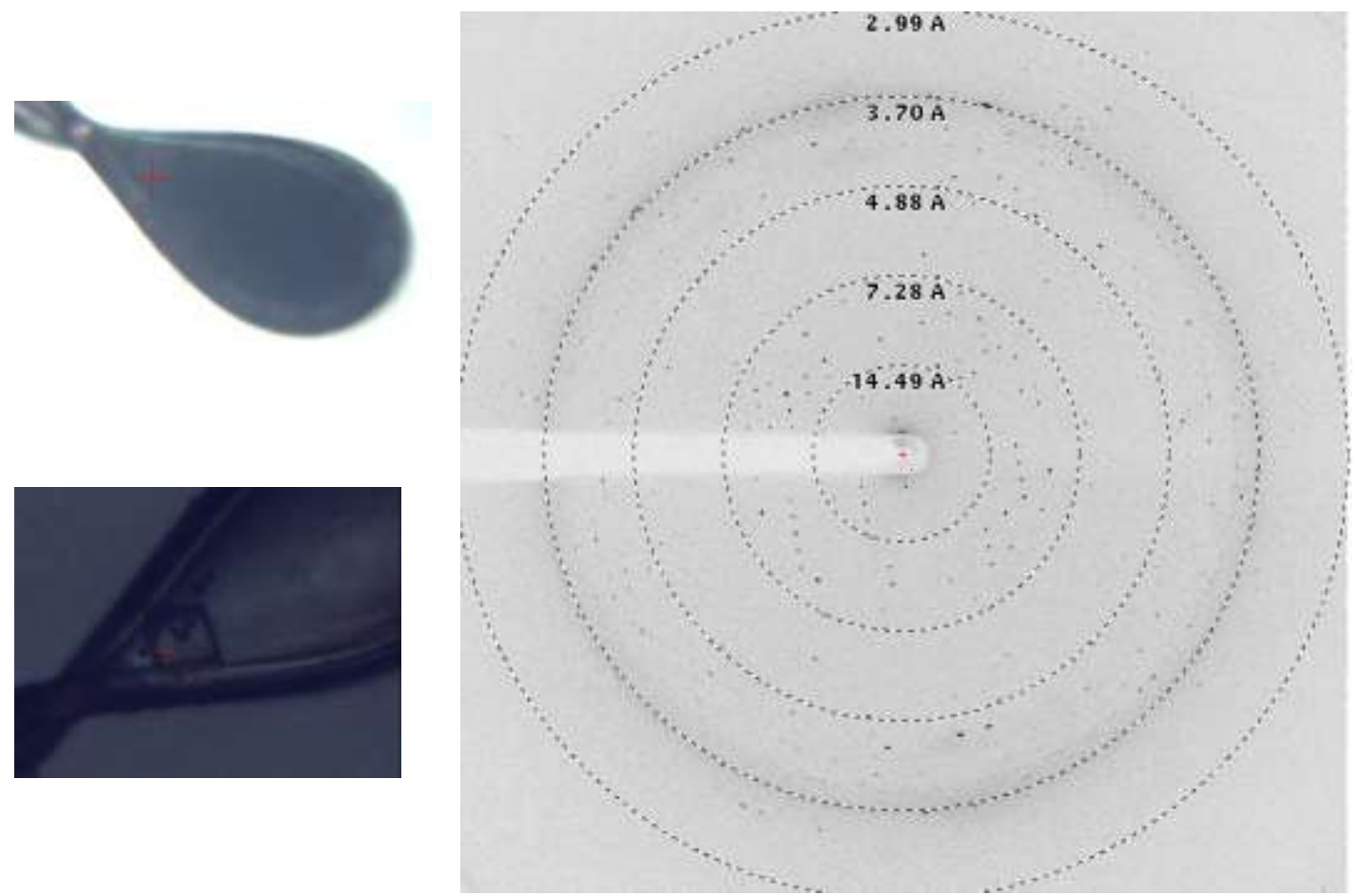

B

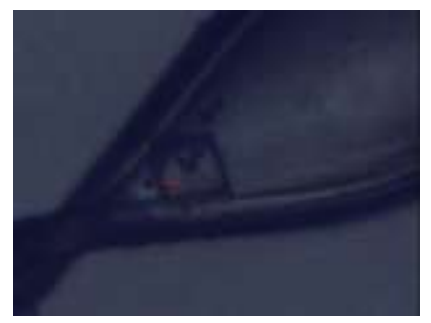

C

\section{A}

B

Abbildung 1.21. Vermessung von Kristallen des Fusionskonstrukts ecke10MMD_Hs. (A) Gut streuender Kristall nach direktem Gefrieren in flüssigen $\mathrm{N}_{2}$, unmittelbar vor der Aufnahme erster Beugungsdaten (Kristall ist im Bereich des roten Fadenkreuzes lokalisiert). Der Loop erscheint matt, da die Hochsalz-Kristallisationsbedingung keine ausreichenden Frostschutzeigenschaften aufwies. (B) Der in A kaum sichtbare Kristall nach Annealing. (C) Mit Synchrotronstrahlung an der Beamline ID23-2 (ESRF) aufgenommene Beugungsbild des Kristalls nach Annealing. Das schlecht definierte Reflexmuster ist Resultat der hohen Kristall-Mosaizität.

\section{I.2.7.3. Weitere Optimierungsexperimente}

Um qualitativ bessere Kristalle des Fusionskonstrukts zu erhalten, wurde nach neuen Kristallisationsbedingungen gesucht. Da Kristalle von ecke10MMD_Hs bis dato ausschließlich in Gegenwart hoher Salzkonzentrationen entstanden, kam der bislang nicht verwendete und auf Hochsalzbedingungen basierende SparseMatrix Screen SaltRX (Hampton Research) zum Einsatz. Um das Kristallwachstum anzuregen, wurde Mikroseeding angewendet. Das Screening 
ergab folgende Pufferbedingung, unter der nach 2 Tagen bei RT Monokristalle entstanden:

- $\quad 1.5 \mathrm{M} \mathrm{Li}_{2} \mathrm{SO}_{4}, 0.1 \mathrm{M}$ Tris$\cdot \mathrm{HCl} 8.5 \quad$ (SaltRX, Bedingung 71)

Die Kristalle lagen in zwei unterschiedlichen Formen vor - vornehmlich in einer abgerundeten Schildform, analog zu den bisher gezüchteten Kristallen, und selten in Form eines gut definierten Sechsecks (Abbildung I.22., A). Nach ca. 24 Stunden erreichten die Scheiben ihre finale Größe $(10 \times 10 \times 30 \mu \mathrm{m})$. Durch den Austausch von Lithiumsulfat gegen Ammoniumsulfat gelang es in weiteren Mikroseeding-Experimenten, unter verschiedenen Mischverhältnissen der beiden Salze reproduzierbar Monokristalle zu züchten:

- $\quad 1.2 \mathrm{M} \mathrm{Li}_{2} \mathrm{SO}_{4}, 0.2 \mathrm{M}(\mathrm{NH} 4)_{2} \mathrm{SO}_{4}, 0.1 \mathrm{M}$ Tris. $\mathrm{HCl} 8.5$

- $\quad 0.8 \mathrm{M} \mathrm{Li}_{2} \mathrm{SO}_{4}, 0.6 \mathrm{M}(\mathrm{NH} 4)_{2} \mathrm{SO}_{4}, 0.1 \mathrm{M}$ Tris. $\mathrm{HCl} 8.5$

- $0.4 \mathrm{M} \mathrm{Li}_{2} \mathrm{SO}_{4}, 1.0 \mathrm{M}(\mathrm{NH} 4)_{2} \mathrm{SO}_{4}, 0.1 \mathrm{M}$ Tris. $\mathrm{HCl} 8.5$

Die in der Auflistung erstgenannte Präzipitationsbedingung brachte die größten Kristalle hervor (Abbildung I.22., B). Diese wuchsen über einen Zeitraum von bis zu einer Woche und erreichten maximale Dimensionen von $30 \times 60 \times 60 \mu \mathrm{m}$. Eine Tendenz zur bevorzugten Bildung von hexagonalen Kristallen konnte nicht gefunden werden. 
A

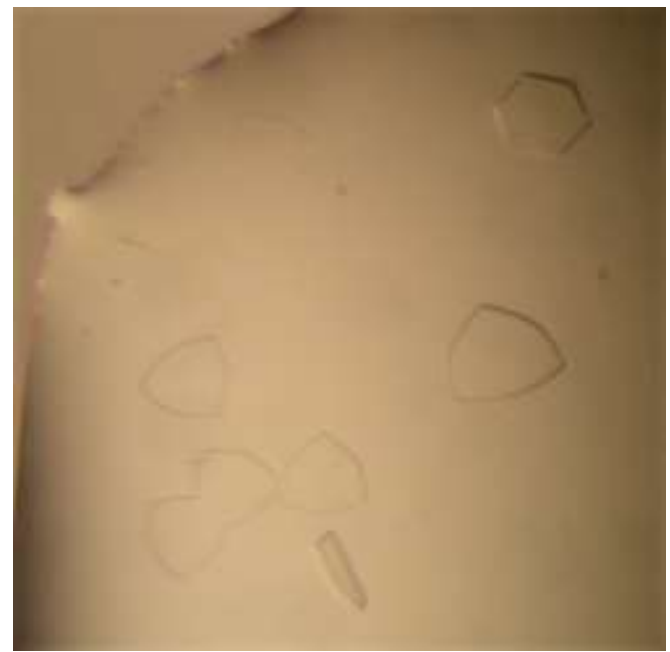

B

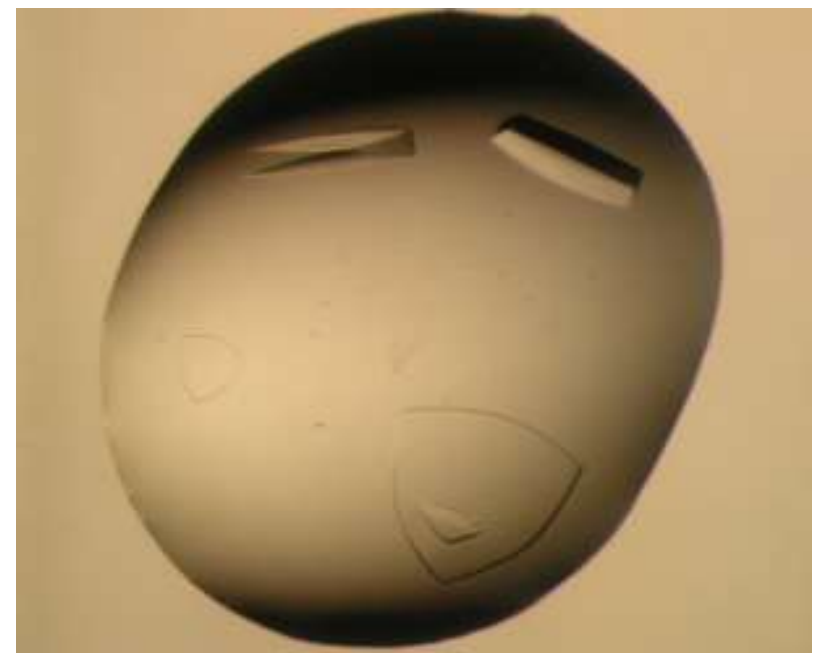

Abbildung I.22. Reproduzierbar erhaltene Kristalle von ecke10MMD_Hs. (A) Das Protein kristallisierte in zwei unterschiedlichen Formen, wobei hexagonale Kristalle im Verhältnis sehr selten vorkamen. (B) Größte Monokristalle des Fusionskonstrukts.

Zur weiteren Optimierung wurden Additiva und Detergenzien in die Kristallisationstests eingebunden. Unter Verwendung von Sodium-Malonat und PEGMME 5.000 entstanden dabei rundliche Scheiben (Abbildung I.23., A).

A

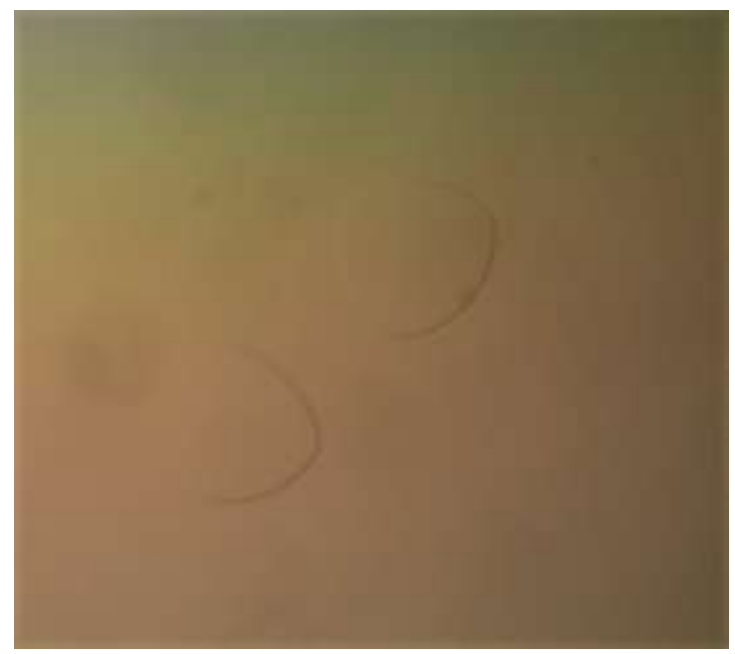

B

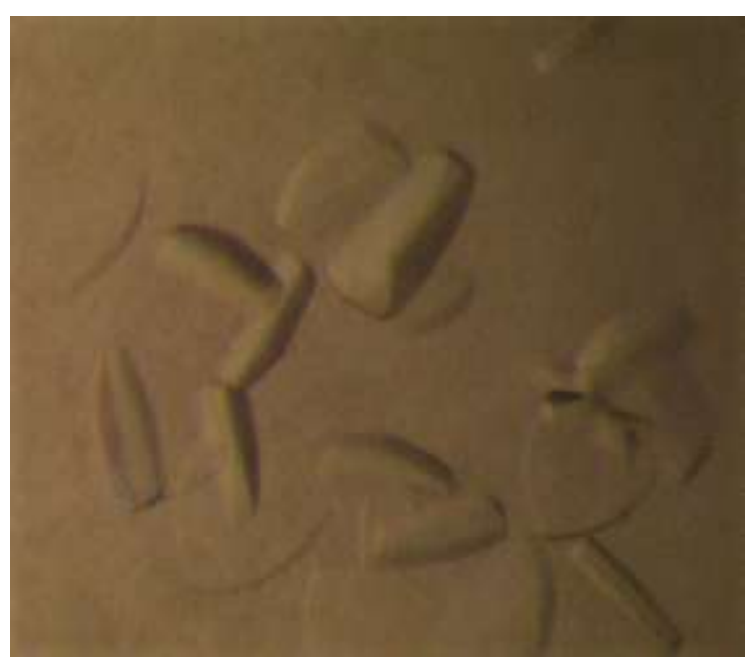

Abbildung I.23. Kristalle von ecke10MMD_Hs unter dem Einfluss von Additiva. (A) In Gegenwart von Sodium-Malonat und PEGMME 5.000 erhaltene, rundliche Kristalle. (B) Infolge der Zugabe von Bariumchlorid kompakter gewachsene Kristalle des Fusionskonstrukts. 
Demnach gelang es, Kristalle von ecke10MMD_Hs in insgesamt drei unterschiedlichen Formen zu züchten. In Gegenwart des Additivs Bariumchlorid konnten indes deutlich dickere Scheiben (Abbildung 1.23., B) erhalten werden. Im Gegensatz dazu hatten Detergenzien keinen Einfluss auf die Kristalle. Unter geringfügiger Abänderung der optimierten Kristallisationsbedingungen war es möglich, Kristalle auch in Gegenwart der ATP-Analoga AppCp, AppNHp, ATPyS und MgADP.AlF 4 sowie im Komplex mit $\mathrm{PP}_{\mathrm{i}}$ zu erzeugen. Diese unterschieden sich in ihrem Habitus nicht von den nativen Kristallen.

Des Weiteren wurden unterschiedliche Kryoprotektanten für das Einfrieren der Kristalle herangezogen. Dabei fanden Ammoniumsulfat, Lithiumsulfat und Sodium-Malonat in einer Konzentration von jeweils $2 \mathrm{M}$ Verwendung. In späteren Messungen zeigte sich, dass die Salze in dieser Konzentration gute Gefrierschutzeigenschaften aufwiesen. Ein paar Kristalle wurden hingegen ohne Kryobehandlung in flüssigen Stickstoff überführt. Schließlich wurden auch einige Kristalle in Gegenwart von Lithium- und Ammoniumsulfat kontrolliert dehydriert. Nachfolgende Diffraktionsmessungen an Beamline ID23-2 am ESRF ergaben jedoch, dass die Kristalle trotz intensiver Optimierung und deutlicher visueller Qualitätssteigerung nur bis 7-8 Å beugten. 


\section{I.3. Diskussion}

\section{I.3.1. Verwendung von Dictyostelium discoideum als Expressions- system und des Myosin-Fusionssystems als Expressionsver- stärker}

Der niedere Eukaryot Dictyostelium discoideum wurde als Wirt für die rekombinante Expression von DHC-Konstrukten herangezogen, da er bedeutende Vorteile gegenüber anderen eukaryotischen Expressionssystemen sowie gegenüber Bakterienzellen bietet. So zeichnen sich Dictyostelium-Zellen im Vergleich zu Zellkulturen von Säugetier- oder Insektenzellen durch ein schnelles Wachstum aus (Sussman, 1987). Dictyostelium kann in großen Mengen Protein sezernieren und benötigt kein Serum oder andere tierische Proteine für das Wachstum (Dittrich et al, 1994; Heikoop et al, 1998). Folglich können große Zellmengen unkompliziert und kostengünstig in Schüttelkulturen oder Fermentoren hergestellt werden. Des Weiteren besitzt Dictyostelium keine Zellwand und kann daher unter milden Bedingungen lysiert werden, was proteolytischen Effekten vorbeugt. Dies ist besonders vorteilhaft gegenüber Hefezellen, deren rigide Zellwand einen schonenden Zellaufschluss erschwert. Im Gegensatz zu Bakterienzellen ist Dictyostelium in der Lage, posttranslationale Proteinmodifikationen durchzuführen (Heikoop et al, 1998). Auch enthält der Organismus alle Chaperone, die für die korrekte Faltung vieler eukaryotischer Proteine erforderlich sind. Bakterienzellen hingegen lagern eukaryotische Proteine aufgrund fehlender Faltungshelfer oft in unlöslichen inclusion bodies ab.

Um die Proteinexpression in Dictyostelium discoideum zu verstärken und den Protein-Aufreinigungsprozess $\mathrm{zu}$ vereinfachen, wurde von dem MyosinFusionssystem (Kollmar, 2006) Gebrauch gemacht. Dieses basiert auf der Verwendung der 87 kDa großen Motor-Domäne des Klasse-II-Myosins (MMD) als N-terminales Fusionskonstrukt. Da die MMD zu den am stärksten exprimierten Proteinen in Dictyostelium gehört, kann das Expressionslevel des 
Fusionspartners deutlich verstärkt werden. Zusätzlich ermöglicht die MMD aufgrund ihrer ATP-abhängigen Bindung an Aktin einen schnellen und sehr spezifischen Affinitätsaufreinigungsschritt. Zu diesem Zweck wurden die Zellen in Gegenwart von alkalischer Phosphatase lysiert. Das Enzym hydrolysiert ATP, wodurch die Ausbildung des stabilen Akto-Myosin-Komplexes induziert wird. Nach einem sich daran anschließenden Zentrifugationsschritt kann der AktoMyosin-Komplex isoliert und das Myosin-Fusionsprotein somit unkompliziert von allen löslichen zellulären Proteinen abgetrennt werden. Die darauffolgende Zugabe von ATP zieht die Dissoziation des Akto-Myosin-Komplexes nach sich. Nach erneuter Zentrifugation kann das resolubilisierte Myosin-Fusionsprotein dann von sedimentierten Aktinfilamenten und daran gebundenem Fremdprotein separiert und anschließend durch Säulenchromatographie aufgereinigt werden. Schließlich kann auch der Vorgang der Strukturbestimmung durch die Verwendung des Myosin-Fusionssystems stark beschleunigt werden. Da die Struktur der $87 \mathrm{kDa}$ großen MMD bekannt ist, besteht die Möglichkeit, das Phasenproblem des fusionierten Proteins mittels der Methode des Molekularen Ersatzes zu lösen.

\section{I.3.2. Möglichkeiten, die zytoplasmatische DHC homogen in größeren Mengen zu erhalten}

Zu Beginn stellte sich die Frage, wie die zytoplasmatische DHC, die mit einem Molekulargewicht von etwa $520 \mathrm{kDa}$ zu den größten Proteinen in eukaryotischen Zellen zählt, in den für kristallographische Strukturuntersuchungen benötigten Mengen gewonnen werden kann. Eine Möglichkeit wäre gewesen, zytoplasmatisches Dynein direkt aus Zellextrakten oder z. B. aus Rinder- oder Schweinehirnen zu isolieren und aufzureinigen. In Wirbeltieren kommen die meisten Untereinheiten der DHC jedoch in unterschiedlichen Spleißvarianten vor und unterliegen darüber hinaus verschiedenen post-translationalen Modifikationen. So entstehen sehr heterogene Präparationen, die für die Strukturanalyse ungeeignet sind. Die Aufreinigung aus z. B. Hefezellextrakten 
würde hingegen nicht genug Protein für kristallographische Untersuchungen liefern. Folglich bestand die einzige Möglichkeit, größere Mengen an homogener zytoplasmatischer DHC zu erhalten, in der rekombinanten Herstellung entweder des Gesamtlängen-Proteins oder aber einzelner Domänen. Die Expression der DHC in voller Länge wurde nicht in Betracht gezogen, da die hohe Flexibilität des Proteins strukturelle Untersuchungen praktisch unmöglich gemacht hätte. Daher wurde das Ziel verfolgt, das Protein systematisch in kleinere Abschnitte zu unterteilen, die einzeln exprimiert und kristallisiert werden sollten.

Unsere Arbeitsgruppe setzt sich mit der strukturellen Rekonstitution des Dynein-Dynaktin-Komplexes von Dictyostelium discoideum als Modellsystem auseinander. Der Schleimpilz besitzt genau ein Homologon zu jeder der Untereinheiten des Dynein-Dynaktin-Komplexes aus Säugetieren. Folglich ist er diesem noch immer sehr ähnlich und demnach das wahrscheinlich einfachste Modell. Da Dictyostelium discoideum in dieser Arbeit zudem als Expressionssystem diente, wurde neben der humanen zytoplasmatischen DHC auch die des niederen Eukaryoten in strukturelle Untersuchungen eingebunden.

\section{I.3.3. Herstellung von Konstrukten der zytoplasmatischen DHC und Expression in Dictyostelium discoideum}

\section{I.3.3.1. Strategie zur Bestimmung von Fragmentgrenzen}

Die Herstellung stabiler Fragmente setzt die Verwendung geeigneter Domänengrenzen voraus. Anhaltspunkte für deren Findung geben im Allgemeinen Domänen- und Sekundärstruktur-Vorhersageprogrammen sowie Homologie-Vergleiche und Proteolyse-Experimente.

Die Bestimmung initialer Domänengrenzen für die Schweren Dynein-Ketten von Mensch und Dictyostelium discoideum basierte auf folgender Vorgehensweise: Die DHC des Basidiomyzeten Ustilago maydis wird von zwei Genen codiert (Straube et al, 2001), die auf verschiedenen Chromosomen lokalisiert sind und in zwei mRNAs transkribiert werden. Demzufolge setzt sich 
seine Schwere Kette aus zwei separat exprimierten Proteinen zusammen. PD Dr. Martin Kollmar konnte zahlreiche weitere Pilze innerhalb der Klasse der Basidiomyzeten (z. B. Laccaria bicolor, Gelatoporia subvermispora, Agaricus bisporus var. Bisporus und Schizophyllum commune) identifizieren, die die DHC in zwei getrennten Genen codieren. Interessanterweise unterschied sich der Trennpunkt der DHC-Gene in diesen Pilzen deutlich von dem in Ustilago maydis. Die beiden Trennpositionen wurden mittels vergleichender Sequenzanalyse in die zytoplasmatische DHC von Mensch und Dictyostelium discoideum übertragen und als Grenzen für Expressionskonstrukte herangezogen.

\section{I.3.3.2. Viele Abschnitte der DHC konnten in großen Mengen exprimiert werden}

Unter Verwendung von Dictyostelium discoideum als Expressionssystem und des Myosin-Fusionssystems als Expressionsverstärker gelang es, zahlreiche Teilbereiche der DHC in großen Mengen herzustellen. Demnach schienen beide Trennpositionen günstig für die Definition von Fragmentgrenzen zu sein. Auch andere Grenzen lieferten stabile Fragmente. Auffällig war, dass die Fusionskonstrukte der DHC von Mensch im Allgemeinen wesentlich höhere Expressionsraten aufwiesen als die von Dictyostelium discoideum. Über Gründe für diesen Befund kann nur spekuliert werden. Da Dictyostelium discoideum als Wirt diente, scheint es möglich, dass die exprimierten DHC-Konstrukte endogenes Dynein in seiner Funktionsweise beeinträchtigten, wodurch die toxisch wirkenden Proteine proteolytisch abgebaut würden.

\section{I.3.3.3. Der Großteil der hergestellten Fusionskonstrukte unterlag starker Aggregation}

$\mathrm{Ni}^{2+}$-NTA-Aufreinigungstests ergaben, dass nur wenige Fusionskonstrukte in der Lage waren, effektiv an das Säulenmaterial zu binden. Dies deutete darauf hin, dass der N-terminale Affinitäts-Tag bei einem Großteil der Proteine einer 
sterischen Abschirmung unterlag und daher nur unzureichend für Interaktionen mit der Säulenmatrix zur Verfügung stand. Durch den darauffolgenden Einsatz löslichkeitsfördernder Additiva, die eine Relaxation des Moleküls (Bondos \& Bicknell, 2003) und eine damit einhergehende Freilegung des Affinitäts-Tags bewirken sollten, konnte keine verbesserte Aufreinigung erzielt werden. Auch das Einbringen eines C-terminalen Histidin-Tags in die DHC-Konstrukte, wodurch die Proteine an beiden Enden einen Affinitäts-Tag trugen, erwies sich als wenig hilfreich. Da auch dem C-terminalen Histidin-Tag der Zugang zum Säulenmaterial verwehrt schien, wurde von einer Aggregation der entsprechenden Fusionsproteine ausgegangen. Weitere Bindungsexperimente zielten auf die Verwendung unterschiedlicher Säulenmaterialien ab. Als Affinitätsmatrices wurden $\mathrm{Co}^{2+}-\mathrm{NTA}$ und $\mathrm{Ni}^{2+}-$ IDA herangezogen. Mit $\mathrm{Co}^{2+}-\mathrm{NTA}$ wurde der Effekt eines $\mathrm{zu} \mathrm{Ni}^{2+}$ alternativen lons auf die Aufreinigung der Fusionskonstrukte untersucht. Verschiedene zweiwertige lonen können unterschiedliche Bindungseigenschaften aufweisen und die Interaktion zwischen Protein und Matrix beeinflussen (Sulkowski, 1989). Das Material $\mathrm{Ni}^{2+}-$ IDA besitzt im Vergleich zu $\mathrm{Ni}^{2+}$-NTA eine zusätzliche Koordinationsstelle für die Wechselwirkung mit dem Histidin-Tag tragenden Protein. Dies könnte eine verbesserte Anbindung der Proteine an das Säulenmaterial zur Folge haben. Außerdem wurden DEAE als Kationenaustauscher, SP als Anionenaustauscher sowie Hydroxylapatit als gemischter lonenaustauscher in die Tests eingebunden. Während die Proteine nur eine schwache Affinität zu $\mathrm{Co}^{2+}-\mathrm{NTA}, \mathrm{Ni}^{2+}-\mathrm{IDA}, \mathrm{DEAE}$ und SP zeigten, konnten sie über Hydroxylapatit effektiv aufgereinigt werden. Die anschließende Bestimmung des Oligomerisierungszustands der aufgereinigten Proben mittels analytischer Gelfiltration bestätigte den Verdacht, dass sämtliche Fusionsproteine, deren $\mathrm{Ni}^{2+}-\mathrm{NTA}$-chromatographische Aufreinigung fehlschlug, starker Aggregatbildung unterlagen. In diesem Zusammenhang ist anzumerken, dass die für den Gelfiltrationslauf aufkonzentrierten Proben keine Tendenz zur Präzipitation zeigten. Demnach bildeten die Proteine stabile, lösliche Aggregate aus. Ein möglicher Grund für das Aggregationsverhalten ist, dass die Fragmentgrenzen ungünstig gewählt worden waren. Dies könnte dazu geführt 
haben, dass den entsprechenden Domänen strukturelle Einheiten fehlten, woraufhin Aggregation über daraus hervorgegangene hydrophobe Bereiche erfolgte. Ebenso wäre denkbar, dass die aus dem DHC-Ringverbund „entrissenen“ Proteinabschnitte über offengelegte hydrophobe Oberflächen aggregierten, die normalerweise von anderen Domänen abgedeckt sind. $\mathrm{Da}$ undefinierte Aggregate für strukturelle Untersuchungen unbrauchbar sind, wurden die entsprechenden Fusionskonstrukte nicht weiter berücksichtigt. Im Gegensatz dazu lagen die über $\mathrm{Ni}^{2+}$-NTA aufgereinigten Proteine als Dimere vor.

\section{I.3.3.4. Die DHC-Konstrukte konnten nur als Fusionsprotein in für die Kristallisation ausreichenden Mengen Iöslich erhalten werden}

Um einer potenziellen Beeinträchtigung der Kristallisation durch die MMD vorzubeugen, sollten neben den sich als homogen erwiesenen MyosinFusionsproteinen auch die entsprechenden DHC-Konstrukte in Kristallisationstests eingesetzt werden. Da zwischen MMD und DHC-Konstrukt eine TEVSchnittstelle lokalisiert ist, sollte unter Verwendung von TEV-Protease eine Trennung der beiden Komponenten erreicht werden. Trotz des Einsatzes von Enzym in stark überschüssiger Menge, gelang es nicht, die MMD vom jeweiligen Fusionskonstrukt abzuspalten. $\mathrm{Da}$ die Aktivität der Protease an anderen Proteinen mit TEV-Spaltstelle eindeutig nachgewiesen werden konnte, war zu vermuten, dass die fehlgeschlagene Restriktion auf eine Unzugänglichkeit der Schnittstelle für das Enzym zurückzuführen war. Tatsächlich ging eine Vergrößerung des räumlichen Abstandes zwischen MMD und TEV-Spaltstelle mit einer erfolgreichen Trennung des Myosin-Tags von den Konstrukten einher. Dazu wurde den DHC-Konstrukten am N-Terminus eine TEV-Spaltsequenz einkloniert, aufgrund dessen die Fusionsproteine zwei aufeinanderfolgende Schnittstellen beinhalteten. Jedoch zeigte sich, dass die DHC-Konstrukte nach Beseitigung der MMD instabil wurden und auszuflocken begannen.

Im Anschluss daran wurde versucht, die Konstrukte ohne MMD in Dictyostelium discoideum herzustellen. Allerdings war davon auszugehen, dass 
die DHC-Konstrukte in Abwesenheit der MMD eine stark reduzierte Expressionsrate aufweisen würden. Dies bestätigte sich in nachfolgenden Expressionstests, in denen kein einziges Konstrukt in größeren Mengen hergestellt werden konnte.

Schließlich wurde E. coli als Expressionssystem herangezogen. Zwar wurden die Konstrukte in den Bakterienzellen stark exprimiert, lagen trotz Reduktion der IPTG-Konzentration und Inkubationstemperatur aber überwiegend unlöslich in inclusion bodies vor. Demnach war es nicht gelungen, die DHC-Konstrukte in für die Strukturanalyse ausreichenden Mengen zu erhalten, sodass lediglich die entsprechenden Fusionsproteine in Kristallisationstests eingesetzt werden konnten.

\section{I.3.4. Kristallisation des Fusionskonstrukts ecke1MMD_Dd}

Das Konstrukt ecke1Dd umfasst den "Stiel“, die AAA-Domänen 5+6 sowie den C-Terminus der zytoplasmatischen DHC von Dictyostelium discoideum (Abbildung I.24.) und besitzt ein Molekulargewicht von $\sim 250 \mathrm{kDa}$. Die hochaufgelöste Struktur dieses Proteinabschnitts würde wertvolle Informationen darüber liefern, wie allosterische Konformationsänderungen über den „Stiel“ bis zum C-Terminus des Motorproteins übermittelt werden. Außerdem könnte der Frage nachgegangen werden, welche Rolle dabei dem buttress sowie dem distalen C-Terminus, der in den zytoplasmatischen Dyneinen vieler Pilze fehlt, zukommt. 


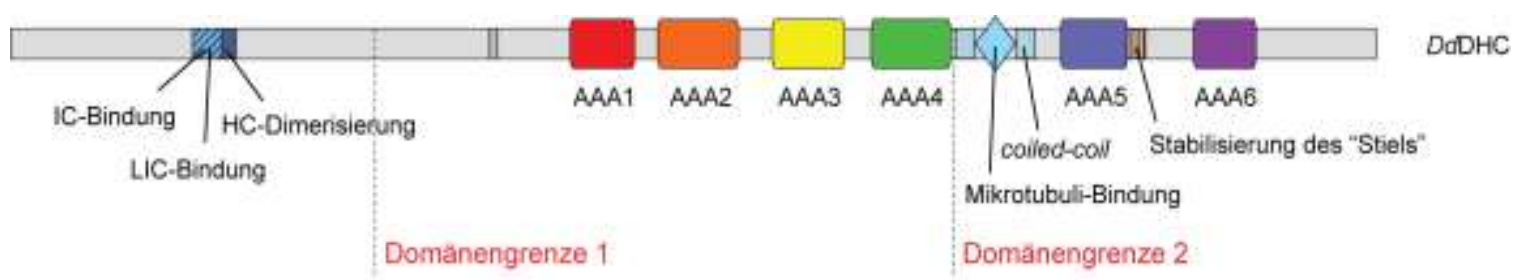

ecke1Dd
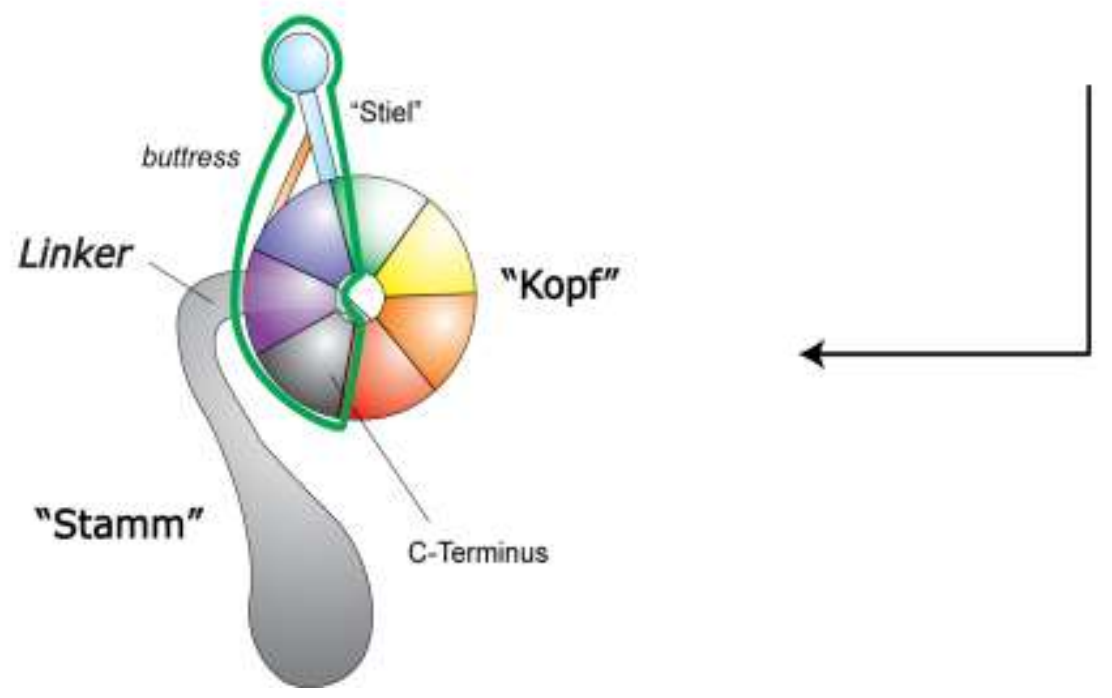

Abbildung I.24. Schematische Kennzeichnung des Teilbereichs der DHC von Dictyostelium discoideum, den das Konstrukt ecke1Dd sequenzbasiert (oben, als grün eingefärbter Querbalken) bzw. strukturell (unten, als grüne Umrandung) umfasst.

Die anfängliche Suche nach Kristallisationsbedingungen wurde mit sogenannten Sparse Matrix Screens (Jancarik \& Kim, 1991) durchgeführt. Diese umfassen eine begrenzte Anzahl unterschiedlichster Pufferbedingungen, die auf der statistischen Analyse erfolgreicher Fällungsreagenzien basieren. Sparse Matrix Screens liefern oftmals erste Hinweise auf erfolgversprechende Kristallisationsbedingungen, die daraufhin optimiert werden können. Die Fusionsproteine wurden sowohl im Komplex mit MgADP als auch MgADP. $\mathrm{VO}_{4}$ in die Screens eingesetzt. Die MMD liegt in Gegenwart dieser Nukleotide in deutlich voneinander abweichenden Konformationen vor (Gulick \& Rayment, 1997; Smith 
\& Rayment, 1996), wobei beide Zustände die Kristallisation des Fusionsproteins begünstigen könnten.

\section{I.3.4.1. ecke1MMD_Dd bildete nach Einbindung von Hydroxylapatit in den Aufreinigungsprozess erste Kristalle}

Für ecke1MMD_Dd wurden zunächst keine Kristalle erhalten. Hierfür waren möglicherweise Abbauprodukte des über $\mathrm{Ni}^{2+}$-NTA-Chromatographie und anschließende Gelfiltration aufgereinigten Proteins verantwortlich, die den Kristallisationsprozess beeinträchtigten. Um die Fremdproteine zu beseitigen, wurde die ursprüngliche 2-Stufen-Aufreinigung durch die lonenaustauschChromatographie über Hydroxylapatit ergänzt. Dieses Material ist eine interessante Alternative zu den klassischen lonenaustauschern. Seine funktionellen Gruppen sind zum einen positiv geladene Kalziumgruppen, an welche das Protein über negativ geladene Carboxygruppen anbindet, zum anderen negativ geladene Phosphatgruppen, die mit positiv geladenen Aminogruppen des Proteins komplexieren (Bernardi et al, 1972). Somit handelt es sich bei Hydroxylapatit um einen gemischten lonenaustauscher, der aufgrund seiner einzigartigen Bindungseigenschaften in der Lage ist, Abbauprodukte, die über herkömmliche Chromatographie-Methoden nur schlecht von dem gewünschten Protein separiert werden können, effektiv zu beseitigen. Obwohl die Fremdproteine in nur geringem Maße entfernt werden konnten, ergaben sich in nachfolgenden Kristallisationstests für ecke1MMD_Dd im Komplex mit MgADP bei Raumtemperatur erste Treffer. Die Kristalle waren jedoch sehr zahlreich und sehr klein $(5 \times 5 \times 10 \mu \mathrm{m})$. In Mikroseeding-Experimenten sollte daraufhin der Entstehung überschüssiger Keime und daraus resultierender „Kristallschauer“ vorgebeugt werden. Durch Seeding kann der Nukleationsvorgang kontrolliert werden, sofern es in der sogenannten metastabilen Zone des Phasendiagramms erfolgt. Diese ist dadurch charakterisiert, dass keine spontane Nukleation stattfinden kann, sehr wohl aber Kristallwachstum möglich ist. Werden also feine Kristallsplitter in die übersättigten Probentropfen eingebracht, können infolge der 
begrenzten Menge an Wachstumskeimen größere Kristalle entstehen. Die metastabile Zone konnte durch stufenweise Reduktion der Präzipitant- oder Proteinkonzentration ermittelt werden. Kam es gerade noch zu keiner spontanen Ausbildung von Nukleationskeimen bzw. lagen gerade noch keine Kristalle vor, befand man sich in der Regel innerhalb der metastabilen Zone des Phasendiagramms. Allerdings gelang es durch Mikroseeding nicht, größere Kristalle zu erhalten. Im Anschluss daran wurden Grid-Screen-Experimente durchgeführt. Diese basieren auf einer stufenweisen Veränderung einzelner Komponenten der Kristallisationsbedingung, wobei alle anderen Parameter beibehalten werden. Innerhalb dieser Toleranzbereiche konnten keine Tendenzen für das Wachstum größerer Kristalle gefunden werden. Auch nach proteolytischer Abspaltung des $\mathrm{N}$-terminalen Histidin-Tags, der aufgrund seiner undefinierten Konformation den Kristallisationsprozess störend beeinflussen kann, bildete das Protein keine größeren Kristalle.

\section{I.3.4.2. Durch reduktive Methylierung des Proteins konnten größere Kristalle gezüchtet werden, die allerdings starke visuelle Mängel aufwiesen und schlecht beugten}

Um Kristalle von ecke1MMD_Dd in für die Strukturanalyse geeigneter Qualität zu erhalten, wurde daraufhin ein neuer Weg eingeschlagen. Dieser zielte auf die Veränderung der Oberflächenbeschaffenheit des Proteins ab. Zu diesem Zweck wurde die Methode der reduktiven Methylierung angewandt, wodurch sich primäre Aminogruppen zu den entsprechenden Dimethylderivaten des Amins umsetzen lassen. Methyliert werden dabei alle dem Solvens zugänglichen Lysine und der N-Terminus des Proteins. Der Modifikationsprozess soll bewirken, dass die langkettigen hydrophilen Lysin-Seitenketten, welche die Kristallisation erschweren oder verhindern können, hydrophober werden und weniger stark mit dem Lösungsmittel wechselwirken. Die stabilisierte Proteinoberfläche kann die Ausbildung eines Kristallgitters zur Folge haben (Rayment, 1997). In der darauffolgenden Größenausschluss-Chromatographie, die der Abtrennung der 
verwendeten Reduktionsmittel vom Fusionskonstrukt diente, zeigte sich, dass das modifizierte Protein zwei Fraktionen früher von der Gelfiltrationssäule eluiert wurde als natives ecke1MMD_Dd. Da der Größenunterschied zwischen den beiden Proteinen (auf dem SDS-Gel liefen die Proteinbanden in etwa auf gleicher Höhe) sehr gering war und der Vorgang der reduktiven Methylierung keine Veränderung der Sekundär- und Tertiärstruktur nach sich zieht (Rypniewski et al, 1993), scheiden diese Faktoren als Begründung für das divergente Laufverhalten aus. Die Antwort liegt möglicherweise in der durch den Modifikationsprozess hervorgerufenen erhöhten Hydrophobizität des Proteins. So könnte es sein, dass das methylierte Konstrukt geringfügig mit dem Säulenmaterial wechselwirkte, wodurch es zurückgehalten und verzögert eluiert wurde. Das modifizierte Fusionskonstrukt bildete Kristalle aus, die wesentlich größer waren (30 x 30 x $100 \mu \mathrm{m})$ als die nativen Kristalle. Allerdings besaßen sie stark ausgeprägte Hohlräume. Da die Stäbchen ihre finale Größe bereits nach ca. 24 Stunden erreichten, waren die visuellen Mängel möglicherweise auf ihr schnelles Wachstum zurückzuführen - die Kanten wuchsen so schnell, dass die Grundfläche nicht „aufgefüllt“ werden konnte. In Diffraktionsmessungen an Beamline ID23-2 am ESRF in Grenoble stellte sich heraus, dass die Kristalle nur bis maximal $9-10 \AA$ beugten.

\section{I.3.4.3. Die Etablierung neuer Kristallisationsbedingungen in Kombination mit Mikroseeding brachte kompakte Kristalle hervor - allerdings keine nennenswerte Verbesserung der Beugungskraft}

Um kompaktere Kristalle zu erhalten sowie Fehlordnungen im Kristallgitter vorzubeugen, wurde eine Retardation des Kristallwachstums angestrebt. Zu diesem Zweck wurde das Protein in geringeren Konzentrationen in Kristallisationstests eingesetzt, die Probenplatten bei reduzierten Temperaturen gelagert sowie die Reservoirlösungen mit unterschiedlichen Mengen an Öl überschichtet, wodurch eine Verzögerung des Diffusionsprozesses erreicht 
werden sollte (Chayen, 1997). Trotz zahlreicher Versuche war es nicht möglich, stabilere Kristalle zu erhalten. Daraufhin wurde nach neuen Kristallisationsbedingungen gesucht. In Mikroseeding-Versuchen mit zuvor nicht verwendeten Sparse Matrix Screens gelang es, visuell stark verbesserte Kristalle zu züchten, die in anschließenden Verfeinerungsexperimenten derart optimiert werden konnten, dass sie keine Hohlräume mehr aufwiesen. Da die optisch fehlerfreien Kristalle ebenfalls nach ca. 24 Stunden ihre endgültige Größe, gingen die ursprünglichen Mängel wohl nicht auf ihr schnelles Wachstum, sondern höchstwahrscheinlich auf die ungünstig gewählten Kristallisationsbedingungen zurück. Des Weiteren konnten Kristalle auch im Komplex mit verschiedenen ATP-Analoga erhalten werden. Diese können unterschiedliche stabilisierende Effekte auf das Fusionsprotein ausüben und demnach das Beugungsvermögen der Kristalle beeinflussen. Außerdem wurden verschiedene Gefrierschutzmittel für die Kristalle benutzt. Dadurch sollte ein möglichst schonendes Schockgefrieren erreicht und der Entstehung von Unordnung im Kristallgitter vorgebeugt werden. Schließlich wurden auch kontrollierte Dehydrierungsversuche mit einigen Kristallen durchgeführt. Zu diesem Zweck wurde die Präzipitant-Konzentration der Reservoirlösung stufenweise erhöht, wobei dem Kristall eine mehrstündige Äquilibrierungszeit gegen die jeweils nächsthöher konzentrierte Reservoirlösung gewährt wurde. Die daraus resultierende Reduktion des Lösungsmittelanteils im Kristall kann mit einer dichteren Packung und einer deutlich verbesserten Beugungskraft einhergehen (Heras \& Martin, 2005). Erneute Diffraktionsmessungen an Beamline ID23-2 am ESRF in Grenoble zeigten, dass die Kristalle trotz intensiver Optimierung weiterhin nur unzureichend beugten. Reflexe konnten bis maximal 7-8 Å detektiert werden.

\section{I.3.5. Kristallisation des Fusionskonstrukts ecke10MMD_Hs}

Das Fusionskonstrukt ecke10 Hs beinhaltet den mechanischen Hebelarm (Linker) sowie die primäre energieerzeugende Einheit der zytoplasmatischen DHC (AAA1-Domäne) von Mensch (Abbildung I.25.) und besitzt ein Molekulargewicht 
von $160 \mathrm{kDa}$. Anhand der hochaufgelösten Struktur dieses Proteinabschnitts könnte der Frage nachgegangen werden, wie es Dynein gelingt, die in Form von ATP bereitgestellte Energie in den Kraftschlag des Linkers umzuwandeln.

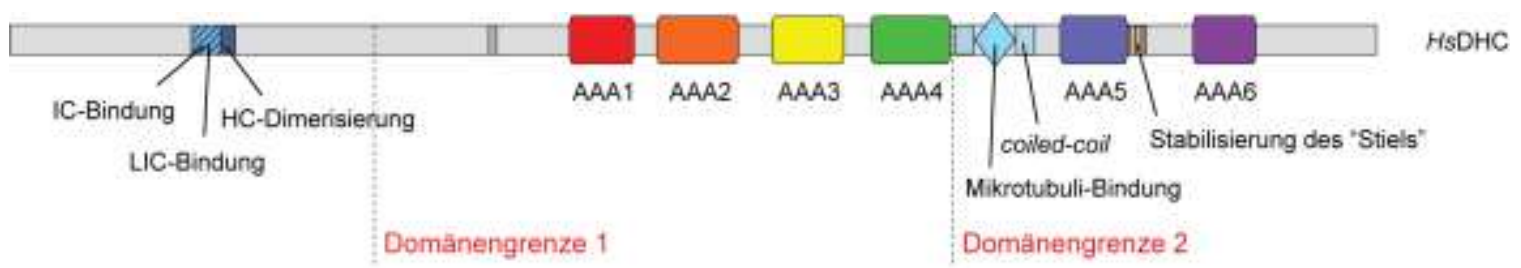

ecke10Hs
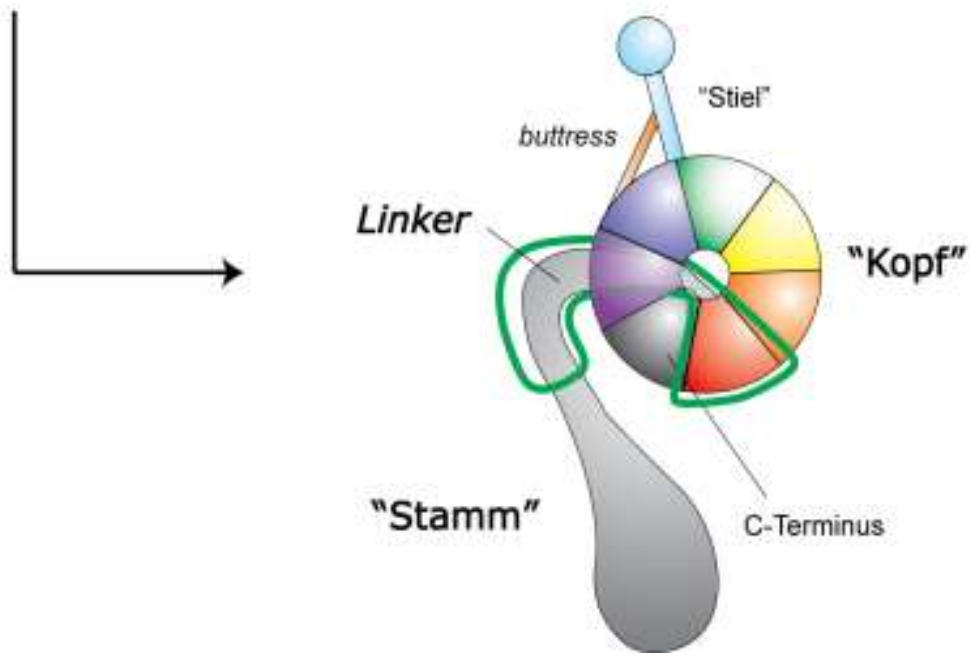

Abbildung I.25. Schematische Kennzeichnung des Teilbereichs der DHC von Mensch, den das Konstrukt ecke10Hs sequenzbasiert (oben, als grün eingefärbter Querbalken) bzw. strukturell (unten, als grüne Umrandung) umfasst. 


\section{I.3.5.1. ecke10MMD_Hs bildete Monokristalle, die nicht reproduziert werden konnten - ein direkt gefrorener Kristall streute bis ca. $3.8 \AA$}

Für ecke10MMD_Hs entstand in anfänglichen Kristallisationstests im Komplex mit MgADP. $\mathrm{VO}_{4}$ bei Raumtemperatur feinkristallines Material. Ein anschließender Grid-Screen um die erfolgreiche Kristallisationsbedingung brachte stark verwachsene Kristalle hervor. Mit Protein in geringfügig reduzierter Konzentration gelang es dann, Monokristalle zu erhalten, die sich allerdings nicht reproduzieren ließen. Testmessungen an Beamline ID23-2 am ESRF ergaben, dass die mit Glyzerol kryogeschützten Kristalle nur bis ca. 8-9 A streuten. Einige Kristalle wurden hingegen direkt in flüssigen Stickstoff eingefroren. Dabei sollte getestet werden, ob die Hochsalz-Pufferbedingungen unter denen die Kristalle wuchsen, kryotauglich sind. Zwar zeigte ein Kristall Reflexe bis ca. $3.8 \AA$, jedoch wies dieser eine stark ausgeprägte Mosaizität auf. Da das Lösungsmittel im Loop nicht transparent erschien, war davon auszugehen, dass es über keine ausreichenden Frostschutzeigenschaften verfügte. Demnach ging die hohe Mosaizität des Kristalls höchtswahrscheinlich auf das direkte Schockgefrieren zurück. Um der Unordnung im Kristall entgegenzuwirken, wurde daraufhin von der Technik des Annealings Gebrauch gemacht. Dabei wurde der gefrorene Kristall am Goniometer mehrmals für wenige Sekunden über eine den Stickstoffstrahl unterbrechende Metallplatte auf Raumtemperatur gebracht und danach erneut gefroren. Dadurch kann eine verbesserte Reorganisation der in sich verschobenen Mosaikblöcke erreicht werden (Harp et al, 1998). Die Mosaizität des Kristalls blieb aber zu hoch, als dass die aufgenommenen Daten hätte prozessiert werden können. Trotzdem konnte aus den Testmessungen geschlossen werden, dass die gezüchteten Kristalle grundsätzlich dazu imstande sind, die Strahlung in für die Strukturanalyse ausreichendem Maße zu beugen. 
I.3.5.2. Unter neuen Kristallisationsbedingungen entstanden in Kombination mit Mikroseeding deutlich größere Kristalle, die reproduzierbar waren - allerdings keine nennenswerte Verbesserung des Streuvermögens

Um Kristalle reproduzierbar $\mathrm{zu}$ erhalten, wurde nach neuen Kristallisationsbedingungen gesucht. Mit einem bis dahin nicht verwendeten Sparse Matrix Screen gelang es in Mikroseeding-Experimenten, Monokristalle des Fusionskonstrukts auch reproduzierbar zu erzeugen. Durch Variation einzelner Pufferkomponenten und den Gebrauch verschiedener Additiva konnten die Kristalle daraufhin sowohl in Größe als auch Dicke deutlich optimiert werden. Insgesamt wurden Kristalle von ecke10MMD_Hs in drei unterschiedlichen Formen erhalten. Außerdem gelang die Co-Kristallisation des Proteins mit verschiedenen ATP-Analoga. Ferner wurden verschiedene Kryoprotektanten für das Einfrieren der Kristalle herangezogen. Andere Kristalle wurden nach kontrollierter Dehydration hingegen direkt in flüssigen Stickstoff überführt. Allerdings zeigte sich in Beugungsexperimenten an Beamline ID23-2 am ESRF in Grenoble, dass das Diffraktionsvermögen der Kristalle trotz zahlreicher Optimierungsschritte und deutlicher visueller Verbesserung nicht der atomaren Strukturlösung genügte. Die besten Kristalle streuten bis maximal 7-8 A. 


\section{Strukturelle Charakterisierung des Capping- Proteins Cap32/34}

\section{II.1. Einleitung}

\section{II.1.1. Aktin}

Aktin ist ein in allen eukaryotischen Zellen vorkommendes Strukturprotein. Es ist das am stärksten vertretene zelluläre Protein und kann in Nichtmuskelzellen einen Anteil von über $5 \%$, in Muskelzellen sogar von über $20 \%$ am Gesamtprotein ausmachen (Kabsch \& Vandekerckhove, 1992). Mit einer Sequenzidentität von mindestens $85 \%$ vom Mensch bis zu den Algen ist Aktin ein hochkonserviertes Protein, welches eine zentrale Rolle in einer Vielzahl zellulärer Prozesse wie Phagozytose, Migration und dem intrazellulären Transport durch das Zytoplasma einnimmt (Pollard et al, 2001). Dabei kann Aktin in zwei unterschiedlichen Formen vorliegen - als monomeres und als filamentöses Aktin.

\section{II.1.1.1. Monomeres Aktin}

Die monomere Form von Aktin wird als G-Aktin (globuläres Aktin) bezeichnet und besitzt eine molekulare Masse von $43 \mathrm{kDa}$. In Säugetieren gibt es sechs unterschiedliche Aktin-Isoformen. Diese werden gewebespezifisch exprimiert und entsprechend ihres isolelektrischen Punkts in drei Klassen eingeteilt (Garrels \& Gibson, 1976):

- a-Aktine: drei Isoformen, die spezifisch in Muskelzellen lokalisiert sind (Skelettmuskulatur, Herzmuskulatur, glatte Muskulatur)

- $\beta$-Aktin: nichtmuskuläre Form, die Hauptbestandteil des Zytoskeletts ist

- y-Aktine: zwei Isoformen, davon eine nichtmuskuläre und eine in der glatten Muskulatur vorkommende Form 
Die Aktin-Isoformen bestehen aus einer Polypeptidkette von 374 Aminosäuren (Nichtmuskel-Isoformen) bzw. 375 Aminosäuren (Muskel-Isoformen) und unterscheiden sich nur geringfügig in ihrer Primärsequenz. Die Unterschiede sind dabei auf ihre N-terminalen Aminosäuresequenzen begrenzt (Khaitlina, 2001), die zudem verschiedenen post-translationalen Modifikationen unterliegen können (Ampe und Vandekerckhove, 1999). Die N-terminalen Abschnitte sorgen möglicherweise für eine spezifische Segregation der Aktin-Isoformen bzw. mRNAs in distinkte subzelluläre Kompartimente (Ampe und Vandekerckhove, 1999; Hill \& Gunning, 1993; Hoock et al, 1991).

Die Struktur von monomerem Aktin konnte erstmals im Jahr 1990 mittels des hochauflösenden Verfahrens der Röntgenkristallographie beschrieben werden (Kabsch et al, 1990). Da für Kristallisationsversuche hochkonzentriertes Protein erforderlich ist, wurde Aktin, um der Filamentbildung entgegenzuwirken, im Komplex mit DNase I kristallisiert. Das Molekül verfügt über eine globuläre Struktur mit einer räumlichen Ausdehnung von $5.5 \mathrm{~nm} \times 5.5 \mathrm{~nm} \times 3.5 \mathrm{~nm}$ (Bremer \& Aebi, 1992). Das Aktin-Monomer umfasst zwei Domänen, die sich in jeweils zwei Subdomänen aufgliedern (Abbildung II.1.).

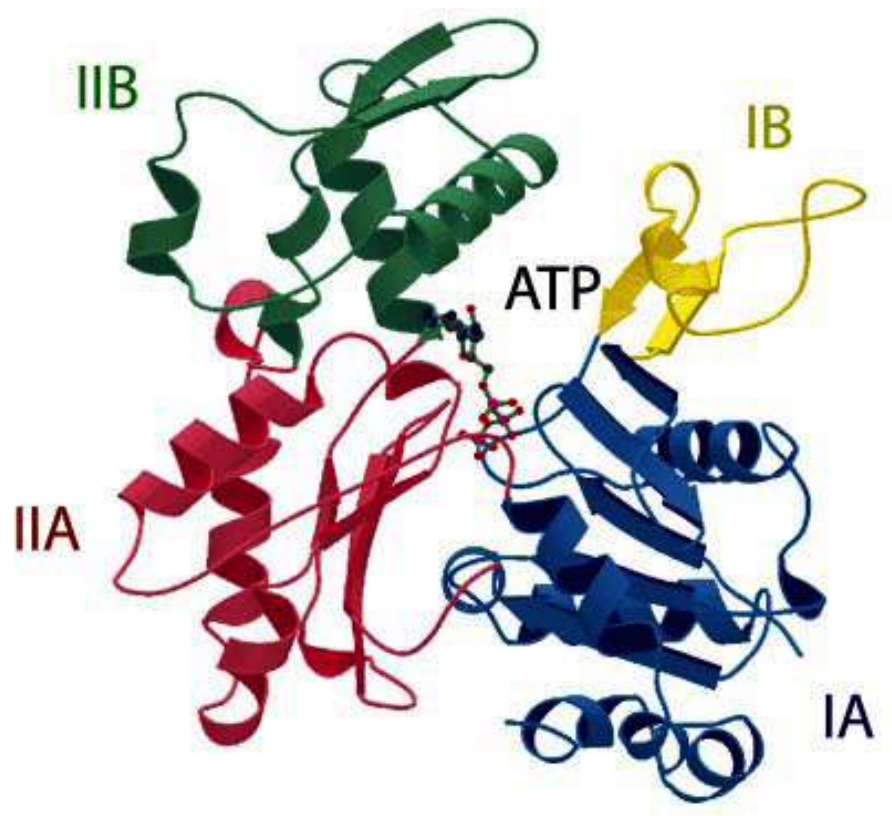

Abbildung II.1. Struktur von G-Aktin (Abbildung nach Löwe et al, 2004). Die beiden Domänen (I und II) sind durch eine Furche getrennt, in der ATP und ein $\mathrm{Ca}^{2+}$-Ion komplexiert vorliegen. Die einzelnen Subdomänen sind in unterschiedlichen Farben dargestellt. 
Die beiden Domänen sind so voneinander getrennt, dass ein Spalt entsteht, der die hochaffine Bindungstasche für ein Nukleotid (ATP oder ADP) und ein divalentes Kation $\left(\mathrm{Mg}^{2+}\right.$ oder $\left.\mathrm{Ca}^{2+}\right)$ enthält. G-Aktin besitzt zusätzlich weitere Bindestellen für mono- und divalente Kationen mit Affinitäten im mikromolaren (Carlier, 1989) und millimolaren (Zimmerle et al, 1987) Bereich. Diese sind an der salzinduzierten Aktivierung von Monomeren beteiligt. Da in den meisten Zellen die Konzentration an $\mathrm{Mg}^{2+}$ weitaus höher ist als die Konzentration freier $\mathrm{Ca}^{2+}$ lonen, ist die hochaffine Bindestelle für das divalente Kation in vivo aller Voraussicht nach mit $\mathrm{Mg}^{2+}$ besetzt. In vitro wird $\mathrm{Mg}^{2+}$ hingegen durch freie $\mathrm{Ca}^{2+}$ Ionen des verwendeten Puffers verdrängt (Gershman et al, 1986). Abhängig davon, ob sich $\mathrm{Mg}^{2+}$ oder $\mathrm{Ca}^{2+}$ an diese Stelle anlagert, weist G-Aktin distinkte Eigenschaften auf. Zudem kann das Aktin-Monomer mit ADP und ATP verschiedene Nukleotide binden. Diese haben wesentlichen Einfluss auf die Dynamik, Bindungsaffinität, Struktur und Regulation des Aktins (Estes et al, 1992; Kinosian et al, 1993).

\section{II.1.1.2. Filamentöses Aktin}

Aktinfilamente (F-Aktin) besitzen eine doppelhelikale Struktur, in der 13 Monomere über eine Länge von $37 \mathrm{~nm}$ für einen vollen Umgang benötigt werden (Holmes \& Kabsch, 1991). Mit einem Durchmesser von 6-8 nm stellen Aktinfilamente die dünnsten filamentösen Strukturen des Zytoskeletts dar und werden deshalb auch als Mikrofilamente bezeichnet. Die Polymere werden durch schwache, nicht-kovalente Wechselwirkungen zusammengehalten. Jedes Monomer hat mit vier weiteren Kontakt (Abbildung II.2.), womit das hohe Maß an Kooperativität bei der Polymerisation erklärt werden kann (Holmes et al, 1990). Darüber hinaus liegen alle Monomere im Filament in der gleichen „Kopf“-zu„Schwanz"-Orientierung vor, wodurch eine strukturelle Polarität generiert wird. Die Polarität kann dabei durch die Dekoration der Aktinfilamente mit Myosin S1, der Myosinkopfdomäne, gezeigt werden. Das Protein bindet mit einem Neigungswinkel von $45^{\circ}$ an Aktin, aufgrund dessen die Filamente im 
Elektronenmikroskop ein pfeilartiges Aussehen annehmen (Huxley, 1963; Ishikawa et al, 1969; Wegner, 1976). Die Enden werden entsprechend als „spitzes“ und „stumpfes“ Ende bezeichnet.

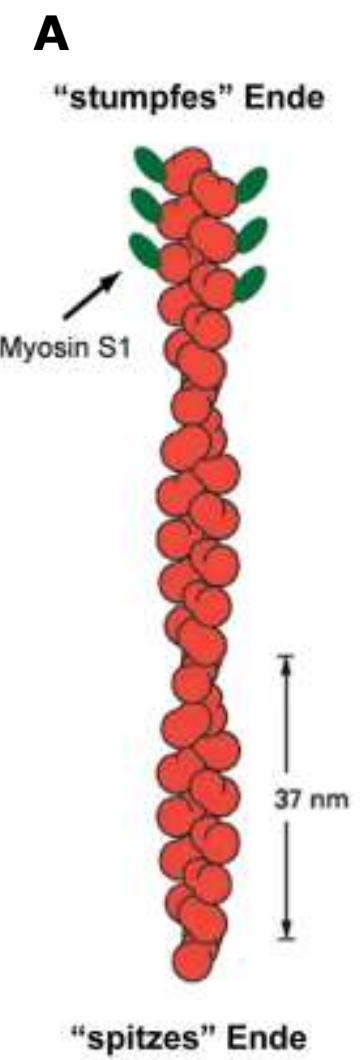

B

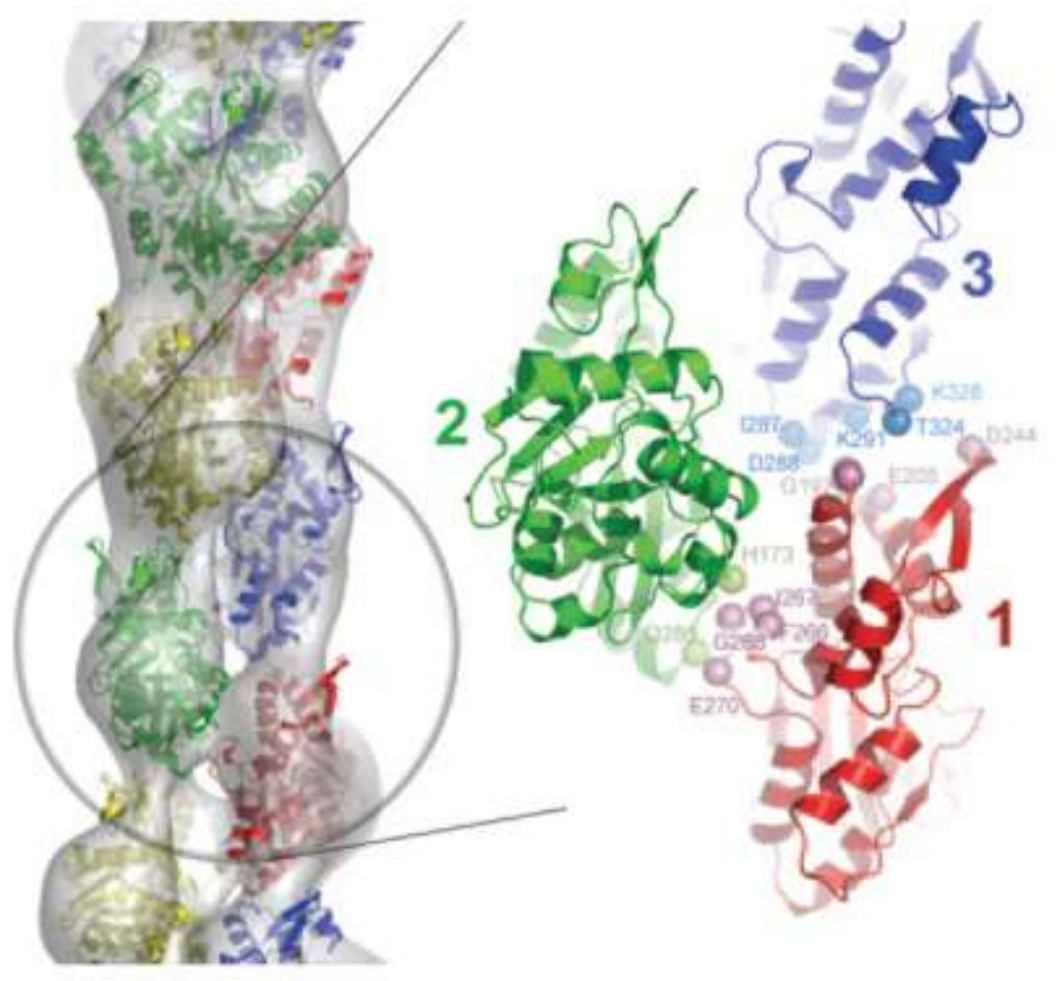

Abbildung II.2. Struktur von F-Aktin [Abbildungen modifiziert nach Lodish et al, 2001 (A) sowie Kudryashov et al, 2005 (B, C)]. (A) Helikal gewundenes, zweisträngiges Aktinfilament. Ein Umgang erstreckt sich über ca. $37 \mathrm{~nm}$. Die Bezeichnung der Filamentenden als „spitzes“ und „stumpfes“ Ende lässt sich aus der Dekoration mit Myosin S1 ableiten. (B) Aktinfilament mit vier Untereinheiten je Protofilament. Die einzelnen Protomere sind dabei in unterschiedlichen Farben dargestellt. (C) Detailansicht von drei G-Aktin-Bausteinen im Filament.

Obwohl die helikale Form von F-Aktin bereits im Jahr 1963 identifiziert werden konnte (Hanson \& Lowy, 1963), gelang es erst kürzlich, mithilfe der Röntgenbeugung an Fasern, die räumliche Struktur der Aktineinheiten innerhalb des Filaments hochaufgelöst ( $3.3 \AA$ ) zu bestimmen (Oda et al, 2009). Bis dahin konnte die Umwandlung des globulären Einzelbausteins in F-Aktin nur anhand 
von groben Modellen beschrieben werden (Holmes et al, 1990, 2003). Die Struktur deckte auf, dass das Protomer innerhalb des Filaments eine flachere Konformation aufweist. Diese wird durch eine $20^{\circ}$-Drehung der beiden Domänen zueinander hervorgerufen. Dadurch gelangt ein in den Vorgang der ATPHydrolyse involvierter und evolutionär stark konservierter Glutamat-Rest (in Position 137) näher an das $y$-Phosphat, wodurch die Hydrolyse von gebundenem ATP induziert wird (Oda et al, 2009).

\section{II.1.1.3. Aktin-Polymerisation}

Aktin-Monomere lagern sich unter physiologischen Bedingungen spontan zu Filamenten zusammen (Oosawa, 1972). Der Polymerisationsvorgang kann dabei in vier Phasen unterteilt werden: Aktivierung, Nukleation, Elongation und Fließgleichgewicht (Abbildung II.3.).

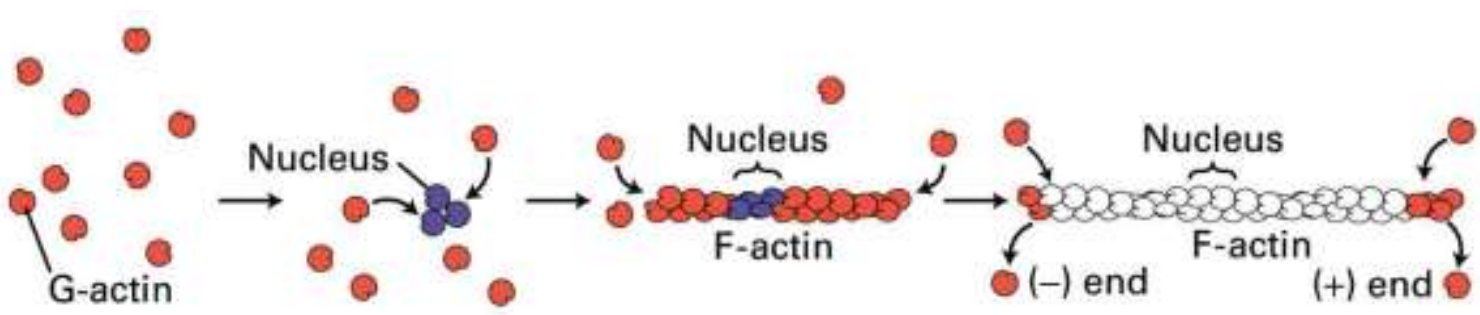

Aktivierung Nukleation Elongation Fließgleichgewicht

Abbildung II.3. Aktin-Polymerisation (Abbildung modifiziert nach Lodish et al, 2001). Erklärungen siehe Text.

Bei der initialen Aktivierung bewirkt die Anlagerung von mono- oder divalenten Kationen an Bindestellen mit niedriger Affinität zu ATP/ADP-G-Aktin eine konformationelle Änderung im Protein (Rich \& Estes, 1976). Der darauffolgende Nukleationsvorgang beinhaltet die Bildung eines Dimers aus zwei aktivierten Aktin-Monomeren und die anschließende Verknüpfung zu einem stabilen Trimer, auch Nukleationskeim genannt (Carlier, 1989, 1998; Sheterline et al, 1995). 
Dieser Prozess ist thermodynamisch ungünstig und läuft sehr langsam ab (Pollard, 1984). Von daher handelt es sich bei der Nukleation um den geschwindigkeitsbestimmenden Schritt der Aktinpolymerisation. Ist diese Schwelle erst einmal überwunden, wachsen Aktinfilamente durch die Anbindung von Monomeren an beide Enden jedoch schnell. Die Elongation dauert so lange an, bis die G-Aktin-Konzentration die sogenannte kritische Konzentration unterschreitet. Die Filamentenden haben unterschiedliche Polymerisationskinetiken für G-Aktin. Das „stumpfe“ Ende verfügt über eine hohe Assoziationsund geringe Dissoziationsrate, woraus sich eine niedrige kritische Aktinkonzentration (0.05-0.1 $\mu \mathrm{M}$ ) ergibt (Kondo \& Ishiwata, 1976; Wegner, 1976). Dem gegenüber steht das „spitze“ Ende, welches aufgrund einer niedrigen Assoziations- und hohen Dissoziationsrate eine um den Faktor 10-15 höhere kritische Aktinkonzentration $(0.5-0.7 \mu \mathrm{M})$ aufweist (Amann \& Pollard, 2000). Dadurch ist die Einbaurate von G-Aktin in das Filament am "stumpfen“ Ende wesentlich höher ( $\rightarrow$ Plus-Ende) als am „spitzen“ Ende ( $\rightarrow$ Minus-Ende). Die G-Aktin-Konzentration liegt unter physiologischen Bedingungen zwischen den kritischen Konzentrationsbereichen der beiden Filamentenden $(\sim 0.1 \mu \mathrm{M})$. Dies führt am Plus-Ende zu einer Nettopolymerisation und am Minus-Ende zu einer Nettodepolymerisation. Dabei herrscht ein Fließgleichgewicht vor, in dem in gleichem Maße ATP-G-Aktin am Plus-Ende in das Filament inkorporiert und ADP-G-Aktin am Minus-Ende wieder entlassen wird (Kuhn \& Pollard, 2005; Weber, 1999; Wegner, 1976). Dieser sogenannte "Tretmühlenmechanismus“ ist von signifikanter Bedeutung für eine Reihe von Aktin-abhängigen Bewegungsabläufen in der Zelle, wie z. B. für die Ausbildung von Lamellipodien und Filopodien. Hierbei handelt es sich um dynamische Strukturen, die dem Vorschub der Zellmembran dienen (Theriot \& Mitchison, 1991).

Während die Aktinfilamente in nichtmuskulären Zellen einer dynamischen Umgestaltung unterliegen, sind sie in Muskelzellen streng geordnet und bilden im Verbund mit Myosinfilamenten die hochspezialisierte Einheit der Krafterzeugung. Die Plus-Enden der Aktinfilamente sind in den sogenannten Z-Scheiben (Zwischenscheiben), welche die Sarkomere begrenzen, verankert. Dort werden 
sie durch a-Aktinin quervernetzt. Das sehr große Protein Nebulin ( $800 \mathrm{kDa})$ verläuft parallel zum Aktinfilament und ist analog zu diesem in der Z-Scheibe inseriert. Vermutlich bindet Nebulin entlang der dünnen Filamente und reguliert deren Länge (Pappas et al, 2008).

\section{II.1.1.4. Aktin-bindende Proteine}

Um den Erfordernissen dynamischer Bewegungsvorgänge in Zellen gerecht werden zu können, müssen Aktinfilamente schnell polymerisiert und depolymerisiert werden (Winder \& Ayscough, 2005). Wie zuvor erwähnt, erfolgt die spontane Nukleation von Aktin sehr langsam, da es sich hierbei um einen energetisch ungünstigen Vorgang handelt. In vivo liegen die AktinUmschlagsraten allerdings etwa 100-fach höher als in vitro (Pak et al, 2008). Dies ist darin begründet, dass die Zelle über ein großes Repertoire an Aktinbindenden Proteinen verfügt, die die Aktin-Polymerisation und die Lebensdauer der Mikrofilamente präzise regulieren (Winder \& Ayscough, 2005). Aktinbindende Proteine können gemäß ihrer Funktion und Wirkungsweise auf die Aktinorganisation in insgesamt sieben Gruppen kategorisiert werden (dos Remedios et al, 2003):

\section{- G-Aktin-bindende Proteine}

\section{Proteine als Nukleotidaustauschfaktoren}

Profiline katalysieren den Austausch von ADP zu ATP an G-Aktin und vermitteln so die schnelle Polymerisation ATP-beladener Monomere. Demzufolge können die Proteine das rapide Wachstum von Aktinfilamenten stimulieren (Selden et al, 1999; Sun et al, 1995).

Monomer-sequestrierende Proteine, wie $z$. B. Profilin und Thymosin $\beta 4$.

Diese Proteine binden vornehmlich an ATP-beladene Monomere und bewirken dadurch eine sterische Behinderung der spontanen 
Filamentpolymerisation. Auf diese Weise wird ein Reservoir an ATPgebundenen Aktin-Molekülen erzeugt, wodurch eine spätere schnelle Polymerisation möglich ist (Carlier, 1993; Huff et al, 2001).

Proteine als Nukleationsfaktoren, wie z. B. der Arp2/3-Komplex und Formine. Diese Proteine beschleunigen den geschwindigkeitsbestimmenden Nukleationsschritt und stimulieren dadurch die Bildung neuer Aktinfilamente. Der Arp2/3-Komplex etwa enthält ein Arp2- und Arp3-Monomer, die dem Aktin strukturell sehr ähnlich sind. So ist der Komplex in der Lage, die Aktinpolymerisation als „Pseudonukleationskeim“ zu katalysieren. Allerdings bedarf es dazu einer Aktivierung durch sogenannte NPFs (nucleationpromoting factor), den WASP (Wiskott-Aldrich syndrome protein) und WAVE (WASP family verprolin homology protein)-Proteinen, da der Arp2/3-Komplex über keine nennenswerte intrinsische Aktivität verfügt (Carlier et al, 2003; Pollard \& Borisy, 2003).

- F-Aktin-depolymerisierende Proteine, wie z. B. ADF/Cofilin und Twinfilin. Diese Proteine fördern die Depolymerisation am Minus-Ende der Aktinfilamente. Dies führt zu einer erhöhten Konzentration von ATP-G-Aktin im Gleichgewichtszustand, in dessen Folge eine schnellere Polymerisation am Plus-Ende ermöglicht wird (Bamburg, 1999; Palmgren et al, 2002).

- F-Aktin-verkappende Proteine, wie z. B. Capping-Protein, Gelsolin und Tropomodulin.

Diese Proteine binden an die Enden von Filamenten und verhindern so den Austausch von Monomeren. Der Vorgang wird als Capping bezeichnet (vom engl. to cap = abdecken). Ein ubiquitärer Vertreter ist das Capping-Protein, das analog zu Gelsolin das Plus-Ende des Filaments bedeckt (Winder \& Ayscough, 2005). Tropomodulin bindet hingegen an das Minus-Ende von FAktin (Weber, 1999). 
- F-Aktin-schneidende Proteine, wie z. B. Gelsolin, Adseverin und Villin. Diese Proteine lagern sich seitlich an Aktinfilamente an und können durch Veränderung ihrer Konformation Filamentbrüche herbeiführen (Silacci et al, 2004).

- F-Aktin-vernetzende Proteine, wie z. B. a-Aktinin, Filamin, Fimbrin und Arp2/3.

Diese Proteine können Verbindungen zwischen den Filamenten herstellen, sodass aus einzelnen Filamenten Bündel und Netzwerke entstehen (dos Remedios et al, 2003; Otto, 1994).

- F-Aktin-stabilisierende Proteine, wie z. B. Tropomyosin und Nebulin.

Diese Proteine binden entlang von F-Aktin, wodurch die Filamente stabilisiert werden (Vilfan, 2001; Pappas et al, 2008).

\section{- Motorproteine}

Myosine nutzen die Filamente als "Leitschiene", an der sie sich entlang bewegen (Molloy \& Veigel, 2003).

Trotz der Vielzahl an regulatorischen Proteinen, reichen einige wenige Vertreter aus, um in vitro auf Aktin basierende Motilität zu erzeugen (Loisel et al, 1999). Dazu gehören Proteine der ADF/Cofilin-Familie, das Capping-Protein, der Arp2/3-Komplex, ein Aktivator des Arp2/3-Komplexes und Profilin.

Die Aktivität von Aktin-bindenden Proteinen kann vielfältig kontrolliert werden. So bewirkt eine erhöhte, intrazelluläre $\mathrm{Ca}^{2+}$-Konzentration beispielsweise die Aktivierung von Villin und Adseverin (Blanchard et al, 1989). Dagegen werden z. B. das Capping-Protein und Gelsolin durch saure Phospholipide (PIPs) wie das Phosphatidylinositol-4,5-bisphosphat (PI4,5P2), welches eine zentrale Stellung in der intrazellularen Signaltransduktion einnimmt, gehemmt (Kim et al, 2007). Andere Aktin-bindende Proteine, wie ADF/Cofilin und Profilin können 
durch Phosphorylierung und Dephosphorylierung spezifischer Aminosäurereste reguliert werden.

\section{II.1.1.5. Das dendritische Nukleationsmodell}

Das dendritische Nukleationsmodell wurde erstmals 1998 von Mullins beschrieben (Mullins et al, 1998) und im Jahr 2001 durch Pollard erweitert (Pollard et al, 2001). Es postuliert die Entstehung verzweigter Aktinnetzwerke am vorderen Ende migrierender Zellen (Leitsaum) sowie den Recyclingmechanismus der Aktin-Monomere (Abbildung II.4.).

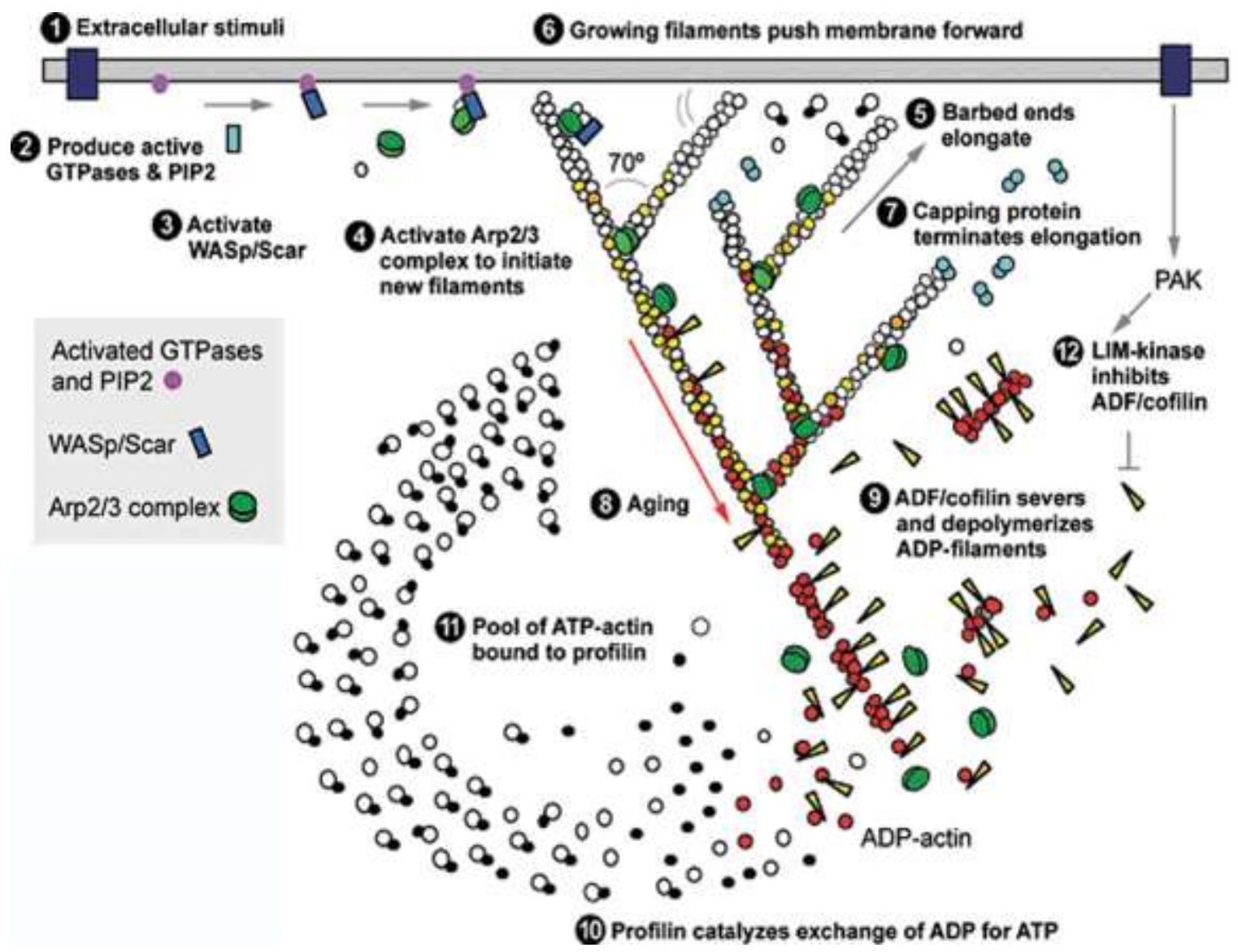

Abbildung II.4. Dendritisches Nukleationsmodell (Abbildung nach Pollard, 2007).

Einzelheiten siehe Text. 
Jede Zelle besitzt einen Vorrat an monomeren Aktin-Molekülen, der im Bedarfsfall zur Filamentbildung verwendet werden kann. Dies wird erreicht durch G-Aktin-sequestrierende Proteine, wie Profilin und Thymosin $\beta 4$, die dafür sorgen, dass die Nukleation von Filamenten bzw. jegliche Polymerisation unterbunden wird. Extrazelluläre Stimuli, wie z. B. chemotaktische Faktoren, binden an Rezeptoren der Plasmamembran (1) und aktivieren intrazelluläre Signalmoleküle (2). Über GTPasen und PI4,5P2 werden daraufhin NPFs, wie z. B. WASP/N-WASP (N-WASP = neuronales WASP), die ursprünglich in autoinhibierter Form vorliegen, aktiviert (3). Im Anschluß daran wird der Arp2/3Komplex, der nur eine geringe intrinsische Nukleierungsaktivität zeigt, durch Bindung von aktiviertem WASP/N-WASP stimuliert (4) (Pollard und Borisy, 2003). Durch eine Konformationsänderung des Komplexes werden Arp2 und Arp3 in direkte räumliche Nähe gebracht, sodass ein stabiler Nukleationskeim aus Arp2, Arp3 und dem WASP/N-WASP-gebundenen Aktin-Monomer gebildet werden kann (Mullins et al, 1998; Robinson et al, 2001). Der Arp2/3-Komplex lagert sich an die Seite bereits vorhandener Aktinfilamente an und initiiert dort die Aussprossung neuer Filamente in einem charakteristischen Winkel von $70^{\circ}$. Dadurch nimmt das entstehende Netzwerk eine Y-förmige Zweigstruktur an (Mullins et al, 1998). Die Aktinfilamente werden daraufhin in Richtung des zur Zelloberfläche hin ausgerichteten Plus-Endes verlängert (5), sodass eine Protrusion der Plasmamembran erreicht wird (6). Dieser gerichtete Elongationsvorgang wird nach wenigen Sekunden durch F-Aktin-verkappende Proteine, wie das Capping-Protein oder Gelsolin gehemmt (7) (Cooper \& Schafer, 2000; Sun et al, 1999). Der Einbau von ATP-Aktin in das Filament induziert die Hydrolyse von gebundenem ATP. Das Nukleotid hat eine Halbwertszeit von etwa 2 Sekunden (Blanchoin \& Pollard, 2002), wobei das anorganische Phosphat $\left(\mathrm{P}_{\mathrm{i}}\right)$ zunächst eng am neugebildeten Filament gebunden bleibt. $P_{i}$ dissoziiert mit einer Halbwertszeit von etwa 350 Sekunden sehr langsam, wodurch eine Reifung der Untereinheiten entlang des Aktinfilaments beobachtet werden kann (8). Nach Freisetzung von $\mathrm{P}_{\mathrm{i}}$, tritt eine Destabilisierung der ADP-beladenen Monomere im Polymer ein, da diese eine verringerte Bindungsaffinität zueinander aufweisen (Carlier, 1990). 
Dadurch wird die Depolymerisation von Aktin-Molekülen am Minus-Ende des Filaments begünstigt. ADF/Cofilin, das im proximalen Bereich des Leitsaums der Zelle angereichert ist, beschleunigt den Depolymerisationsprozess. Das Protein bindet an ADP-Aktin und verändert die Verdrillung der Aktinhelix, aufgrund dessen die Aktin-Untereinheiten im Filament weiter destabilisiert werden (9) (Svitkina \& Borisy, 1999; Pavlov et al, 2007). Als Folge lösen sich ADP-AktinMonomere vom Filamentende ab und liegen erneut frei löslich im Zytoplasma vor. Profilin konkurriert mit ADF/Cofilin um G-Aktin und katalysiert den Nukleotidaustausch von ADP zu ATP (10). So werden Aktin-Untereinheiten wieder in den ATP-Monomer-Pool überführt und stehen für die Inkorporation am Plus-Ende der Filamente zur Verfügung (11). In einem parallelen Signalweg kann ADF/Cofilin von der LIM-Kinase phosphoryliert und dadurch inhibiert werden (12). Dies resultiert in einer verlangsamten Depolymerisation von Aktinfilamenten (Meng et al, 2004).

\section{II.1.1.6. Capping-Protein}

Das Capping-Protein (CP) ist ein Heterodimer, bestehend aus einer $\alpha$ - und $\beta$ Untereinheit, das hochaffin $\left(\mathrm{K}_{d}=0.1-5 \mathrm{nM}\right)$ an das Plus-Ende von Aktinfilamenten bindet. Dabei reicht ein einzelnes CP-Molekül aus, um das Plus-Ende zu bedecken (Bearer, 1991; Kim et al, 2007). Capping bewirkt eine Stabilisierung des Filamentendes, da dort der Austausch von Aktin-Monomeren unterbunden wird (Wear \& Cooper, 2004). Dies führt zu einer lokalen Erhöhung des freien GAktin-Spiegels, wodurch Zellen aus dem Ruhezustand heraus die

Filamentbildung initiieren können (Disanza et al, 2005). CP ist in allen eukaryotischen Zellen vertreten. Dies deutet darauf hin, dass das Protein ein allgemeiner Bestandteil des Aktinzytoskeletts sind (Cooper \& Sept, 2008).

Im Jahr 1998 konnte CP erstmalig rekombinant exprimiert werden. Dazu wurden die beiden Untereinheiten in einen Vektor einkloniert und simultan hergestellt (Soeno et al, 1998). Das Heterodimer erwies sich unter einer großen Bandbreite an physiologischen Bedingungen sowie in Gegenwart verschiedener 
Salzkonzentrationen und pH-Werte als löslich und aktiv (Wear \& Cooper, 2004). Die bakterielle Expression einzelner Untereinheiten führte hingegen zur Entstehung instabiler und vorwiegend unlöslicher Produkte (Remmert et al, 2000).

Capping-Proteine wurden bereits in den 1960ern unter dem Namen „ßAktinin" aus Muskelgewebe isoliert und charakterisiert. 1980 gelang es Isenberg et al erstmals, ein nichtmuskuläres CP aufzureinigen (aus Acanthamoeba castellanii) und dessen Anbindung an das Plus-Ende des Aktinfilaments zu zeigen (Isenberg et al, 1980). Aufgrund dieser Eigenschaft erhielt es den Namen "Capping-Protein“. In der Folgezeit konnten Proteine dieser Familie aus einer Vielzahl anderer Organismen und Gewebe isoliert und charakterisiert werden. Diese umfassen Dictyostelium discoideum (Schleicher et al, 1984), Xenopus laevis (Ankenbauer et al, 1989), Saccharomyces cerevisae (Amatruda \& Cooper, 1992), Drosophila melanogaster (Hopmann et al, 1996), sowie Neutrophile (DiNubile et al, 1995), Erythrozyten (Kuhlman \& Fowler, 1997), Leukozyten (Maun et al, 1996), das Rinderhirn (Kilimann \& Isenberg, 1982) und die Skelettmuskulatur des Huhns (Casella et al, 1986).

Während Wirbellose einzelne Isoformen der $\alpha$ - und $\beta$-Untereinheit besitzen, konnten in Wirbeltieren bisher je drei Isoformen der beiden Untereinheiten identifiziert werden (mit Ausnahme von Maus und Ratte, für die erst kürzlich eine vierte Isoform gefunden werden konnte; Kollmar, persönliche Mitteilung). Davon werden je zwei Isoformen - $\alpha 1$, $\alpha 2$ bzw. $\beta 1, \beta 2$ - in somatischen Zellen exprimiert, eine Isoform - $\alpha 3$ bzw. $\beta 3$ - kommt hingegen spezifisch in männlichen Keimzellen vor (Hart et al, 1997; Miyagawa et al, 2002; Yoshimura et al, 1999). Die somatischen a-Isoformen werden von zwei Genen kodiert und in verschiedenen Zellen und Geweben unterschiedlich stark exprimiert. Spezifische Funktionen der $\alpha$-Isoformen sind nicht bekannt. Die Isoformen $\alpha 1$ und $\alpha 2$ besitzen ähnliche Aminosäuresequenzen ( 85 \% Übereinstimmung), divergieren in dieser Hinsicht indes stark von Isoform a3 ( 36 \% Übereinstimmung) (Hart et al, 1997). Die somatischen $\beta$-Isoformen werden durch alternatives Spleißen eines Gens produziert und ebenfalls gewebsspezifisch exprimiert (Schafer et al, 
1994b; von Bülow et al, 1997). Die $\beta 1$-Isoform befindet sich an der Z-Scheibe im Sarkomer von quergestreifter Muskulatur und wird deshalb als "Muskelisoform“ bezeichnet. Isoform $\beta 2$ kommt vornehmlich in nichtmuskulären Zellen vor, wo es im Zytoplasma in der Nähe von Membran-Aktin-Verbindungen lokalisiert ist. Demnach handelt es sich hierbei um die „Nichtmuskelisoform“. Die $\beta 2$-Isoform ist aber auch im Muskelgewebe zu finden, jedoch nicht an den Z-Scheiben, sondern in der Zellperipherie sowie an den interkalierenden Scheiben. Hart und Cooper konnten zeigen, dass die Isoformen $\beta 1$ und $\beta 2$ nicht in der Lage sind, sich im Muskel zu komplementieren. Dies deutet auf modifizierte Funktionen der beiden Proteine hin (Hart \& Cooper, 1999). Die somatischen $\beta$-Isoformen unterscheiden sich in ihrer Aminosäuresequenz lediglich durch eine kurze C-terminale Region (Schafer et al, 1994b). Isoform $\beta 3$ beinhaltet zusätzlich eine N-terminale Extension, ist davon abgesehen aber identisch mit Isoform $\beta 2$ (von Bülow et al, 1997).

Die CP-Isoformen werden in verschiedenen Zellen und Geweben in unterschiedlichen Mengenverhältnissen exprimiert. Während die $\alpha 1 / \beta 1$-Isoform beispielsweise in der Skelettmuskulatur dominiert, befindet sich das $\alpha 1 / \beta 2$ Isoform ganz vornehmlich in der Milz (Hart et al, 1997; Schafer et al, 1994b). In Erythrozyten wird fast ausschließlich das $\alpha 1 / \beta 2$-Heterodimer exprimiert (Kuhlman \& Fowler, 1997).

F-Aktin-Bindungsstudien ergaben, dass die C-terminalen Regionen beider Untereinheiten für die vollständige Aktinbindung notwendig sind und die Entfernung der beiden Bereiche einen kompletten Verlust der CPBindungsaktivität zur Folge hat (Wear \& Cooper, 2004; Kim et al, 2004). Die Cterminalen Abschnitte sind aber auch unabhängig voneinander in der Lage, an FAktin zu assoziieren, wenn auch mit stark reduzierter Affinität. Während die Entfernung der $28 \mathrm{C}$-terminalen AS der CP $\mathrm{\alpha}$-Untereinheit eine um den Faktor 5.000 verminderte Capping-Aktivität nach sich zog, bewirkte der Verlust des $\beta$-CTerminus (34 AS) eine 300-fach reduzierte Capping-Aktivität (Wear \& Cooper, 2004). In Mutationsexperimenten konnte eine Anhäufung evolutionär stark konservierter, basischer Aminosäuren innerhalb der C-terminalen Region der $\alpha$ - 
Untereinheit als primäre F-Aktin-Bindestelle identifiziert werden (Wear et al, 2003).

Die im Jahr 2003 aufgeklärte Kristallstruktur von rekombinantem CP aus der Skelettmuskulatur von Huhn (CapZ $\alpha 1 / \beta 1)$ deckte auf, dass die C-Termini der beiden Untereinheiten eine amphipathische a-Helix enthalten und aus der Proteinstruktur herausragen (Yamashita et al, 2003). Der C-terminale Bereich der $\alpha$-Untereinheit besetzt eine hydrophobe Tasche auf der Oberfläche der $\beta$ Untereinheit und wird dadurch stabilisiert. Dagegen gibt es keine spezifischen Wechselwirkungen zwischen dem $\beta$-C-Terminus und dem Restprotein. Folgerichtig ist dieser Proteinabschnitt durch eine stark ausgeprägte Flexibilität charakterisiert. Die deutlichen Mobilitätsunterschiede zwischen den beiden Enden konnten in molekulardynamischen Studien bestätigt werden (Bhattacharya et al, 2006).

Die Frage wie das CP-Molekül an Aktinfilamente bindet, hat viele Spekulationen und Diskussionen hervorgerufen. Im Folgenden wird ein auf kryoelektronenmikroskopischen Aufnahmen des Aktin-CP-Komplexes (Auflösung $23 \AA$ ) basierendes Modell vorgestellt (Narita et al, 2006). In diesem Experiment konnten beide CP-Untereinheiten identifiziert sowie deren relative Position zu den Aktin-Protomeren am Plus-Ende des Filaments gezeigt werden. Dabei stellte sich heraus, dass die $\mathrm{N}$-terminalen Bereiche der CP $\beta$-Untereinheit und der $\alpha-\mathrm{C}$ Terminus primäre Kontakte mit den letzten beiden Protomeren des Filaments bilden. Computergestützte Modellierungen brachten ferner hervor, dass der flexible $\beta$-C-Terminus in der Lage ist, an einen hydrophoben Abschnitt des letzten Aktin-Protomers zu binden. Dies würde sich decken mit der Interaktion einer Reihe anderer Proteine (z. B. Gelsolin und Vitamin-D-Bindeprotein) mit Aktin, die durch hydrophobe Reste einer amphipathischen $\alpha$-Helix vermittelt wird (Dominguez, 2004; Hertzog et al, 2004). Aufbauend auf diesen Befunden wurde folgendes zweistufige Modell für die Interaktion von CP mit Aktin postuliert (Abbildung II.5.; Narita et al, 2006): 
1. Das C-terminale Segment der $\alpha$-Untereinheit bindet an die beiden letzten Protomere des Filaments. Die Kontakte basieren auf elektrostatischen Wechselwirkungen zwischen basischen Aminosäuren innerhalb des CPProteinabschnitts und sauren Aminosäuren am Filamentende.

2. Der flexible $\beta$-C-Terminus bindet über seine amphipathische $\alpha$-Helix in die hydrophobe Vertiefung zwischen den Subdomänen IA und IIA des letzten AktinProtomers.

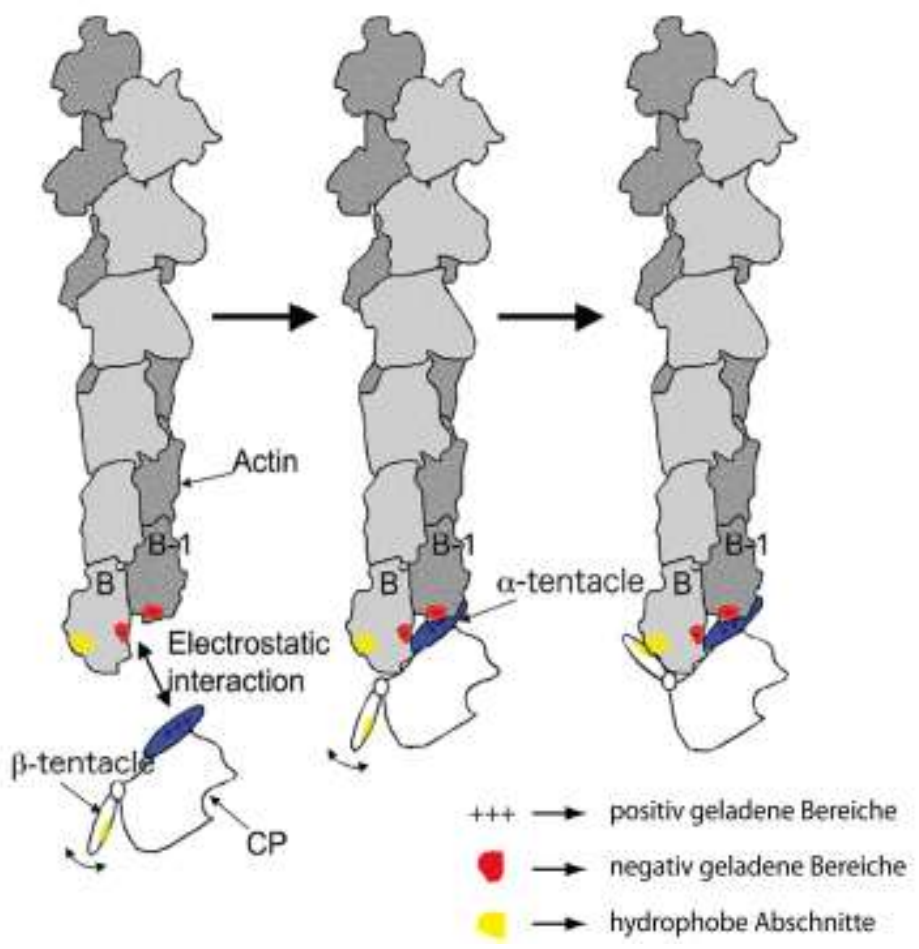

\begin{abstract}
Abbildung II.5. Mechanismus der Anbindung von $\mathrm{CP}$ an F-Aktin (Abbildung modifiziert nach Narita et al, 2006). Im ersten Schritt der Interaktion bindet der CP $\alpha$-C-Terminus elektrostatisch an die beiden letzten Protomere des Filaments. Anschließend dockt der amphipathische CP $\beta$-C-Terminus an das letzte Aktinprotomer an, wobei die Wechselwirkung hydrophober Natur ist.
\end{abstract}

\section{II.1.1.6.1. Regulation der CP-Aktivität}

Für verschiedene Proteine konnte ein Einfluss auf die CP-Capping-Aktivität nachgewiesen werden. Diese binden entweder direkt an das Heterodimer oder assoziieren mit dem Plus-Ende von Aktinfilamenten, wodurch sie eine Verdrängung von CP erreichen. 


\section{- Direkte Regulation}

V-1 (Myotrophin) ist ein kleines Protein $(12 \mathrm{kDa})$, welches in einer Vielzahl zellulärer Prozesse involviert ist, wie z. B. der Synthese von Katelochaminen, der Insulinsekretion und der Entwicklung des Kleinhirns. Die röntgenkristallographische Struktur von CP komplexiert mit V-1 konnte vor kurzem aufgeklärt werden (Hernandez-Valladares et al, 2010; Takeda et al, 2010). Dabei stellte sich heraus, dass der Hemmstoff an die primäre F-Aktin-Interaktionsstelle andockt, wodurch CP aus sterischen Gründen nicht mehr in der Lage ist, an das Filament zu assoziieren. Dies erklärt, warum V-1 die CP-Capping-Aktivität vollständig inhibieren, aber kein Uncapping hervorrufen kann (Bhattacharya et al 2006) - nach der Anbindung von CP an das Filament ist die Andockstelle des Antagonisten tief zwischen den letzten beiden Aktinprotomeren verborgen und somit unzugänglich. Des Weiteren weisen die Strukturen von nativem und mit V1 komplexiertem CP starke konformationelle Unterschiede auf, die gemäß computergestützter Analysen auf eine Rotationsbewegung zweier rigider Domänen des Heterodimers (diese entsprechen nicht den Untereinheiten a und ß) relativ zueinander zurückzuführen sind (Takeda et al, 2010).

CARMIL (vom engl. Capping-protein, Arp2/3 and myosin ! linker) ist ein Multidomänen-Protein mit einer molekularen Masse von $150 \mathrm{kDa}$. Das Protein wurde zuerst in Dictyostelium discoideum beschrieben (Jung et al, 2001), wo es sich am Leitsaum sowie in endozytotischen Zellextensionen befindet. Die Ausschaltung von CARMIL in Dictyostelium geht mit einer reduzierten Effizienz der chemotaktischen Aggregation sowie mit abnehmenden Pinozytoseraten einher (Jung et al, 2001). In funktionellen Studien konnte gezeigt werden, dass CARMIL die Eigenschaft besitzt, bereits gebundenes CP vom Aktinfilament zu entfernen. Allerdings kann es dessen Capping-Aktivität nicht vollständig hemmen (Cooper \& Sept, 2008). Erst kürzlich wurde die Kristallstruktur des Heterodimers im Komplex mit einem Teilabschnitt von CARMIL, der das CP-Bindemotiv [LXHXTXXRPK(6X)P] enthielt, beschrieben (Hernandez-Valladares et al, 2010; Takeda et al, 2010). Die Bindung des Fragments erstreckte sich quer über die postulierten rigiden CP-Domänen und zog keine nennenswerten 
Konformationsänderungen im Heterodimer nach sich. Da dem Protein ebenfalls instrinsische Flexibilität nachgewiesen werden konnte (Hernandez-Valladares et al, 2010; Takeda et al, 2010), schlugen die Autoren folgendes Szenario für CARMIL-induziertes Uncapping vor:

1. Nach initialer Anbindung an das Plus-Ende geht CP infolge dadurch hervorgerufener struktureller Änderungen von einem schwach- in einen hochaffinen Zustand für F-Aktin über.

2. Die Bindung von CARMIL an CP bewirkt, dass das Heterodimer wieder in den Zustand niedriger F-Aktin-Affinität überführt und in diesem arretiert wird. Dies hat allosterisches Uncapping zur Folge, wodurch CP das Filamentende verlässt. Da die beiden F-Aktin-Bindungsstellen von CP (C-terminaler Bereich der $\alpha$ - und $\beta$ Untereinheit) nicht an der Interaktion mit CARMIL beteiligt sind, kann der Antagonist die Capping-Aktivität des Proteins nicht vollständig hemmen.

Das saure Phospholipid PI4,5P2 ist ebenfalls fähig, direkt an CP zu binden und dessen Capping-Aktivität zu inhibieren (Heiss \& Cooper, 1991). Außerdem besitzt das Lipid Uncapping-Aktivität (Kim et al, 2007). So konvertierte ursprünglich mit CP verkapptes F-Aktin nach Zugabe von PI4,5P2 zu wachsenden Filamenten. Computergestützte Docking-Experimente deuten darauf hin, dass PI4,5P2 elektrostatisch an drei stark konservierte, basische Aminosäuren nahe des CP $\alpha$-C-Terminus anbindet, die für den initialen Kontakt mit Aktin wichtig sind (Kim et al, 2007; Narita \& Maéda, 2007). Folglich würde das Lipid eine kompetitive Hemmung der F-Aktin-Bindung bewirken. Dem Phospholipid kommt vermutlich eine sehr wichtige Funktion in amöboiden Bewegungen, wie $z$. B. von Dictyostelium, zu. Da PI4,5P2 Bestandteil der Zellmembran ist, könnte es durch die Hemmung von membrannahem CP die Zellmotilität fördern.

\section{- Indirekte Regulation}

Formine konkurrieren mit CP um das Plus-Ende von Aktinfilamenten und können so die Capping-Aktivität des Proteins indirekt beeinflussen. Sie zeichnen sich 
durch zwei charakteristische Domänen aus - die sogenannten formin homology domains 1 und 2 (FH1, FH2) (Zigmond et al, 2003; Pollard, 2004; Wallar \& Alberts, 2003). Formine können sowohl die Nukleation als auch die Elongation von F-Aktin katalysieren. Zur Nukleation ist die hochkonservierte FH2-Domäne erforderlich. Ein FH2-Dimer kann als Nukleationskeim der Aktinpolymerisation fungieren, indem es Aktin-Dimere stabilisiert (Sagot et al, 2002). Um die Elongation zu fördern, binden Formine an die Plus-Enden von Aktinfilamenten. Obwohl die FH2-Domänen aufgrund ihrer hohen Affinität dauerhaft am Filamentende gebunden bleiben, können sich dort neue Aktinuntereinheiten anlagern. Formine sind demnach prozessive Anti-Capper. Für das schnelle Wachstum der Filamente sind die Prolin-reichen FH1-Domänen entscheidend, die mit Profilin interagieren und dadurch Profilin-gebundenes ATP-Aktin rekrutieren. Die Folge sind sehr lange, unverzweigte Filamente (Sagot et al, 2002).

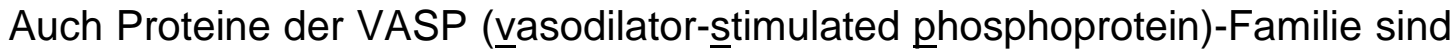
in der Lage, die Aktivität von CP indirekt zu regulieren. VASP ist an den Spitzen von Filopodien lokalisiert, wo es vermutlich Capping unterbindet, um eine rasche Verlängerung dieser Strukturen zu unterstützen (Applewhite et al, 2007; Mejillano et al, 2004).

\section{II.1.1.6.2. Funktionen in zellulären Prozessen}

CP konnte in verschiedenen Studien, sowohl in vivo (Bear et al, 2002; Hug et al, 1995; Iwasa \& Mullins, 2007) als auch in vitro (Loisel et al, 1999; van der Gucht et al, 2005) eine wesentliche Rolle in amöboiden Bewegungsprozessen zugeordnet werden. So ist bekannt, dass die Migrationsgeschwindigkeit von Dictyostelium-Zellen bei Überexpression von CP deutlich zunimmt, wohingegen eine Unterexpression den gegenteiligen Effekt nach sich zieht (Hug et al, 1995). $\mathrm{CP}$ wirkt an der Ausbildung von Lamellipodien am Leitsaum migrierender Zellen mit. Es zeigte sich, dass CP nach der Zugabe von chemotaktischen Substanzen (cAMP) zu Dictyostelium-Zellen zur Zellperipherie rekrutiert wird und die Aktin- 
Polymerisation initiiert (Eddy et al, 1997). Auch in Melanomzellen von Säugern, Xenopus-Fibroblasten sowie Drosophila-S2-Zellen konnte CP hauptsächlich im distalen Bereich von Lamellipodien identifiziert werden (Iwasa \& Mullins, 2007; Mejillano et al, 2004; Miyoshi et al, 2006).

Insgesamt stellen diese Beobachtungen ein Paradoxon dar. CP, das der Termination der Filamentverlängerung dient, scheint ebenso den Aufbau von Aktinnetzwerken zu fördern und amöboide Bewegungen zu beschleunigen. Die von Carlier und Pantaloni aufgestellte Funneling-Hypothese (von engl. funnel = Trichter) versucht dieses Paradoxon zu klären und begründet die zwingende Beteiligung von CP an der Ausbildung des Leitsaums (Carlier \& Pantaloni, 1997). Die Hypothese basiert auf der Notwendigkeit der Entstehung möglichst kurzer und starrer Filamente nahe der Zellspitze, um die für den mechanischen Vorschub der Membran erforderliche Kraft erzeugen zu können. Insofern wird postuliert, dass die vom Arp2/3-Komplex gebildeten, verzweigten Filamente in stochastischer Weise von CP besetzt werden. Während „ältere“ Filamente somit hauptsächlich gecappt sind, unterliegen "neuere“ (membrannahe) Filamente kaum Capping. Die Folge ist eine erhöhte Konzentration an G-Aktin, da der Einbau von Monomeren in „ältere“ Filamente blockiert ist. Die weitere Polymerisation nicht verkappter Filamente resultiert in der Entstehung breit angelegter Zellfortsätze, der sogenannten Lamellipodien (Abbildung II.6.). Demnach setzt die Funneling-Hypothese die Funktion von CP mit der eines Trichters gleich, der den Fluss von Aktin-Monomeren auf einen kleinen Teil der Filamente begrenzt (selektive Filamentverlängerung) und dadurch schnelle Zellmigration ermöglicht (Carlier \& Pantaloni, 1997).

Wird die CP-Capping-Aktivität hingegen durch z. B. PI4,5P2 oder VASP gehemmt, überwiegt die Elongation einzelner Filamente. So entstehen lange Filamente, die anschließend durch das Protein Fascin gebündelt und stabilisiert werden können. Das Resultat sind Filopodien, fingerförmige Ausstülpungen der Plasmamembran (Abbildung II.6.). 


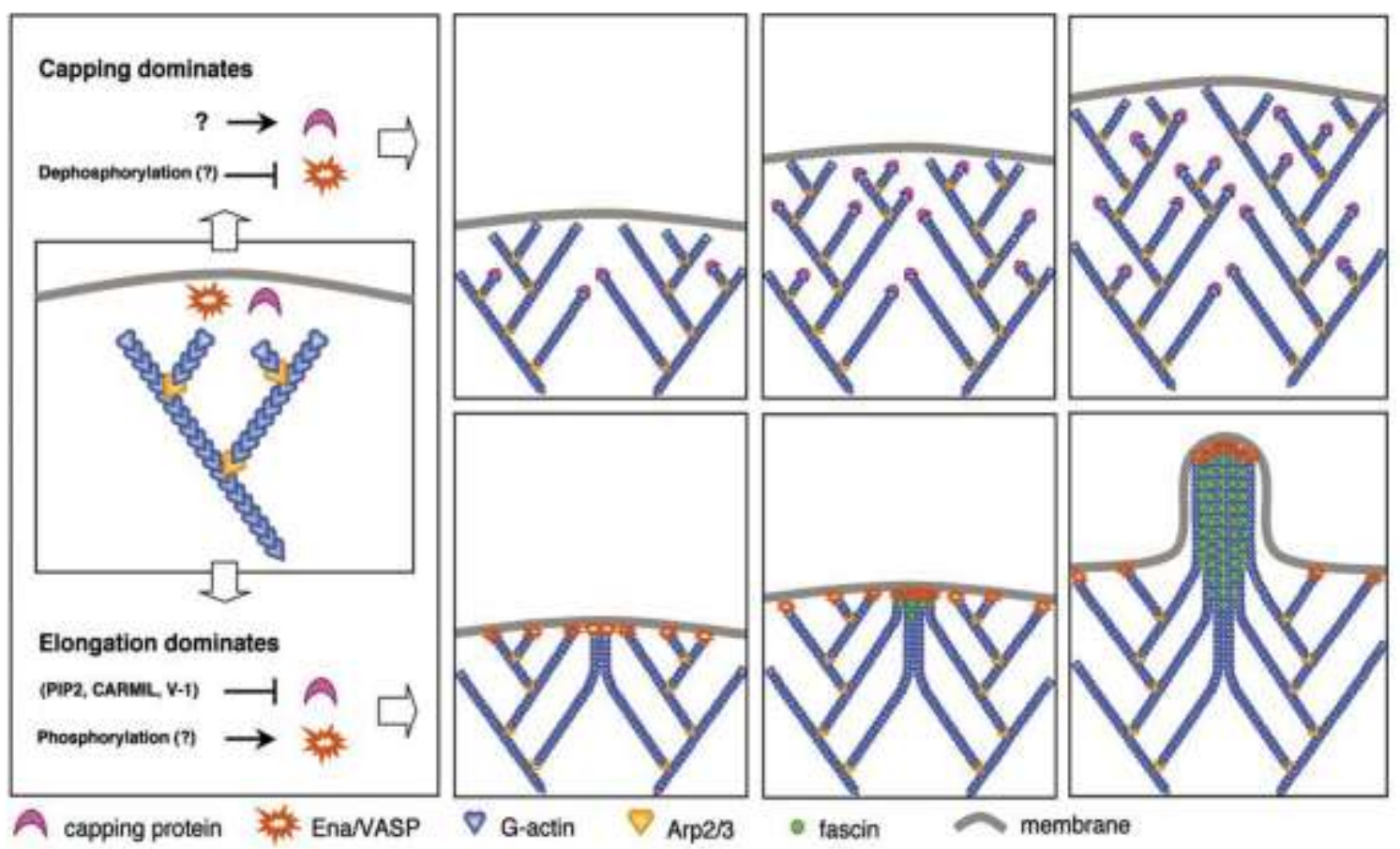

Abbildung II.6. Modell für die Entstehung unterschiedlicher F-Aktin-Architekturen in Abhängigkeit von der CP-Capping-Aktivität (Abbildung nach Mejillano et al, 2004). Der aktivierte Arp2/3Komplex bildet verzweigte Netzwerke, die je nach CP-Aktivität durch eine funktionell und strukturell distinkte Aktin-Organisation charakterisiert sind. Unter Bedingungen, in denen Capping dominiert, entstehen bevorzugt Lamellipodien (oben). Wird die Aktivität von CP hingegen inhibiert, kommt es zur Ausbildung von Filopodien (unten).

CP nimmt daneben auch eine wichtige Rolle in der Skelettmuskulatur ein. Dort ist es an den Z-Scheiben des Sarkomers lokalisiert und wird deshalb als CapZ bezeichnet (Casella et al, 1986). Die Plus-Enden der Mikrofilamente sind ebenfalls an der Z-Scheibe zu finden, wobei jedes Ende von einem CapZMolekül besetzt wird (Schafer et al, 1993). Es konnte gezeigt werden, dass die Ausschaltung von CapZ mit einem stark gestörten Aufbau von Myofibrillen im Mäuseherz korreliert (Schafer et al, 1995). Potenzielle Funktionen von CapZ umfassen die Verankerung der Mikrofilamente in der Z-Scheibe und die Unterbindung der Filamentelongation ins benachbarte Sarkomer (Littlefield \& Fowler, 1998; Littlefield et al, 2001). Des Weiteren konnte eine Interaktion von CapZ mit dem muskelspezifischen Protein Nebulin nachgewiesen werden, das ebenfalls in der Z-Scheibe inseriert. Die Ausschaltung von Nebulin während der 
Myofibrillogenese bewirkt eine reduzierte Anreicherung von CapZ an den ZScheiben sowie eine fehlerhafte Ausrichtung der Plus-Enden von F-Aktin. Dies deutet darauf hin, dass die Anbindung von CapZ an Nebulin von essentieller Bedeutung für die korrekte Positionierung und Stabilisierung und somit für die Längenkontrolle der Mikrofilamente ist (Pappas et al, 2008).

$\mathrm{CP}$ ist ferner Bestandteil des sehr großen Proteinkomplexes Dynaktin (Schafer et al, 1994a). Bei Dynaktin handelt es sich um den Co-Faktor von zytoplasmatischem Dynein, der für alle Formen von Dynein-abhängiger Bewegung erforderlich ist (Schroer, 2004). Dynaktin beinhaltet unter anderem ein Aktin-ähnliches Minifilament, an dessen Plus-Ende CP lokalisiert ist. Welche Rolle das Protein im Dynaktin-Komplex einnimmt, ist allerdings unklar. Bisher konnte kein Nachweis erbracht werden, dass CP ein notwendiger Bestandteil von Dynaktin ist. So hatte die Nullmutation von CP aus Hefe keinerlei Effekte auf die Funktion von Dynein (Moore et al, 2008). Im Gegensatz dazu zog die Nullmutation anderer Dynaktin-Komponenten, wie z. B. Arp1, einen kompletten Verlust der Dynein-Funktionalität nach sich.

\section{II.1.2. Zielsetzung der Arbeit}

Die Struktur der CP-,Muskelisoform“ (GgCapZ) konnte bereits im Jahr 2003 in atomarer Auflösung aufgeklärt werden (Yamashita et al, 2003). Für zytoplasmatisches CP liegen hingegen bis heute keine hochaufgelösten Strukturinformationen vor. Im Gegensatz zu Aktinfilamenten in Muskelzellen, die durch eine hohe Stabilität und gleichbleibende Länge charakterisiert sind, unterliegt das Aktinzytoskelett in nichtmuskulären Zellen, insbesondere während der Zellmigration, starken Umgestaltungen. Dies legt die Vermutung nahe, dass CapZ der dauerhaften Stabilisierung von F-Aktin dient, wohingegen sich zytoplasmatisches CP dynamisch an Aktinfilamente anlagert, um so effektiv zur Ausbildung des Leitsaums beitragen zu können. Vor diesem Hintergrund scheint es möglich, dass die CP-Varianten unterschiedliche Aktin-Capping-Eigenschaften aufweisen. Um diesem Aspekt auf struktureller Ebene zu begegnen, 
sollte mit Cap32/34 aus Dictyostelium discoideum ein erstes zytoplamatisches $\mathrm{CP}$ in atomarer Auflösung beschrieben werden. 


\section{II.2. Ergebnisse}

\section{II.2.1. Klonierung, Expression und Isolierung von Cap32/34}

Die beiden Untereinheiten des Cap32/34-Moleküls wurden unter Verwendung des auf $\mathrm{pETDuet}{ }^{\mathrm{TM}}$-1 (Novagen) basierenden Vektors pETmD1-mako simultan in E. coli exprimiert. Das Plasmid enthält zwei multiple Klonierungsstellen (MCS), wobei MCS1 N-terminal einen Okta-Histidin-Tag an das einklonierte Gen fusioniert. Cap32 und Cap34 wurden ausgehend von cDNA aus Dictyostelium mittels PCR amplifiziert und daraufhin über die Schnittstellen BsrGl und Mlul bzw. Ncol und HindIII in MCS1 (Cap32) und MCS2 (Cap34) ligiert. Nach Transformation in E. coli-Zellen des Stammes XL2-blue wurde die Plasmid-DNA positiver Klone in den Expressionsstamm BL21(DE3)-CodonPlus eingebracht, woraufhin die Zellen für Expressionstests in LB-Amp-Cam-Medium angezogen wurden. Zwar zeigte sich, dass das Protein bei $37^{\circ} \mathrm{C}$ überproduziert wurde, allerdings fast vollständig in unlöslichen inclusion bodies vorlag. Durch die anschließende Reduktion der Expressionstemperatur auf $22^{\circ} \mathrm{C}$ konnte Cap32/34 aber in großen Mengen löslich erhalten werden. Das Protein wurde, wie in Punkt III.4.8. beschrieben, über $\mathrm{Ni}^{2+}$-NTA-Chromatographie und Gelfiltration aufgereinigt (Abbildung II.7.). Aus $5 \mathrm{~g}$ Zellen konnten im Durchschnitt ca. $30 \mathrm{mg}$ an homogenem Protein erhalten werden. Nachdem Cap32/34 mittels eines Vivaspin-Konzentrators (MWCO 30.000) auf eine Konzentration von $10 \mathrm{mg} / \mathrm{ml}$ gebracht worden war, wurde es entweder unmittelbar für Kristallisationstests verwendet, oder nach Zugabe von $3 \%$ Sukrose zum Aufbewahrungspuffer aliquotiert, in flüssigen Stickstoff gefroren und bei $-80^{\circ} \mathrm{C}$ aufbewahrt. Aufgetaute Proben wurden im Kühlraum auf Eis gelagert und blieben im Durchschnitt über einen Zeitraum von 8 Wochen stabil. Vor der Kristallisation wurde das Protein jeweils für 5 Minuten bei $10.000 \mathrm{~g}$ zentrifugiert, um gröbere Partikel zu entfernen. 

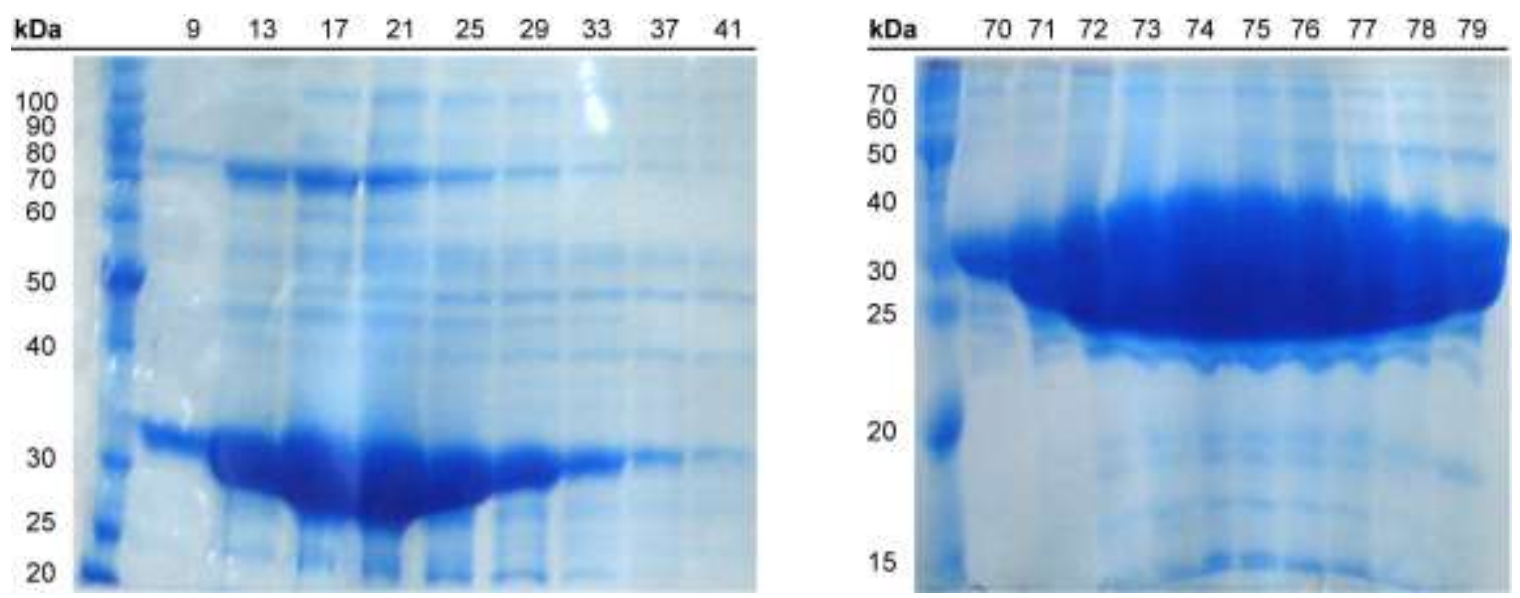

Abbildung II.7. SDS-Gele (15\% links, $17.5 \%$ rechts) der Aufreinigung von Cap32/34. Der Protein-Standard ist mit den jeweiligen Größenangaben am jeweils linken Rand gezeigt. Die Zahlen über den Gelen entsprechen den jeweiligen Elutions-Fraktionen. (Links) SDS-Gel nach $\mathrm{Ni}^{2+}$-NTA-chromatographischer Aufreinigung. (Rechts) SDS-Gel nach GrößenausschlussChromatographie.

\section{II.2.2. Kristallisation von Cap32/34}

Die anfängliche Suche nach Kristallisationsbedingungen erfolgte im 24-WellFormat nach der Hanging-Drop-Methode. Dazu wurden Protein und Präzipitationsmittel im Konzentrationsverhältnis 1:1 (2 $\mu \mathrm{l}+2 \mu \mathrm{l})$ verwendet, wobei die Sparse Matrix Screens Wizard 1-4 und Crystal-Screen 1+2 zum Einsatz kamen. Die Platten wurden bei $20^{\circ} \mathrm{C}$ gelagert und regelmäßig auf Kristallisationstreffer untersucht. Nach 2 Tagen bildeten sich unter einer Bedingung [Wizard 3, Bedingung $19 \rightarrow 25 \%$ (w/v) PEG 1.500, $0.1 \mathrm{M}$ $\mathrm{MMT} / \mathrm{NaOH}$ 6.5] kleine Nadeln, die sich fächerförmig aneinanderlagerten (Abbildung II.8., A). Jedoch gelang es weder in Grid-Screen-Experimenten noch durch Mikroseeding, einzelne Kristalle zu erhalten. In der Zwischenzeit (nach 7 Tagen) entstanden in einer weiteren Bedingung [Wizard 1, Bedingung $21 \rightarrow$ $20 \%(w / v)$ PEG 8.000, Hepes 7.5] Kristallnadeln. Diese wuchsen einzeln (Abbildung II.8., B) und erreichten nach ca. 10 Tagen eine maximale Größe von $10 \times 10 \times 300 \mu \mathrm{m}$. Daher wurde den stark verwachsenen Kristallen nicht weiter nachgegangen. Für das Vermessen wurden daraufhin einige Monokristalle in 
eine Kryolösung, bestehend aus der Kristallisationsbedingung einschließlich $20 \%$ Glyzerol (v/v), überführt und in flüssigen Stickstoff gefroren.

A

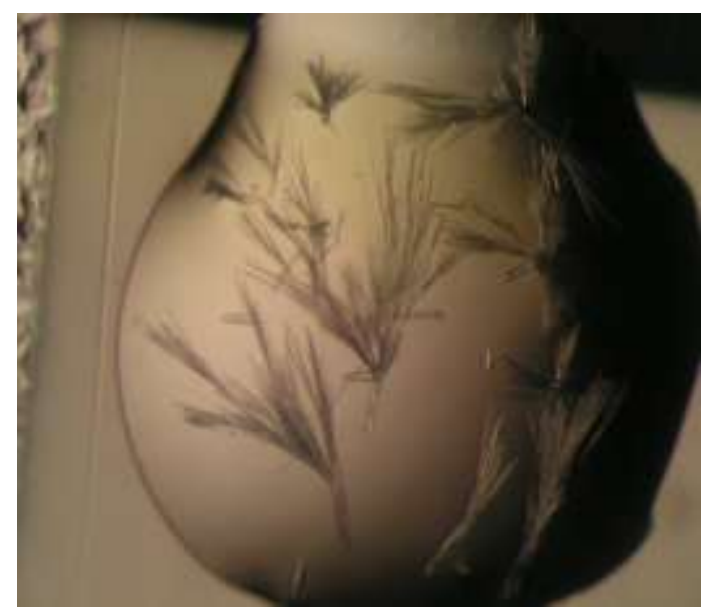

B

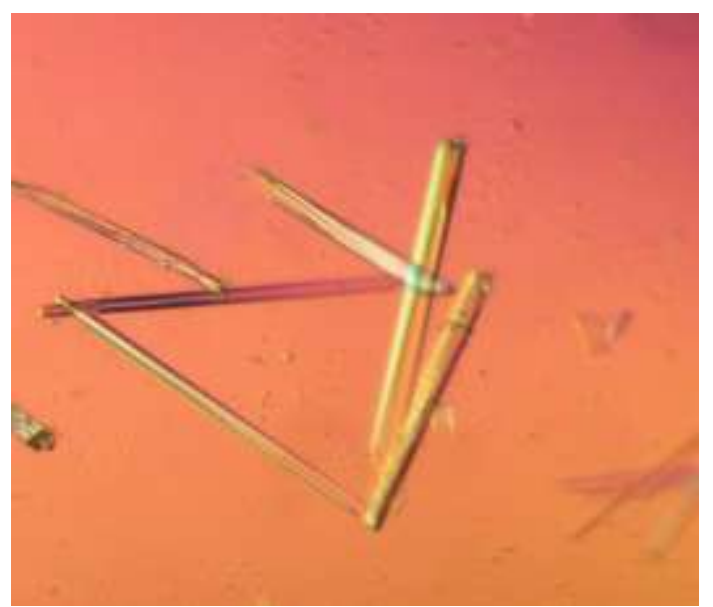

Abbildung II.8. Kristalle von Cap32/34. (A) Ursprünglich erhaltene, stark verwachsenen Kristalle des Heterodimers. (B) Monokristalle, die kurze Zeit später unter einer anderen Kristallisationsbedingung erhaltenen worden waren, im polarisierten Licht.

\section{II.2.2.1. Soaking nativer Kristalle und Co-Kristallisation von Cap32/34 mit PI4,5P2 und diC8-PI4,5P2}

Als nächstes sollten Kristalle von Cap32/34 auch im Komplex mit sauren Phospholipiden (PIPs) erhalten werden, deren inhibitorische Effekt auf Vertreter der CP-Familie gut dokumentiert ist (Heiss \& Cooper, 1991). Um einen ersten Eindruck über die Fähigkeit des Proteins, an diese Lipide zu binden, zu erhalten, wurde ein PIP-Strip-Bindungstest durchgeführt. Bei den PIP-Strips handelt es sich um hydrophobe Membranen, auf deren Oberfläche unterschiedliche Phospholipide einschließlich der PIPs aufgetragen sind (Abbildung II19., A). Es zeigte sich, dass Cap32/34 in der Lage ist, mit Phosphatidylinositol-4,5bisphosphat (PI4,5P2) zu interagieren - allerdings nur schwachaffin. Alle anderen Lipide wurden nicht gebunden (Abbildung II.9., B). 
B
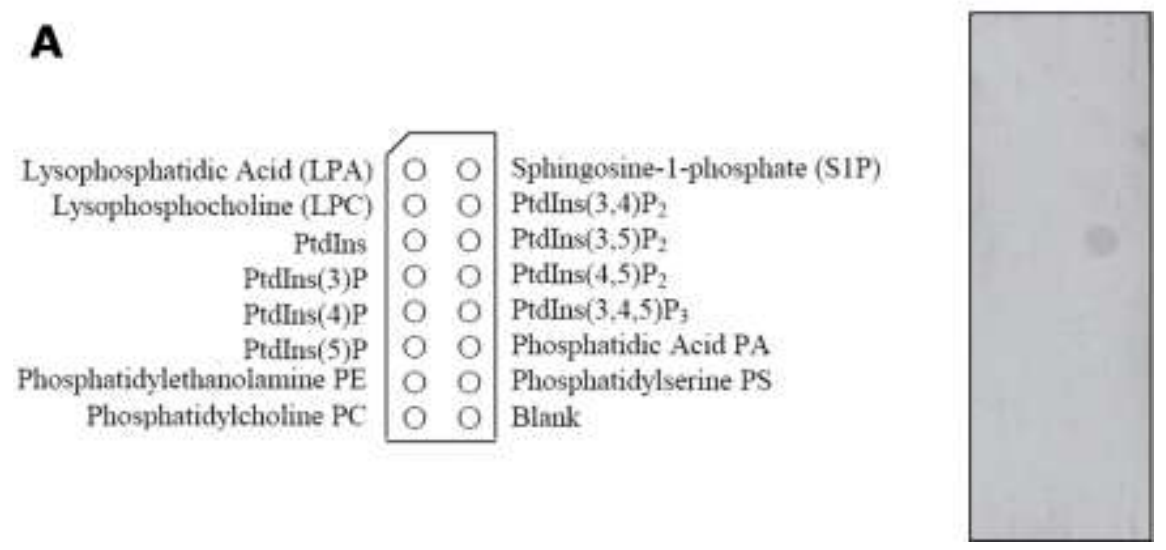

Abbildung II.9. PIP-Strip-Inkubationstest. (A) Legende der für den Lipid-Bindetest herangezogenen Membran. (B) Membran nach Detektion von gebundenem Cap32/34 mittels Chemiluminiszenz.

Daraufhin wurden sowohl Soaking- als auch Co-Kristallisationsexperimente durchgeführt, um einen Substrat-Komplex zu erhalten. Dabei kam neben PI4,5P2 (Echelon Biosciences) auch synthetisches Dioctanoyl-Phosphatidylinositol-4,5bisphosphat (diC8-PI4,5P2; Echelon Biosciences) zum Einsatz, welches aufgrund verkürzter Fettsäureschwänze eine bessere Wasserlöslichkeit aufweist als das natürlich vorkommende Phosphoinositid. Für Soaking wurden native Kristalle für unterschiedliche Zeiten (1,5,10 Minuten) in $50 \mu \mathrm{l}$ künstlicher Mutterlauge [20\% (w/v) PEG 8.000, Hepes 7.5], versetzt mit $0.2 \mathrm{mM} \mathrm{PI4,5P2}$ oder $4 \mathrm{mM}$ diC8-PI4,5P2, inkubiert und nach Überführung in den Gefrierschutzpuffer [20\% (w/v) PEG 8.000, Hepes 7.5, $20 \%$ (v/v) Glyzerol] in flüssigen Stickstoff schockgefroren. Für Co-Kristallisationsexperimente wurde das Protein mit einem 2-fachen molaren Überschuss an PI4,5P2 bzw. einem 2und 5-fachen molaren Überschuss an diC8-PI4,5P2 versetzt und nach kurzer Inkubationszeit für Kristallisationsversuche verwendet. Dabei wurde um die für native Kristalle erfolgreiche Pufferbedingung gescreent. Allerdings konnten zunächst keine Kristallisationstreffer erzielt werden. Anschließend wurde das Grid-Screen-Experiment wiederholt, wobei Mikroseeding mit feinen Cap32/34Kristallfragmenten angewendet wurde, um das Kristallwachstum anzuregen. Bei 
einem molaren Verhältnis von 1:2 von Protein zu Ligand entstanden nun in Gegenwart beider Lipide Nadeln. Diese wuchsen wesentlich langsamer (ca. 3 Wochen) als die nativen Kristalle, erreichten jedoch sehr ähnliche Dimensionen. Unter der Verwendung von $17 \%$ (w/v) PEG 8.000, $0.1 \mathrm{M}$ Hepes 7.5 als Präzipitationsmittel konnten die größten Kristalle gezüchtet werden. Für das Einfrieren der Kristalle kam erneut Glyzerol in einer Endkonzentration von $20 \%$ (v/v) als Kryoprotektant zum Einsatz. Ein molares Verhältnis von 1:5 von Protein zu diC8-PI4,5P2 brachte indes keine Kristalle hervor.

\section{II.2.3. Datensammlung}

Die Aufnahme der Beugungsdaten erfolgte an der Röntgenquelle ID23-2 des ESRF in Grenoble bei $100 \mathrm{~K}$ und einer Wellenlänge $\lambda=0.8726 \AA$ mit einem MarCCD-Detektor. Die Kristalle wurden um $1^{\circ}$ pro aufgenommenes Röntgenbeugungsbild gedreht, um aus diesen zweidimensionalen Bildern eine dreidimensionale Struktur des Proteins berechnen zu können. Für die Messung wurde die Strategie der helikalen Datensammlung gewählt (Flot et al, 2010), um den Strahlenschaden der Kristalle möglichst gering zu halten. Abbildung II.10., A zeigt das Bild einer hochaufgelösten Beugungsaufnahme aus der Datensammlung eines nativen Cap32/34-Kristalls (Abbildung II.10., B). Insgesamt konnten Reflexe bis maximal $1.9 \AA$ detektiert werden. 
A

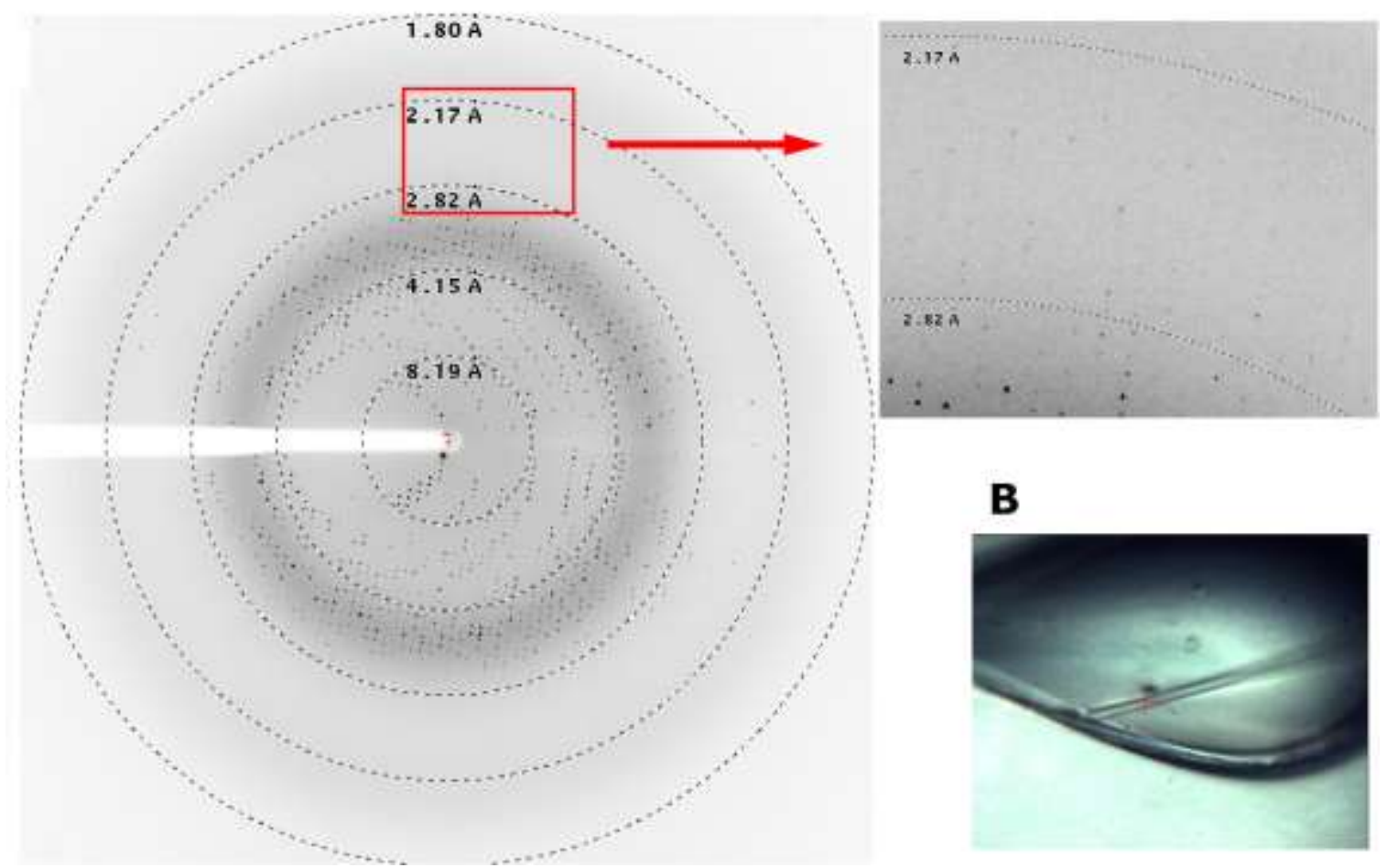

Abbildung II.10. Vermessung von Cap32/34-Kristallen. (A) Mit Synchrotronstrahlung an der Beamline ID23-2 (ESRF) aufgenommenes Beugungsbild eines nativen Cap32/34-Kristalls. Der rot markierte Ausschnitt ist vergrößert dargestellt. (B) Kristall des Heterodimers im Loop.

\section{II.2.4. Datenprozessierung}

Die Datenprozessierung, welche die Bestimmung der Raumgruppe und Zellparameter sowie die Reduktion der Daten umfasst, wurde mit dem Programm XDS (Kabsch, 2010) durchgeführt. Sowohl natives als auch derivatisiertes Cap32/34 kristallisierte in der primitiv tetragonalen Raumgruppe $\mathrm{P} 4_{1}$ mit folgenden Zellparametern: $a=124.5 \AA, b=124.5 \AA, c=77.5 \AA, \alpha=\beta=\gamma=90^{\circ}$. Die Bestimmung der genauen Raumgruppe ergab sich aus der Untersuchung der systematischen Auslöschungen einzelner Reflexe. Die serielle Abwesenheit von Reflexen mit 00I: $I=4 n+1,4 n+2,4 n+3$ ließ darauf schließen, dass die Kristalle entweder der Raumgruppe $\mathrm{P} 4_{1}$ oder $\mathrm{P} 4_{3}$ angehören. Da diese enantiomer zueinander sind, konnte $\mathrm{P} 4_{1}$ erst durch die erfolgreiche Lösung des 
Phasenproblems als wahre Raumgruppe identifiziert werden. Die Kristalle von nativem und mit Substrat versetztem Cap32/34 unterschieden sich in ihrem Streuvermögen nicht nennenswert voneinander. Der beste Datensatz resultierte aus der Vermessung eines nativen Cap32/34-Kristalls und hatte eine Auflösung von 2.2 A. Er wies in der höchsten Auflösungsschale (2.3-2.2 $\AA$ ) einen $R_{\text {sym }}$-Wert von $76,5 \%$ und ein Signal-Rausch-Verhältnis $(I / \sigma l)$ von 3.83 auf. Dabei umfasste der Datensatz 145 Röntgenbeugungsbilder mit insgesamt 367.874 Reflexen, von denen 60.185 einzigartig waren. Dies entspricht einer Multiplizität von 6.1. Die Vollständigkeit der Daten betrug 99.8 \% (Abbildung II.11.).

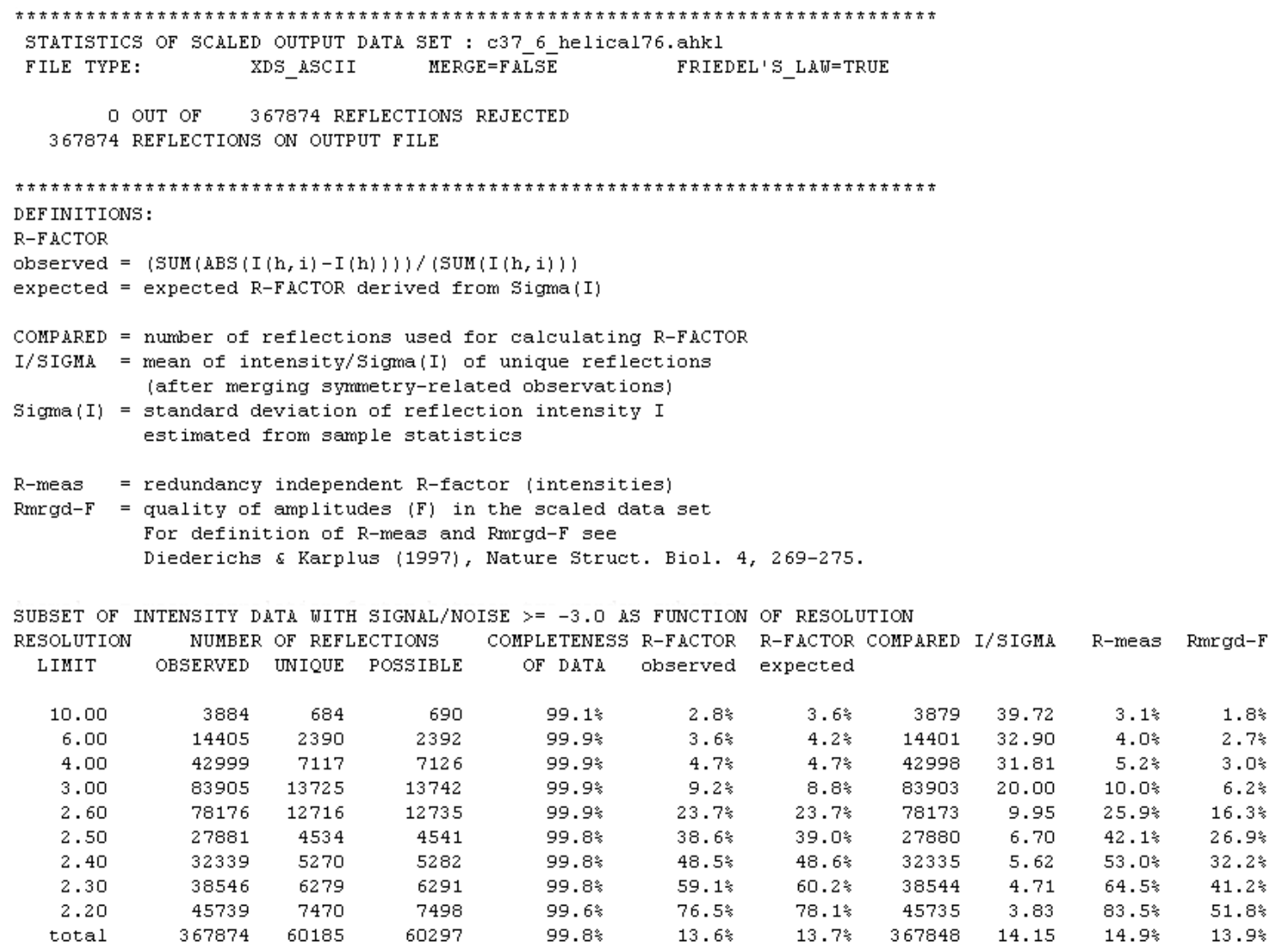

Abbildung II.11. Prozessierung der Daten. Ausschnitt aus der Datei XSCALE.LP, die die Statistik des skalierten Datensatzes zeigt. 


\section{II.2.5. Strukturbestimmung durch Molekularen Ersatz}

Um initiale Phasen für die Strukturaufklärung zu erhalten, wurde in dieser Arbeit von der Methode des Molekularen Ersatzes Gebrauch gemacht (Rossmann, 2001). Für die Modell-Suche und die Verfeinerung der Struktur fand das Programm CNS v1.2 (Brünger et al, 1998) Verwendung. Als Such-Modell bei der Durchführung des Molekularen Ersatzes dienten die Atomkoordinaten von GgCapZ (Yamashita et al, 2003), wobei die Wassermoleküle und der flexible $\beta$ C-Terminus (Asn-252-Asn-277) weggelassen wurden. Die Sequenzidentität zwischen Cap32/34 und GgCapZ beträgt $36.6 \%$ für die $\alpha$-Untereinheiten (Cap34, GgCapZa) und 54.3 \% für die $\beta$-Untereinheiten (Cap32, GgCapZß).

Das Prinzip des Molekularen Ersatzes basiert auf einer 6-dimensionalen Suche des Modells in den Daten der zu charakterisierenden Struktur. Durch Zerlegung des 6-dimensionalen Problems in eine Rotations- und Translationsfunktion kann der Suchvorgang erheblich beschleunigt werden. Die zunächst stattfindende Rotationssuche hat das Ziel, die Orientierung des Modells im Kristallgitter zu bestimmen. Dabei wird es in bestimmten Gradschritten im Raum gedreht und eine ortsunabhängige Pattersson-Karte berechnet. Diese wird daraufhin mit der Pattersson-Karte aus den experimentellen Daten verglichen. Die Orientierungen mit den besten Korrelationen zwischen den beiden Pattersson-Funktionen werden als höchste Maxima ausgewiesen. Praktisch werden Rotationsfunktionen bei verschiedenen Auflösungsbereichen durchgeführt. Für die Modell-Suche von Cap32/34 wurden die jeweils 10 höchsten Maxima der Rotationsfunktion für die Auflösungsbereiche 15-4 A, 12-3 $\AA$ And $10-4 \AA$ ermittelt (Abbildung II.12.). Bei einer Drehung des Modells um die Euler-Winkel $21^{\circ}, 68^{\circ}$ und $320^{\circ}$ konnte in allen Bereichen ein deutlich herausragendes Maximum gefunden werden. Nach Ausführung der Drehung wird durch die Berechnung der Translationsfunktion die genaue Lage des vororientierten Modells in der asymmetrischen Einheit ermittelt. Dazu wurde eine Translationssuche ausgehend von der Rotationsfunktion im Bereich 15-4 durchgeführt. Für die Drehung $21^{\circ}, 69^{\circ}$ und $318^{\circ}$ ergab sich dabei ein 
Hauptmaximum (Abbildung II.13.). Nach Festhalten dieses ersten Moleküls wurde mit einem zweiten Such-Modell eine erneute Translationssuche durchgeführt, die ein weiteres Maximum lieferte. Cap32/34 lag somit in zwei Kopien in der asymmetrischen Einheit vor.

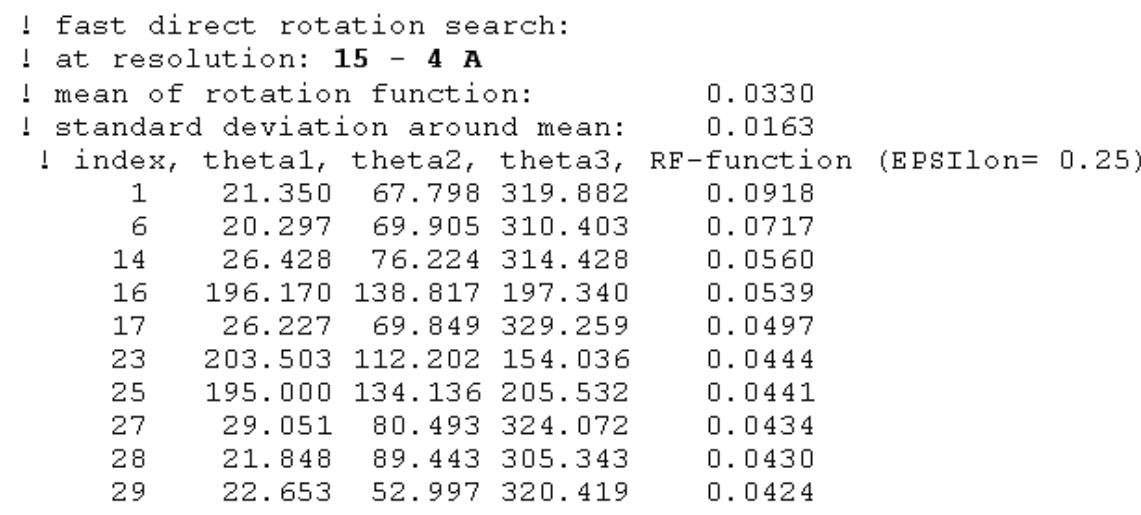

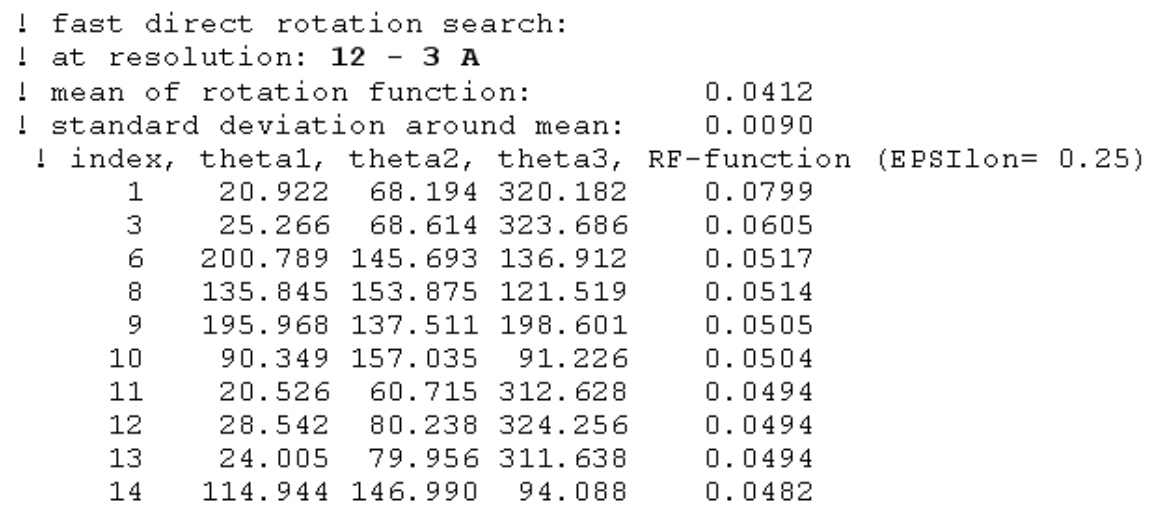

! fast direct rotation search:

! at resolution: $\mathbf{1 0}-\mathbf{4} \mathrm{A}$

! mean of rotation function: 0.0346

! standard deviation around mean: 0.0165

! index, theta1, theta2, theta3, RF-function (EPSIlon=0.25)

$\begin{array}{lllll}1 & 21.434 & 67.798 & 319.966 & 0.0928\end{array}$

$\begin{array}{lllll}6 & 20.297 & 69.905 & 310.403 & 0.0774\end{array}$

$\begin{array}{lllll}11 & 26.428 & 76.224 & 314.428 & 0.0619\end{array}$

$\begin{array}{lllll}16 & 202.415 & 112.258 & 153.619 & 0.0534\end{array}$

$\begin{array}{lllll}17 & 198.511 & 136.477 & 202.021 & 0.0519\end{array}$

$18 \quad 26.227 \quad 69.849 \quad 329.259 \quad 0.0516$

$20 \quad 21.848 \quad 89.443 \quad 305.343 \quad 0.0498$

$\begin{array}{lllll}24 & 18.361 & 80.437 & 295.829 & 0.0459\end{array}$

$26 \quad 191.130 \quad 152.504 \quad 108.870 \quad 0.0452$

$28 \quad 206.111 \quad 105.883 \quad 141.597 \quad 0.0445$

Abbildung II.12. Ergebnisse der Rotationssuche für die verschiedenen Auflösungsbereiche. Gezeigt sind jeweils die zehn höchsten Maxima. 
! translation search

! at resolution: 15 - $\mathbf{4} \mathbf{A}$

! molecular structure file: 1IZN.mtf

! input coordinates: 1IZN.pdb

\begin{tabular}{|c|c|c|c|c|c|c|c|c|c|}
\hline & & thetal & theta2 & theta 3 & trans $x$ & transy & transz & monitor & packing \\
\hline R\# & 1 & 20.66 & 68.71 & 317.73 & -31.71 & 38.99 & -0.31 & 0.268 & 0.3039 \\
\hline $\mathrm{R \#}$ & 2 & 20.68 & 68.72 & 317.78 & -31.71 & 39.01 & 0.26 & 0.268 & 0.3040 \\
\hline $\mathrm{R \#}$ & 3 & 20.66 & 68.72 & 317.79 & -31.70 & 39.02 & 4.83 & 0.267 & 0.3040 \\
\hline R\# & 4 & 198.06 & 136.05 & 202.10 & -61.75 & 3.32 & 0.36 & 0.144 & 0.2588 \\
\hline R\# & 5 & 20.63 & 68.73 & 317.79 & -31.68 & 39.04 & 1.82 & 0.268 & 0.3040 \\
\hline R\# & 6 & 202.44 & 112.32 & 154.22 & -18.91 & 36.34 & -0.23 & 0.129 & 0.2851 \\
\hline $\mathrm{R \#}$ & 8 & 29.39 & 79.27 & 322.43 & -28.55 & 5.87 & 0.72 & 0.143 & 0.1861 \\
\hline $\mathrm{R \#}$ & 9 & 22.55 & 91.79 & 306.79 & -30.00 & 6.79 & -1.78 & 0.126 & 0.1993 \\
\hline $\mathrm{R \#}$ & 10 & 23.29 & 51.98 & 318.58 & -17.31 & 59.13 & -0.12 & 0.115 & 0.2106 \\
\hline
\end{tabular}

$>>>$ mean of monitor values:

! translation search

! at resolution: $15-\mathbf{4} \mathbf{A}$

! molecular structure file: 1IZNdimer.mtf

! input coordinates: 1IZNdimer.pdb

\begin{tabular}{|c|c|c|c|c|c|c|c|c|}
\hline & theta 1 & theta 2 & theta 3 & trans $\mathrm{x}$ & trans $\mathrm{Y}$ & trans 2 & monitor & packing \\
\hline R\# & 21.02 & 68.00 & 319.72 & 31.57 & -22.90 & 74.70 & 0.444 & 0.5893 \\
\hline R\# & 21.03 & 68.37 & 319.78 & 31.26 & -22.54 & 74.14 & 0.447 & 0.5886 \\
\hline R\# & 21.37 & 68.41 & 320.07 & 30.36 & -22.98 & 81.17 & 0.430 & 0.5888 \\
\hline R\# & 198.32 & 136.19 & 201.52 & 4.41 & -60.64 & 23.70 & 0.239 & 0.5525 \\
\hline $\mathrm{R \#}$ & 21.12 & 68.23 & 319.89 & 31.29 & -22.59 & 74.30 & 0.445 & 0.5894 \\
\hline $\mathrm{R \#}$ & 201.85 & 112.09 & 154.72 & 32.65 & -47.27 & 50.01 & 0.215 & 0.5158 \\
\hline R\# & 28.18 & 79.98 & 321.64 & -37.43 & 1.69 & 60.17 & 0.232 & 0.3791 \\
\hline R\# & 22.27 & 89.13 & 303.82 & 20.52 & -41.51 & 67.20 & 0.232 & 0.5008 \\
\hline 10 & 22.95 & 52.89 & 320.26 & 58.63 & 32.07 & 17.84 & 0.243 & 0.5837 \\
\hline
\end{tabular}

$>>>$ mean of monitor values:

0.31551

$\gg>>$ standard deviation around mean:

0.10298

Abbildung II.13. Ergebnisse der Translationssuche für den Auflösungsbereich 15-4 A. Gezeigt sind jeweils die zehn höchsten Maxima.

\section{II.2.6. Modellbau und Modellverfeinerung}

Da die ermittelten Phasen lediglich Annäherungen an die realen Phasen darstellen und durch das herangezogene Such-Modell fehlerbehaftet sind, ist es notwendig, die Struktur zu verfeinern. So soll eine sukzessive Annäherung an die tatsächliche Elektronendichte erreicht werden. Als Startpunkt für den 
Verfeinerungsprozess diente ein Homologiemodell von Cap32/34. Dieses wurde mithilfe des Swiss-Model-Dienstes (www.swissmodel.expasy.org) anhand der vorhandenen Koordinaten von GgCapZ (den flexiblen C-Terminus ausgenommen) als Vorlage erstellt. Die Darstellung der Struktur und der Elektronendichte sowie die manuelle Strukturmodifikation erfolgten mit dem Programm Coot (Emsley et al, 2010). Die experimentelle Elektronendichtekarte zeigte klare Dichte für das Rückgrat und die meisten Seitenketten für zwei Cap32/34-Moleküle. Daraufhin wurde das Homologiemodell in die Dichte eingepasst. Es zeigte sich, dass die C-terminalen Bereiche beider Untereinheiten (Ala-248-Gly-272 von Cap32, Ile-265-Lys-282 von Cap34) als auch die Schleifenregionen in den Bereichen Lys-136-Glu-149 und Tyr-79-Pro-89 (Cap32) sowie Lys-94-Glu-108 (Cap34) nur sehr schwach oder gar nicht definiert waren. Deshalb wurden entsprechende Bereiche zunächst ausgespart, da die vorhandenen Lücken in der Dichte keinen sinnvollen Modellbau ermöglicht hätten. Mit dem Strukturmodell wurde anschließend eine erste Verfeinerung mit CNS (Auflösung 50-2.2 $)$ gerechnet. Dies geschah mithilfe von Molekulardynamik-Simulation (simulated annealing), Positions- und Temperaturfaktorverfeinerung sowie durch Elektronendichtemittelung, nach Standardprotokollen, wie in CNS implementiert. Für das Startmodell lag der Arbeits-RFaktor $\left(R_{\text {work }}\right)$ bei $45 \%$. Er konnte nach der ersten Verfeinerungsrunde auf $39 \%$ reduziert werden. Nach manuellem Modell-Umbau und weiteren Verfeinerungsrunden sank der Arbeits-R-Faktor auf $26 \%$. Der freie R-Faktor $\left(\mathrm{R}_{\text {free }}\right)$, der mit $5 \%$ der Reflexe berechnet wird, die nicht zur Verfeinerung herangezogen werden, sank von anfänglich $44,5 \%$ auf $31 \%$. Während der Strukturverfeinerung war darauf zu achten, dass der Arbeits-R-Faktor und der freie R-Faktor, der ein objektives Maß für die Qualität des Modells darstellt, nicht weiter als $5 \%$ auseinander driften. Dadurch sollte einer Überanpassung des Atommodells an die Daten vorgebeugt werden. Die unter Einbeziehung des bis dahin verfeinerten Modells gerechnete Elektronendichte ließ nun in nahezu allen Loop-Regionen einen deutlichen Verlauf der Hauptkette erkennen. Diese Bereiche wurden ergänzt, die fehlenden Seitenketten eingebaut und so das Modell im Wechsel mit 
weiteren Verfeinerungsrunden und Dichteberechnungen (50-2.2 $\AA$ ) schrittweise verbessert. Nachdem die Seitenketten bestmöglich platziert waren, wurden Wassermoleküle in die Dichtekarte eingebaut. Diese wurden nur dann ins Modell integriert, wenn sie auch nach mehreren Runden der Verfeinerung noch durch ausreichend Elektronendichte beschrieben werden konnten und sich in einer Distanz von 2.2 bis $3.4 \AA$ zu einem Wasserstoffbrückendonator oder -akzeptor befanden. Nachdem der freie R-Faktor durch den automatischen Verfeinerungsprozess nicht weiter minimiert werden konnte, galt die Verfeinerung der Modellstruktur bei einem $R_{\text {work }}$ von $22.6 \%$ und einem $R_{\text {free }}$ von $26.5 \%$ als abgeschlossen.

Für die Datensätze der Kristalle aus Soaking- und Co-Kristallisationsexperimenten konnte leider keine zusätzliche Elektronendichte detektiert werden, die einen Rückschluss auf die Anwesenheit von PI4,5P2 oder diC8-PI4,5P2 erlaubt hätte.

Das endgültige Modell besteht aus zwei Cap32/34-Molekülen und 328 Wassermolekülen (Tabelle II.1.). Beide Kopien in der asymmetrischen Einheit wiesen innerhalb ihrer Cap32-Untereinheit keine interpretierbare Elektronendichte für den die AS Gln-140-Gln-145 umfassenden Loop-Bereich sowie für die C-terminale Domäne (Ser-252-Gly-272) auf. Auch der am N-Terminus der Cap32-Untereinheit lokalisierte Okta-Histidin-Tag konnte aufgrund fehlender Elektronendichte nicht in das Atommodell integriert werden. Für die Cap34Untereinheit wurden alle Aminosäuren mit Ausnahme von Lys-271-Lys-282 bzw. Phe-273-Lys-282 (zweiten Kopie in der asymmetrischen Einheit) am C-Terminus in der Elektronendichtekarte gefunden. Die Analyse der Qualität des erhaltenen Modells erfolgte mittels Molprobity (Davis et al, 2007) und zeigte eine gute Geometrie bei $95.9 \%$ der Aminosäuren in den bevorzugten Regionen und $4.1 \%$ der Reste in der erlaubten Region des Ramachandran-Plots (Abbildung II.14.). 
Tabelle II.1. Kristall-Daten und Modell-Verfeinerung

\section{Kristall-Daten}

\section{Raumgruppe}

Gitterkonstanten

$$
\begin{aligned}
& a, b, c[\AA]] \\
& \alpha, \beta, y\left[{ }^{\circ}\right]
\end{aligned}
$$

Auflösung $[\AA]$

Vollständigkeit der Daten [\%]

Unabhängige Reflexe

Redundanz der Daten

$R_{\text {sym }}[\%]^{\dagger}$

$<|/ \sigma|>$
$\mathrm{P}_{1}$

$124.5,124.5,77.5$

$90,90,90$

50-2.2 (2.3-2.2)

99.8 (99.6)

60.185

$6.1(6.1)$

14.9 (83.5)

$14.2(3.8)$

\begin{tabular}{|c|c|}
\hline Auflösung $[\AA ̊]$ & $50.0-2.2$ \\
\hline$R_{\text {work }}^{\ddagger}$ & 22.6 \\
\hline$R_{\text {free }} \S$ & 26.5 \\
\hline \multicolumn{2}{|l|}{ R.m.s.-Abweichungen } \\
\hline Bindungslänge $[\AA ̊]$ & 0.008 \\
\hline Bindungswinkel $\left[{ }^{\circ}\right]$ & 1.36 \\
\hline \multicolumn{2}{|l|}{ Anzahl der Atome } \\
\hline davon Protein & 8.069 \\
\hline davon Wassermoleküle & 328 \\
\hline Durchschnittlicher B-Faktor $[\AA]$ & 15.4 \\
\hline \multicolumn{2}{|l|}{ Ramachandran Reste } \\
\hline in bevorzugten Regionen [\%] & 95.9 \\
\hline In erlaubten Regionen [\%] & 4.1 \\
\hline
\end{tabular}

\section{Modell-Verfeinerung}

Die Werte in den Klammern beziehen sich auf die höchste Auflösungsschale.

${ }^{\dagger} R_{\text {sym }}=\Sigma_{h} \Sigma_{i} /(h)-l_{i}(h) / / \Sigma_{h} \Sigma_{i} l_{i}(h)$, wobei $l_{i}(h)$ und $/(h)$ die ite und durchschnittliche Messung der Intensität von Reflex $h$ sind.

${ }^{\ddagger} R_{\text {work }}=\Sigma_{h}\left|F_{o}-F_{c}\right| / \Sigma_{h} F_{o} \mid$, wobei $F_{o}$ und $F_{c}$ die beobachteten und berechneten Strukturfaktor-Amplituden von Reflex $h$ sind.

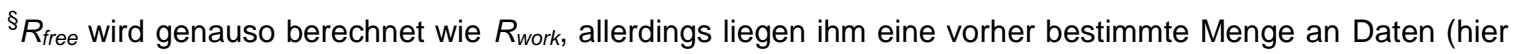
$5 \%$ ) zugrunde, die nicht in die Verfeinerung mit einbezogen werden. 
A

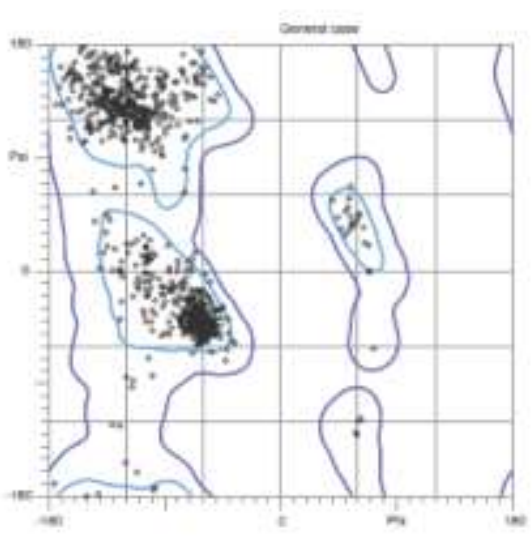

C

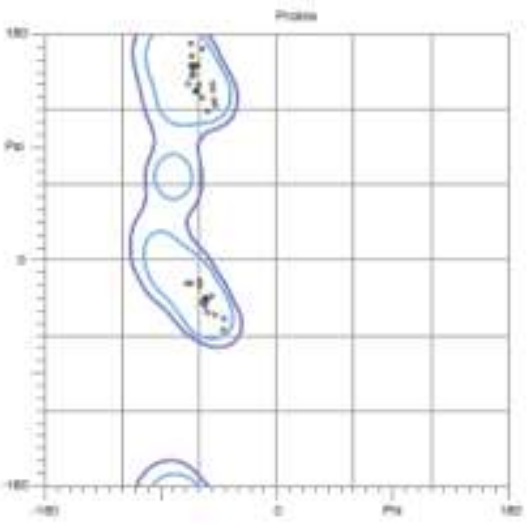

B

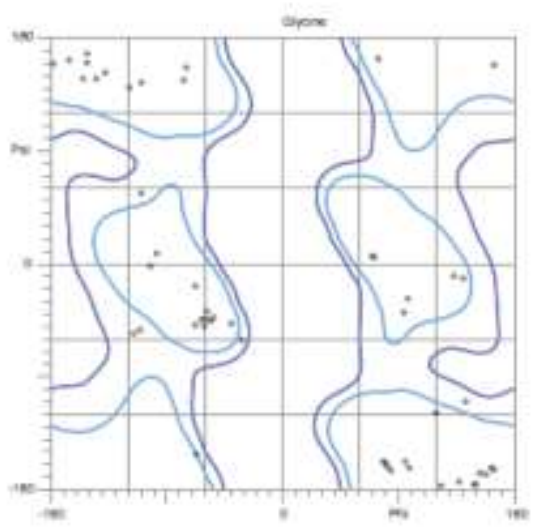

D

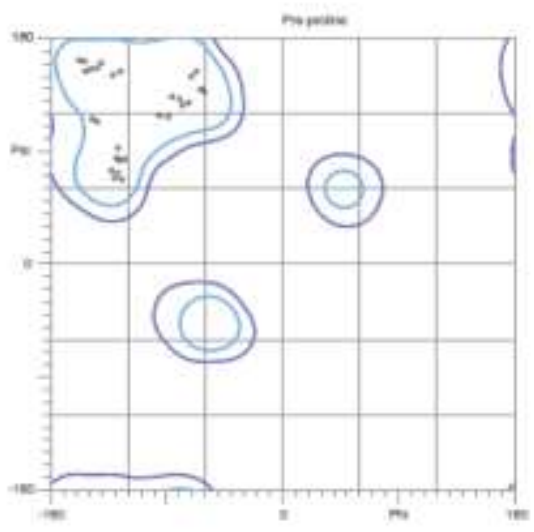

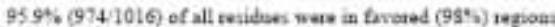

$100.0 \%(1016 / 1016)$ of all residoes were in allowed $(-99.8 \%)$ regions

Abbildung II.14. Ramachandran-Diagramme der verfeinerten Cap32/34-Struktur (mit Molprobity erstellt). Die Positionen der Aminosäurereste sind durch Kreise dargestellt. Die hellblau umgrenzten Bereiche entsprechen den energetisch bevorzugten $\Phi / \psi$-Kombinationen der Seitenketten, die violett umgrenzten Regionen den erlaubten Konformationswinkeln.

Gezeigt sind Ramachandran-Diagramme für alle Aminosäurereste (A), für Glyzine (B), für Aminosäuren, die direkt vor Prolinen liegen (C) und für Proline (D).

\section{II.2.7. Überblick über die Struktur von Cap32/34}

In diesem Abschnitt wird die Kristallstruktur von Cap32/34 aus Dictyostelium discoideum beschrieben. Dabei handelt es sich um die erste hochaufgelöste Struktur eines zytoplasmatischen Capping-Proteins. Um strukturelle Vergleiche mit spezifisch in Muskelgewebe lokalisiertem GgCapZ (Yamashita et al, 2003) einfacher zu gestalten, werden Cap32 und Cap34 im Folgenden auch als $\beta$ - und $\alpha$-Untereinheit bezeichnet.

Das Cap32/34-Molekül ähnelt der Gestalt eines Pilzes, bestehend aus einer stiel- und hutförmigen Komponente (Abbildung II.15.). 


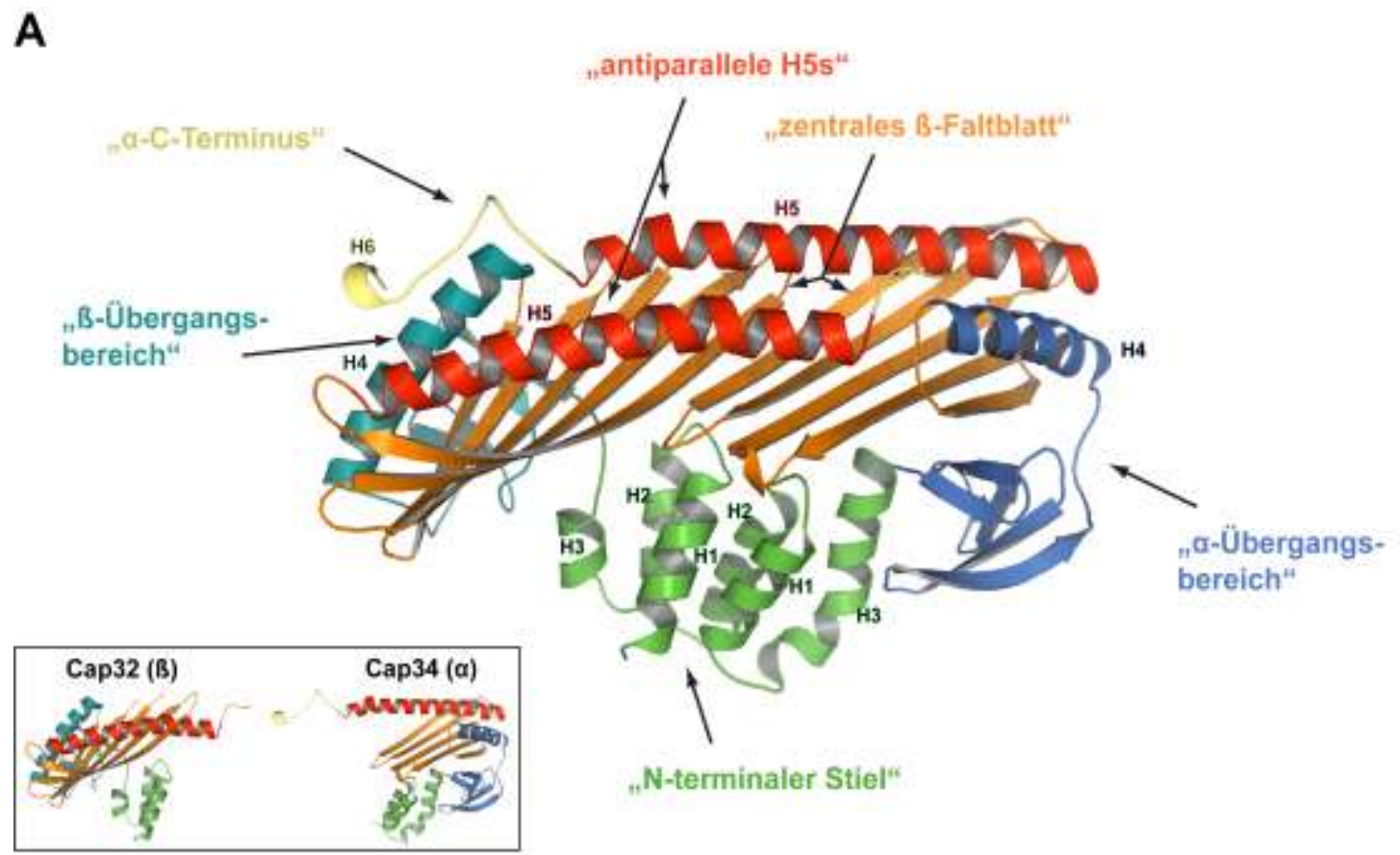

B

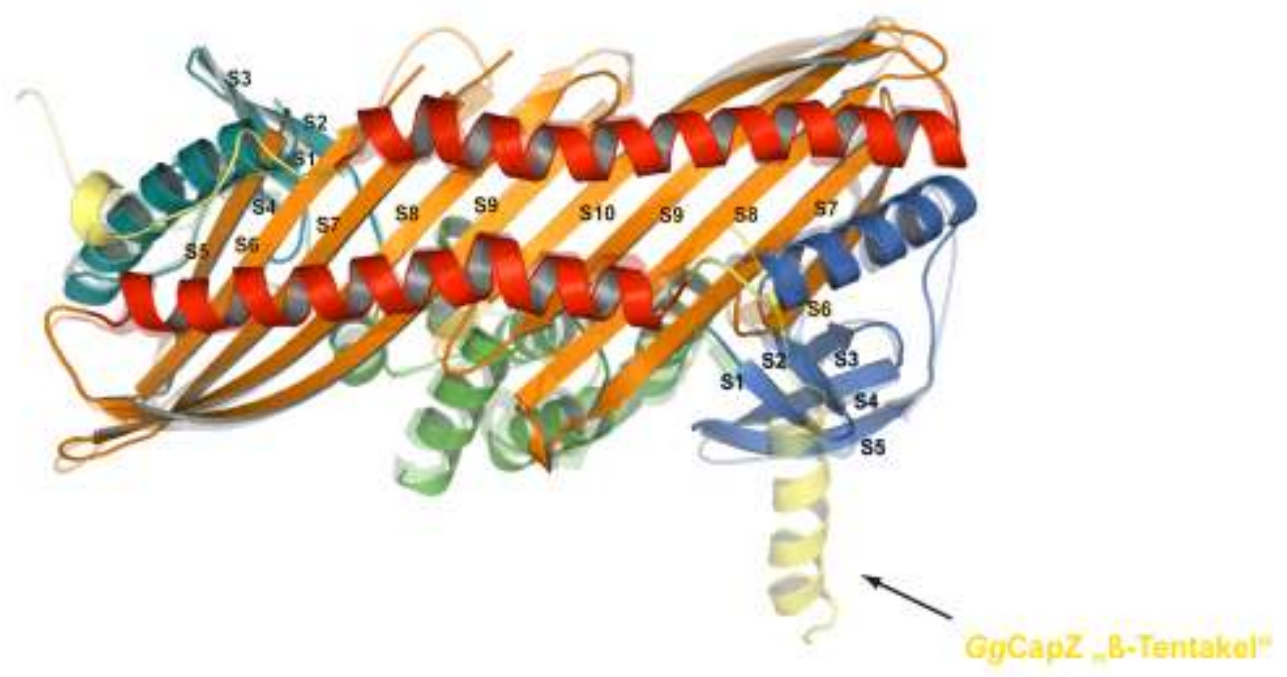

Abbildung II.15. Bänder-Darstellung der Gesamtstruktur von Cap32/34 mit beschrifteten Sekundärstrukturelementen. Die einzelnen strukturellen Motive sind unterschiedlich eingefärbt und gekennzeichnet. (A) Ansicht des Proteins von vorne. Die a-helikalen Elemente $(\mathrm{H})$ sind beschriftet. Im umrahmten Kasten sind die beiden Untereinheiten des Heterodimers gezeigt, um zu veranschaulichen, welche Bereiche der Gesamtstruktur auf Cap32 und Cap34 entfallen. (B) Aufsicht auf das Cap32/34-Molekül. Die $\beta$-Faltblätter (S) sind beschriftet. Zum Vergleich ist die Struktur des Homologen GgCapZ transparent dargestellt. Das „ $\beta$-Tentakel“ ist dabei gekennzeichnet. 
Der Aufbau des Proteins kann in 4 Abschnitte unterteilt werden: N-terminaler „Stiel“ (1), Übergang von „Stiel“ zu „Hut“ (2), „Hut“ (3) und C-terminaler Bereich (4). Der „Stiel“ ist aus je 3 antiparallelen $\alpha$-Helices der N-terminalen Regionen beider Untereinheiten ( $\mathrm{H} 1-3)$ aufgebaut und in einem Sechs-Helix-Bündel organisiert. Die Übergangsbereiche zwischen "Stiel“ und „Hut" setzen sich aus jeweils einer das $\beta$-Faltblatt flankierenden $N$-terminalen Helix $(\mathrm{H} 4)$ und $5 \beta$ Strängen der $\alpha$-Untereinheit ( $\alpha S 1-5)$ ( $\rightarrow$ „a-Übergangsbereich“) bzw. $4 \beta$ Strängen der $\beta$-Untereinheit ( $\beta S 1-4)(\rightarrow$ „, $\beta$-Übergangsbereich“) zusammen. Im Vergleich enthält der „a-Übergangsbereich“ des GgCapZ-Moleküls lediglich $3 \beta$ Stränge. Außerdem ist die als Bindeglied zwischen „Stiel“ und „Hut" fungierende Loop-Region innerhalb des "a-Übergangsbereichs" in den beiden CP-Varianten durch einen deutlich abweichenden Verlauf charakterisiert. Der „Hut“ umfasst ein zehnsträngiges antiparalleles $\beta$-Faltblatt, wobei beide Untereinheiten mit jeweils fünf Strängen (aS6-10 bzw. $\beta S 5-9$ ) an der Ausbildung dieser Struktur beteiligt sind. Interessanterweise konnte in Cap32/34 ein Großteil der LoopRegion zwischen $\beta S 6$ und $\beta S 7$ infolge mangelnder Elektronendichte nicht in das Strukturmodell eingefügt werden, wohingegen der Proteinabschnitt in GgCapZ hoch geordnet ist. Auf mögliche Ursachen hierfür wird im Diskussionsteil eingegangen. Als weiterer Unterschied weist der die Stränge $\beta S 8$ und $\beta S 9$ verbindende Loop innerhalb des Cap32/34-Moleküls keine Sekundärstruktur auf („random coil“), während er in GgCapZ einen kurzen helikalen Abschnitt enthält. Die hutförmige Komponente wird vervollständigt von zwei nebeneinander auf dem zehnsträngigen $\beta$-Faltblatt aufliegenden $\alpha$-Helices (H5) (eine von jeder Untereinheit), die antiparallel zueinander verlaufen. Der C-terminale Bereich der $\alpha$-Untereinheit beinhaltet ein $\alpha$-helikales Element mit einer halben Umdrehung (H6) und ragt aus der pilzähnlichen Struktur heraus. Die Helix interagiert dabei über die stark konservierte Aminosäure Trp-267 hydrophob mit der Oberfläche der $\beta$-Untereinheit, wodurch eine Stabilisierung des $\alpha$-C-Terminus eintritt. Für den C-terminalen Abschnitt der $\beta$-Untereinheit war hingegen keine Elektronendichte sichtbar. Dies wurde bereits für ebenfalls unter neutralem $\mathrm{pH}$ gezüchtete Kristalle von GgCapZ berichtet (Yamashita et al, 2003). Folglich 
wurde auf ein hohes Maß an Flexibilität innerhalb dieser als „ß-Tentakel“ bezeichneten Region geschlossen. Allerdings gelang es Yamashita et al (2003), durch das Überführen nativer GgCapZ-Kristalle in saure Lösung den C-Terminus der $\beta$-Untereinheit zu stabilisieren und dessen Struktur zu charakterisieren. Dabei stellte sich heraus, dass das eine amphipathische $\alpha$-Helix enthaltende Segment aus der pilzähnlichen Struktur herausragt, ohne spezifische Bindungen mit dem Restprotein einzugehen (Abbildung II.15., B). Für Cap32/34 konnte der Proteinabschnitt durch Soaking nativer Kristalle in azide Lösung indes nicht stabilisiert werden.

Trotz einer nur geringen Sequenzidentität ( $9 \%$ ) besitzen Cap32 und Cap34 sehr ähnliche Sekundär- und Tertiärstrukturen. Der hohe Grad an struktureller Konserviertheit wird durch eine mittlere quadratische Abweichung (r.m.s.d.) von $\sim 4.0 \AA$ verdeutlicht, welche aus der Überlagerung der beiden Untereinheiten über 195 äquivalente $\mathrm{C}_{\alpha}$-Atome resultiert (Abbildung II.16.; der N-terminale „Stiel“ wurden infolge unterschiedlicher Ausrichtung von der Berechnung ausgenommen). Die Untereinheiten sind im Heterodimer so angeordnet, dass die Kristallstruktur eine pseudozweifache Rotationssymmetrie zeigt (Abbildung II.15.).

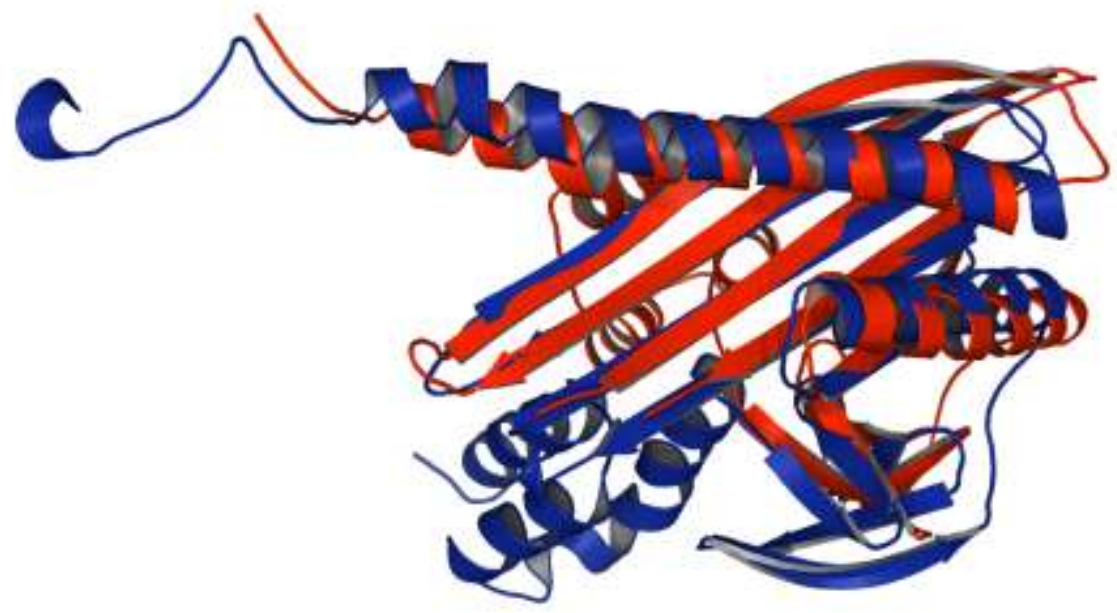

Abbildung II.16. Superpositionierung der Untereinheiten Cap32 (Rot) und Cap34 (Blau). Von der Berechnung des r.m.s.d.-Wertes blieb der N-terminale „Stiel“ aufgrund stark divergenter Ausrichtung ausgenommen. 
Die Strukturen der beiden in der asymmetrischen Einheit vorkommenden Cap32/34-Moleküle weisen keine nennenswerten Unterschiede auf (r.m.s.d. von $\sim 0.3 \AA$ für 512 gleiche $\mathrm{C}_{\alpha}$-Atome).

Ein Vergleich der Dictyostelium discoideum Cap32/34-Struktur mit der Struktur von GgCapZ offenbart große Ähnlichkeiten im Gesamtaufbau. Die Proteine konnten mit einem r.m.s.d.-Wert von $1.7 \AA$ über $496 \mathrm{C}_{\alpha}$-Atome überlagert werden (das flexible „ $\beta$-Tentakel“ wurde von der Berechnung ausgenommen).

\section{II.2.8. Interaktion zwischen Cap32 und Cap34}

Zwischen Cap32 ( $\beta$-Untereinheit) und Cap34 ( $\alpha$-Untereinheit) bestehen ausgeprägte Wechselwirkungen. Demzufolge liegt dem Heterodimer eine hohe Stabilität zugrunde, was durch eine für $\mathrm{CP}$ berichtete Schmelztemperatur von $58^{\circ} \mathrm{C}$ (Cooper \& Sept, 2008) belegt wird. Die intermolekularen Kontakte erstrecken sich über jeweils $24 \%\left(3.600 \AA^{2}\right)$ der lösungsmittelzugänglichen Oberfläche der beiden Untereinheiten (Cap32 $\rightarrow 15.500 \AA^{2}$; Cap34 $\rightarrow$ $\left.14.700 \AA^{2}\right)$. Davon entfallen $\sim 72 \%\left(2.600 \AA^{2}\right)$ auf Wechselwirkungen zwischen den C-terminalen Bereichen („Hut") und $~ 20 \%\left(720 \AA^{2}\right)$ auf solche zwischen den N-terminalen Abschnitten („Stiel“).

Die Dimerisierung der beiden Untereinheiten erfolgt unter anderem über Wasserstoffbrückenbindungen zwischen den Hauptketten der AS-Bereiche Asp197-Val-205 (aS10) und Lys-188-Thr-196 (BS9; Abbildung II.17., A). Daraus geht eine Verknüpfung der $\beta$-Stränge $\alpha$ S6-10 und $\beta$ S5-9 zu einem zehnsträngigen antiparallelen $\beta$-Faltblatt hervor. Des Weiteren gibt es starke hydrophobe Interaktionen zwischen dem zentralen $\beta$-Faltblatt und den darauf aufliegenden $\alpha$-Helices H5 (Abbildung II.17., C). Auch die Helices H5 selbst sind über hydrophobe Kontakte dicht aneinander gepackt. 
A

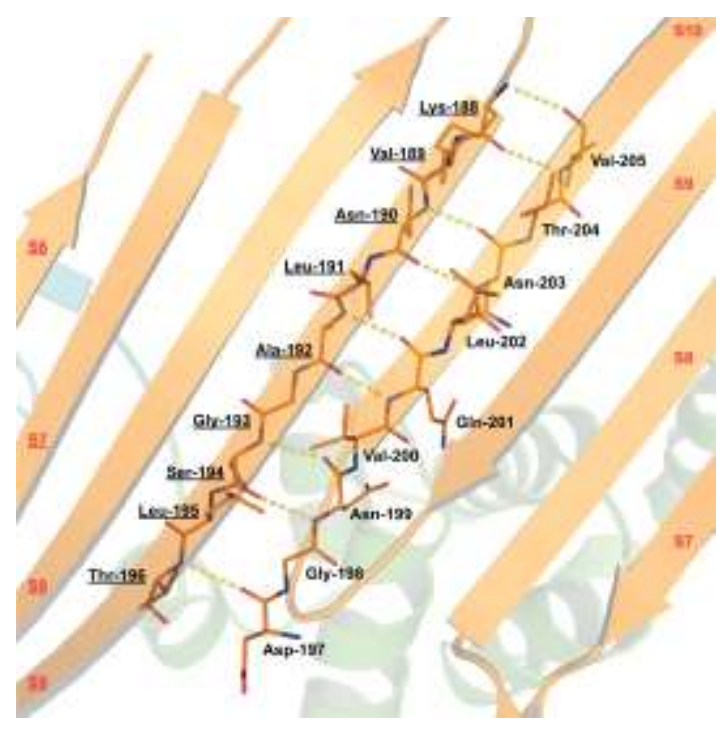

B

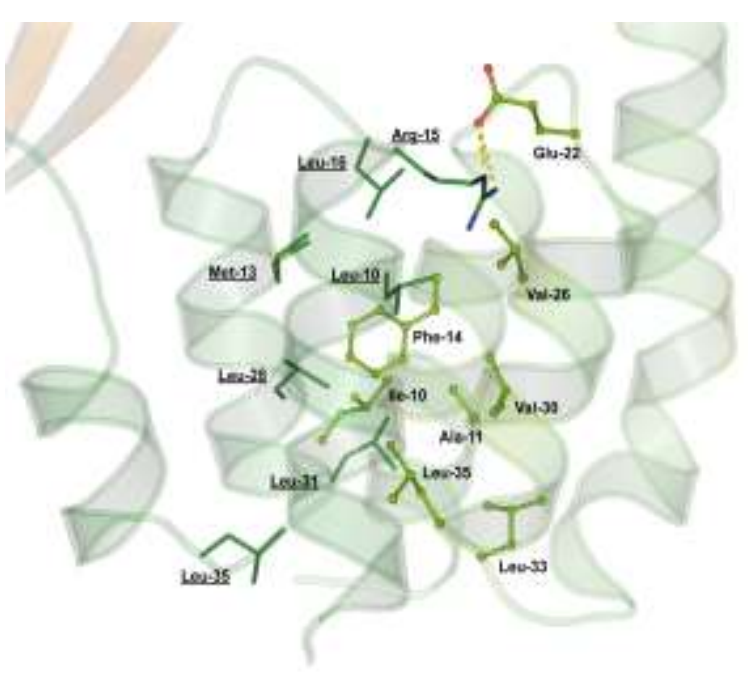

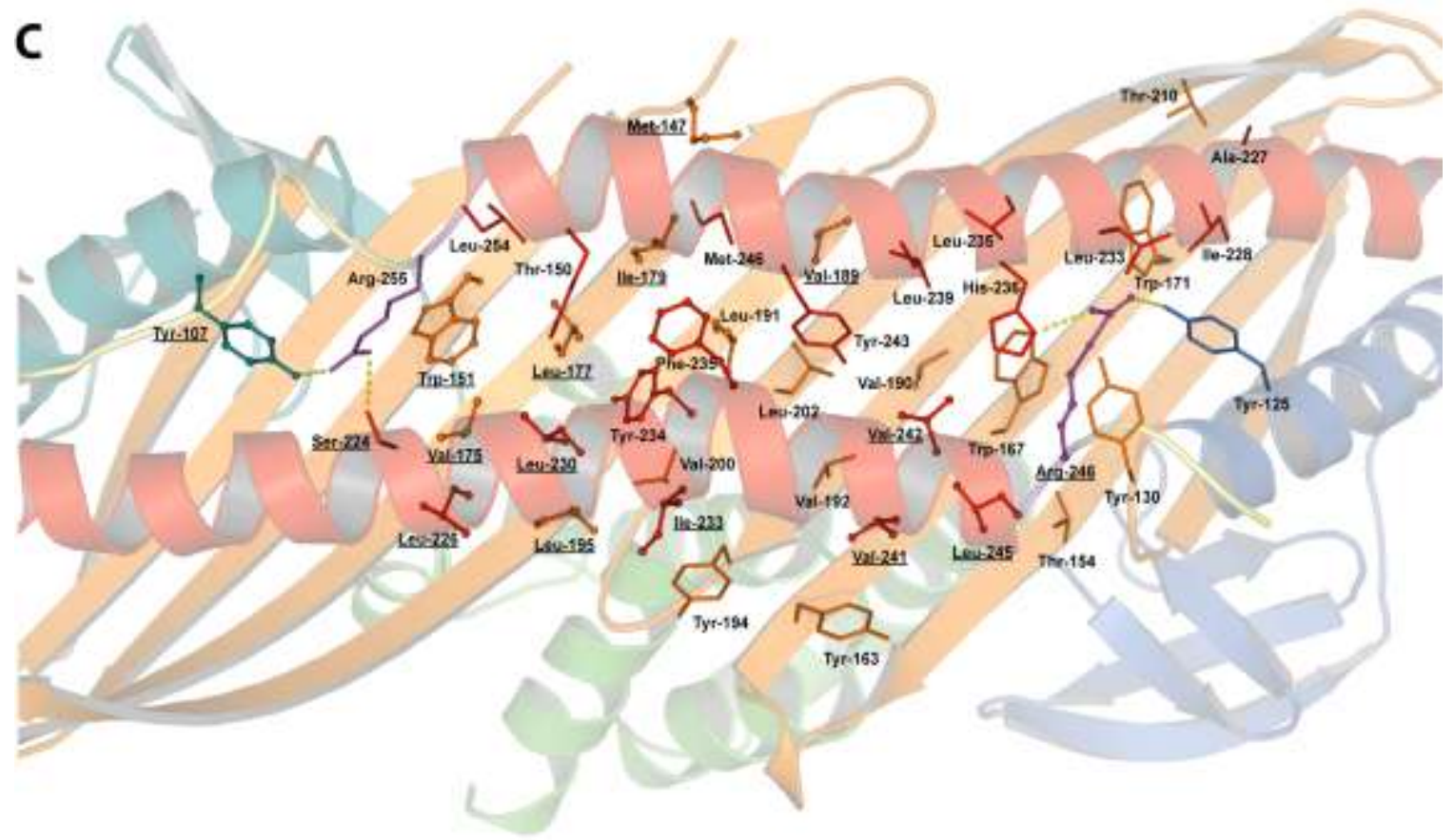

Abbildung II.17. Kontakte zwischen Cap32 und Cap34. Die involvierten AS-Seitenketten sind dargestellt und beschriftet. Gelb punktierte Linien markieren Wasserstoffbrückenbindungen. Aminosäuren und Sekundärstrukturelemente, deren Namen unterstrichen sind, gehören zu Cap32 ( $\beta$-Untereinheit). (A) Verknüpfung der $\beta$-Stränge $\alpha S 10$ und $\beta S 9$ zu einem zehnsträngigen $\beta$-Faltblatt. (B) Interaktionen im Bereich des $\mathrm{N}$-terminalen „Stiels" sowie (C) der hutförmigen Komponente des Heterodimers. 
Ferner tragen die hoch konservierten AS Arg-255 der a-Untereinheit und Arg-246 der $\beta$-Untereinheit (Abbildung II.17., C; Violett eingefärbt), die symmetrieäquivalent am C-terminalen Ende der Helices H5 lokalisiert sind, zu den intermolekularen Wechselwirkungen bei. Arg-255 ( $\alpha$ ) bildet Wasserstoffbrückenbindungen mit den AS Tyr-107 und Ser-224 der $\beta$-Untereinheit aus, während Arg-246 ( $\beta$ ) Wasserstoffbrücken mit den AS Tyr-125 und His-236 der $\alpha$ Untereinheit formt.

Innerhalb der N-terminalen Domänen interagieren Cap32 und Cap34 über die $\alpha$-Helices $\mathrm{H} 1$ und $\mathrm{H} 2$ miteinander. Die Bindungen sind vornehmlich hydrophober Natur und führen zur Entstehung eines kompakten Vier-Helix-Bündels (Abbildung II.17., B). Außerdem werden die Kontakte durch eine intermolekulare Salzbrücke zwischen den AS Glu-22 ( $\alpha$ ) und Arg-15 ( $\beta$ ) verstärkt.

Die Analyse der Grenzfläche zwischen den beiden Untereinheiten verdeutlicht, warum $\mathrm{CP}$ ausschließlich in heterodimerer Form vorkommt und nicht aus zwei $\alpha$ - bzw. $\beta$-Untereinheiten gebildet werden kann. 


\section{II.3. Diskussion}

\section{II.3.1. Kristallisation von Cap32/34 und Erhalt von Substrat- Komplexen}

Funktionelles CP konnte erstmals von Soeno et al rekombinant hergestellt werden, indem die beiden Untereinheiten simultan von einem Vektor aus exprimiert wurden (Soeno et al, 1998). Werden die Untereinheiten hingegen einzeln exprimiert, entstehen instabile und vorwiegend unlösliche Produkte (Remmert et al, 2000). Davon ausgehend wurden Cap32 und Cap34 in einem auf pETDuet ${ }^{\mathrm{TM}}-1$ (Novagen) basierende Vektor coexprimiert und konnten als stabiles Heterodimer in großen Mengen löslich erhalten werden. Cap32/34 wurde über $\mathrm{Ni}^{2+}$-NTA-Chromatographie und Gelfiltration bis zur Homogenität aufgereinigt und bildete gleich in anfänglichen Kristallisationstests mit Sparse Matrix Screens qualitativ hochwertige Kristalle. Diese wuchsen in Stäbchenform und besaßen durchschnittliche Dimensionen von $10 \times 10 \times 300 \mu \mathrm{m}$. CP konnte bereits im Komplex mit verschiedenen Antagonisten, beispielsweise CARMIL und V1, strukturell beschrieben werden (Hernandez-Valladares et al, 2010; Takeda et al, 2010). Über die Interaktion mit sauren Phospholipiden (PIPs), die ebenfalls einen hemmenden Einfluss auf das Protein ausüben, ist indes wenig bekannt. Daher wurde das Ziel verfolgt, Kristalle von Cap32/34 auch im Komplex mit PIPs zu erhalten. Um einen Eindruck darüber zu erlangen, an welche Phospholipide das Molekül zu binden in der Lage ist, wurde ein PIP-Strip-Inkubationstest durchgeführt. Dabei konnte Cap32/34 lediglich eine schwachaffine Bindung an Phosphatidylinositol-4,5-bisphosphat (PI4,5P2) nachgewiesen werden. Für PI4,5P2 wurde unter den Phospholipiden der mit Abstand größte inhibitorische Effekt auf Vertreter der CP-Familie berichtet (Heiss \& Cooper, 1991). Demnach lagen die anderen Lipide möglicherweise in zu geringen Mengen vor, als dass eine Interaktion mit Cap32/34 hätte detektiert werden können. Im Anschluss daran wurden native Kristalle des Heterodimers zur Charakterisierung von Substrat-Komplexen in Soaking-Experimente eingesetzt. Als Substrate fanden 
sowohl PI4,5P2 als auch diC8-PI4,5P2 Verwendung. Das synthetische Phospholipid diC8-PI4,5P2 wurde herangezogen, da seine beiden Fettsäuren aus jeweils nur 8 C-Atomen bestehen (bei PI4,5P2 sind es 18 bzw. 20 C-Atome). Dadurch konnte es im Vergleich zu PI4,5P2 wesentlich besser in Lösung gebracht und in höheren Konzentrationen in Soaking-Experimente eingesetzt werden (diC8-PI4,5P2 $\rightarrow 4 \mathrm{mM}$; PI4,5P2 $\rightarrow 0.2 \mathrm{mM}$ ). Von der ebenfalls erhältlichen diC4-Variante wurde abgesehen, da PI4,5P2 mit abnehmender Länge seiner Fettsäureschwänze zunehmend schwach an CP bindet (Kim et al, 2007). Soaking zielte darauf ab, dass das Substrat durch Diffusion zwischen den Wasserkanälen der einzelnen Proteinmoleküle innerhalb des Kristalls an seinen Bindungsort gelangt. Um zu verhindern, dass der Zugang zur potenziellen Bindungsstelle für das Phospholipid durch Kristallkontakte blockiert ist, wurden zudem Co-Kristallisationsexperimente mit PI4,5P2 und diC8-PI4,5P2 durchgeführt. In Mikroseeding-Experimenten konnten in Gegenwart beider Lipide Kristallnadeln gezüchtet werden, deren Erscheinungsbild dem der nativen Kristalle entsprach.

\section{II.3.2. Datensammlung und Lösung des Phasenproblems}

Die Kristalle wurden mit der Rotationsmethode unter Stickstoffstrom bei $100 \mathrm{~K}$ an der Mikrofokus-Röntgenquelle ID23-2 am ESRF in Grenoble vermessen, welche durch eine besonders intensive Röntgenstrahlung charakterisiert ist. Um den Strahlenschaden der Kristalle gering zu halten, wurde von der Strategie der helikalen Datensammlung Gebrauch gemacht (Flot et al, 2010). Dabei wird der Kristall während der Aufnahme eines Datensatzes zwischen zwei definierbaren Positionen bewegt, wodurch eine schrittweise Bestrahlung zuvor nicht exponierter Kristallbereiche erreicht wird. Demnach ermöglicht die helikale Datensammlung eine gleichmäßige Verteilung der Strahlenbelastung auf den zu vermessenden Kristallabschnitt, wodurch der Entstehung starker Strahlenschäden vorgebeugt werden kann. Dies erlaubt längere Expositionszeiten pro Aufnahme, infolgedessen qualitativ bessere Daten erhalten werden können. Die 
Methode der helikalen Datensammlung eignet sich insbesondere für in Stäbchenform gewachsene Kristalle, wie sie für Cap32/34 vorlagen, da Messdaten über ihre gesamte Länge aufgenommen werden können.

In Diffraktionsmessungen zeigte sich, dass die gezüchteten Kristalle gute Beugungseigenschaften aufwiesen. Die besten Kristalle von nativem und mit Substrat versetztem Cap32/34 lieferten vollständige Daten bis maximal 2.2$2.4 \AA$. Die Kristalle konnten der primitiv tetragonalen Raumgruppe $\mathrm{P} 4_{1}$ zugeordnet werden. Das Phasenproblem wurde über die Methode des Molekularen Ersatzes gelöst, wobei die Kristallstruktur von GgCapZ als SuchModell diente. Die Struktur von Cap32/34 konnte bei einer Auflösung von $2.2 \AA$ bis zu einem $R_{\text {work }}$ von $22.6 \%$ und einem $R_{\text {free }}$ von $26.6 \%$ verfeinert werden. Leider stellte sich heraus, dass die Datensätze der gesoakten und in Gegenwart von Lipid gezüchteten Kristalle keine zusätzliche Elektronendichte lieferten. Demnach gelang es nicht, Protein-Substrat-Komplexe zu erhalten.

\section{II.3.3. Analyse der Cap32/34-Struktur und Vergleich mit dem Homologen GgCapZ}

\section{II.3.3.1. Die CP-Varianten zeigen deutliche Übereinstimmungen im Gesamtaufbau, wobei die $\beta$-Untereinheiten strukturell kon- servierter sind als die $\alpha$-Untereinheiten}

Die Kristallstrukturen der beiden CP-Varianten besitzen eine stark konservierte Architektur. Dies wird durch eine mittlere quadratische Abweichung von $\sim 1.7 \AA$ belegt, die sich aus der Überlagerung der beiden Moleküle über 496 äquivalente $\mathrm{C}_{\alpha}$-Atome ergibt (der flexible $\beta$-C-Terminus von $\mathrm{GgCapZ}$ wurde ausgenommen). Auf die einzelnen Untereinheiten entfällt dabei ein r.m.s.d.-Wert von $1.9 \AA(\alpha)$ und $~ 1.2 \AA$ ( $\beta$ ) (Abbildung II.18.). Im Vergleich zu den $\alpha$-Untereinheiten liegen den Strukturen der $\beta$-Untereinheiten demnach deutlich größere Übereinstimmungen zugrunde. Dieser Befund deckt sich mit dem höheren Grad an Sequenzähnlichkeit zwischen den $\beta$-Untereinheiten der beiden CP-Varianten (54.3\% Identiät gegenüber $36.6 \%$ für die $\alpha$-Untereinheiten). Sequenzanalysen 
von 12 Capping-Proteinen deckten auf, dass die Homologie der $\beta$-Untereinheiten generell höher ist als die der $\alpha$-Untereinheiten (Cooper \& Sept, 2008). Dies ist möglicherweise auf die Art der Anbindung des Proteins an Aktinfilamente zurückzuführen. Elektronenmikroskopische Aufnahmen des Aktin-CP-Komplexes deuten darauf hin, dass sich die primären Kontakte des Heterodimers mit F-Aktin über ausgedehnte Teilbereiche der $\beta$-Untereinheit erstrecken, wohingegen sich die Beteiligung der $\alpha$-Untereinheit auf ihren C-Terminus beschränkt (Narita et al, 2006).

A

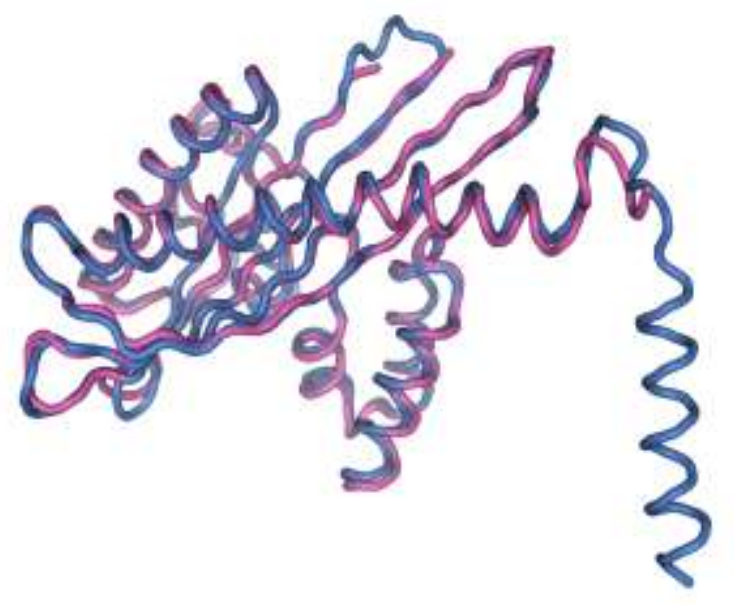

B

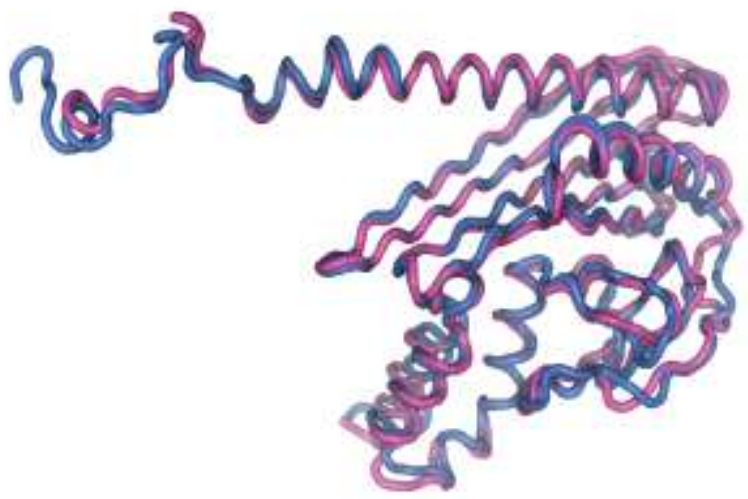

Abbildung II.18. Superpositionierung der Untereinheiten der CP-Homologen Cap32/34 und GgCapZ. (A) Überlagert sind Cap32 ( $\beta$ ) und GgCapZ $\beta$ sowie (B) Cap34 ( $\alpha$ ) und GgCapZa. Die Untereinheiten von Cap32/34 und GgCapZ sind Violett bzw. Blau eingefärbt.

Hart und Cooper (1999) gelang der Nachweis, dass sich die somatischen $\beta$ Isoformen im Muskelgewebe nicht komplementieren können. Daraus leiteten sie $a b$, dass sie modifizierte Funktionen besitzen. Wie bereits erwähnt, zeigen die $\beta$ Untereinheiten von Cap32/34 und CapZ sehr große Übereinstimmungen im Gesamtaufbau. Somit verleihen die Strukturen obiger These keinen Nachdruck. Allerdings könnte dem amphipathischen „ $\beta$-Tentakel” diesbezüglich eine zentrale Rolle zukommen. In Anbetracht seiner hohen Sequenzvariabilität innerhalb der 
Isoformen ( 19\% Identität zwischen „ $\beta$-Tentakel” von GgCapZ $\beta 1$ und GgCapZ $\beta 2$ ), wäre es denkbar, dass das Proteinsegment über die hydrophile Seite spezifisch mit anderen Proteinen interagiert, während die konservierten hydrophoben Reste die Anbindung an Aktin vermitteln. Darin könnten die modifizierten Eigenschaften der $\beta$-Isoformen begründet sein.

\section{II.3.3.2. Ein basischer Loop-Bereich, der in GgCapZ hoch geordnet ist, unterliegt in Cap32/34 einem hohen Maß an Beweglich- keit und fungiert möglicherweise als Bindungsstelle}

Trotz großer topologischer Ähnlichkeiten deckt die Kristallstruktur von Cap32/34 zwei signifikante Unterschiede zwischen den CP-Varianten auf.

Aufgrund mangelnder Elektronendichte war es nicht möglich, den AS-Bereich Gln-140-Gln-145 des die Stränge S6 und S7 verbindenden Loops (Thr-137Met-147) innerhalb der $\beta$-Untereinheit in das Modell zu integrieren (Abbildung II.19.). Der GgCapZ-Struktur liegt für die im Folgenden als Linker $\beta S 6-S 7$ ( $\beta$ steht für die $\beta$-Untereinheit) bezeichnete Schleifenregion hingegen eine hohe Ordnung zugrunde (Yamashita et al, 2003). Der stark abweichende Flexibilitätsgrad ist möglicherweise darin begründet, dass LinkerßS6-S7 in Cap32/34 von Dictyostelium discoideum und potenziell in allen zytoplasmatischen CappingProteinen als Interaktionsstelle fungiert und damit einhergehend ausgeprägten konformationellen Änderungen unterliegt. Aus dem in Abbildung II.20. dargestellten Sequenzvergleich geht hervor, dass LinkerßS6-S7 bis zu zwei basische Aminosäuren enthält (Lys-142 und Lys-143 in Cap32/34 von Dictyostelium discoideum), die sich ausgehend von der GgCapZ-Kristallstruktur lösungsmittelexponiert an dessen Spitze befinden. 


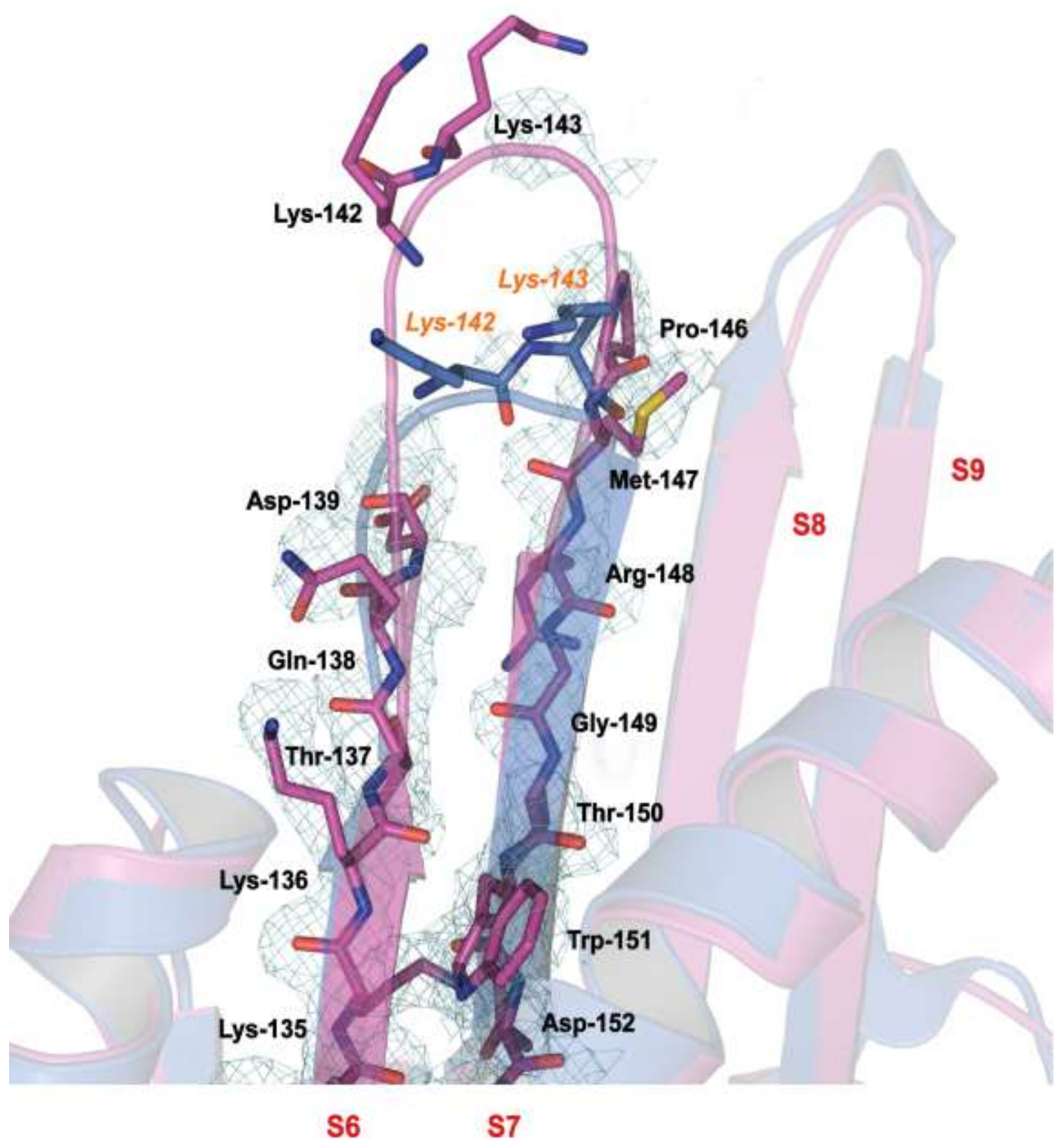

Abbildung II.19. Ausschnitt aus den überlagerten Strukturen von Cap32/34 (Violett) und GgCapZ (blau), der LinkerßS6-S7 und die daran angrenzenden Aminosäuren zeigt. Für Cap32/34 ist die finale 2Fo-Fc-Elektronendichte (Cyan) bei einem Konturierungslevel von $2 \sigma$ dargestellt. Der Verlauf der Loop-Spitze (Gln-140-Gln-145) sowie die Lokalisation der AS-Reste Lys-142 und Lys-143 basieren auf hypothetischen Aspekten. Für GgCapZ sind die gut geordneten Reste Lys142 und Lys-143 gezeigt, um deren Position an der Front der Schleifenregion zu demonstrieren. Im Hintergrund sind die $\beta$-Stränge (S6-S9) des zentralen, zehnsträngigen Faltblatts sichtbar. 


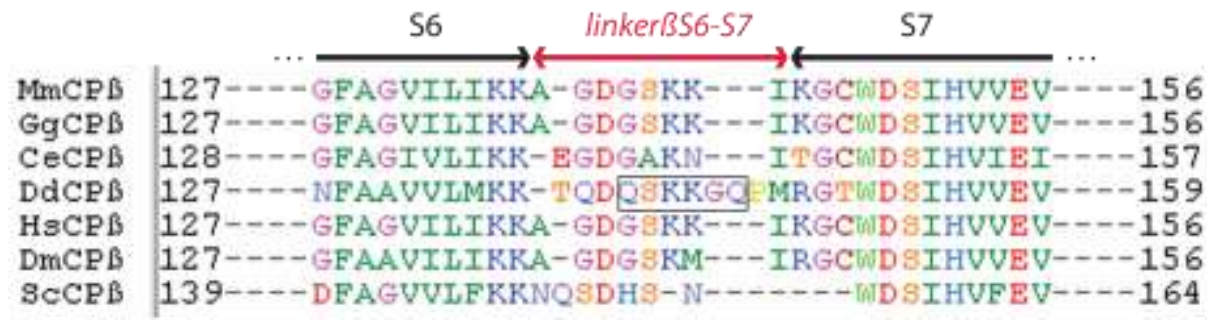

Abbildung II.20. Aminosäuresequenz-Vergleich von LinkerßS6-S7, einschließlich der daran angrenzenden Regionen verschiedener Organismen [Mus musculus (Mm), Gallus gallus (Gg), Caenorhabditis elegans (Ce), Dictyostelium discoideum (Dd), Homo sapiens (Hs), Drosophila melanogaster (Dm) und Saccharomyces cerevisae (Sc)]. Innerhalb der CP-Sequenz von Dictyostelium sind diejenigen AS-Reste in einem Kästchen eingerahmt, für die keine interpretierbare Elektronendichte vorlag. Oberhalb des Sequenzvergleichs sind die Sekundärstrukturelemente basierend auf der Kristallstruktur von Cap32/34 angegeben.

Da keine sauren Aminosäuren am vorderen Ende von LinkerßS6-S7 lokalisiert sind, ist dieser Abschnitt durch eine stark positive Oberflächenladung charakterisiert (Abbildung II.21.) und demnach grundsätzlich in der Lage, an negativ geladene Interaktionspartner zu binden.

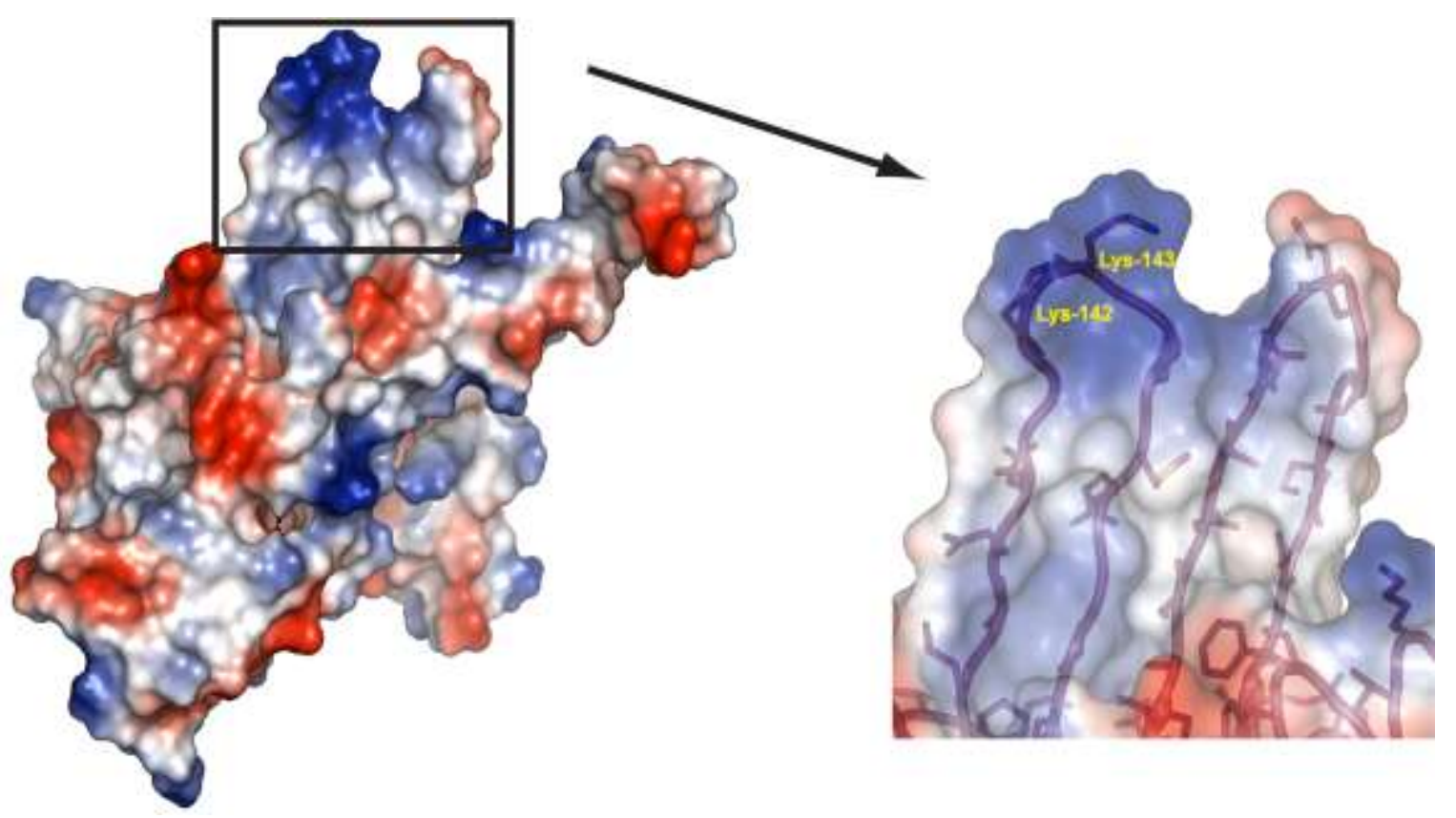

Abbildung II.21. Elektrostatisches Potenzial an der Oberfläche von Cap32 ( $\beta$-Untereinheit). Der Verlauf des vorderen Abschnitts von LinkerßS6-S7 (Gln-140-Gln-145) basiert auf hypothetischen Aspekten. Positiv geladene Bereiche sind Blau, negativ geladene Bereiche Rot eingefärbt. Auf der linken Seite ist die elektrische Ladung über die gesamte Moleküloberfläche gezeigt. Rechts ist LinkerßS6-S7 einschließlich der inn umgebenden Regionen vergrößert abgebildet. Die Oberflächenladung ist transparent dargestellt, die AS-Reste Lys-142 und Lys-143 sind beschriftet. 
Ferner kann dem Sequenzvergleich entnommen werden, dass Cap32/34 infolge der C-terminalen Flankierung von Lys-142 und Lys-143 durch die Reste Gly-144, Gln-145 und Pro-146 über einen um drei Aminosäuren verlängerten LinkerßS6S7 verfügt. Jedoch ist unklar, welche Auswirkungen diese Verlängerung auf seine hypothetische Funktion als Interaktionsstelle hat.

Nachfolgend werden zwei potenzielle Bindungspartner von LinkerßS6-S7 diskutiert - Aktin und Phospholipide.

\section{II.3.3.3. Potenzielle Interaktionspartner der basischen Loop-Region}

\section{- Interaktion mit Aktin}

In einer kürzlich veröffentlichten NMR-Studie konnte gezeigt werden, dass die Anbindung des Inhibitors V-1 an zytoplasmatisches CP von Maus ( $\alpha 1 / \beta 2)$ signifikante chemische Verschiebungen der den LinkerßS6-S7 umfassenden Aminosäuren Ala-137-lle-144 nach sich zog (Zwolak et al, 2010a). Dies legt die Vermutung nahe, dass das Proteinsegment wesentlich zur Interaktion mit Aktin beiträgt. Bisher konnte nur der sogenannten „basischen Triade“, drei stark konservierten basischen Aminosäuren nahe des C-Terminus der CP $\alpha$ Untereinheit, eine grundlegende Beteiligung an der Aktinbindung nachgewiesen werden (Kim et al, 2007). Diese Reste sind lösungsmittelexponiert und bilden einen positiv geladenen Abschnitt auf dem CP-Molekül, der vermutlich für den initialen Kontakt mit Aktin verantwortlich ist (Narita et al, 2006). LinkerßS6-S7 erweitert das elektropositive Oberflächenpotenzial und würde demzufolge eine vereinfachte Assoziation des Proteins an F-Aktin ermöglichen. Tatsächlich gingen Mutationen der Reste Lys-142 und Lys-143 in zytoplasmatischem CP von Maus $(\alpha 1 / \beta 2)$ mit einer stark reduzierten Bindungsaffinität zu Aktin einher (Zwolak et al, 2010b), wohingegen die gleichen Mutationen in GgCapZ keine nennenswerten Auswirkungen auf die Interaktion mit Aktinfilamenten hatten (Kim et al, 2010). Darüber hinaus zeigen die Kristallstrukturen von Cap32/34 und GgCapZ in Hinblick auf LinkerßS6-S7 deutliche konformationelle Unterschiede. Demnach wäre es denkbar, dass die Fähigkeit dieses Proteinsegments, an Aktin 
zu binden, auf zytoplasmatisches CP begrenzt ist. Diese Eigenschaft wäre aller Voraussicht nach darin begründet, dass sich das Protein an die spezifischen Anforderungen im Bereich des hochdynamischen Leitsaums der Zelle angepasst hat. So könnte der initiale Kontakt von CP mit F-Aktin über unterschiedliche Abschnitte des Proteins vermittelt werden. Dadurch hätte CP größere Möglichkeiten die Filamentpolymerisation zu hemmen und könnte mit hoher Effizienz zur Ausbildung des Leitsaums beitragen.

\section{- Interaktion mit Phospholipiden}

Aufgrund seines stark positiven elektrostatischen Potenzials stellen auch die am Aufbau von Biomembranen beteiligten Phospholipide mögliche Interaktionspartner von LinkerßS6-S7 dar. Für CP ist gut dokumentiert, dass es durch saure Phospholipide (PIPs), insbesondere durch PI4,5P2, inhibiert wird (Heiss \& Cooper, 1991; Kim et al, 2007). Neutrale Phospholipide haben indessen keinen Einfluss auf die Aktivität des Proteins (Heiss \& Cooper, 1991). Auch zahlreiche andere Aktin-bindende Proteine, wie z. B. Filamin und Gelsolin, werden durch PI4,5P2 reguliert. Die Interaktion ist dabei grundsätzlich elektrostatischer Natur und erfolgt über positiv geladene Bereiche auf der Moleküloberfläche. Interessanterweise erwies sich in einer computergestützten Analyse von zytoplasmatischem CP von Mensch ( $\alpha 1 / \beta 2)$ ein den Linker $\beta S 6-S 7$ enthaltender Abschnitt, der sich über insgesamt 18 AS erstreckt, als besonders geeignet für die Anbindung sowohl an negativ geladene Lipid-Kopfgruppen als auch an neutrale Phospholipide (Smith et al, 2006). Als ausschlaggebende Kriterien hierfür wurden dessen Lösungsmittelzugänglichkeit und ausgeprägter amphipathischer Charakter angeführt. Die hydrophile Seite zeichnet sich dabei durch einen hohen Anteil von basischen gegenüber sauren Aminosäuren aus. PI4,5P2 konnte zwar Uncapping-Aktivität nachgewiesen werden (Kim et al, 2007), allerdings ist völlig unklar wie das Lipid Uncapping hervorrufen kann. Möglicherweise wird die Loslösung des Heterodimers vom Plus-Ende des FAktins durch die elektrostatische Bindung von PI4,5P2 an LinkerßS6-S7 eingeleitet. 
Außerdem scheinen neben PIPs auch andere Phospholipide hochaffin mit CP zu interagieren. So konnte beobachtet werden, dass das Heterodimer in aktivierten Makrophagen und Blutplättchen fähig ist, sich gleichzeitig an Membranen und Aktinfilamente anzulagern (Hartwig et al, 1989, 1995). Darüber hinaus scheint $\mathrm{CP}$ in den Mikrovilli der Epithelzellen eine stabile Verknüpfung von F-Aktin und Plasmamembran herzustellen (Schafer et al, 1992). Die Beteiligung von PIPs an diesen Prozessen ist ausgeschlossen, da die Lipide die Dissoziation des CPAktin-Komplexes induzieren. Ausgehend von den weiter oben erwähnten Ergebnissen von Smith et al (2006) könnte LinkerßS6-S7 auch in die Interaktion mit neutralen Phospholipiden involviert sein. Für die Aktin-bindenden Proteine Gelsolin und Filamin wurde berichtet, dass sie in vitro an Vesikel, bestehend aus einem Gemisch der neutralen Phospholipide Phosphatidylglyzerol und Phosphatidylcholin assoziieren können, wobei dieser Vorgang keine funktionale Hemmung der Proteine nach sich zieht (Méré et al, 2005). Demnach könnte es sein, dass LinkerßS6-S7 in der Lage ist, an Membranbereiche zu binden, die mit bestimmten neutralen Phospholipiden angereichert sind. Infolge der daraus resultierenden Verankerung von Filamenten an die Plasmamembran, die idealerweise kurzzeitig und dynamisch erfolgt, könnte das F-Aktin-„Gerüst“ der Lamellipodien fixiert und so der für die Zellmigration nötige Vortrieb verstärkt werden.

Allerdings sei daran erinnert, dass dem Cap32/34-Molekül in Lipid-Bindetests mit PIP-Strips keine Wechselwirkung mit neutralen Phospholipiden nachgewiesen werden konnte. Solche Dot-Blot-,Schnelltests“ sind jedoch mit großer Vorsicht zu bewerten, da die Lipide in nicht physiologischer Umgebung vorliegen. Die Membranen sind durch unterschiedliche Kombinationen und Mischverhältnisse an Lipiden charakterisiert. Insofern ist es möglich, dass Cap32/34 zwar nicht mit einzelnen neutralen Phospholipiden interagiert, sehr wohl aber an Gemische dieser binden kann. 


\section{II.3.3.4. Mögliche Bindestelle der sarkomeren CP-Variante für die Z-Scheiben im Muskelgewebe}

Ein zweiter großer Unterschied zwischen Cap32/34 und GgCapZ geht aus dem Vergleich der B-Faktor-Verteilung über die beiden Moleküle hervor. Der Temperaturfaktor B beschreibt eine dynamische Unordnung im Kristall durch die thermische Bewegung der Atome um ihre Gleichgewichtslagen und eine statische Unordnung, die darauf zurückzuführen ist, dass die Moleküle in unterschiedlichen Einheitszellen nicht exakt die gleiche Position und Orientierung haben. Wie in Abbildung II.22. gezeigt, besitzt der die Aminosäuren Glu-104Leu-117 umfassende Bereich innerhalb der $\alpha$-Untereinheit des GgCapZ-Moleküls einen wesentlich höheren durchschnittlichen B-Faktor als der entsprechende Abschnitt (Glu-96-lle-111) in Cap32/34 ( $85 \AA^{2}$ gegenüber $\left.\sim 27 \AA^{2}\right)$. Des Weiteren liegen den Proteinsegmenten in beiden CP-Varianten deutliche strukturelle Unterschiede zugrunde. Der AS-Abschnitt Glu-96-Ser-102 formt in Cap32/34 einen $\beta$-Strang, wohingegen der Bereich in GgCapZ keine Sekundärstruktur aufweist. Zudem sind die Polypeptidketten in den Regionen Ala-103-Ile-111 (Cap32/34) bzw. Glu-111-Leu-117 (GgCapZ) durch einen stark abweichenden Verlauf charakterisiert (Abbildung II.22.).

CapZ befindet sich in Muskelzellen an den Z-Scheiben des Sarkomers, wobei es bis dato keine Anhaltspunkte für mögliche Interaktionsstellen gibt. Erst kürzlich wurde von einer Bindung des Heterodimers an das muskelspezifische Protein Nebulin berichtet, dessen vermutete Funktion die Lokalisierung von CapZ an die Z-Scheiben ist (Pappas et al, 2008). Allerdings lagert sich auch zytoplasmatisches CP in vitro an Nebulin an. In Myozeten, in welchen beide CPVarianten vertreten sind, konnte hingegen nur CapZ an den Z-Scheiben gefunden werden (Pappas et al, 2008). 


\section{Cap32/34}

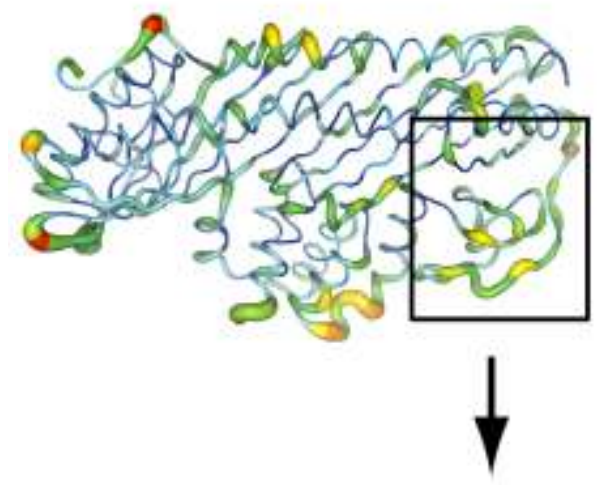

GgCapZ

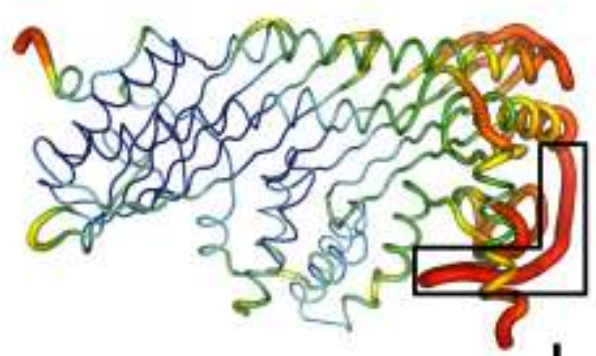

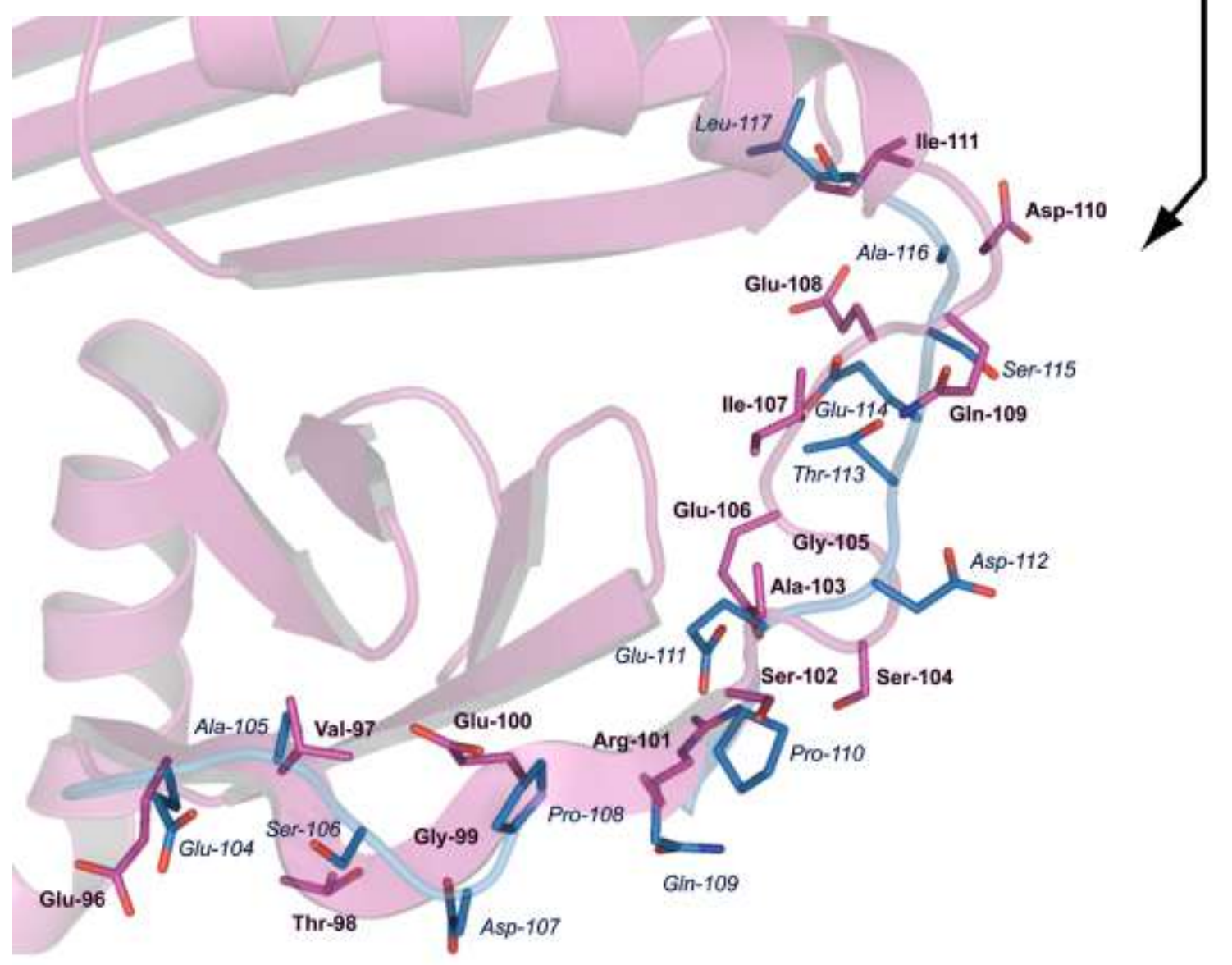

Abbildung II.22. Struktur von Cap32/34 und GgCapZ in B-Faktor-Farbkodierung (oben). Das in der Struktur von GgCapZ umrandete Proteinsegment weist auffallend hohe B-Faktoren auf, wohingegen der entsprechende Abschnitt in Cap32/34 gut geordnet ist. Die Farbkodierung wurde von Blau $\left(20 \AA^{3}\right)$ nach Rot $\left(90 \AA^{3}\right)$ gewählt. Unten ist die in der Cap32/34-Struktur markierte Region vergrößert dargestellt. Dabei sind die Strukturen der CP-Homologen im Bereich der stark abweichenden B-Faktoren überlagert (Cap32/34 in Violett, GgCapZ in Blau) sowie die entsprechenden Aminosäure-Seitenketten dargestellt und beschriftet. 
Demzufolge vermittelt entweder ein anderes Protein als Nebulin die Rekrutierung von sarkomerem CP an die Z-Scheiben, oder aber CapZ bindet direkt an diese Strukturen. Dabei könnte dem Proteinsegment Glu-111-Leu-117 innerhalb der aUntereinheit des GgCapZ-Moleküls in Anbetracht seiner Lösungsmittelzugänglichkeit, seiner hohen konformationellen Flexibilität und des strukturellen Unterschieds zu Cap32/34 eine begleitende Rolle zukommen. Begleitend deshalb, da hauptsächlich die CP $\beta$-Untereinheit für die Assoziation an die ZScheiben verantwortlich ist (Schafer et al, 1994b). Außerdem wäre denkbar, dass Isoform-spezifische Interaktionspartner an diesen Proteinabschnitt binden. Dafür spricht, dass sich die variablen Stellen der somatischen GgCapZ a-Isoformen gerade in diesem Bereich des Moleküls (und in der nachfolgenden Helix) anhäufen (Abbildung II.23.).
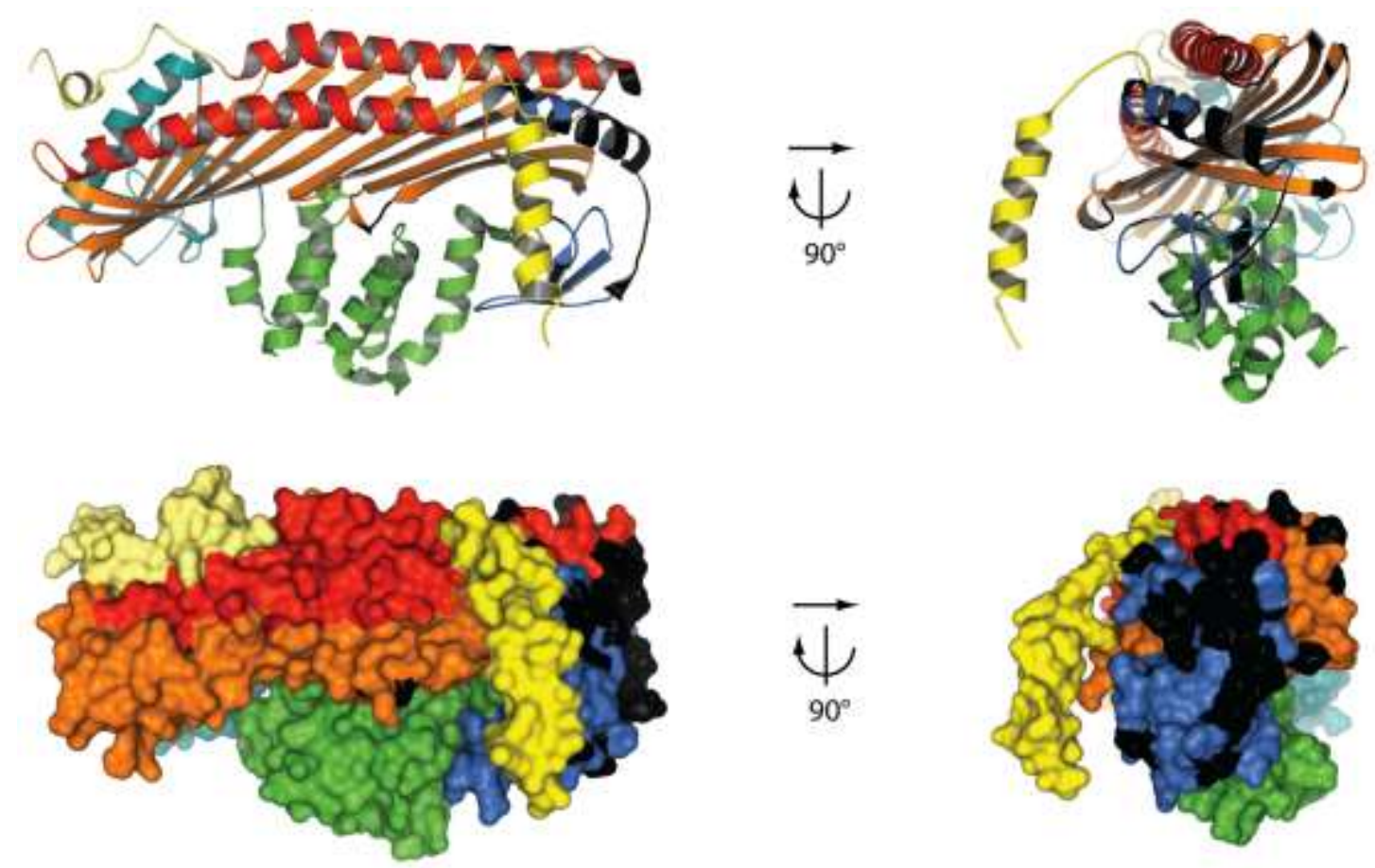

Abbildung II.23. Sequenzunterschiede zwischen den somatischen GgCapZ a-Isoformen, aufgetragen auf das Modell des GgCapZ-Heterodimers. Die Struktur des Proteins ist in Bänderdarstellung (oben) sowie in raumfüllender Darstellung (unten) gezeigt. Die Abschnitte, in denen die a-Isoformen in ihren AS-Sequenzen voneinander abweichen, sind schwarz eingefärbt. Von links nach rechts wurden die Strukturen jeweils um $90^{\circ}$ in die Ebene gedreht. Deutlich ist zu erkennen, dass die Unterschiede der $\alpha$-Untereinheiten hauptsächlich am rechten äußeren Rand liegen. 


\section{Material und Methoden}

\section{III.1. Material}

\section{III.1.1. Geräte}

Allgemeine Arbeitsmittel

Chromatographie-Säulen

GE Healthcare, Freiburg

Dialyseschläuche (MWCO 8-10 kDa, 25 mm)

Geltrocknungsfolien

Roth, Karlsruhe

Hämazytometer (Zählkammer)

Plastik-Handsäulchen

Promega, USA

Vivaspin Konzentrator (MWCO 30, 50, 100 kDa)

Sigma, Deisenhofen

Pierce, USA

Sartorius, Göttingen

Brutschrank

Function Line B6/UB6

Heraeus, Hanau

Elektrophoreseapparaturen

Agarose Gele: Mini-Sub Cell GT

Biorad, München

Electrophoresis Power Supply - Power P300

Biorad, München

SDS-Gelelektrophorese-Apparatur

Biorad, München

Elektroporationsapparatur

Gene Pulser II, Pulse Controller Plus

Biorad, München

FPLC-Anlage

ÄKTA-Purifier

Pharmacia, Schweden

PCR-Apparatur

PCR Sprint

Hybaid, Heidelberg 
$\mathrm{pH}-$ Meter

pB-11

Sartorius, Göttingen

Schüttelinkubator

Certomat $\mathrm{R}$

Braun, Melsungen

Innova 2300 Platform Shaker

New Brunswick Sci., USA

Schüttler

KS 10

Bühler $\mathrm{GmbH}$, Tübingen

Multitron

Infors AG, Schweiz

Shaker S-4

ELMI, Lettland

Ultraschall-Homogensiator

Sonopuls HD 2200

Bandelin, Berlin

UV-Absorptionsspektrometer

ChemStation

Agilent Tech., Böblingen

DU-70 Spectrophotometer

Beckmann, Dreieich

\section{Zentrifugen}

Avanti J-20 (JA 30.5, JLA 8.1)

Beckmann, Dreieich

Avanti J-30 I

Beckmann, Dreieich

Tischzentrifuge 5415 D

Eppendorf, Hamburg

\section{III.1.2. Chemikalien/Reagenzien}

$30 \%$ (w/v) Acrylamid/0.8\% (w/v) Bisacrylamid-Lsg. Roth, Karlsruhe

Alkalische Phosphatase

Boehringer, Mannheim

Ampicillin

Sigma, Deisenhofen

Adenosin-5'-diphosphat (ADP)

Sigma, Deisenhofen

Adenosin-5'-triphisphat (ATP)

Sigma, Deisenhofen 
Bacto Hefeextrakt

Bacto Trypton

Benzamidin Hydrochlorid-Hydrat

Boran-Dimethylamin-Komplex

Chloramphenicol

Desoxynukleosid-5'-triphosphate für die PCR

Dithiothreitol (DTT)

DNase I

Expand $^{\mathrm{TM}}$ High Fidelity PCR System (Taq + Tgo)

Expand $^{\mathrm{TM}}$ Long Template PCR System

(Taq + Tgo)

Geneticin (G418 Sulfat)

Imidazol

Isopropyl- $\beta$-D-thiogalactopyranosid (IPTG)

Kanamycin

Leupeptin

$\mathrm{Ni}^{2+}$-NTA Superflow

$\mathrm{N}, \mathrm{N}, \mathrm{N}^{\prime}, \mathrm{N}^{\prime}$-Tetramethylethylendiamin (TEMED)

$\mathrm{N}_{\alpha}$-p-Tosyl-L-Arginin-methylester hydrochlorid (TAME)

$\mathrm{N}_{\alpha}$-p-Tosyl-L-Lysin-chlormethylketon (TLCK)

Penicillin/Streptomycin

Pepstatin

Phenylmethansulfonsäurefluorid (PMSF)

Polyethylenglycol (PEG 550, 1.000, 4.000, 6.000, $8.000,10.000,12.000,20.000)$

Polyethylenglycolmonomethylether (PEGMME 2.000, 5.000)

Protease Inhibitor Cocktail Tabletten (EDTA frei)

RNase A

T4-DNA-Ligase
Difco, USA

Difco, USA

Sigma, Deisenhofen

Sigma, Deisenhofen

Sigma, Deisenhofen

Boehringer, Mannheim

Sigma, Deisenhofen

ICN Biomedicals Inc., USA

Roche, Mannheim

Roche, Mannheim

Calbiochem., USA

Merck, Darmstadt

Roth, Karlsruhe

Serva, Heidelberg

Sigma, Deisenhofen

Qiagen, Hilden

Sigma, Deisenhofen

Sigma, Deisenhofen

Sigma, Deisenhofen

Gibco BRL, Eggenstein

Sigma, Deisenhofen

Sigma, Deisenhofen

Hampton, USA

Hampton, USA

Roche, Mannheim

Sigma, Deisenhofen

Boehringer, Mannheim 
TEV-Protease

Thrombin
Roche, Mannheim

Roche, Mannheim

Alle weiteren Chemikalien wurden entweder von Sigma, Merck oder Roth bezogen, oder waren im institutseigenen Chemikalienlager vorrätig.

\section{III.1.3. Größenstandards}

DNA-Molekular-Gewichts-Marker: 1 kBp Leiter

Protein-Molekular-Gewichts-Marker: Benchmark
Fermentas, St. Leon-Rot

Fermentas, St. Leon-Rot

\section{III.1.4. Plasmide}




\begin{tabular}{|c|c|c|}
\hline Plasmid & Funktion & Quelle \\
\hline pDXA-mako2b & $\begin{array}{l}\text { Vektor für die Expression von } \\
\text { DHC-Konstrukten als His8- } \\
\text { Myosin-Motor-Domänen- } \\
\text { Fusionsprotein in Dictyostelium- } \\
\text { Zellen }\end{array}$ & $\begin{array}{l}\text { von PD Dr. M. Kollmar, } \\
\text { MPI Göttingen }\end{array}$ \\
\hline pDXA-mako1 & $\begin{array}{l}\text { Vektor für die Expression von } \\
\text { DHC-Konstrukten mit His,-Tag in } \\
\text { Dictyostelium-Zellen }\end{array}$ & $\begin{array}{l}\text { von PD Dr. M. Kollmar, } \\
\text { MPI Göttingen }\end{array}$ \\
\hline pETmako17/m15 & $\begin{array}{l}\text { Vektor für die Expression von } \\
\text { DHC-Konstrukten mit His }{ }_{8}-\text { Tag in } \\
\text { E. coli-Zellen }\end{array}$ & $\begin{array}{l}\text { von PD Dr. M. Kollmar, } \\
\text { MPI Göttingen }\end{array}$ \\
\hline pETmD1-mako & $\begin{array}{l}\text { Tandem-Vektor für die simultane } \\
\text { Expression von Cap32 und } \\
\text { Cap34 in E. coli-Zellen }\end{array}$ & $\begin{array}{l}\text { pETDuet }^{T M}-1 \text { von } \\
\text { Novagen }\end{array}$ \\
\hline
\end{tabular}

\section{III.1.5. Primer}

Alle verwendeten Oligonukleotide wurden von der Firma Eurofins MWG Operon mit HPSF-Qualität synthetisiert. Restriktionsschnittstellen, die über die Oligonukleotide in Sequenzen eingefügt wurden, sind unterstrichen dargestellt.

\begin{tabular}{|c|c|}
\hline Name & Sequenz $\left(5^{`} \rightarrow 3^{`}\right)$ \\
\hline \multirow[t]{2}{*}{ ecke1_Hs for } & 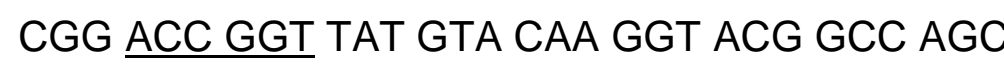 \\
\hline & ACC TCC GAT G \\
\hline ecke1_Hs rev & CCG ACG CGT TTA CTC TGT GCA CAA GAC TGC \\
\hline
\end{tabular}


GAC AC

ecke2_Hs for

ecke3_Hs for

ecke4_Hs for

ecke5_Hs for

ecke5_Hs rev

ecke6_Hs rev

ecke7_Hs for

ecke8_Hs for

ecke9_Hs rev

ecke10_Hs rev

ecke11_Hs rev

ecke12_Hs for

ecke14_Hs for

ecke17_Hs for

ecke17_Hs rev
CGG ACC GGT TAT GTA CAA GGT TAC ACT TGG CTG GCC GAA CAC AAG

CGG ACC GGT TAT GTA CAA GGT AGG AAG ATC

AAA GAG ACA GTC GAC

CGG ACC GGT TAT GTA CAA GGT TGG GAA AAA

ACA AGT GAA AC

CGG ACC GGT TAT GTA CAA GGT GAG GAG AAG

AGC GCC CTG GAG

CCG ACG CGT TTA TCC AAA CCA ATT CAA CAC ACA CCT GTT G

CCG ACG CGT TTA CGT GTC TAC TGA GTG CTG CTC CAA C

CGG ACC GGT TAT GTA CAA GGT GTC AGG CCT CAC ATC CGT G

CGG ACC GGT TAT GTA CAA GGT TTG GAG GCC AGG CTG GGG GG

CCG ACG CGT TTA TCC AAA CCA ATT CAA CAC ACA CCT GTT G

CCG ACG CGT TTA GAT TAA CTG CCG GTC GGG CTT G

CCG ACG CGT TTA GGC TTG TGT CAT TGT CAA ATA GCA GC

CGG ACC GGT TAT GTA CAA GGT TTG GAG GCC AGG CTG GGG GG CGG ACC GGT TAT GTA CAA GGT TAT CAG ATC ACC CAG ATC AAT CAT GGC CGG ACC GGT TAT GTA CAA GGT AGA ATA TTC CGT CAA CCT CAA GGC CCG ACG CGT TTA AGT GCT CCG GTT TAC TTT TGC 
C

ecke1_Dd for

ecke1_Ddrev

ecke2_Dd for

ecke3_Dd for

ecke3_Ddrev

ecke4_Dd for

ecke5_Ddrev

ecke6_Ddrev

ecke7_Ddrev

ecke8_Dd for

ecke9_Dd for

ecke9_Ddrev

ecke10_Ddfor

ecke10TEV_Hs for
CGG ACC GGT TAT GTA CAA GGT GGT GAA TGG TCA CCA GAA GC

CCG ACG CGT TTA AAT ATC AGA TTT CCA TGA ACT GAT TGA AAC

CGG ACC GGT TAT GTA CAA GGT TGG GAA CAA CAA AGT GAA AAC CGG ACC GGT TAT GTA CAA GGT GAG GAT CAA CAA ATA AAT GTT GAT TCA CC CCG ACG CGT TTA GGT TTC AAC TGA TAA TTT CTC CAA CTC

CGG ACC GGT TAT GTA CAA GGT AAG AGA CCA AAG ATT AGA GGT GC CCG ACG CGT TTA TTC TTT TTC TTG TGG ATC AAA TGG TTC ATT TG

CCG ACG CGT TTA AAT CAT TTC ACG ATC TGG TTT AAT CAT GG

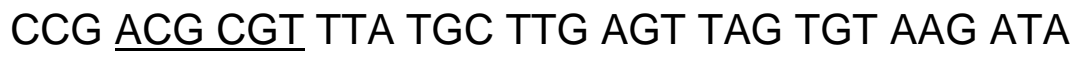
ACA ACG

CGG ACC GGT TAT GTA CAA GGT CAT CAA ATT CTC AAT ATC AAT CAT GGT G

CGG ACC GGT TAT GTA CAA GGT CAT GCT TGG

TTA TCT GAA CAT CG

CCG ACG CGT TTA TTC ACC AAA CCA ATC CAA AAC ACA AC

CGG ACC GGT TAT GTA CAA GGT CGT GTT TTC CGT CAA CCA CAA G

CGG ACC GGT TAT GTA CAA GGT GAA AAC CTG TAT TTT CAG GGC TTG GAG GCC AGG CTG GGG GG 
ecke19TEV_Hs for CGG ACC GGT TAT GTA CAA GGT GAA AAC CTG TAT TTT CAG GGC AGG AAG ATC AAA GAG ACA GTC GAC

ecke1TEV_Dd for

CGG ACC GGT TAT GTA CAA GGT GAA AAC CTG TAT TTT CAG GGC GGT GAA TGG TCA CCA GAA GC ecke12CT_Hs rev CCG ACG CGT TTA ATG ATG GTG ATG ATG GTG ATG ATG GGT AGT TCC AAA CCA ATT CAA CAC ACA CCT GTT G

ecke16CT_Hs rev CCG ACG CGT TTA ATG ATG GTG ATG ATG GTG ATG ATG GGT AGT TCC AAA CCA ATT CAA CAC ACA CCT GTT G

ecke5CT_Ddrev CCG ACG CGT TTA ATG ATG GTG ATG ATG GTG ATG ATG GGT AGT TTC TTT TTC TTG TGG ATC AAA TGG TTC ATT TG

Cap32 for GGT TAT GTA CAA GGT ACA GAA AAG CAA TTA AGT TGT TGT CTC G

Cap32 rev CCG ACG CGT ACT ACC AGC AAG ATT TAC TTT ACC AG

Cap34 for CC GCC ATG GCC TCA AAT CAA GAA CTC GTT CAA ATC

Cap34 rev CCG ACG CGT AAG CTT TTA TTT ATT GAG TTC ATT GGC AAT TTT GAA GTT TTT $G$

\section{III.1.6. Zellstämme}

E. coli XL2-blue

E. coli BL21(DE3)-CodonPlus

Dictyostelium AX3-ORF ${ }^{+}$
Stratagene, Heidelberg

Stratagene, Heidelberg von PD Dr. M. Kollmar 


\section{III.1.7. Medien für die Kultivierung von E. coli- und Dictyostelium- Zellen}

\section{LB-Medium}

$10 \mathrm{~g} / \mathrm{l}$ Bacto Trypton; $5 \mathrm{~g} / \mathrm{l}$ Bacto Hefeextrakt; $10 \mathrm{~g} / \mathrm{l} \mathrm{NaCl}$.

Das Medium wird mit $\mathrm{NaOH}$ auf $\mathrm{pH} 7.2$ eingestellt und 20 Minuten bei $121^{\circ} \mathrm{C}$ autoklaviert.

\section{LB-Agar}

$15 \mathrm{~g} / \mathrm{l}$ Agar in LB-Medium

\section{HL-5c-Medium}

$5 \mathrm{~g} / \mathrm{l} \mathrm{Bacto} \mathrm{Hefeextrakt;} 2.5 \mathrm{~g} / \mathrm{l}$ Bacto Trypton; $2.5 \mathrm{~g} / \mathrm{l}$ Casein Pepton; $5 \mathrm{~g} / \mathrm{l}$

Proteose Pepton; $10 \mathrm{~g} / \mathrm{l}$ D-Glucose; $1.2 \mathrm{~g} / \mathrm{K} \mathrm{KH}_{2} \mathrm{PO}_{4}$ (wasserfrei); $0.35 \mathrm{~g} / \mathrm{l}$ $\mathrm{Na}_{2} \mathrm{HPO}_{4}$ (wasserfrei).

Das Medium wird 20 Minuten bei $121^{\circ} \mathrm{C}$ autoklaviert.

\section{III.2. Molekularbiologische Methoden}

\section{III.2.1. Primer-Design}

Beim Design der Primer gilt es einige wichtige Grundregeln zu beachten, um die Wahrscheinlichkeit einer spezifischen Anbindung an die Matrize zu erhöhen. In Hinsicht auf ihre Länge sollten die Primer aus mindestens 18 Basenpaaren bestehen. Bei der Sequenz ist darauf zu achten, dass der GC-Gehalt zwischen 40-60 \% liegt, und das 3`er Ende von einem Cytosin oder Guanin flankiert wird. Allerdings sollte eine längere Abfolge dieser Basen vermieden werden, um 
Fehlhybridisierungen vorzubeugen. Die beiden Primer eines Primer-Paares dürfen keine zueinander komplementären Sequenzen aufweisen, da die Formierung von Dimeren eine fundamentale Störung des PCR-Prozesses zur Folge hat. Außerdem sollte die Schmelztemperatur der beiden Primer möglichst nah beieinander liegen. Zur Abschätzung der Schmelztemperatur wurde von folgender Formel Gebrauch gemacht:

$\mathrm{T}_{\mathrm{m}}=59.9+0.41 \cdot(\mathrm{GC}) \%-600 / \mathrm{n} ; \mathrm{n}=$ Anzahl der Basenpaare.

Die Primer wurden über das Internet von der Firma Eurofins MWG Biotech (Eberberg) bestellt.

\section{III.2.2. Polymerase-Ketten-Reaktion (PCR)}

Mittels PCR (Saiki et al, 1988) können in vitro selektiv definierte DNA-Abschnitte amplifiziert werden. Der PCR-Prozess teilt sich dabei in mehrere Schritte. Zunächst erfolgt die Denaturierung der doppelsträngigen DNA bei $95^{\circ} \mathrm{C}$ für eine Minute. Oligonukleotide, die das zu amplifizierende DNA-Fragment definieren, können daraufhin bei einer niedrigeren Temperatur $\left(T_{\text {anneal }}=T_{m}-5-10^{\circ} \mathrm{C}\right)$ an die nun einzelsträngige Ziel-DNA hybridisieren (Annealing). Im Anschluss daran synthetisiert eine thermostabile DNA-Polymerase in Gegenwart von Nukleotiden die komplementären Stränge der DNA-Matrize (Elongation). Durch die Amplifikationszyklen, bestehend aus Denaturierung, Primer-Hybridisierung und Elongation, wird das gewünschte DNA-Fragment exponentiell vervielfältigt. Abhängig von der Größe des zu amplifizierenden DNA-Abschnitts wurde entweder auf das Expand ${ }^{\mathrm{TM}}$ High Fidelity PCR System $(\leq 4 \mathrm{kBp})$ oder auf das Expand $^{\mathrm{TM}}$ Long Template PCR System (> $4 \mathrm{kBp}$ ) von Roche zurückgegriffen. Die Annealing-Temperatur richtet sich nach den Schmelzpunkten des eingesetzten Primer-Paares, und muss demnach für jedes Primer-Paar angepasst werden. Überstieg der zu vervielfältigende DNA-Abschnitt eine Größe von 2 kB, wurde eine Elongationstemperatur von $68^{\circ} \mathrm{C}$ gewählt. Ansonsten erfolgte die Elongation bei $72^{\circ} \mathrm{C}$. 


\section{III.2.3. DNA-Aufreinigung aus PCR-Ansätzen}

Um die DNA von PCR-Produkten aufzureinigen, wurde nach dem Protokoll des NucleoSpin ${ }^{\circledR}$ Extract-II-Kits von Macherey-Nagel verfahren (PCR Clean-Up User Manual, 2011, Macherey-Nagel). Diese Methode dient der Entfernung von Enzymen aus PCR-Ansätzen.

\section{III.2.4. Spaltung von DNA mit Restriktionsenzymen}

Restriktionsendonukleasen sind Nukleinsäure-modifizierende Enzyme, die doppelsträngige DNA sequenzspezifisch schneiden können. Dabei entstehen Fragmente mit definierten Enden. Die enzymatische Spaltung von DNA erfolgte nach Herstellerangaben mit spezifischen Reaktionspuffern. Die Restriktionsdauer betrug 60 Minuten bei $37^{\circ} \mathrm{C}$. Das Produkt wurde anschließend über AgaroseGelelektrophorese identifiziert. Restriktionsendonukleasen und deren Puffer wurden von der Firma Fermentas (St. Leon Rot) bestellt.

\section{III.2.5. Agarosegelelektrophorese}

Die Auftrennung, Identifizierung oder Isolierung von DNA-Fragmenten erfolgte über die Standardmethode der Agarosegelelektrophorese. Die AgaroseKonzentration wurde dabei in Abhängigkeit von der Fragmentgröße gewählt. Die Gellösung wurde mit Ethidiumbromid (Endkonzentration: $0.5 \mu \mathrm{g} / \mathrm{ml}$ ) versetzt. Ethidiumbromid interkaliert in die DNA und fluoresziert unter UV-Licht, wodurch die DNA-Banden sichtbar werden. Die DNA-Proben wurden mit 6x DNALadepuffer versetzt und gemeinsam mit einem Längenmarker auf das Gel aufgetragen. Die elektrophoretische Auftrennung erfolgte über 50 Minuten bei 120 Volt. Als Puffersystem diente TAE. Im Anschluss an den Gellauf konnten die Banden unter dem UV-Licht sichtbar gemacht und wenn erforderlich isoliert werden. 


\section{III.2.6. DNA-Isolierung aus Agarosegelen}

Zur Isolierung und Aufreinigung von DNA-Fragmenten wurde das NucleoSpin ${ }^{\circledR}$ Extract-II-Kit von Macherey-Nagel verwendet. Dazu wurde das zu isolierende DNA-Fragment mit einem Skalpell aus dem Agarose-Gel ausgeschnitten und in ein $2 \mathrm{ml}$ Reaktionsgefäß überführt. Anschließend wurde nach den Herstellerangaben vorgegangen (Gel Extraction User Manual, 2011, MachereyNagel).

\section{III.2.7. Ligation linearer DNA}

Doppelsträngige DNA-Fragmente können über die T4-DNA-Ligase zusammengefügt werden. Dies ist möglich, da das Enzym unter ATP-Verbrauch die freien 3'Hydroxyl- und 5'-Phosphatenden miteinander verbinden kann. Dazu wurde die mit Restriktionsenzymen verdaute Plasmid-DNA mit dem analog verdauten Insert im molaren Verhältnis Vektor:Insert von 1:1 bis 1:3 gemischt. Dem Reaktionsansatz $(8 \mu \mathrm{l})$ wurden daraufhin $1 \mu \mathrm{l}$ Ligasepuffer (10x) und $1 \mu \mathrm{l}$ T4-DNA-Ligase (Boehringer) zugegeben. Die Ligation war nach 2 Stunden bei RT beendet.

\section{III.3. Zellbiologische Methoden}

\section{III.3.1. Hitzeschock-Transformation von DNA in kompetente E. coli- Zellen}

Die Hitzeschock-Transformation wurde durchgeführt, um kompetenten Zellen fremde Plasmid-DNA zuzuführen. Dazu wurde zunächst ein Aliquot mit $100 \mu \mathrm{l}$ an kompetenten Zellen auf Eis aufgetaut. Auf die Zugabe des gesamten Ligationsansatzes zu den Zellen folgte eine 30-minütige Inkubation auf Eis. Daraufhin wurden die Zellen 30 Sekunden bei $42^{\circ} \mathrm{C}$ einem Hitzeschock ausgesetzt und der Reaktionsansatz sofort danach für 5 min auf Eis gestellt. Der 
gesamte Ansatz wurde auf Agar-Platten, die zu Selektionszwecken ein oder mehrere Antibiotika enthielten, ausplattiert. Wurde die DNA in E. coli XL2-blue (Stratagene) eingebracht, diente Ampicillin $(80 \mu \mathrm{g} / \mathrm{ml})$ als Antibiotikum. Im Falle von E. coli BL21(DE3)-CodonPlus (Stratagene) kam zusätzlich Chloramphenicol (35 $\mu \mathrm{g} / \mathrm{ml})$ zum Einsatz. Die Platten wurden anschließend mit dem Deckel nach unten über Nacht bei $37^{\circ} \mathrm{C}$ inkubiert.

\section{III.3.2. Kultivierung und Lagerung von transformierten Bakterien}

Nach der Transformation wurden Einzelkolonien gepickt und in mit $4 \mathrm{ml}$ Selektivmedium befüllte Greinerröhrchen überführt. Die Zellkulturen wurden daraufhin über Nacht bei $37^{\circ} \mathrm{C}$ schüttelnd inkubiert. Um einen Glyzerinstock herzustellen wurden in einem $2 \mathrm{ml}$ Reaktionsgefäß $800 \mu \mathrm{l}$ einer Übernachtkultur mit $200 \mu \mathrm{l}$ Glyzerin vermengt. Der Ansatz wurde gut durchmischt, in flüssigem Stickstoff schockgefroren und bei $-80^{\circ} \mathrm{C}$ gelagert.

\section{III.3.3. Mini- und Midi-Präparation von Plasmid-DNA}

Mini- und Midi-Präparationen wurden unter Verwendung des NucleoSpin ${ }^{\circledR}$ Plasmid-Kits bzw. des NucleoBond ${ }^{\circledR}$ PC-100-Kits von Macherey-Nagel durchgeführt. Dabei wurde jeweils nach Herstellerangaben verfahren (Plasmid DNA Purification User Manual, 2011, Macherey-Nagel). Die Mini-Präparation diente dazu, die Transformanten mittels anschließendem Restriktionsverdau auf den Gehalt an richtigem Expressionsplasmid zu testen. In den Test wurden $2 \mathrm{ml}$ einer entsprechend beimpften E. coli Übernachtkultur eingesetzt. Das korrekte Expressionsplasmid wurde daraufhin mittels Midi-Präparation im größeren Maßstab isoliert. Dazu wurde in der Regel von $100 \mathrm{ml}$ einer E. coli Übernachtkultur Gebrauch gemacht. 


\section{III.3.4. Konzentrationsbestimmung von DNA}

Zur Bestimmung der DNA-Konzentration wurde die Absorption der entsprechenden Probe an einem Spektralphotometer bei einer Wellenlänge von $260 \mathrm{~nm}$ gemessen. Dazu wurden in der Regel $5 \mu$ DNA in $995 \mu$ l TE-Puffer gelöst $(\rightarrow$ Verdünnung 1:200). Die Messung erfolgte in einer Quarzküvette, wobei TEPuffer als Referenz diente. Aus der ermittelten Absorption bei $260 \mathrm{~nm}$ kann die

DNA-Konzentration berechnet werden: $A_{260}=1$ entspricht $50 \mu \mathrm{g}$ an doppelsträngiger DNA (Sambrook et al, 1989). Wird zudem $A_{280}$ (Absorptionsmaximum von Proteinen) gemessen, können über das Verhältnis von $A_{260} / A_{280}$ Rückschlüsse auf den Reinheitsgrad der Probe gezogen werden. Bei Werten von 1.8-2.0 galt die DNA als rein. Höhere Werte deuten auf Kontamination durch RNA hin, niedrigere Werte sind ein Anzeichen für Proteinverunreinigung.

\section{III.3.5. DNA-Sequenzierung}

Die DNA-Sequenzierung erfolgte extern durch die Firma Eurofins MWG Operon (Ebersberg). Dazu wurden $2 \mu \mathrm{g}$ der DNA in $20 \mu \mathrm{l}$ autoklaviertem Wasser gelöst $(\rightarrow$ Konzentration: $100 \mathrm{ng} / \mu \mathrm{l}$ ) und zusammen mit den Sequenzierprimern zur Sequenzanalyse verschickt. Mit Hilfe des Programms BioEdit (Ibis Biosciences, USA) wurden die erhaltenen Sequenzen über ein Sequenzalignment mit der jeweiligen Gen-/Vektorsequenz verglichen.

\section{III.3.6. Bestimmung der Proteinkonzentration}

Zur Bestimmung der Proteinkonzentration wurde ein Bradford-Test durchgeführt (Bradford, 1976). Für den Messvorgang wurden kleine Mengen der Proteinlösung $(1-10 \mu \mathrm{l})$ mit Wasser auf ein Endvolumen von $20 \mu \mathrm{l}$ gebracht und daraufhin in eine Einmalküvette (Plastibrand ${ }^{\circledR}$ PS, Roth) mit $980 \mu \mathrm{l}$ Bradford-Reagenz überführt. Der Ansatz wurde sorgfältig gemischt und 5 Minuten im Dunkeln 
inkubiert. Anschließend erfolgte die Bestimmung der Absorption in einem Spektralphotometer bei einer Wellenlänge von $595 \mathrm{~nm}$. Über eine Proteinstandardkurve, die mit definierten Mengen an RinderserumalbuminLösung (BSA) erstellt wurde, konnte anhand der gemessenen Absorptionswerte der Proteingehalt der jeweiligen Probe ermittelt werden.

\section{III.3.7. Kultivierung von Dictyostelium discoideum}

Zur Anzucht wurden Dictyostelium-Zellen in Petrischalen unter $10 \mathrm{ml} \mathrm{HL-5c}$ Medium in Gegenwart von Penicillin $(100 \mathrm{U} / \mathrm{ml})$ und Streptomycin $(100 \mu \mathrm{g} / \mathrm{ml})$ gehalten. Bei Erreichen der Konfluenz (in der Regel nach 3 Tagen) wurden die Platten mit frischem Medium versetzt, nachdem ein Großteil der Zellen durch Abspülen mit HL-5c Medium entfernt worden war. Mit diesen Zellen wurden gegebenenfalls neue Petrischalen angeimpft, oder sie wurden zur weiteren Anzucht in Schüttelkulturen verwendet. Für die präparative Proteinaufreinigung erfolgte die Anzucht der AX3-ORF ${ }^{+}$-Zellen in Erlemeyerkolben (100 ml bis $5 \mathrm{I}$ ) in Schüttelkultur. Die Zellen wurden dabei bis zu einer Dichte von $7 \cdot 10^{6}$ bis $1 \cdot 10^{7}$ bei $22^{\circ} \mathrm{C}$ und $180 \mathrm{Upm}$ kultiviert. Die Generationszeit der Zellen divergierte abhängig von dem zu exprimierenden Fusionskonstrukt zwischen 8 und 20 Stunden.

\section{III.3.8. Transformation von Dictyostelium discoideum}

AX3-ORF ${ }^{+}$-Zellen wurden bis zu einer Dichte von $2-3 \cdot 10^{6}$ Zellen/ml kultiviert. Daraufhin wurden sie durch 5-minütige Zentrifugation bei $1.000 \mathrm{~g}$ geerntet. Nach zweimaligem Waschen mit kaltem Elektroporationspuffer (10 mM K-Phosphat, $\mathrm{pH}$ 6.1; $50 \mathrm{mM}$ Saccharose) wurden die Zellen im gleichen Puffer zu einer Endkonzentration von $2 \cdot 10^{7}$ Zellen $/ \mathrm{ml}$ resuspendiert. $0.8 \mathrm{ml}$ dieser ZellSuspension wurden mit 20-40 $\mu \mathrm{g}$ DNA vermischt und in eine vorgekühlte $0.4 \mathrm{~cm}$ Elektroporationsküvette (Biozym Scientific $\mathrm{GmbH}$ ) transferiert. Die Elektroporation erfolgte bei einer Spannung von $1.2 \mathrm{kV}$, einer Kondensator- 
kapazität von $3 \mu \mathrm{F}$ und einem Widerstand von $600 \Omega$. Die sich daraus ergebenden Zeitkonstanten bewegten sich um den Wert $0.7 \mathrm{~ms}$. Sofort danach wurde die Elektroporationsküvette für 10 Minuten auf Eis gestellt und anschließend je $300 \mu \mathrm{l}$ der Zell-Suspension in zwei zuvor mit $10 \mathrm{ml} \mathrm{HL-5c}$ Medium gefüllte $10 \mathrm{~cm}$ Petrischale überführt. Um Selektionsdruck auf die transformierten Zellen auszuüben, wurde das Medium nach einer Erholungsphase von 24 Stunden durch HL-5c Medium, versetzt mit 5 oder 10 $\mu \mathrm{g} / \mathrm{ml}$ Geneticin, ausgetauscht. Die in dieser Arbeit verwendeten Vektoren für Dictyostelium (pDXA-mako1, pDXA-mako2b) enthalten ein Gen für G418, so dass die Transformanten mit 5 bis $10 \mu \mathrm{g} / \mathrm{ml}$ G418 selektiert werden können.

\section{III.3.9. Konservierung von Dictyostelium-Sporen}

AX3-ORF ${ }^{+}$-Zellen wurden axenisch bis zu einer Dichte von $3-5 \cdot 10^{6}$ Zellen $/ \mathrm{ml}$ kultiviert und daraufhin für 5 Minuten bei $1.000 \mathrm{~g}$ zentrifugiert. Die Zellen wurden zwei Mal mit kaltem MES-Puffer (20 mM MES, pH 6.8; $0.2 \mathrm{mM} \mathrm{CaCl}_{2}, 2 \mathrm{mM}$ $\mathrm{MgCl}_{2}$ ) gewaschen und mit dem gleichen Puffer auf eine Dichte von $2 \cdot 10^{8}$ Zellen/ml resuspendiert. Von dieser Zellsuspension wurde dann $1 \mathrm{ml}$ auf einer 10 cm MES-Agar Platte (MES-Puffer plus $2 \%$ Agar) ausgebracht. Die Platten wurden so lange offen unter dem Abzug stehen gelassen, bis der Agar nicht mehr nass aber noch glänzend war. Danach wurden sie mit dem Deckel nach unten gelagert, bis sich die Zellen entwickelt und Fruchtkörper ausgebildet haben (in der Regel nach 3-4 Tage). Die Sporen wurden durch kräftiges Abklopfen im Deckel der Petrischale gesammelt und in $1 \mathrm{ml} 10 \%$ iger Glyzerol-Lösung aufgenommen. Anschließend wurden $100 \mu \mathrm{l}$ Aliquots bei $-80^{\circ} \mathrm{C}$ eingefroren. Zum Animpfen wurde ein Aliquot bei RT aufgetaut und zur Regeneration in eine mit $1 \mathrm{ml} \mathrm{HI}-5 \mathrm{c}$ Medium gefültten Vertiefung einer 24-Multi-Well-Platte (Greiner) gegeben. Nach 24 Stunden bei $22^{\circ} \mathrm{C}$ wurde das Medium dann gegen HL-5c Medium, versetzt mit der entsprechenden Menge an Geneticin (G418), gewechselt. Nach Erreichen der Konfluenz wurden die Zellen in eine Petrischale mit $10 \mathrm{ml}$ Resistenzmedium überführt. 


\section{III.4. Proteinchemische Methoden}

\section{III.4.1. Analytische Reinigung von DHC-Konstrukten aus Dictyostelium-Zellen}

Von einer dicht bewachsenen Petrischale $(10 \mathrm{~cm})$ mit Dictyostelium-Zellen des Stammes $\mathrm{AX}-\mathrm{ORF}^{+}$wurde das Nährmedium abgezogen. Daraufhin wurden die Zellen auf der Platte in $1 \mathrm{ml}$ Bonner's Lösung $(10 \mathrm{mM} \mathrm{NaCl}, 10 \mathrm{mM} \mathrm{KCl}, 2 \mathrm{mM}$ $\mathrm{CaCl}_{2}$ ) aufgenommen und in einem $1.5 \mathrm{ml}$ Eppendorf-Cup 10 Minuten bei $600 \mathrm{~g}$ zentrifugiert. Der Überstand wurde verworfen und die Zellen in $0.5 \mathrm{ml}$ eiskaltem Lyse-Puffer resuspendiert (Lyse-Puffer: $50 \mathrm{mM}$ Tris. $\mathrm{HCl}$, pH 8.0; $2 \mathrm{mM}$ EDTA; 0.2 mM EGTA; 1 mM DTT; 5 mM Benzamidin; 40 $\mathrm{g} / \mathrm{ml}$ TLCK; 1:100 Protease Inhibitor Mix 1; $10 \mu \mathrm{M}$ PMSF). Im Anschluss daran wurde der Ansatz mit $0.5 \mathrm{ml}$ eiskaltem Lyse-Puffer, dem $1 \%$ Nonidet P-40 und $15 \mu \mathrm{g} / \mathrm{ml}$ RNase (auf das Endvolumen bezogen) zugegeben wurde, versetzt und gut gemischt. Nach 10minütiger Zentrifugation bei $16.100 \mathrm{~g}$ bei $4^{\circ} \mathrm{C}$ wurden Überstand und Sediment mittels SDS-Gelelektrophorese analysiert.

\section{III.4.2. Analytische Reinigung von Myosin-Motor-Fusionsproteinen aus Dictyostelium-Zellen}

Von einer dicht bewachsenen Petrischale $(10 \mathrm{~cm})$ mit Dictyostelium-Zellen des Stammes AX3-ORF ${ }^{+}$wurde das Nährmedium abgezogen. Daraufhin wurden die Zellen auf der Platte in $1 \mathrm{ml}$ Bonner`s Lösung aufgenommen und in einem $1.5 \mathrm{ml}$ Eppendorf-Cup 10 Minuten bei $600 \mathrm{~g}$ zentrifugiert. Der Überstand wurde verworfen und die Zellen in $0.5 \mathrm{ml}$ eiskaltem Lyse-Puffer resuspendiert (LysePuffer: $50 \mathrm{mM}$ Tris $\cdot \mathrm{HCl}$, pH 8.0; 2 mM EDTA; $0.2 \mathrm{mM}$ EGTA; $1 \mathrm{mM}$ DTT; $5 \mathrm{mM}$ Benzamidin; $40 \mu \mathrm{g} / \mathrm{ml}$ TLCK; 1:100 Protease Inhibitor Mix 1 (10 mg/ml TAME, $8 \mathrm{mg} / \mathrm{ml}$ TPCK, $0.2 \mathrm{mg} / \mathrm{ml}$ Pepstatin, $0.5 \mathrm{mg} / \mathrm{ml}$ Leupeptin); $10 \mu \mathrm{M}$ PMSF). Im 
Anschluss daran wurde der Ansatz mit $0.5 \mathrm{ml}$ eiskaltem Lyse-Puffer, dem $1 \%$ Nonidet P-40, $15 \mu \mathrm{g} / \mathrm{ml}$ RNase (auf das Endvolumen bezogen) und $1 \mathrm{U}$ alkalische Phosphatase zugegeben wurde, versetzt und gut gemischt. Nach 10 -minütiger Zentrifugation bei $16.100 \mathrm{~g}$ bei $4^{\circ} \mathrm{C}$ wurde das Pellet in $100 \mu \mathrm{l}$ eiskaltem Extraktions-Puffer (50 mM HEPES. $\mathrm{NaOH}, \mathrm{pH}$ 7.3; $100 \mathrm{mM} \mathrm{NaCl} ; 30$ $\mathrm{mM} \mathrm{KAc} ; 10 \mathrm{mM} \mathrm{MgAc}$; $5 \mathrm{mM}$ Benzamidin; $20 \mathrm{mM} \mathrm{ATP)}$ homogenisiert und erneut für 10 Minuten bei $16.100 \mathrm{~g}$ bei $4^{\circ} \mathrm{C}$ zentrifugiert. Schließlich wurden Überstand und Sediment mittels SDS-Gelelektrophorese analysiert.

\section{III.4.3. Aufreinigung der Fusionskonstrukte ecke1MMD_Dd und ecke10MMD_Hs}

\section{III.4.3.1. Präparative Aufreinigung}

Als Ausgangsmaterial zur präparativen Aufreinigung der Myosin-Fusionsproteine dienten Dictyostelium-Zellen des Stammes AX3-ORF ${ }^{+}$, die in $\mathrm{HL}-5 \mathrm{c}$ Medium, versetzt mit Penicillin/Streptomycin-Lösung und $5 \mathrm{bzw} .10 \mu \mathrm{g} / \mathrm{ml}$ Geneticin, bis zu einer Dichte von $6 \cdot 10^{6}-1 \cdot 10^{7}$ Zellen/ml angezogen wurden. Die Kultur wurde 8 Minuten bei $1.500 \mathrm{~g}$ zentrifugiert und das Zell-Pellet mit eiskaltem PBS-Puffer (80 mM Na $2 \mathrm{HPO}_{4}, \mathrm{pH} 7.4 ; 20 \mathrm{mM} \mathrm{NaH}{ }_{2} \mathrm{PO}_{4} ; 100 \mathrm{mM} \mathrm{NaCl}$ ) gewaschen. Nach erneuter Zentrifugation wurde das Nass-Gewicht der gesammelten Zellen bestimmt und diese in $4 \mathrm{ml}$ eiskaltem Lyse-Puffer pro Gramm Zellen resuspendiert (Lyse-Puffer: $50 \mathrm{mM}$ Tris. $\mathrm{HCl}, \mathrm{pH}$ 8.0; $2 \mathrm{mM}$ EDTA; $0.2 \mathrm{mM}$ EGTA; $1 \mathrm{mM}$ DTT; $5 \mathrm{mM}$ Benzamidin; $40 \mu \mathrm{g} / \mathrm{ml}$ TLCK; 1:100 Protease Inhibitor Mix 1, $10 \mu \mathrm{M}$ PMSF). Anschließend wurden der Suspension $2 \mathrm{ml}$ eiskalter LysePuffer pro Gramm Zellen, versetzt mit $1 \%$ Nonidet P-40, $15 \mu \mathrm{g} / \mathrm{ml}$ RNase (auf das Endvolumen bezogen) und $100 \mathrm{U}$ alkalischer Phosphatase, zugegeben und der Ansatz gemischt. Das Lysat wurde für 40 Minuten bei $40.000 \mathrm{~g}$ bei $4^{\circ} \mathrm{C}$ zentrifugiert. Der Überstand wurde verworfen und das Sediment in $120 \mathrm{ml}$ eiskaltem Extraktions-Puffer (50 mM HEPES. $\mathrm{NaOH}, \mathrm{pH}$ 7.3; $100 \mathrm{mM} \mathrm{NaCl}$; $30 \mathrm{mM} \mathrm{KAc} ; 10 \mathrm{mM} \mathrm{MgAc} ; 5 \mathrm{mM}$ Benzamidin; $10 \mu \mathrm{M}$ PMSF) resuspendiert. Nach erneuter Zentrifugation für 40 Minuten bei $40.000 \mathrm{~g}$ wurde das Pellet in 
$3 \mathrm{ml}$ eiskaltem Extraktions-Puffer pro Gramm Zellen, versetzt mit $20 \mathrm{mM}$ ATP, gründlich homogenisiert. Das Homogenisat wurde schließlich für 60 min bei $45.000 \mathrm{~g}$ bei $4^{\circ} \mathrm{C}$ zentrifugiert und der Überstand bei einer Flussrate von $1 \mathrm{ml} / \mathrm{min}$ bei $4^{\circ} \mathrm{C}$ auf eine mit Niedrig-Salz-Puffer (50 mM HEPES. $\mathrm{NaOH}$, pH 7.3; $30 \mathrm{mM}$ KAc) äquilibrierte $\mathrm{Ni}^{2+}$-NTA Säule (XK16/40, GE Healthcare) gegeben. Die Säule wurde daraufhin bei einer Flussrate von $2 \mathrm{ml} / \mathrm{min}$ mit 8 Säulenvolumina NiedrigSalz-Puffer, gefolgt von 10 Säulenvolumina Hoch-Salz-Puffer (50 mM HEPES. $\mathrm{NaOH}, \mathrm{pH}$ 7.3; $300 \mathrm{mM} \mathrm{KAc)}$ und 10 Säulenvolumina Niedrig-SalzPuffer, versetzt mit $45 \mathrm{mM}$ Imidazol, gewaschen. Das gebundene Fusionsprotein wurde mit einem linear ansteigenden Gradienten aus Niedrig-Salz-Puffer und Imidazol-Puffer $(0.5 \mathrm{M}$ Imidazol. $\mathrm{HCl}, \mathrm{pH} 7.3)$, der sich über 6 Säulenvolumina erstreckte, von der Säule eluiert und in $1 \mathrm{ml}$ Fraktionen gesammelt. Die Fraktionen wurden anschließend mittels SDS-Gelelektrophorese analysiert, die Protein-enthaltenden Fraktionen vereinigt und über Nacht bei $4^{\circ} \mathrm{C}$ gegen Gelfiltrations-Puffer (50 mM Tris. $\mathrm{NaOH}, \mathrm{pH} 8.0 ; 100 \mathrm{mM} \mathrm{NaCl} ; 1 \mathrm{mM} \mathrm{MgAc}$, 0.5 mM EDTA, $0.1 \mathrm{mM}$ EGTA, $1 \mathrm{mM}$ DTT) dialysiert. Am nächsten Morgen wurde die dialysierte Probe mithilfe eines Vivaspin-Konzentrators (100.000 MWCO) eingeengt. Danach wurde die mit Gelfiltrations-Puffer voräquilibrierte Gelfiltrationssäule (Hi Load 16/60 Superdex 200, GE Healtcare) mit der Proteinlösung beladen, wobei die Elution bei einer Flussrate von $0.5 \mathrm{ml} / \mathrm{min}$ erfolgte. Die Myosin-Fusionsprotein-haltigen Fraktionen wurden vereinigt, aufkonzentriert und in Kristallisationstests eingesetzt.

\section{III.4.3.2. Optimierte Aufreinigung und reduktive Methylierung von ecke1MMD_Dd}

Das Protein wurde, wie oben beschrieben, über $\mathrm{Ni}^{2+}$-NTA-Chromatographie aufgereinigt und über Nacht bei $4^{\circ} \mathrm{C}$ gegen Niedrig-Salz-lonenaustausch-Puffer (50 mM KP, pH 7.0; 100 mM NaCl) dialysiert. Am nächsten Morgen wurde die dialysierte Probe unter Verwendung eines Vivaspin-Konzentrators (MWCO 100.000) auf ein Volumen von $8 \mathrm{ml}$ gebracht und im Batch-Verfahren mit 
keramischem Hydroxylapatit (Typ1, Sigma) aufgereinigt. Dazu wurde die Probe in eine Plastik-Handsäule (20 ml, Disposable Plastic Columns, Pierce) überführt, die zuvor mit $2 \mathrm{ml}$ voräquilibriertem Hydroxylapatit $(50 \mathrm{mM} \mathrm{KP}$, pH 7.0; $100 \mathrm{mM}$ $\mathrm{NaCl}$ ) beladen worden war. Um eine gute Durchmischung zu gewährleisten, wurde der Ansatz für 40 Minuten bei $4^{\circ} \mathrm{C}$ im Kühlraum auf einem Schüttler inkubiert. Das Säulenmaterial wurde mit 8 Säulenvolumina Niedrig-Salz-Puffer (50 mM KP, pH 7.0; 100 mM NaCl), gefolgt von 8 Säulenvolumina Hoch-SalzPuffer (100 mM KP, pH 7.0; 600 mM NaCl) gewaschen. Das gebundene Protein

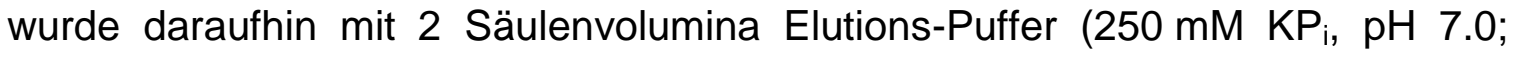
$800 \mathrm{mM} \mathrm{NaCl}$ ) eluiert. Anschließend wurde das Protein so weit verdünnt, dass es erneut in Niedrig-Salz-Puffer $(50 \mathrm{mM} \mathrm{KP}$, pH 8.0; $100 \mathrm{mM} \mathrm{NaCl}$ ) vorlag. Nachdem die Probe mittels eines Vivaspin-Konzentrators (MWCO 100.000) auf $10 \mathrm{mg} / \mathrm{ml}$ eingeengt worden war, wurde sie reduktiv methyliert. Hierfür wurden folgende Lösungen frisch hergestellt:

- $1 \mathrm{M}$ DMAB in $50 \mathrm{mM} \mathrm{NaP}$, $\mathrm{pH} 7.0$

- $1 \mathrm{M}$ Formaldehyd in $50 \mathrm{mM} \mathrm{NaP}$, $\mathrm{pH} 7.0$

- $1 \mathrm{M}$ Ammoniumsulfat in $50 \mathrm{mM} \mathrm{NaP}, \mathrm{pH} 7.0$

Alle Arbeitsschritte erfolgten auf Eis. Die Inkubationen wurden im Dunkeln durchgeführt. Um das Protein chemisch zu modifizieren, wurde je $1 \mathrm{ml}$ der konzentrierten Proteinlösung mit $20 \mu \mathrm{LMAB}$ versetzt, die Lösung kurz gemischt und dann sofort $40 \mu \mathrm{l}$ Formaldehyd zugegeben. Nach erneut vorsichtigem Vermengen wurde der Ansatz 2 Stunden auf Eis inkubiert. Dieser Schritt wurde noch einmal wiederholt. Es folgte die Zugabe von $10 \mu \mathrm{L}$ DMA zur Probe, die anschließend über Nacht auf einem Schüttler inkubiert wurde. Am nächsten Morgen wurde der Ansatz mit $100 \mu \mathrm{l}$ Ammoniumsulfat versetzt, um das restliche Formaldehyd zu binden. Die Reaktion war nach einer Stunde abgeschlossen. Nach einem abschließenden Gelfiltrationslauf wurde die Probe aufkonzentriert und in Kristallisationstests eingesetzt. 


\section{III.4.4. Bindungstests der Fusionskonstrukte an verschiedene Säulenmaterialien}

Für Bindungstests wurden die Fusionsproteine, wie in Punkt III.4.3. beschrieben, extrahiert, wobei das Endvolumen $500 \mu \mathrm{l}$ betrug. Zur Aufreinigung kamen kleine Plastik-Handsäulchen (10 ml; Disposable Plastic Columns, Pierce) zum Einsatz, die mit $200 \mu \mathrm{l}$ des jeweils voräquilibrierten Säulenmaterials $\left(\mathrm{Ni}^{2+}-\mathrm{NTA}, \mathrm{Co}^{2+}-\mathrm{NTA}\right.$, $\mathrm{Ni}^{2+}-$ IDA, DEAE, SP, Hydroxylapatit) beladen wurden. Daraufhin wurde das Protein auf die Säule gegeben, diese abgedichtet und der Ansatz für 40 Minuten bei $4^{\circ} \mathrm{C}$ im Kühlraum auf einem Schüttler inkubiert. Nach Auffangen des Durchflusses und anschließendem Spülen des Säulenmaterials wurde das gebundene Protein eluiert. Schließlich wurden Durchlauf-, Wasch- und Elutionsproben mittels SDS-Gelelektrophorese analysiert.

\section{III.4.5. Abspaltung der Myosin-Motor-Domäne von den Fusions- proteinen}

Zur Abspaltung des Myosin-Tags von den Fusionskonstrukten wurde die TEVSchnittstelle genutzt, die sich zwischen dem DHC-Konstrukt und der N-terminal lokalisierten MMD befindet. Hierfür wurde das über $\mathrm{Ni}^{2+}$-NTA-Chromatographie vorgereinigte Protein mit jeweils $10 \mu \mathrm{g}$ TEV-Protease pro mg Protein versetzt. Im Anschluss wurde die Proteinlösung über Nacht bei $4^{\circ} \mathrm{C}$ im Kühlraum gegen TEVSpaltpuffer (20 mM Tris, pH 8.0; $200 \mathrm{mM} \mathrm{NaCl}$ ) dialysiert. Am nächsten Morgen wurde der Verdau auf eine $\mathrm{Ni}^{2+}$-NTA-Säule aufgetragen. Da sowohl MMD als auch TEV-Protease mit einem Histidin-Tag ausgestattet waren, banden sie an die Säulenmatrix. Das DHC-Konstrukt hingegen lief durch die Säule, wodurch es von Enzym und Myosin-Tag separiert werden konnte.

\section{III.4.6. Abspaltung des Histidin-Tags von den Fusionsproteinen}


Zur Abspaltung des Histidin-Tags wurde die Thrombin-Schnittstelle genutzt, die sich zwischen dem Myosin-Fusionskonstrukt und dem N-terminal lokalisierten Histidin-Tag befindet. Hierfür wurde das über $\mathrm{Ni}^{2+}$-NTA-Chromatographie vorgereinigte Protein mit jeweils $15 \mathrm{U}$ Thrombin pro $\mathrm{mg}$ Protein versetzt. Daraufhin wurde die Proteinlösung über Nacht bei $4^{\circ} \mathrm{C}$ im Kühlraum gegen Thrombin-Spaltpuffer (50 mM Tris. $\mathrm{NaOH}, \mathrm{pH} 8.0 ; 100 \mathrm{mM} \mathrm{NaCl} ; 1 \mathrm{mM}$ DTT) dialysiert. Am nächsten Morgen wurde der Verdau auf eine $\mathrm{Ni}^{2+}-\mathrm{NTA}$-Säule gegeben, um unvollständig verdautes Protein von Histidin-Tag-freiem Protein zu trennen. Der Durchfluss wurde aufkonzentriert und auf eine Gelfiltrationssäule geladen, wodurch eine Separation von Protein und Restriktionsenzym erreicht wurde.

\section{III.4.7. Expressionstests von DHC-Konstrukten in E. coli-Zellen}

Anhand von Expressionstests sollte ermittelt werden, ob die Konstrukte der zytoplasmatischen DHC von Mensch und Dictyostelium discoideum löslich in E. coli exprimiert werden. Dazu wurden entsprechende Kolonien des E. coli Stammes BL21(DE3)-CodonPlus von Platte in jeweils $20 \mathrm{ml}$ LB-Amp-Cam Medium überführt und bei $37^{\circ} \mathrm{C}$ im Schüttler (150 Upm) angezogen. Nach Erreichen einer $\mathrm{OD}_{600}$ von $0.4-0.6$ wurde die jeweilige Kultur mit 0.1 bzw. $0.2 \mathrm{mM}$ IPTG versetzt, um die Proteinexpression zu induzieren. Die Expressionstemperatur betrug 25 bzw. $37^{\circ} \mathrm{C}$. Als Kontrollansatz wurden Zellen verwendet, deren Anzucht bis auf die Zugabe von IPTG analog erfolgte. Im Anschluss daran wurden die Ansätze für 10 Minuten bei $6.000 \mathrm{~g}$ zentrifugiert, mit jeweils $1 \mathrm{ml}$ Lyse-Puffer (20 mM Hepes, 7.3; $50 \mathrm{mM} \mathrm{NaCl}, 1 \mathrm{mM}$ DTT) resuspendiert und mittels Ultraschall aufgeschlossen. Dabei wurden die Suspensionen jeweils dreimal für 30 Sekunden bei einer Intensität von $50 \%$ beschallt. Nach jedem Durchgang wurde den Proben, die während des gesamten Aufschlusses auf Eis lagerten, eine Abkühlungszeit von 60 Sekunden gewährt. Nach erfolgtem Aufschluss wurden die Suspensionen jeweils mit einer Spatelspitze DNase 
versetzt und für 15 Minuten bei $16.000 \mathrm{~g}$ zentrifugiert. Schließlich wurden die Proben mittels SDS-PAGE auf Expressionsstärke und Löslichkeit untersucht.

\section{III.4.8. Rekombinante Expression von Cap32/34 in E. coli-Zellen}

Für die bakterielle Überexpression von Cap32/34 wurde der auf pETDuet $^{\mathrm{TM}}{ }_{-1}$ (Novagen) basierende Vektor pETmD1-mako gewählt. Das Plasmid enthält zwei multiple Klonierungsstellen (MCS), in die je ein Ziel-Gen eingebracht werden kann. MCS1 fusioniert N-terminal einen Hexa-Histidin-Tag an das einklonierte Gen, wodurch eine spezifische Aufreinigung des Genprodukts über $\mathrm{Ni}^{2+}$ Affinitäts-Chromatographie ermöglicht wird. Für die Anzucht der Zellen wurde eine Einzelkolonie des E. coli Stammes BL21(DE3)-CodonPlus von Platte in $50 \mathrm{ml}$ LB-Amp-Cam-Medium überführt. Die Kultur wurde über Nacht bei $37^{\circ} \mathrm{C}$ und $150 \mathrm{Upm}$ geschüttelt. Am darauffolgenden Tag wurde die gesamte Vorkultur zu 1 I LB-Amp-Cam-Medium zugegeben und anschließend in einem $5 \mathrm{I}$ Schikanen-Kolben im Schüttler bei $120 \mathrm{Upm}$ und $37^{\circ} \mathrm{C}$ bis zu einer $\mathrm{OD}_{600}$ von 0.4-0.6 kultiviert. Für die Induktion der Proteinexpression wurde IPTG in einer Endkonzentration von $0.2 \mathrm{mM}$ verwendet und die Kultur über Nacht bei $22^{\circ} \mathrm{C}$ weiter geschüttelt. Danach wurden die Zellen durch Zentrifugation für 15 min bei $6.000 \mathrm{~g}$ geerntet und in $4 \mathrm{ml}$ Lyse-Puffer (20 mM Hepes, 7.3; $50 \mathrm{mM} \mathrm{NaCl}, 1 \mathrm{mM}$ DTT, $1 / 2$ Tablette Protease-Inhibitor) pro Gramm Zellen resuspendiert. Es folgte Zellaufschluss über Ultraschall. Dabei wurde die Suspension dreimal für jeweils 30 Sekunden bei einer Intensität von $70 \%$ beschallt. Nach jedem Durchgang wurde dem Ansatz, der während des gesamten Aufschlusses auf Eis lagerte, eine Abkühlungszeit von 60 Sekunden gewährt. Nach dem Aufschluss wurde die Suspension mit einer Spatelspitze DNase versetzt und für 40 Minuten bei 30.000 $\mathrm{g}$ zentrifugiert. Der Überstand wurde bei einer Flussrate von $1 \mathrm{ml} / \mathrm{min}$ bei $4^{\circ} \mathrm{C}$ auf eine mit Niedrig-Salz-Puffer (50 mM HEPES. $\mathrm{NaOH}, \mathrm{pH}$ 7.3; $30 \mathrm{mM} \mathrm{KAc}$ ) äquilibrierte $\mathrm{Ni}^{2+}$-NTA Säule gegeben. Die Säule wurde daraufhin bei einer Flussrate von $2 \mathrm{ml} / \mathrm{min}$ mit 8 Säulenvolumina Niedrig-Salz-Puffer, gefolgt von 10 Säulenvolumina Hoch-Salz-Puffer (50 mM HEPES-NaOH, pH 7.3; 300 mM KAc) 
und 10 Säulenvolumina Niedrig-Salz-Puffer, versetzt mit $45 \mathrm{mM}$ Imidazol, gewaschen. Das gebundene Protein wurde mit einem linear ansteigenden Gradienten aus Niedrig-Salz-Puffer und Imidazol-Puffer $(0.5 \mathrm{M}$ Imidazol-HCl, $\mathrm{pH}$ 7.3), der sich über 6 Säulenvolumina erstreckte, von der Säule eluiert und in $1 \mathrm{ml}$ Fraktionen gesammelt. Die Fraktionen wurden mittels SDS-Gelelektrophorese analysiert, die Protein-enthaltenden Fraktionen vereinigt und über Nacht bei $4^{\circ} \mathrm{C}$ gegen Gelfiltrations-Puffer (20 mM Hepes, $\mathrm{pH}$ 7.3; $100 \mathrm{mM} \mathrm{NaCl} ; 1 \mathrm{mM} \mathrm{MgAc}$, $0.5 \mathrm{mM}$ EDTA, $0.1 \mathrm{mM}$ EGTA, $1 \mathrm{mM}$ DTT) dialysiert. Am nächsten Morgen wurde die dialysierte Probe mithilfe eines Vivaspin-Konzentrators (30.000 MWCO) eingeengt und ein Gelfiltrationslauf durchgeführt. Die mit GelfiltrationsPuffer voräquilibrierte Gelfiltrationssäule wurde anschließend mit der Proteinlösung beladen, wobei die Elution bei einer Flussrate von $0.5 \mathrm{ml} / \mathrm{min}$. erfolgte. Die Protein-enthaltenden Fraktionen wurden vereinigt, aufkonzentriert und in Kristallisationstests eingesetzt.

\section{III.4.9. PIP-Strip-Inkubationstest}

Bei den PIP-Strips der Firma Echelon (USA) handelt es sich um hydrophobe Membranen, auf deren Oberfläche verschiedene Phospholipide in einer Konzentration von jeweils 100 pmol aufgebracht sind. Die Membranen wurden lichtgeschützt mit PBS inklusive $3 \%$ BSA (fettsäurefrei) für $1 \mathrm{~h}$ schüttelnd bei RT blockiert und nach Zugabe des zu untersuchenden Proteins $(10-100 \mu \mathrm{g} / \mathrm{ml}$ in PBS) entweder für $1 \mathrm{~h}$ bei RT oder über Nacht bei $4^{\circ} \mathrm{C}$ im Dunkeln geschwenkt. Nach 3-maligem Waschen mit PBS wurde die Membran mit einem peroxidgekoppelten anti-Histidin-Antikörper (1:500-1:5000 in PBS) für $2 \mathrm{~h}$ bei RT inkubiert und 3x mit PBS gewaschen. Gebundenes Protein wurde mittels Chemilumineszenz detektiert.

\section{III.5. Kristallographische Methoden}




\section{III.5.1. Kristallisationsexperimente}

Für Kristallisationsexperimente fand die Methode der Dampfdiffusion im sitzenden oder im hängenden Tropfen Verwendung. Die Tropfen wurden dabei entweder auf einem Plateau (Sitting-Drop) oder auf einem Deckglas (HangingDrop), welches daraufhin invertiert wurde, platziert. Im 96-Well-Maßstab wurden die Kristallisationsplatten (Low-Profile, Greiner) über ein automatisches Pipettiersystem (Mosquito, Molecular Dimensions) nach der Hanging-Drop Methode mit Protein und Präzipitant im Verhältnis 1:1 $(0.2 \mu \mathrm{l}+0.2 \mu \mathrm{l})$ beladen, wobei das Reservoirvolumen $100 \mu \mathrm{l}$ betrug. In späteren Optimierungsansätzen wurden auch andere Verhältnisse von Protein zu Fällungsmittel (2:1, 1:2) gewählt. Um ein abgeschlossenes System zu gewährleisten, wurden die Platten mit einer transparenten Folie abgedichtet (View Seal, Greiner). Zur Kristallisation im hängenden Tropfen wurden 24-Well Platten (VDX-Platten, Hampton Research) herangezogen, deren Reservoir-Ränder mit Silikonfett benetzt wurden. Dabei wurden Protein und Fällungsmittel per Hand im Verhältnis 1:1 $(2 \mu \mathrm{l}+2 \mu \mathrm{l})$ zusammen pipettiert, wobei zuvor jeweils $400 \mu \mathrm{l}$ an Reservoirlösung in die Vertiefungen vorgelegt wurden. Anfängliche Kristallisationsversuche wurden mit kommerziell erhältlichen Sparse Matrix Screens von Hampton Research (Crystal Screen 1+2, Index), Qiagen (JCSG Core 1-4) und Emerald Biosystems (Wizard $1+2)$ durchgeführt. Für Optimierungsversuche wurde von selbst hergestellte Lösungen Gebrauch gemacht. Die Qualität der Kristalle wurde durch Mikroseeding und den Einsatz von Additiva und Detergenzien (Additiv- und Detergenz-Screen, Hampton Research) optimiert. Die Platten wurden bei $4^{\circ} \mathrm{C}$ und $20^{\circ} \mathrm{C}$ aufbewahrt und in regelmäßigen Abständen mithilfe eines Olympus SZX12 Stereo Mikroskops kontrolliert. Kristalle wurden mit einer Olympus Digitalkamera dokumentiert.

\section{III.5.2. Additiv- und Detergenz-Screens}


Um den Einfluss von Additiva/Detergenzien auf die Kristalle im 96-Well-Maßstab zu testen, wurden die entsprechenden Kristallisationsplatten zunächst vollautomatisch mit Protein und Fällungsmittel beladen. Daraufhin wurde das jeweilige Additiv/Detergenz ebenfalls vollautomatisch in die Probentropfen eingebracht. Dabei wurde ein Verhältnis von 3:2:1 von Protein:Präzipitant: Additiv/Detergenz gewählt. Für Ansätze im 24-Well-Maßstab wurde dasselbe Konzentrationsverhältnis verwendet, wobei die einzelnen Komponenten per Hand zusammen pipettiert wurde.

\section{III.5.3. Mikroseeding}

Für Mikroseeding-Ansätze im 96-Well-Maßstab wurden die entsprechenden Kristallisationsplatten zunächst vollautomatisch mit Protein und Fällungsmittel beladen. Anschließend wurde die Seed-Lösung ebenfalls vollautomatisch in die Probentropfen eingebracht, wobei das Verhältnis von Protein:Präzipitant:Seed 3:2:1 betrug (in Kombination mit Additiva/Detergenzien wurden Protein: Präzipitant:Additiv/Detergenz:Seed im Verhältnis 5:3:1:1 eingesetzt). Für Mikroseeding-Ansätze im 24-Well-Maßstab wurden die manuell pipettierten Probentropfen für 6 Stunden bei $20^{\circ} \mathrm{C}$ voräquilibriert. Daraufhin wurde ein Katzenhaar in die Seed-Lösung eingetaucht und zügig durch den Tropfen gezogen (StreakSeeding), wodurch feine Kristallsplitter transferiert wurden.

\section{III.5.4. Färbung der Kristalle und Kontrolle der Identität der kristallisierten Proteine}

Um zu überprüfen, ob die erhaltenen Kristalle aus Protein oder Salz hervorgegangen sind, wurden sie mit dem Coomassie-ähnlichen Farbstoff Izit (Hampton Research) angefärbt. Proteinkristalle verfügen über ausgeprägte Lösungsmittelkanäle, in die der Farbstoff eindringen kann. Die Folge ist eine Blaufärbung des Kristalls. Im Gegensatz dazu bleiben Salzkristalle farblos, da sie zu dicht gepackt sind, als dass der Farbstoff hinein gelangen könnte. Die Identität 
der auskristallisierten Proteine wurde kontrolliert, indem einige Kristalle aus der Mutterlauge in einen kleinen Tropfen Wasser überführt und sorgfältig gewaschen wurden. Der Ansatz wurde anschließend mit SDS-Ladepuffer versetzt, kurz aufgekocht und mittels SDS-PAGE analysiert.

\section{Literaturverzeichnis}

Aguda AH, Burtnick LD \& Robinson RC (2005) The state of the filament. EMBO Rep 6: 220-226

Allan V (2000) Dynactin. Current Biology 10: R432

Amann KJ \& Pollard TD (2000) Cellular regulation of actin network assembly. Curr. Biol 10: R728-730 
Amann KJ \& Pollard TD (2001) The Arp2/3 complex nucleates actin filament branches from the sides of pre-existing filaments. Nat. Cell Bio/ 3: 306-310

Amatruda JF \& Cooper JA (1992) Purification, characterization, and immunofluorescence localization of Saccharomyces cerevisiae capping protein. J. Cell Biol 117: 1067-1076

Ampe C \& Vandekerckhove J (1999) Guidebook to the Cytoskeletal and Motor proteins, $2^{\text {nd }}$ edition, Sambrook and Tooze Publication, Oxford University Press

Ankenbauer T, Kleinschmidt JA, Walsh MJ, Weiner OH \& Franke WW (1989) Identification of a widespread nuclear actin binding protein. Nature 342: 822-825

Applewhite DA, Barzik M, Kojima S-I, Svitkina TM, Gertler FB \& Borisy GG (2007) Ena/VASP proteins have an anti-capping independent function in filopodia formation. Mol. Biol. Cell 18: 2579-2591

Asai DJ \& Koonce MP (2001) The dynein heavy chain: structure, mechanics and evolution. Trends Cell Biol 11: 196-202

Bamburg JR (1999) Proteins of the ADF/cofilin family: essential regulators of actin dynamics. Annu Rev Cell Dev Biol. 15: 185-230

Bear JE, Svitkina TM, Krause M, Schafer DA, Loureiro JJ, Strasser GA, Maly IV, Chaga OY, Cooper JA, Borisy GG \& Gertler FB (2002) Antagonism between Ena/VASP proteins and actin filament capping regulates fibroblast motility. Cell 109: 509-521

Bearer EL (1991) Direct observation of actin filament severing by gelsolin and binding by gCap39 and CapZ. J. Cell Biol 115: 1629-1638

Bernardi G, Giro MG \& Gaillard C (1972) Chromatography of polypeptides and proteins on hydroxyapatite columns: some new developments. Biochim. Biophys. Acta 278: 409-420

Bhattacharya N, Ghosh S, Sept D \& Cooper JA (2006) Binding of myotrophin/V-1 to actin-capping protein: implications for how capping protein binds to the filament barbed end. J. Biol. Chem 281: 31021-31030

Blanchard A, Ohanian V \& Critchley D (1989) The structure and function of alpha-actinin. J. Muscle Res. Cell. Motil 10: 280-289

Blanchoin L, Amann KJ, Higgs HN, Marchand JB, Kaiser DA \& Pollard TD (2000) Direct observation of dendritic actin filament networks nucleated by Arp2/3 complex and WASP/Scar proteins. Nature 404: 1007-1011

Blanchoin L \& Pollard TD (2002) Hydrolysis of ATP by polymerized actin depends on the bound divalent cation but not profilin. Biochemistry 41: 597-602 
Bondos SE \& Bicknell A (2003) Detection and prevention of protein aggregation before, during, and after purification. Anal. Biochem 316: 223-231

Bradford MM (1976) A rapid and sensitive method for the quantification of microgram quantities of protein utilizing the principle of protein-dye binding. Anal. Biochem. 72: 248-254

Bremer A \& Aebi U (1992) The structure of the F-actin filament and the actin molecule. Curr. Opin. Cell Biol 4: 20-26

Brokaw CJ (1989) Direct measurements of sliding between outer doublet microtubules in swimming sperm flagella. Science 243: 1593-1596

Brokaw CJ \& Kamiya R (1987) Bending patterns of Chlamydomonas flagella: IV. Mutants with defects in inner and outer dynein arms indicate differences in dynein arm function. Cell Motil. Cytoskeleton 8: 68-75

Brünger AT, Adams PD, Clore GM, DeLano WL, Gros P, Grosse-Kunstleve RW, Jiang JS, Kuszewski J, Nilges M, Pannu NS, Read RJ, Rice LM, Simonson T \& Warren GL (1998) Crystallography \& NMR system: A new software suite for macromolecular structure determination. Acta Crystallogr. D Biol. Crystallogr 54: 905-921

Burgess SA, Walker ML, Sakakibara H, Knight PJ \& Oiwa K (2003) Dynein structure and power stroke. Nature 421: 715-718

Burkhardt JK, Echeverri CJ, Nilsson T \& Vallee RB (1997) Overexpression of the Dynamitin (p50) Subunit of the Dynactin Complex Disrupts Dynein-dependent Maintenance of Membrane Organelle Distribution. The Journal of Cell Biology 139: $469-484$

von Bülow M, Rackwitz HR, Zimbelmann R \& Franke WW (1997) CP beta3, a novel isoform of an actin-binding protein, is a component of the cytoskeletal calyx of the mammalian sperm head. Exp. Cell Res 233: 216-224

Canton DA, Olsten MEK, Kim K, Doherty-Kirby A, Lajoie G, Cooper JA \& Litchfield DW (2005) The pleckstrin homology domain-containing protein CKIP-1 is involved in regulation of cell morphology and the actin cytoskeleton and interaction with actin capping protein. Mol. Cell. Biol 25: 3519-3534

Carlier MF (1989) Role of nucleotide hydrolysis in the dynamics of actin filaments and microtubules. Int. Rev. Cytol 115: 139-170

Carlier MF (1990) Actin polymerization and ATP hydrolysis. Adv. Biophys 26: 5173

Carlier MF (1993) Cytoskeleton: dynamic actin. Curr. Bio/ 3: 321-323 
Carlier MF (1998) Control of actin dynamics. Curr. Opin. Cell Biol 10: 45-51

Carlier MF \& Pantaloni D (1997) Control of actin dynamics in cell motility. J. Mol. Biol 269: 459-467

Carlier M-F, Wiesner S, Le Clainche C \& Pantaloni D (2003) Actin-based motility as a self-organized system: mechanism and reconstitution in vitro. C. R. Bio/ 326: $161-170$

Carter AP, Cho C, Jin L \& Vale RD (2011) Crystal structure of the dynein motor domain. Science 331: 1159-1165

Carter AP \& Vale RD (2010) Communication between the AAA+ ring and microtubule-binding domain of dynein. Biochem Cell Biol 88: 15-21

Carter AP, Garbarino JE, Wilson-Kubalek EM, Shipley WE, Cho C, Milligan RA, Vale RD \& Gibbons IR (2008) Structure and functional role of dynein's microtubule-binding domain. Science 322: 1691-1695

Casella JF, Maack DJ \& Lin S (1986) Purification and initial characterization of a protein from skeletal muscle that caps the barbed ends of actin filaments. J. Biol. Chem 261: 10915-10921

Chayen NE (1997) The role of oil in macromolecular crystallization. Structure 5: 1269-1274

Cho C, Reck-Peterson SL \& Vale RD (2008) Regulatory ATPase sites of cytoplasmic dynein affect processivity and force generation. J. Biol. Chem 283: 25839-25845

Cooper JA \& Schafer DA (2000) Control of actin assembly and disassembly at filament ends. Curr. Opin. Cell Biol 12: 97-103

Cooper JA \& Sept D (2008) New insights into mechanism and regulation of actin capping protein. Int Rev Cell Mol Biol 267: 183-206

Davis IW, Leaver-Fay A, Chen VB, Block JN, Kapral GJ, Wang X, Murray LW, Arendall WB 3rd, Snoeyink J, Richardson JS \& Richardson DC (2007) MolProbity: all-atom contacts and structure validation for proteins and nucleic acids. Nucleic Acids Res 35: W375-383

DiNubile MJ, Cassimeris L, Joyce M \& Zigmond SH (1995) Actin filament barbedend capping activity in neutrophil lysates: the role of capping protein-beta 2 . Mol. Biol. Cell 6: 1659-1671

Dominguez R (2004) Actin-binding proteins - a unifying hypothesis. Trends Biochem. Sci 29: 572-578 
Dittrich W, Williams KL \& Slade MB (1994) Production and secretion of recombinant proteins in Dictyostelium discoideum. Biotechnology (N.Y.) 12: 614618

Douglas MW, Diefenbach RJ, Homa FL, Miranda-Saksena M, Rikson FJ, Vittone $V$, Byth K \& Cunningham AL (2004) Herpes simplex virus type 1 capsid protein VP26 interacts with dynein light chains RP3 and Tctex1 and plays a role in retrograde cellular transport. J Biol Chem 279: 28522-28530

Echeverri CJ, Paschal BM, Vaughan KT \& Vallee RB (1996) Molecular characterization of the 50-kD subunit of dynactin reveals function for the complex in chromosome alignment and spindle organization during mitosis. J. Cell Biol 132: $617-633$

Eddy RJ, Han J \& Condeelis JS (1997) Capping protein terminates but does not initiate chemoattractant-induced actin assembly in Dictyostelium. J. Cell Biol 139: 1243-1253

Emsley P, Lohkamp B, Scott WG \& Cowtan K (2010) Features and development of Coot. Acta Crystallogr. D Biol. Crystallogr 66: 486-501

Estes JE, Selden LA, Kinosian HJ \& Gershman LC (1992) Tightly-bound divalent cation of actin. J. Muscle Res. Cell. Motil 13: 272-284

Flot D, Mairs T, Giraud T, Guijarro M, Lesourd M, Rey V, van Brussel D, Morawe C, Borel C, Hignette O, Chavanne J, Nurizzo D, McSweeney S \& Mitchell E (2010) The ID23-2 structural biology microfocus beamline at the ESRF. J Synchrotron Radiat 17: 107-118

Garrels JI \& Gibson W (1976) Identification and characterization of multiple forms of actin. Cell 9: 793-805

Gee MA, Heuser JE \& Vallee RB (1997) An extended microtubule-binding structure within the dynein motor domain. Nature 390: 636-639

Gennerich A, Carter AP, Reck-Peterson SL \& Vale RD (2007) Force-induced bidirectional stepping of cytoplasmic dynein. Cell 131: 952-965

Gershman LC, Selden LA \& Estes JE (1986) High affinity binding of divalent cation to actin monomer is much stronger than previously reported. Biochem. Biophys. Res. Commun 135: 607-614

Gibbons IR \& Rowe AJ (1965) Dynein: A Protein with Adenosine Triphosphatase Activity from Cilia. Science 149: 424-426

Gibbons IR, Garbarino JE, Tan CE, Reck-Peterson SL, Vale RD \& Carter AP (2005) The affinity of the dynein microtubule-binding domain is modulated by the conformation of its coiled-coil stalk. J. Biol. Chem 280: 23960-23965 
Gibbons IR, Gibbons BH, Mocz G \& Asai DJ (1991) Multiple nucleotide-binding sites in the sequence of dynein beta heavy chain. Nature 352: 640-643

Goodno CC (1982) Myosin active-site trapping with vanadate ion. Meth. Enzymol 85 Pt B: 116-123

van der Gucht J, Paluch E, Plastino J \& Sykes C (2005) Stress release drives symmetry breaking for actin-based movement. Proc. Natl. Acad. Sci. U.S.A 102: 7847-7852

Gulick AM \& Rayment I (1997) Structural studies on myosin II: communication between distant protein domains. Bioessays 19: 561-569

Gungabissoon RA \& Bamburg JR (2003) Regulation of growth cone actin dynamics by ADF/cofilin. J. Histochem. Cytochem 51: 411-420

Gusnowski EM \& Srayko M (2011) Regulation of dynein-dependent microtubule gliding at the cell cortex: implications for spindle positioning. J. Cell Biol. 194: 377-386

Hanson J \& Lowy J (1963) The structure of F-actin and the actin filaments isolated from muscle. $J$ Mol Biol. 6: 46-60

Harada A, Takei Y, Kanai Y, Tanaka Y, Nonaka S \& Hirokawa N (1998) Golgi Vesiculation and Lysosome Dispersion in Cells Lacking Cytoplasmic Dynein. The Journal of Cell Biology 141: 51-59

Harp JM, Timm DE \& Bunick GJ (1998) Macromolecular crystal annealing: overcoming increased mosaicity associated with cryocrystallography. Acta Crystallogr. D Biol. Crystallogr 54: 622-628

Harrell JM, Murphy PJ, Morishima Y, Chen H, Mansfield JF, Galigniana MD \& Pratt WB (2004) Evidence for glucocorticoid receptor transport on microtubules by dynein. J Biol Chem 279: 54647-54654

Hart MC \& Cooper JA (1999) Vertebrate isoforms of actin capping protein beta have distinct functions in vivo. J. Cell Biol 147: 1287-1298

Hart MC, Korshunova YO \& Cooper JA (1997) Vertebrates have conserved capping protein alpha isoforms with specific expression patterns. Cell Motil. Cytoskeleton 38: 120-132

Hartmann H, Nögel AA, Eckerskorn C, Rapp S \& Schleicher M (1989) Ca2+independent F-actin capping proteins. Cap 32/34, a capping protein from Dictyostelium discoideum, does not share sequence homologies with known actin-binding proteins. J. Biol. Chem 264: 12639-12647 
Hartwig JH, Bokoch GM, Carpenter CL, Janmey PA, Taylor LA, Toker A \& Stossel TP (1995) Thrombin receptor ligation and activated Rac uncap actin filament barbed ends through phosphoinositide synthesis in permeabilized human platelets. Cell 82: 643-653

Hartwig JH, Chambers KA \& Stossel TP (1989) Association of gelsolin with actin filaments and cell membranes of macrophages and platelets. J. Cell Biol 108: 467-479

Heikoop JC, Grootenhuis PD, Blaauw M, Veldema JS, Van Haastert PJ \& Linskens MH (1998) Expression of a bioactive, single-chain choriogonadotropin in Dictyostelium discoideum. Eur J Biochem 256: 259-263

Heiss SG \& Cooper JA (1991) Regulation of CapZ, an actin capping protein of chicken muscle, by anionic phospholipids. Biochemistry 30: 8753-8758

Heras B \& Martin JL (2005) Post-crystallization treatments for improving diffraction quality of protein crystals. Acta Crystallogr. D Biol. Crystallogr 61: $1173-1180$

Hernandez-Valladares M, Kim T, Kannan B, Tung A, Aguda AH, Larsson M, Cooper JA \& Robinson RC (2010) Structural characterization of a capping protein interaction motif defines a family of actin filament regulators. Nat. Struct. Mol. Biol 17: $497-503$

Hertzog M, van Heijenoort C, Didry D, Gaudier M, Coutant J, Gigant B, Didelot G, Préat T, Knossow M, Guittet E \& Carlier M-F (2004) The beta-thymosin/WH2 domain; structural basis for the switch from inhibition to promotion of actin assembly. Cell 117: 611-623

Hightower RC \& Meagher RB (1986) The molecular evolution of actin. Genetics 114: $315-332$

Hill MA \& Gunning P (1993) Beta and gamma actin mRNAs are differentially located within myoblasts. J. Cell Biol 122: 825-832

Holmes KC \& Kabsch W (1991) Muscle proteins: actin. Curr. Opin.Struct. Biol. $1: 270-280$

Holmes KC, Popp D, Gebhard W \& Kabsch W (1990) Atomic model of the actin filament. Nature 347: 44-49

Holmes KC, Angert I, Kull FJ, Jahn W \& Schröder RR (2003) Electron cryomicroscopy shows how strong binding of myosin to actin releases nucleotide. Nature 425: 423-427

Holzbaur EL \& Vallee RB (1994) DYNEINS: molecular structure and cellular function. Annu. Rev. Cell Biol 10: 339-372 
Hoock TC, Newcomb PM \& Herman IM (1991) Beta actin and its mRNA are localized at the plasma membrane and the regions of moving cytoplasm during the cellular response to injury. J. Cell Biol 112: 653-664

Hopmann R, Cooper JA \& Miller KG (1996) Actin organization, bristle morphology, and viability are affected by actin capping protein mutations in Drosophila. J. Cell Biol 133: 1293-1305

Huff T, Müller CS, Otto AM, Netzker R \& Hannappel E (2001) beta-Thymosins, small acidic peptides with multiple functions. Int. J. Biochem. Cell Biol 33: 205220

Hug C, Jay PY, Reddy I, McNally JG, Bridgman PC, Elson EL \& Cooper JA (1995) Capping protein levels influence actin assembly and cell motility in dictyostelium. Cell 81: 591-600

Hughes SM, Vaughan KT, Herskovits JS \& Vallee RB (1995) Molecular analysis of a cytoplasmic dynein light intermediate chain reveals homology to a family of ATPases. Journal of Cell Science 108: 17-24

Huxley HE (1963) Electron Microscope Studies on the Structure of Natural an Synthetic Protein Filaments from striated muscle. J. Mol. Biol 7: 281-308

Höök P (2010) The mechanical components of the dynein motor. ScientificWorldJournal 10: 857-864

Höök P \& Vallee RB (2006) The dynein family at a glance. J. Cell. Sci 119: 43694371

Isenberg G, Aebi U \& Pollard TD (1980) An actin-binding protein from Acanthamoeba regulates actin filament polymerization and interactions. Nature 288: $455-459$

Ishikawa $\mathrm{H}$, Bischoff $\mathrm{R}$ \& Holtzer $\mathrm{H}$ (1969) Formation of arrowhead complexes with heavy meromyosin in a variety of cell types. J. Cell Biol 43: 312-328

Iwasa JH \& Mullins RD (2007) Spatial and temporal relationships between actinfilament nucleation, capping, and disassembly. Curr. Biol 17: 395-406

Jancarik J \& Kim SH (1991) Sparse matrix sampling: a screening method for crystallization of proteins. J. Appl. Cryst. 24: 409-411

Johnston JA, Illing ME \& Kopito RR (2002) Cytoplasmic dynein/dynactin mediates the assembly of aggresomes. Cell Motil Cytoskeleton 53: 26-38

Jung G, Remmert K, Wu X, Volosky JM \& Hammer JA 3rd (2001) The Dictyostelium CARMIL protein links capping protein and the Arp2/3 complex to type I myosins through their SH3 domains. J. Cell Biol 153: 1479-1497 
Kabsch W \& Vandekerckhove J (1992) Structure and function of actin. Annu Rev Biophys Biomol Struct 21: 49-76

Kabsch W, Mannherz HG, Suck D, Pai EF \& Holmes KC (1990) Atomic structure of the actin:DNase I complex. Nature 347: 37-44

Kabsch W (2010) XDS. Acta Crystallogr. D Biol. Crystallogr 66: 125-132

Kardon JR \& Vale RD (2009) Regulators of the cytoplasmic dynein motor. Nat Rev Mol Cell Biol. 10: 854-865

Kardon JR, Reck-Peterson SL \& Vale RD (2009) Regulation of the processivity and intracellular localization of Saccharomyces cerevisiae dynein by dynactin. Proc. Natl. Acad. Sci. U.S.A 106: 5669-5674

Karki S \& Holzbaur EL (1995) Affinity chromatography demonstrates a direct binding between cytoplasmic dynein and the dynactin complex. J. Biol. Chem 270: $28806-28811$

Khaitlina SY (2001) Functional specificity of actin isoforms. Int Rev Cytol. 202: 35-98

Kilimann MW \& Isenberg G (1982) Actin filament capping protein from bovine brain. EMBO J 1: 889-894

Kim K, McCully ME, Bhattacharya N, Butler B, Sept D \& Cooper JA (2007) Structure/function analysis of the interaction of phosphatidylinositol 4,5bisphosphate with actin-capping protein: implications for how capping protein binds the actin filament. J. Biol. Chem 282: 5871-5879

Kim K, Yamashita A, Wear MA, Maéda Y \& Cooper JA (2004) Capping protein binding to actin in yeast: biochemical mechanism and physiological relevance. $J$. Cell Biol 164: 567-580

Kim T, Cooper JA \& Sept D (2010) The interaction of capping protein with the barbed end of the actin filament. J. Mol. Biol 404: 794-802

King SJ \& Schroer TA (2000) Dynactin increases the processivity of the cytoplasmic dynein motor. Nat. Cell Biol 2: 20-24

Kinosian HJ, Selden LA, Estes JE \& Gershman LC (1993) Nucleotide binding to actin. Cation dependence of nucleotide dissociation and exchange rates. J. Biol. Chem 268: 8683-8691

Kollmar M (2006) Use of the myosin motor domain as large-affinity tag for the expression and purification of proteins in Dictyostelium discoideum. Int. J. Biol. Macromol 39: 37-44 
Kon T, Imamula K, Roberts AJ, Ohkura R, Knight PJ, Gibbons IR, Burgess SA \& Sutoh K (2009) Helix sliding in the stalk coiled coil of dynein couples ATPase and microtubule binding. Nat. Struct. Mol. Biol 16: 325-333

Kon T, Sutoh K \& Kurisu G (2011) X-ray structure of a functional full-length dynein motor domain. Nat. Struct. Mol. Biol 18: 638-642

Kondo H \& Ishiwata S (1976) Uni-directional growth of F-actin. J. Biochem 79: 159-171

Koonce MP \& Samsó M (1996) Overexpression of cytoplasmic dynein's globular head causes a collapse of the interphase microtubule network in Dictyostelium. Mol. Biol. Cell 7: 935-948

Kudryashov DS, Sawaya MR, Adisetiyo H, Norcross T, Hegyi G, Reisler E \& Yeates TO (2005) The crystal structure of a cross-linked actin dimer suggests a detailed molecular interface in F-actin. Proc. Natl. Acad. Sci. U.S.A 102: 1310513110

Kuhlman PA \& Fowler VM (1997) Purification and characterization of an alpha 1 beta 2 isoform of CapZ from human erythrocytes: cytosolic location and inability to bind to $\mathrm{Mg} 2+$ ghosts suggest that erythrocyte actin filaments are capped by adducin. Biochemistry 36: 13461-13472

Kuhn JR \& Pollard TD (2005) Real-time measurements of actin filament polymerization by total internal reflection fluorescence microscopy. Biophys. $J$ 88: 1387-1402

Lalli G, Gschmeissner S \& Schiavo G (2003) Myosin Va and microtubule-based motors are required for fast axonal retrograde transport of tetanus toxin in motor neurons. J Cell Sci 116: 4639-4650

Ling SC, Fahrner PS, Greenough WT \& Gelfand VI (2004) Transport of Drosophila fragile $\mathrm{X}$ mental retardation protein-containing ribonucleoprotein granules by kinesin-1 and cytoplasmic dynein. Proc. Natl. Acad. Sci. U.S.A 101: 17428-17433

Littlefield R \& Fowler VM (1998) Defining actin filament length in striated muscle: rulers and caps or dynamic stability. Annu. Rev. Cell Dev. Biol 14: 487-525

Littlefield R, Almenar-Queralt A \& Fowler VM (2001) Actin dynamics at pointed ends regulates thin filament length in striated muscle. Nat. Cell Biol 3: 544-551

Lodish H, Berk A, Zipursky S, Matsudaira P, Baltimore D \& Darnell J (2001) Molecular Cell Biology, $4^{\text {th }}$ edition. W.H. Freeman and Company 
Loisel TP, Boujemaa R, Pantaloni D \& Carlier MF (1999) Reconstitution of actinbased motility of Listeria and Shigella using pure proteins. Nature 401: 613-616

Löwe J, van den Ent $F$ \& Amos LA (2004) Molecules of the bacterial cytoskeleton. Annu Rev Biophys Biomol Struct 33: 177-198

Mallik R, Carter BC, Lex SA, King SJ \& Gross SP (2004) Cytoplasmic dynein functions as a gear in response to load. Nature 427: 649-652

Matthews BW (1968) Solvent content of protein crystals. J. Mol. Bio/ 33: 491-497

Matveeva EA, May AP, He P \& Whiteheart SW (2002) Uncoupling the ATPase activity of the N-ethylmaleimide sensitive factor (NSF) from $20 \mathrm{~S}$ complex disassembly. Biochemistry 41: 530-536

Maun NA, Speicher DW, DiNubile MJ \& Southwick FS (1996) Purification and properties of a $\mathrm{Ca}(2+)$-independent barbed-end actin filament capping protein, CapZ, from human polymorphonuclear leukocytes. Biochemistry 35: 3518-3524

McKenney RJ, Vershinin M, Kunwar A, Vallee RB \& Gross SP (2010) LIS1 and NudE induce a persistent dynein force-producing state. Cell 141: 304-314

Mejillano MR, Kojima S-ichiro, Applewhite DA, Gertler FB, Svitkina TM \& Borisy GG (2004) Lamellipodial versus filopodial mode of the actin nanomachinery: pivotal role of the filament barbed end. Cell 118: 363-373

Meng Y, Takahashi H, Meng J, Zhang Y, Lu G, Asrar S, Nakamura T \& Jia Z (2004) Regulation of ADF/cofilin phosphorylation and synaptic function by LIMkinase. Neuropharmacology 47: 746-754

Mikami A, Paschal BM, Mazumdar M \& Vallee RB (1993) Molecular cloning of the retrograde transport motor cytoplasmic dynein (MAP 1C). Neuron 10: 787796

Mikami A, Tynan SH, Hama T, Luby-Phelps K, Saito T, Crandall JE, Besharse JC \& Vallee RB (2002) Molecular structure of cytoplasmic dynein 2 and its distribution in neuronal and ciliated cells. J. Cell. Sci 115: 4801-4808

Miyagawa $\mathrm{Y}$, Tanaka H, Iguchi N, Kitamura K, Nakamura Y, Takahashi T, Matsumiya K, Okuyama A \& Nishimune Y (2002) Molecular cloning and characterization of the human orthologue of male germ cell-specific actin capping protein alpha3 (cpalpha3). Mol. Hum. Reprod 8: 531-539

Miyoshi T, Tsuji T, Higashida C, Hertzog M, Fujita A, Narumiya S, Scita G \& Watanabe N (2006) Actin turnover-dependent fast dissociation of capping protein in the dendritic nucleation actin network: evidence of frequent filament severing. J. Cell Biol 175: 947-955 
Mocz G \& Gibbons IR (1996) Phase partition analysis of nucleotide binding to axonemal dynein. Biochemistry 35: 9204-9211

Mocz G, Helms MK, Jameson DM \& Gibbons IR (1998) Probing the nucleotide binding sites of axonemal dynein with the fluorescent nucleotide analogue 2'(3')O-(-N-Methylanthraniloyl)-adenosine 5'-triphosphate. Biochemistry 37: 98629869

Molloy JE \& Veigel (2003) Biophysics. Myosin motors walk the way. Science 300: 2045-2046

Moore JK, Li J \& Cooper JA (2008) Dynactin function in mitotic spindle positioning. Traffic 9: 510-527

Mullins RD, Heuser JA \& Pollard TD (1998) The interaction of Arp2/3 complex with actin: nucleation, high affinity pointed end capping, and formation of branching networks of filaments. Proc. Natl. Acad. Sci. U.S.A 95: 6181-6186

Méré J, Chahinian A, Maciver SK, Fattoum A, Bettache N, Benyamin $Y$ \& Roustan C (2005) Gelsolin binds to polyphosphoinositide-free lipid vesicles and simultaneously to actin microfilaments. Biochem. J 386: 47-56

Narita A \& Maéda Y (2007) Molecular determination by electron microscopy of the actin filament end structure. J. Mol. Biol 365: 480-501

Narita A, Takeda S, Yamashita A \& Maéda Y (2006) Structural basis of actin filament capping at the barbed-end: a cryo-electron microscopy study. EMBO J 25: $5626-5633$

Neuwald AF, Aravind L, Spounge JL \& Koonin EV (1999) AAA+: A class of chaperone-like ATPases associated with the assembly, operation and disassembly of protein complexes. Genome Res. 9: 27-43

Oda T, Iwasa M, Aihara T, Maéda Y \& Narita A (2009) The nature of the globularto fibrous-actin transition. Nature 457: 441-445

Ogawa K (1991) Four ATP-binding sites in the midregion of the beta heavy chain of dynein. Nature 352: 643-645

Ogura T \& Wilkinson AJ (2001) AAA+ superfamily ATPases: common structure diverse function. Genes Cells 6: 575-597

Oosawa F (1972) Dynamic properties of F-actin and the thin filament. Nihon Seirigaku Zasshi 34: 96-97

Otto JJ (1994) Actin-bundling proteins. Curr. Opin. Cell Bio/ 6: 105-109 
Pak CW, Flynn KC \& Bamburg JR (2008) Actin-binding proteins take the reins in growth cones. Nat. Rev. Neurosci 9: 136-147

Palmgren S, Vartiainen M \& Lappalainen P (2002) Twinfilin, a molecular mailman for actin monomers. J Cell Sci 115: 881-886

Pappas CT, Bhattacharya N, Cooper JA \& Gregorio CC (2008) Nebulin interacts with CapZ and regulates thin filament architecture within the Z-disc. Mol. Biol. Cell 19: 1837-1847

Pavlov D, Muhlrad A, Cooper J, Wear M \& Reisler E (2007) Actin filament severing by cofilin. $J$ Mol Biol 365: 1350-1358

Pfister KK, Fay RB \& Witman GB (1982) Purification and polypeptide composition of dynein ATPases from Chlamydomonas flagella. Cell Motil 2: 525-547

Piperno G \& Luck DJ (1979) An actin-like protein is a component of axonemes from Chlamydomonas flagella. J. Biol. Chem 254: 2187-2190

Pollard TD (1984) Polymerization of ADP-actin. J. Cell Bio/ 99: 769-777

Pollard TD, Blanchoin L \& Mullins RD (2001) Actin dynamics. J. Cell. Sci 114: 3-4

Pollard TD (2004) Formins coming into focus. Dev. Cell 6: 312-314

Pollard TD \& Borisy GG (2003) Cellular motility driven by assembly and disassembly of actin filaments. Cell 112: 453-465

Presley JF, Cole NB, Schroer TA, Hirschberg K, Zaal KJM \& Lippincott-Schwartz J (1997) ER-to-Golgi transport visualized in living cells. Nature 389: 81-85

Smith CA \& Rayment I (1996) X-ray structure of the magnesium(II).ADP. vanadate complex of the Dictyostelium discoideum myosin motor domain to $1.9 \mathrm{~A}$ resolution. Biochemistry 35: 5404-5417

Rayment I (1997) Reductive alkylation of lysine residues to alter crystallization properties of proteins. Methods Enzymol. 276: 171-179

Reck-Peterson SL \& Vale RD (2004) Molecular dissection of the roles of nucleotide binding and hydrolysis in dynein's AAA domains in Saccharomyces cerevisiae. Proc. Natl. Acad. Sci. U.S.A 101: 1491-1495

Reck-Peterson SL, Yildiz A, Carter AP, Gennerich A, Zhang N \& Vale RD (2006) Single-molecule analysis of dynein processivity and stepping behavior. Cell 126: 335-348 
dos Remedios CG, Chhabra D, Kekic M, Dedova IV, Tsubakihara M, Berry DA \& Nosworthy NJ (2003) Actin binding proteins: regulation of cytoskeletal microfilaments. Physiol. Rev 83: 433-473

Remmert K, Vullhorst D \& Hinssen H (2000) In vitro refolding of heterodimeric CapZ expressed in E. coli as inclusion body protein. Protein Expr. Purif 18: 11-19

Rich SA \& Estes JE (1976) Detection of conformational changes in actin by proteolytic digestion: evidence for a new monomeric species. J. Mol. Biol 104: 777-792

Roberts AJ, Numata N, Walker ML, Kato YS, Malkova B, Kon T, Ohkura R, Arisaka F, Knight PJ, Sutoh K \& Burgess SA (2009) AAA+ Ring and linker swing mechanism in the dynein motor. Cell 136: 485-495

Robinson RC, Turbedsky K, Kaiser DA, Marchand JB, Higgs HN, Choe S \& Pollard TD (2001) Crystal structure of Arp2/3 complex. Science 294: 1679-1684

Rossmann MG (2001) Molecular replacment - historical background. Acta Crystallogr. D Biol. Crystallogr 57: 1360-1366

Rost B, Yachdav G \& Liu J (2004) The PredictProtein server. Nucleic Acids Res 32: W321-326

Rypniewski WR, Holden HM \& Rayment I (2004) Structural consequence of reductive methylation of lysine residues in hen egg lysozyme: An X-ray anlysis at 1.8 Å resolution. Biochemistry 32: 9851-9858

Sagot I, Klee SK \& Pellman D (2002) Yeast formins regulate cell polarity by controlling the assembly of actin cables. Nat. Cell Biol 4: 42-50

Saiki RK, Gelfand DH, Stoffel S, Scharf SJ, Higuchi R, Horn GT, Mullis KB \& Erlich HA (1988) Primer-directed enzymatic amplification of DNA with thermostable DNA polymerase. Science 239: 487-491

Sambrook J, Fritsch EF \& Maniatis T (1989) Molecular Cloning: a laboratory manual. $2^{\text {nd }}$ ed. N.Y., Cold Spring Harbor Laboratory, Cold Spring Harbor Laboratory Press, 1659 p. ISBN 0-87969-309-6

Schafer DA, Gill SR, Cooper JA, Heuser JE \& Schroer TA (1994a) Ultrastructural analysis of the dynactin complex: an actin-related protein is a component of a filament that resembles F-actin. J. Cell Biol 126: 403-412

Schafer DA, Korshunova YO, Schroer TA \& Cooper JA (1994b) Differential localization and sequence analysis of capping protein beta-subunit isoforms of vertebrates. J. Cell Biol 127: 453-465 
Schafer DA, Hug C \& Cooper JA (1995) Inhibition of CapZ during myofibrillogenesis alters assembly of actin filaments. J. Cell Biol 128: 61-70

Schafer DA, Mooseker MS \& Cooper JA (1992) Localization of capping protein in chicken epithelial cells by immunofluorescence and biochemical fractionation. $J$. Cell Biol 118: 335-346

Schafer DA, Waddle JA \& Cooper JA (1993) Localization of CapZ during myofibrillogenesis in cultured chicken muscle. Cell Motil. Cytoskeleton 25: 317335

Schleicher M, Gerisch G \& Isenberg G (1984) New actin-binding proteins from Dictyostelium discoideum. EMBO J 3: 2095-2100

Schliwa M \& Woehlke G (2003) Molecular motors. Nature 422: 759-765

Schmidt DJ, Rose DJ, Saxton WM, \& Strome S (2005) Functional analysis of cytoplasmic dynein heavy chain in Caenorhabditis elegans with fast-acting temperature-sensitive mutations. Mol Biol Cell 16: 1200-1212

Schroer TA \& Sheetz MP (1991) Two activators of microtubule-based vesicle transport. J. Cell Biol 115: 1309-1318

Schroer TA (2004) Dynactin. Annu. Rev. Cell Dev. Biol 20: 759-779

Selden LA, Kinosian HJ, Estes JE \& Gershman LC (1999) Impact of profilin on actin-bound nucleotide exchange and actin polymerization dynamics. Biochemistry 38: 2769-2778

Sheterline P, Clayton J \& Sparrow J (1995) Actin. Protein Profile 2: 1-103

Silacci P, Mazzolai L, Gauci C, Stergiopulos N, Yin HL \& Hayoz D (2004) Gelsolin superfamily proteins: key regulators of cellular functions. Cell Mol Life Sci. 61: 2614-2623

Smith CA \& Rayment I (1996) X-ray structure of the magnesium(II)ADPvanadate complex of the Dictyostelium discoideum myosin motor domain to $1.9 \mathrm{~A}$ resolution. Biochemistry 35: 5404-5417

Smith J, Diez G, Klemm AH, Schewkunow V \& Goldmann WH (2006) CapZ-lipid membrane interactions: a computer analysis. Theor Biol Med Mode/ 3: 30

Sodeik B, Ebersold MW \& Helenius A (1997) Microtubule-mediated Transport of Incoming Herpes Simplex Virus 1 Capsids to the Nucleus. The Journal of Cell Biology 136: 1007-1021 
Soeno Y, Abe H, Kimura S, Maruyama K \& Obinata T (1998) Generation of functional beta-actinin (CapZ) in an E. coli expression system. J. Muscle Res. Cell. Motil 19: 639-646

Straube A, Enard W, Berner A, Wedlich-Söldner R, Kahmann R \& Steinberg G (2001) A split motor domain in a cytoplasmic dynein. EMBO J 20: 5091-5100

Sulkowski E (1989) The saga of IMAC and MIT. Bioessays 10: 170-175

Sun HQ, Kwiatkowska K \& Yin HL (1995) Actin monomer binding proteins. Curr. Opin. Cell Biol 7: 102-110

Sun HQ, Yamamoto M, Mejillano M \& Yin HL (1999) Gelsolin, a multifunctional actin regulatory protein. J. Biol. Chem 274: 33179-33182

Suomalainen M, Nakano MY, Keller S, Boucke K, Stidwill RP \& Greber UF (1999) Microtubule-dependent Plus- and Minus End-directed Motilities Are Competing Processes for Nuclear Targeting of Adenovirus. The Journal of Cell Biology 144: 657-672

Sussman M (1987) Cultivation and synchronous morphogenesis of Dictyostelium under controlled experimental conditions. Methods Cell Biol. 28: 9-29

Svitkina TM \& Borisy GG (1999) Arp2/3 complex and actin depolymerizing factor/cofilin in dendritic organization and treadmilling of actin filament array in lamellipodia. J. Cell Biol 145: 1009-1026

Tai AW, Chuang J-Z, Bode C, Wolfrum U \& Sung C-H (1999) Rhodopsin's Carboxy-Terminal Cytoplasmic Tail Acts as a Membrane Receptor for Cytoplasmic Dynein by Binding to the Dynein Light Chain Tctex-1. Cell 97: 877887

Takeda S, Minakata S, Koike R, Kawahata I, Narita A, Kitazawa M, Ota M, Yamakuni T, Maéda Y \& Nitanai Y (2010) Two distinct mechanisms for actin capping protein regulation - steric and allosteric inhibition. PLOS Biol 8: e1000416

Tang WJ, Bell CW, Sale WS \& Gibbons IR (1982) Structure of the dynein-1 outer arm in sea urchin sperm flagella. I. Analysis by separation of subunits. J. Biol. Chem 257: 508-515

Theriot JA \& Mitchison TJ (1991) Actin microfilament dynamics in locomoting cells. Nature 352: 126-131

Toba S, Watanabe TM, Yamaguchi-Okimoto L, Toyoshima YY \& Higuchi H (2006) Overlapping hand-over-hand mechanism of single molecular motility of cytoplasmic dynein. Proc. Natl. Acad. Sci. U.S.A 103: 5741-5745 
Ueno H, Yasunaga T, Shingyoji C \& Hirose K (2008) Dynein pulls microtubules without rotating its stalk. Proc. Natl. Acad. Sci. U.S.A 105: 19702-19707

Vaisberg EA, Koonce MP \& McIntosh JR (1993) Cytoplasmic dynein plays a role in mammalian mitotic spindle formation. J. Cell Biol 123: 849-858

Vaisberg EA, Grissom PM \& McIntosh JR (1996) Mammalian cells express three distinct dynein heavy chains that are localized to different cytoplasmic organelles. J. Cell Biol 133: 831-842

Vale RD \& Milligan RA (2000) The way things move: looking under the hood of molecular motor proteins. Science 288: 88-95

Valetti C, Wetzel DM, Schrader M, Hasbani MJ, Gill SR, Kreis TE \& Schroer TA (1999) Role of Dynactin in Endocytic Traffic: Effects of Dynamitin Overexpression and Colocalization with CLIP-170. Molecular Biology of the Cell 10: 4107-4120

Vallee RB \& Sheetz MP (1996) Targeting of motor proteins. Science 271: 15391544

Vaughan KT \& Vallee RB (1995) Cytoplasmic dynein binds dynactin through a direct interaction between the intermediate chains and p150Glued. The Journal of Cell Biology 131: 1507-1516

Vilfan A (2001) The binding dynamics of tropomyosin on actin. Biophys J. 81: $3146-3155$

Wallar BJ \& Alberts AS (2003) The formins: active scaffolds that remodel the cytoskeleton. Trends Cell Biol 13: 435-446

Wear MA \& Cooper JA (2004) Capping protein: new insights into mechanism and regulation. Trends Biochem. Sci 29: 418-428

Wear MA, Yamashita A, Kim K, Maéda Y \& Cooper JA (2003) How capping protein binds the barbed end of the actin filament. Curr. Biol 13: 1531-1537

Weber A (1999) Actin binding proteins that change extent and rate of actin monomer-polymer distribution by different mechanisms. Mol. Cell. Biochem 190: 67-74

Wegner A (1976) Head to tail polymerization of actin. J. Mol. Biol 108: 139-150

Winder SJ \& Ayscough KR (2005) Actin-binding proteins. J. Cell. Sci 118: 651654

Yamashita A, Maeda K \& Maéda Y (2003) Crystal structure of CapZ: structural basis for actin filament barbed end capping. EMBO J 22: 1529-1538 
Yoshimura Y, Tanaka H, Nozaki M, Yomogida K, Shimamura K, Yasunaga T \& Nishimune Y (1999) Genomic analysis of male germ cell-specific actin capping protein alpha. Gene 237: 193-199

Zhang Z, Tanaka Y, Nonaka S, Aizawa H, Kawasaki H, Nakata T \& Hirokawa N (1993) The primary structure of rat brain (cytoplasmic) dynein heavy chain, a cytoplasmic motor enzyme. Proc. Natl. Acad. Sci. U.S.A 90: 7928-7932

Zigmond SH, Evangelista M, Boone C, Yang C, Dar AC, Sicheri F, Forkey J \& Pring M (2003) Formin leaky cap allows elongation in the presence of tight capping proteins. Curr. Biol 13: 1820-1823

Zimmerle CT, Patane K \& Frieden C (1987) Divalent cation binding to the highand low-affinity sites on G-actin. Biochemistry 26: 6545-6552

Zwolak A, Fujiwara I, Hammer JA 3rd \& Tjandra N (2010a) Structural basis for capping protein sequestration by myotrophin (V-1). J. Biol. Chem 285: 2576725781

Zwolak A, Uruno T, Piszczek G, Hammer JA 3rd \& Tjandra N (2010b) Molecular basis for barbed end uncapping by CARMIL homology domain 3 of mouse CARMIL-1. J. Biol. Chem 285: 29014-29026

\section{Appendix}

\section{V.1. Abbildungsverzeichnis}

Abbildung I.1. Schematische Darstellung von zytoplasmatischem Dynein.

Abbildung I.2. Modell des Dynaktin-Komplexes.

Abbildung I.3. Schematische Darstellung der Domänen-Architektur der Schweren Dynein-Kette. 
Abbildung I.4. Zylindermodelle der DHC-Motordomäne von Dictyostelium discoideum und Saccharomyces cerevisae.

Abbildung I.5. Hochaufgelöste Struktur der MTBD und eines kurzen Bereichs des "Stiels“.

Abbildung I.6. Modell für den mechanochemischen Zyklus von zytoplasmatischem Dynein.

Abbildung I.7. Schematische Darstellung der Domänen-Organisation der zytoplasmatischen DHC von Dictyostelium discoideum $(D d)$ und Mensch $(H s)$ sowie der Pilze Ustilago maydis (Um) und Laccaria bicolor (Lab).

Abbildung I.8. Überblick über die für anfängliche Expressionstests herangezogenen DHC-Konstrukte von Dictyostelium und Mensch sowie deren Expressionslevel.

Abbildung I.9. Übersicht über alle in die Expressionstests eingebundenen DHC-Konstrukte von Dictyostelium und Mensch sowie deren Expressionslevel.

Abbildung I.10. Elutionsprofile aus den Gelfiltrationsläufen der über Hydroxylapatit vorgereinigten Fusionskonstrukte.

Abbildung l.11. Elutionsprofile aus den Gelfiltrationsläufen der über $\mathrm{Ni}^{2+}$-NTA-Chromatographie vorgereinigten Fusionskonstrukte.

Abbildung I.12. SDS-Gele der Aufreinigung von ecke1MMD_Dd.

Abbildung I.13. Initiale Kristalle von ecke1MMD_Dd im Komplex mit MgADP.

Abbildung l.14. Typische Kristall-„Büschel“ von reduktiv methyliertem ecke1MMD_Dd im Komplex mit MgADP.

Abbildung l.15. Erste Monokristalle, die für reduktiv methyliertes ecke1MMD_Dd gezüchtet werden konnten.

Abbildung I.16. Vermessung von Kristallen des Fusionsproteins ecke1MMD_Dd.

Abbildung I.17. Beispiele für typische Kristalle von reduktiv methyliertem ecke1MMD_Dd.

Abbildung I.18. SDS-Gele der Aufreinigung von ecke10MMD_Hs.

Abbildung I.19. Feinkristallines Material von ecke10MMD_Hs im Komplex mit MgADP. $\mathrm{VO}_{4}$.

Abbildung I.20. Erste Kristalle von ecke10MMD_Hs. 
Abbildung I.21. Vermessung von Kristallen des Fusionskonstrukts ecke10MMD_Hs.

Abbildung I.22. Reproduzierbar erhaltene Kristalle von ecke10MMD_Hs.

Abbildung I.23. Kristalle von ecke10MMD_Hs unter dem Einfluss von Additiva.

Abbildung I.24. Schematische Kennzeichnung des Teilbereichs der DHC von Dictyostelium discoideum, den das Konstrukt ecke1Dd sequenzbasiert bzw. strukturell umfasst.

Abbildung I.25. Schematische Kennzeichnung des Teilbereichs der DHC von Mensch, den das Konstrukt ecke10 Hs sequenzbasiert bzw. strukturell umfasst.

Abbildung II.1. Struktur von G-Aktin.

Abbildung II.2. Struktur von F-Aktin.

Abbildung II.3. Aktin-Polymerisation.

Abbildung II.4. Dendritisches Nukleationsmodell.

Abbildung II.5. Mechanismus der Anbindung von CP an F-Aktin.

Abbildung II.6. Modell für die Entstehung unterschiedlicher F-Aktin Architekturen in Abhängigkeit von der CP-Capping-Aktivität.

Abbildung II.7. SDS-Gele der Aufreinigung von Cap32/34.

Abbildung II.8. Kristalle von Cap32/34.

Abbildung II.9. PIP-Strip-Inkubationstest.

Abbildung II.10. Vermessung von Cap32/34-Kristallen.

Abbildung II.11. Prozessierung der Daten.

Abbildung II.12. Ergebnisse der Rotationssuche.

Abbildung II.13. Ergebnisse der Translationssuche für den Auflösungsbereich 15-4 Å.

Abbildung II.14. Ramachandran-Diagramme der verfeinerten Cap32/34-

Struktur.

Abbildung II.15. Bänder-Darstellung der Gesamtstruktur von Cap32/34.

Abbildung II.16. Superpositionierung der Untereinheiten Cap32 und Cap34.

Abbildung II.17. Kontakte zwischen Cap32 und Cap34. 
Abbildung II.18. Superpositionierung der Untereinheiten der CP-Homologen Cap32/34 und GgCapZ.

Abbildung II.19. Ausschnitt aus den überlagerten Strukturen von Cap32/34 und GgCapZ, der LinkerßS6-S7 und die daran angrenzenden Aminosäuren zeigt.

Abbildung II.20. Aminosäuresequenz-Vergleich von LinkerßS6-S7, einschließlich der daran angrenzenden Regionen verschiedener Organismen.

Abbildung II.21. Elektrostatisches Potenzial an der Oberfläche von Cap32.

Abbildung II.22. Struktur von Cap32/34 und GgCapZ in B-Faktor Farbkodierung.

Abbildung II.23. Sequenzunterschiede zwischen den somatischen GgCapZ a-Isoformen, aufgetragen auf das Modell des GgCapZ-Heterodimers.

\section{V.2. Tabellenverzeichnis}

Tabelle I.1. Überblick über die in den Protein-Aufreinigungstest einbezogenen Additiva, einschließlich der jeweils verwendeten Endkonzentration.

Tabelle I.2. Übersicht über die für Protein-Bindungstests herangezogenen Säulenmatrices, einschließlich der entsprechenden Versuchsbedingungen.

Tabelle I.3. Übersicht über die Präzipitationsbedingungen, unter denen reduktiv methyliertes ecke1MMD_Dd auskristallisierte.

Tabelle II.1. Kristall-Daten und Modell-Verfeinerung 


\section{V.3. Danksagung}

An erster Stelle möchte ich mich bei Herrn PD Dr. Martin Kollmar für die Bereitstellung des vielseitigen Themas und für die jederzeit freundliche und interessierte Betreuung meiner Arbeit herzlich bedanken.

Ein besonderer Dank gilt Herrn Prof. Dr. Griesinger für die Möglichkeit zur Durchführung meiner Dissertation in der Abteilung „NMR-basierte Strukturbiologie" sowie für die ausgezeichneten Arbeitsbedingungen.

Ebenfalls möchte ich mich bei den Mitgliedern meines Thesis-Committees bedanken: Herrn Prof. Dr. Markus Wahl und Herrn Prof. Dr. Burkhard Morgenstern.

Schließlich möchte ich mich auch bei allen Mitarbeitern der Abteilung „NMRbasierte Strukturbiologie“ und den Mitarbeitern der AG Sheldrick an der GeorgAugust-Universität für die Hilfsbereitschaft und freundliche Zusammenarbeit bedanken.

Meinen Eltern danke ich für die immerwährende Unterstützung in jeglicher Hinsicht. 


\section{V.4. Lebenslauf}

Name:

Geburtsdatum:

Geburtsort:

1985-1989

1989-1999

2000-2005

2004-2005

2008-2011
Christian Eckert

10.10.1978

München

Grundschule Rohrbach

Apian-Gymnasium in Ingolstadt

Studium der Biologie an der Universität Regensburg

Anfertigung der Diplomarbeit unter der Betreuung von Herrn Dr. H. Durchschlag am Lehrstuhl für physikalische Biochemie mit dem Thema: „Thermodynamische Untersuchungen der Denaturierung von Lysozym mit Detergenzien und anderen Agenzien"

Abschluss: Diplom-Biologe

(Endnote: 1,3)

Anfertigung der Dissertation unter der Betreuung von Herrn PD Dr. Martin Kollmar am Max-Planck-Institut für Biophysikalische Chemie in Göttingen mit dem Thema: „Kristallographische Untersuchungen zur Schweren Kette von Dynein und dem Capping-Protein Cap32/34“ 